\title{
Kuwaiti Women's Resistance to Patriarchy in the 21st Century: An Exploration of Women's Rights from the Perspectives of Kuwaiti Women
}

\author{
Aseri, Ghadeer M M Gh R.
}

How to cite:

Aseri, Ghadeer M M Gh R. (2016) Kuwaiti Women's Resistance to Patriarchy in the 21st Century: An Exploration of Women's Rights from the Perspectives of Kuwaiti Women. Doctoral thesis, Swansea University.

http://cronfa.swan.ac.uk/Record/cronfa41149

Use policy:

This item is brought to you by Swansea University. Any person downloading material is agreeing to abide by the terms of the repository licence: copies of full text items may be used or reproduced in any format or medium, without prior permission for personal research or study, educational or non-commercial purposes only. The copyright for any work remains with the original author unless otherwise specified. The full-text must not be sold in any format or medium without the formal permission of the copyright holder. Permission for multiple reproductions should be obtained from the original author.

Authors are personally responsible for adhering to copyright and publisher restrictions when uploading content to the repository.

Please link to the metadata record in the Swansea University repository, Cronfa (link given in the citation reference above.) 


\section{KUWAITI WOMEN'S RESISTANCE TO PATRIARCHY IN THE $21^{\mathrm{ST}}$ CENTURY: AN EXPLORATION OF WOMEN'S RIGHTS FROM THE PERSPECTIVES OF KUWAITI WOMEN}

Submitted to Swansea University in fulfilment of the requirements for the Degree of Doctor of Philosophy.

Ghadeer M. Aseri

Supervised by: Dr. Tracey Sagar

Swansea University

Wales

2016 


\section{Summary}

Kuwait's recent history in terms of women's empowerment in the face of a powerful patriarchy presents researchers with an opportunity to investigate and seek to understand a range of phenomena related to the role of women in an Islamic society. In particular, modernising forces are in conflict with patriarchal, conservative, tribal and religious influences, with women's empowerment being one of the main battlegrounds. However, researching women's perceptions about empowerment and interpreting their life experiences within Kuwait society is not so straightforward, as merely raising issues regarding women's equality is extremely controversial. It is also highly problematic to include certain groups of women such as the Bedouin rural dwelling women who live in a highly patriarchal traditionalist environment. Notwithstanding these factors, this study aimed to give a voice to a cohort of women of Kuwait (educated and urbanised) in order to understand their perceptions of life in Kuwait in terms of their societal role, their appearance in the public sphere and potential inequalities and injustices that affect them in their daily lives as well as their hopes for their daughters and sons. A mixed methods research design was implemented with three elements, a survey questionnaire (n437), an in-depth interview study with educated urbanised Kuwaiti women (n20) and interviews with women in key leadership positions which also used in-depth interviews (n5).

In terms of a theoretical framework, as exploratory research this study avoided tying itself to one theory or theoretical perspective but instead considered the findings of this study in the light of the work of a number of authors who are in most cases associated with contrasting contexts. Comparisons were also made where appropriate to do so between the recent developments in Kuwait and those seen in British social history pertaining to women's empowerment. This was done in order to see whether commonalities in social change could sharpen the analysis particularly when evaluating the trajectory of this change.

Offering a much needed first insight into the lives of Kuwaiti women, the study found that the educated urbanised women who took part in the study are highly conscious of the inequalities affecting their lives across a whole range of domains. Equally they are determined to maintain and extend their presence in the public sphere, in the face of patriarchal forces which perceive a women's place as being in the home. In employment, education and politics women overwhelmingly wanted to play a full role in the country's development. However, there was more equivocation and reticence to put forward their views when the matters under consideration were in the private sphere - where Islam is viewed as the source of law and patriarchy remains strong. This implies a 
level of confidence in Kuwaiti women when voicing aspirations for their role in civil society that is not matched when referring to home and family life. 


\section{DECLARATION and STATEMENTS}

\section{DECLARATION}

This work has not previously been accepted in substance for any degree and is not being concurrently submitted in candidature for any degree.

Signed (candidate) Date

\section{STATEMENT 1}

This thesis is the result of my own investigations, except where otherwise stated. A bibliography is appended.

Signed (candidate) Date

\section{STATEMENT 2}

I hereby give consent for my thesis, if accepted, to be available for photocopying and for inter-library loan, and for the title and summary to be made available to outside organisations.

Signed (candidate) Date 


\section{ACKNOWLEDGEMENTS}

First, I would thank my country Kuwait for what she has given me in terms of the education and opportunities that have brought me to the point of presenting this thesis. My aim is to now return this favour through my academic endeavours.

To my parents, my family and my home community, thank you for standing beside me and for all the support you gave me. Thank you for accepting the differences there may be in our personal philosophies.

I would like to thank my friend Jehan who was there to listen and give back ideas and opinions and my son Gabriel Marafi who, for me, embodies the future of Kuwait, one which I see as bright for his generation.

To Joanne Aryan, my little lady, you and all other daughters of Kuwait inspired me to undertake my research and you always helped me to keep focused on the end goal.

Then, of course, there is my partner, with whom I have engaged in a seemingly never-ending exchange of views, particularly about how change should come about.

Finally, thinking of my time preparing this thesis and the research contained therein, I would like to thank my supervisor, Dr. Tracey Sagar for her invaluable feedback, advice and encouragement. 


\section{Table of Contents}

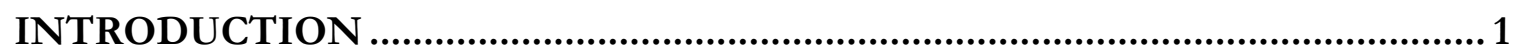

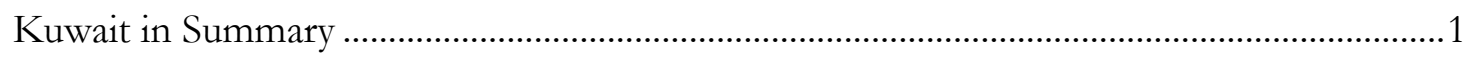

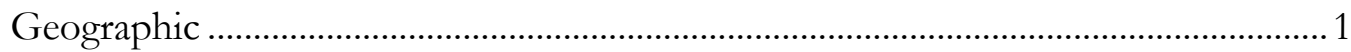

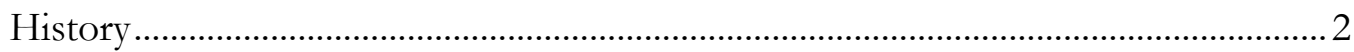

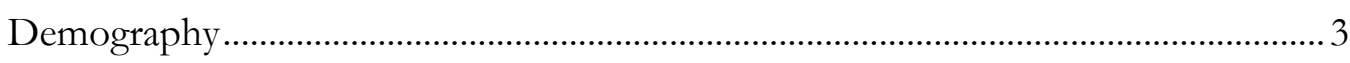

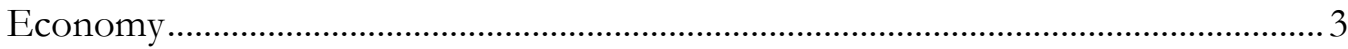

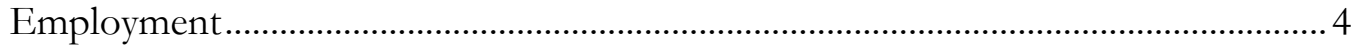

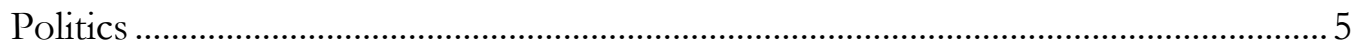

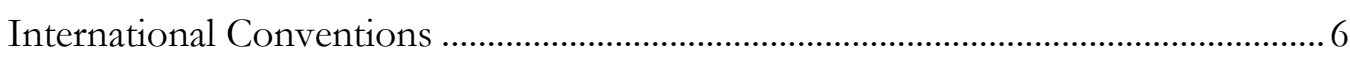

Women's rights and policy development ..................................................................................

Independence and the Constitution ............................................................................

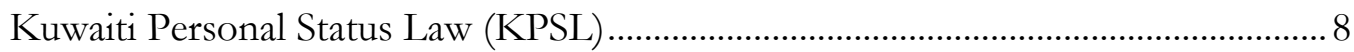

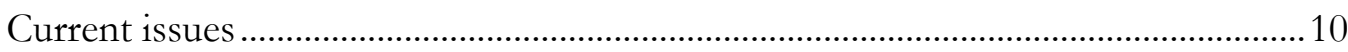

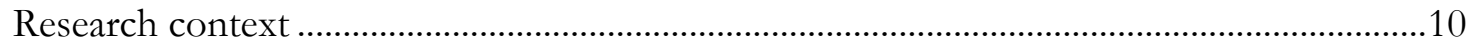

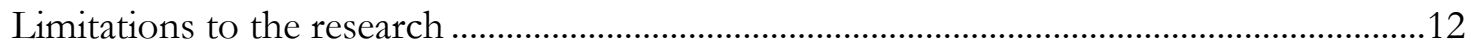

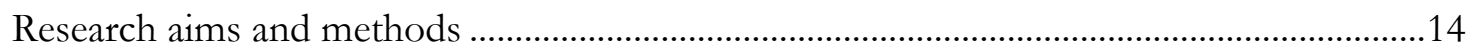

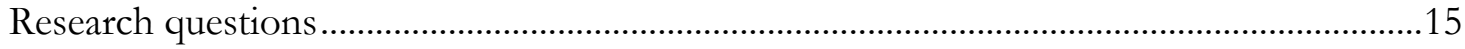

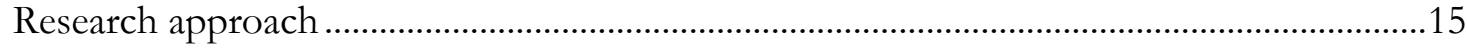

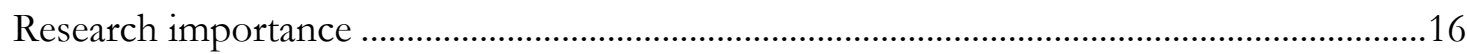

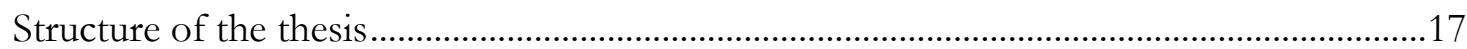

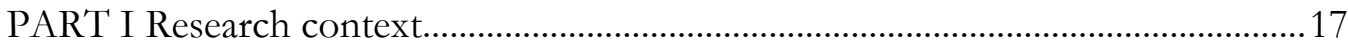

PART II Research approach.......................................................................................... 18

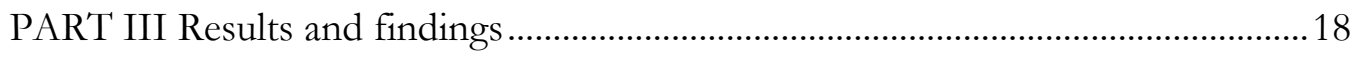

PART IV Evaluation, conclusion and recommendations.............................................20

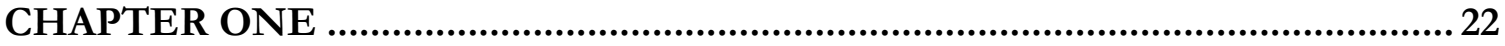

REVIEW OF THE KUWATI CONSTITUTION AND THE LEGAL, SOCIAL AND CULTURAL RIGHTS AFFORDED TO KUWAITI WOMEN ...................... 22

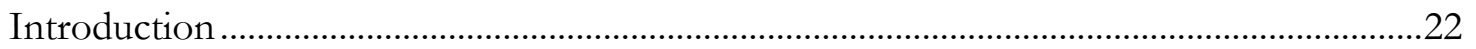

Non-discrimination and access to Justice ........................................................................2 24

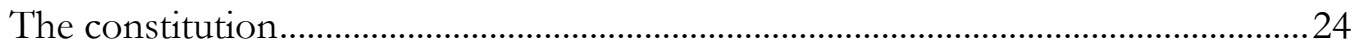




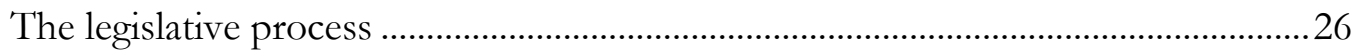

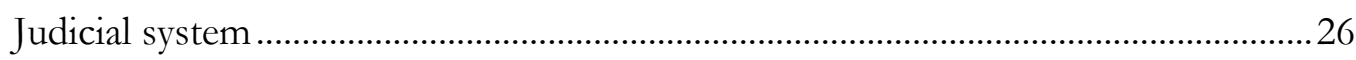

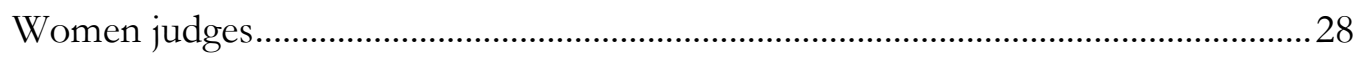

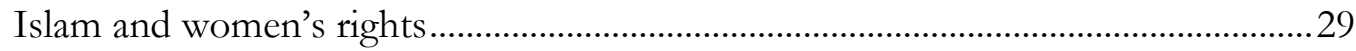

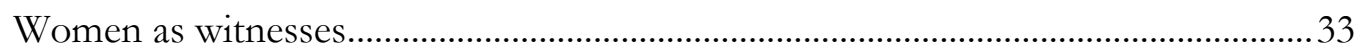

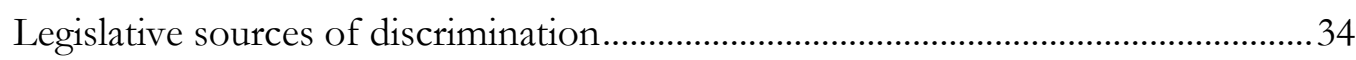

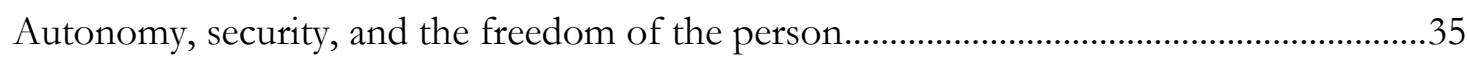

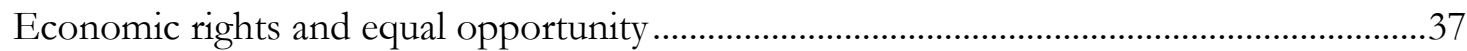

Oil: A force for autocracy and discrimination? .............................................................. 37

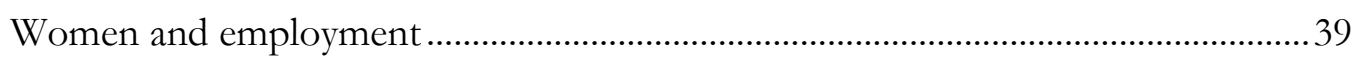

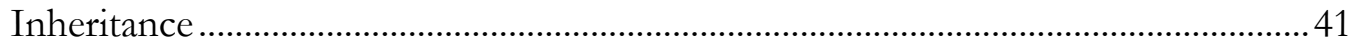

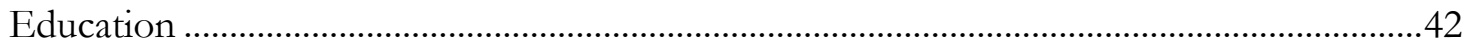

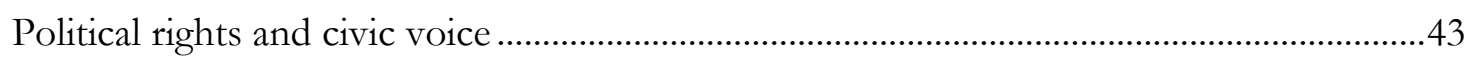

Iraqi occupation adds momentum ............................................................................... 44

The November 1999 parliamentary votes and increasing militancy...........................46

Women achieve suffrage and secure representation ..................................................... 48

Rulers' motivation in extending rights to women ....................................................... 51

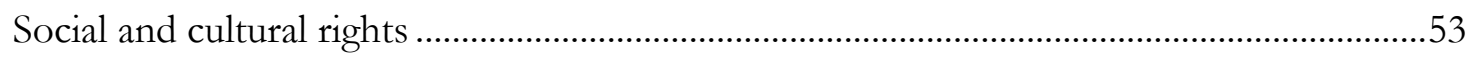

Reproductive rights ………………………................................................................. 54

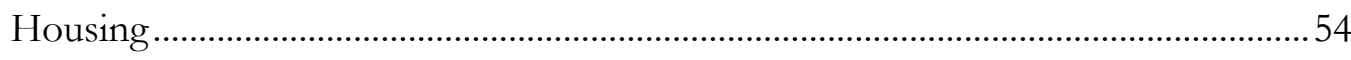

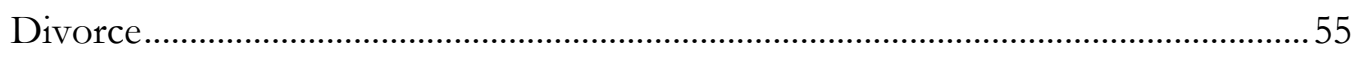

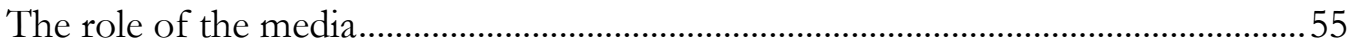

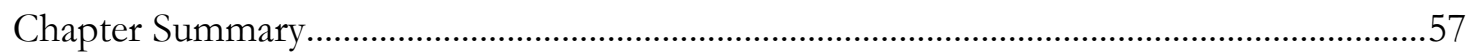

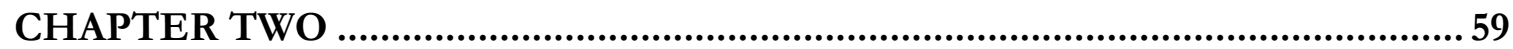

GOOD NEWS AND BAD NEWS: THE TWIN TRACKS OF POLICY DEVELOPMENT IN KUWAIT ........................................................................59

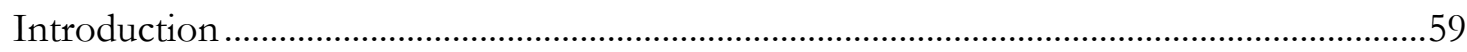

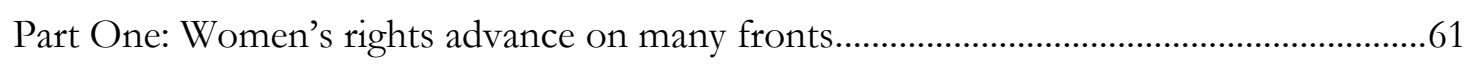

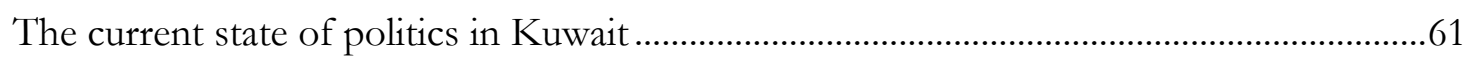

The dualism of women's activism: liberal NGOs and Islamic feminism..............................63

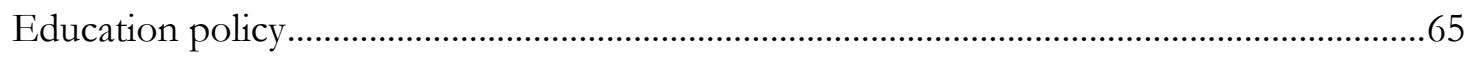

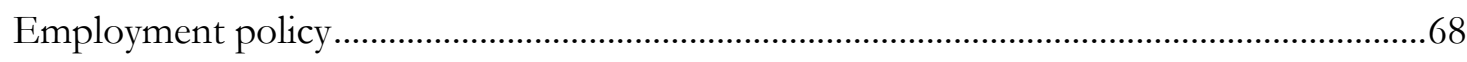

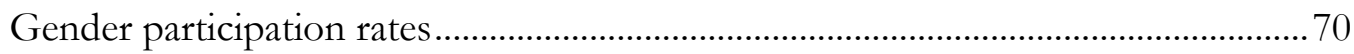


Women in the workplace but not in the boardroom .78

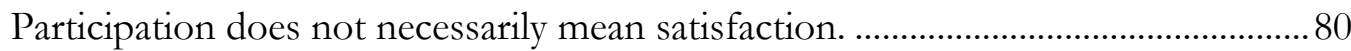

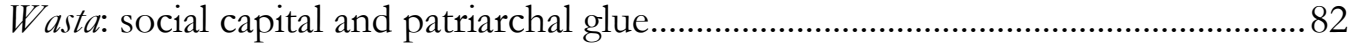

Part Two: No progress in key areas of women's rights .............................................................83

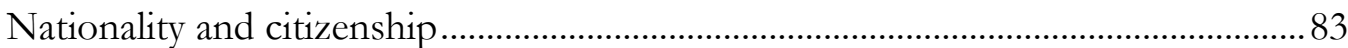

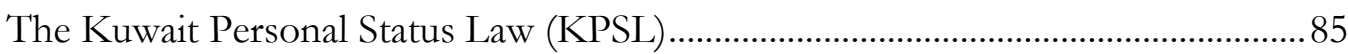

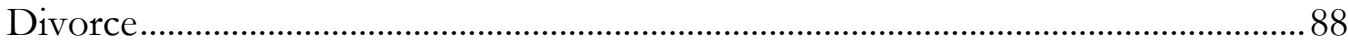

Housing policy ………………………………………..................................................... 93

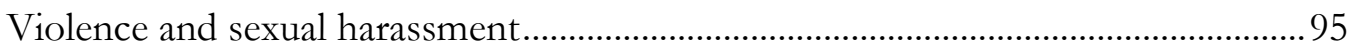

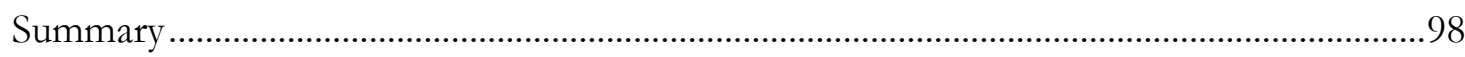

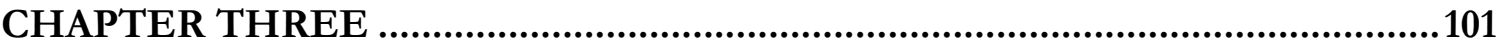
WOMEN'S EMPOWERMENT: SETTING THE THEORETICAL FRAMEWORK

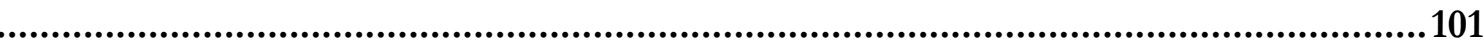

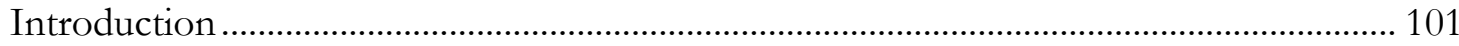

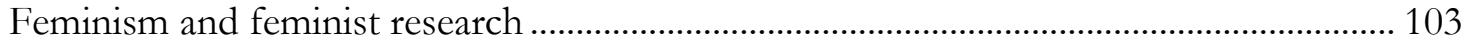

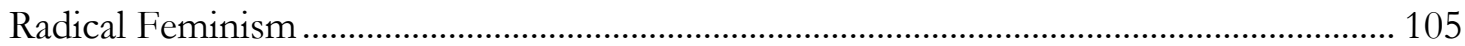

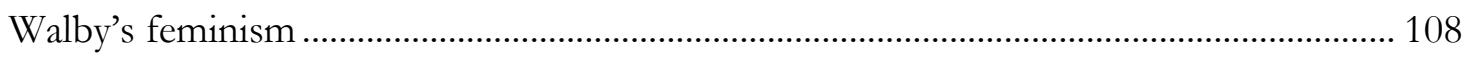

Walby's Complexity Theory................................................................................................109

Walby's approach to analysing change in gender relations ........................................113

Gender Equality Architecture...................................................................................115

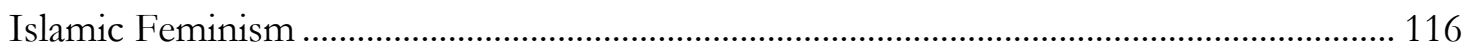

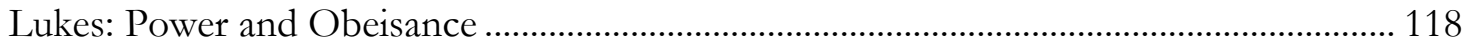

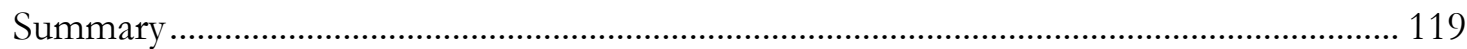

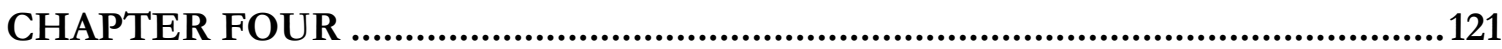

RESEARCH DESIGN AND METHODS EMPLOYED...................................121

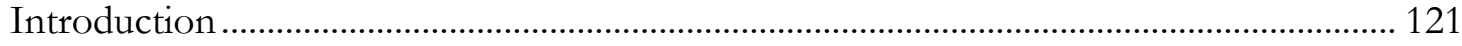

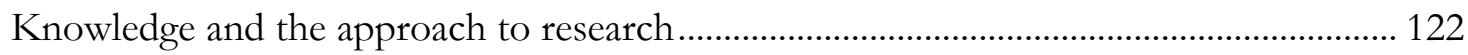

Epistemology and the research paradigm ...................................................................122

Objectivity in qualitative studies................................................................................124

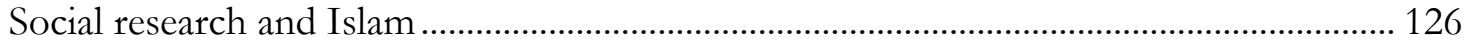

Researching sensitive issues with Muslim women subjects .....................................127

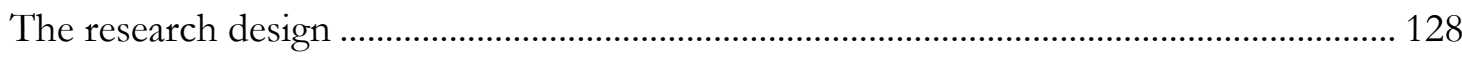

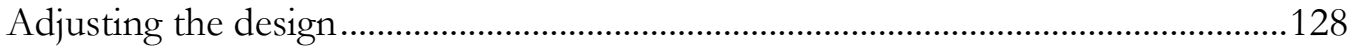


The quantitative study

The qualitative study

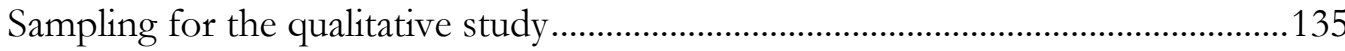

Women in leadership interviews ...............................................................................136

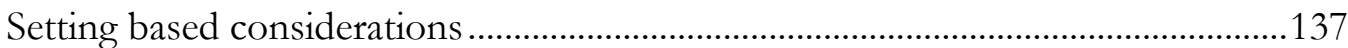

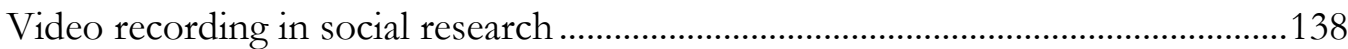

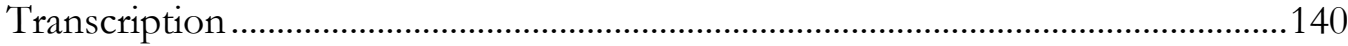

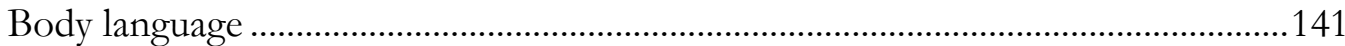

Dress and the researcher-participant relationship ..............................................142

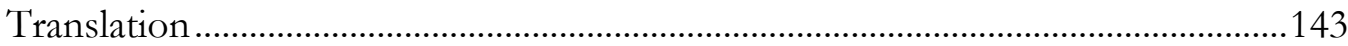

Qualitative data analysis.................................................................................................143

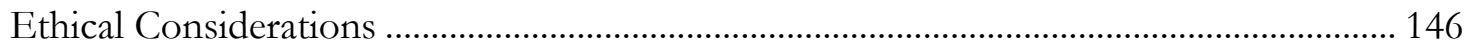

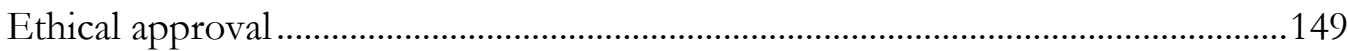

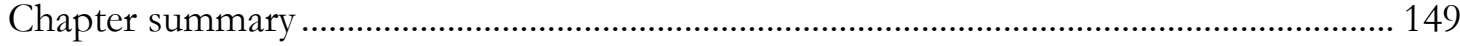

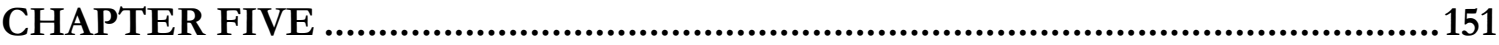

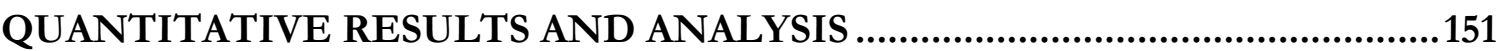

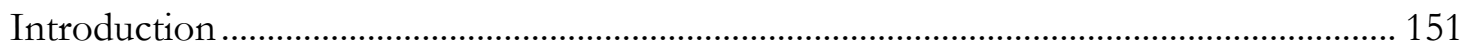

The number of responses, response rate and possible reasons for it ................................. 152

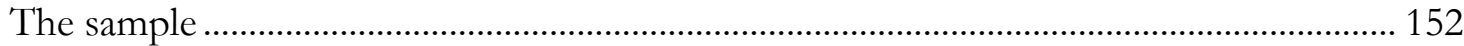

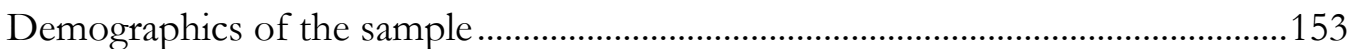

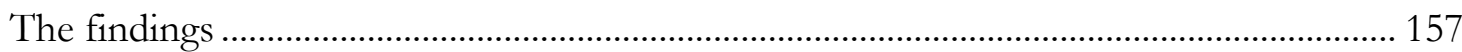

The principle of gender equality .......................................................................................157

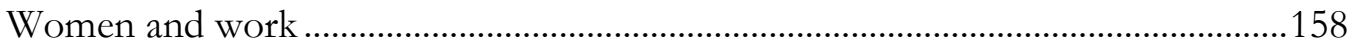

Women and the political domain ................................................................................160

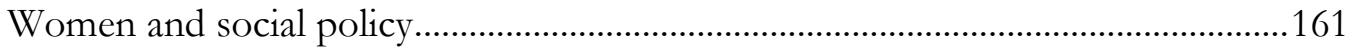

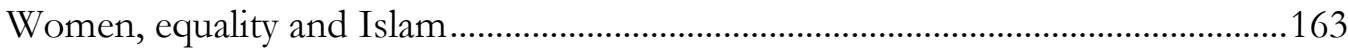

Perspectives on the past, present and future.............................................................164

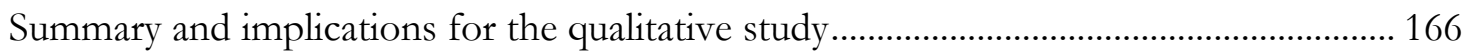

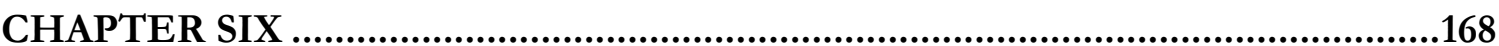

STEPS TO EMPOWERMENT? EXPLORING THE PERCEPTIONS OF EDUCATED AND URBANISED KUWAITI WOMEN ON SOCIAL POLICY

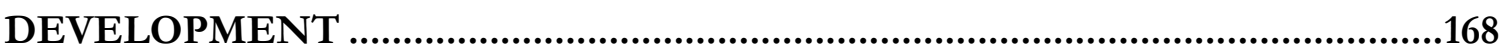

Demographics of the women who took part in the interviews ...............................170 
Empowerment through political participation

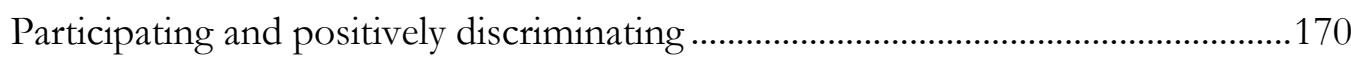

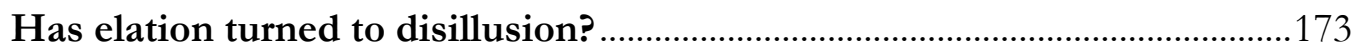

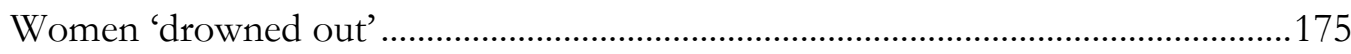

Wasta: social capital mostly possessed by men...........................................................177

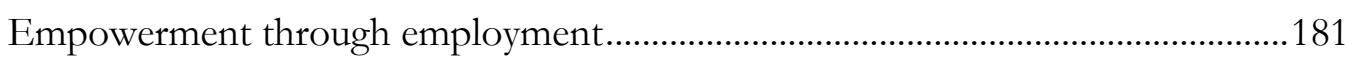

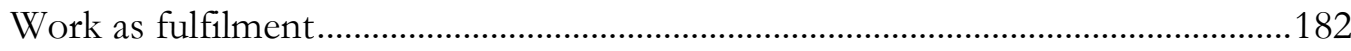

Equality at work ……………………………………….............................................183

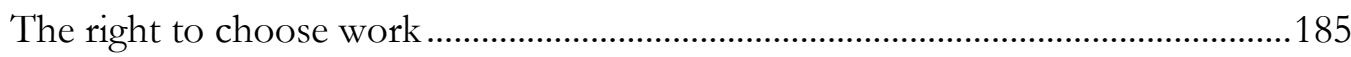

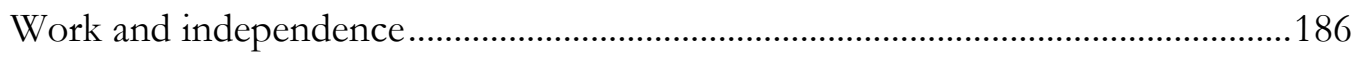

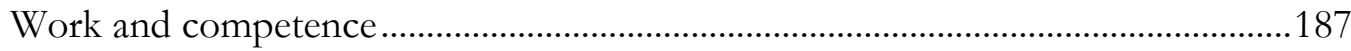

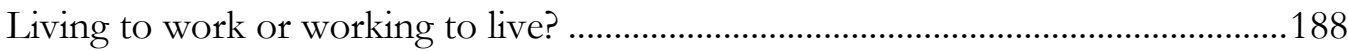

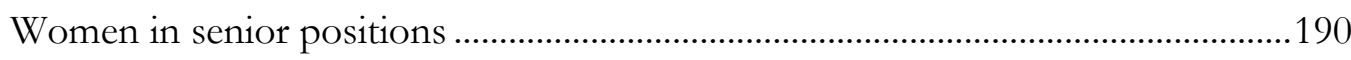

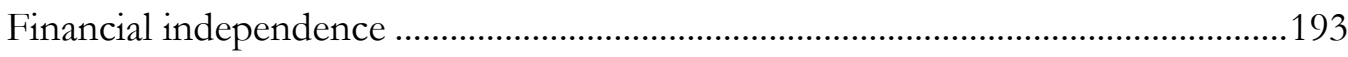

Emotions as a perceived weakness in women ....................................................198

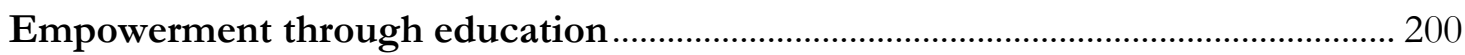

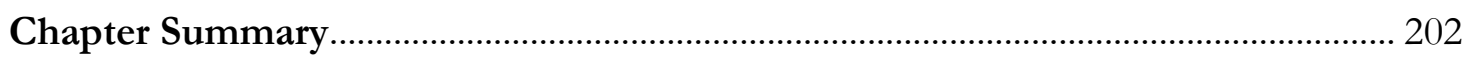

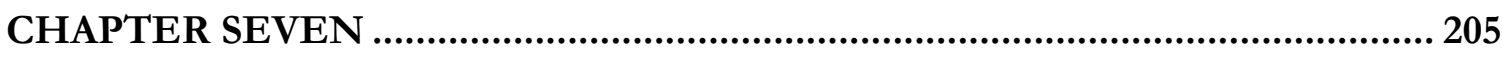

EXPLORING WOMEN'S PERCEPTIONS OF EQUALITY AND SOCIAL

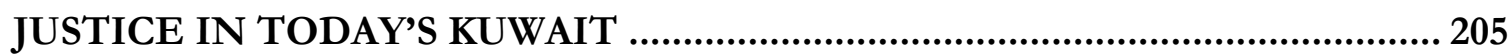

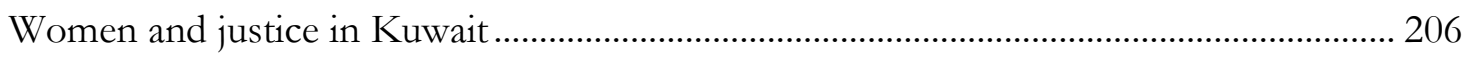

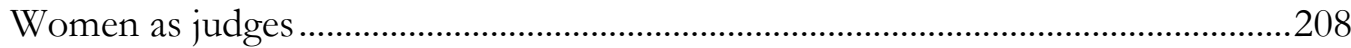

Patriarchy and control of women in public and private.................................................... 214

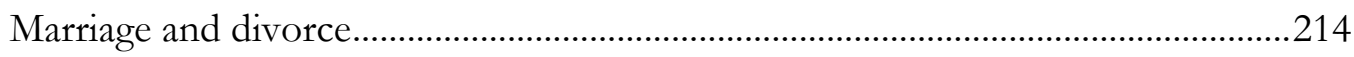

Sharia, patriarchy and control of the private sphere .............................................................. 219

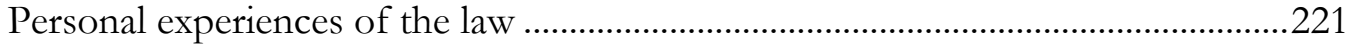

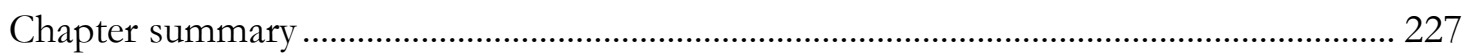

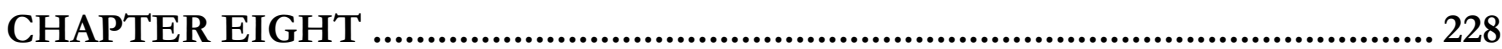

HOPES, AMBITIONS AND ATTITUDINAL CHANGE: EXPORING KUWAITI WOMEN'S PERCEPTIONS ON EQUALITY IN THE FUTURE ..................... 228

Hope

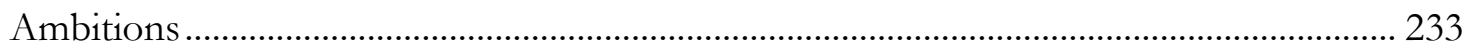

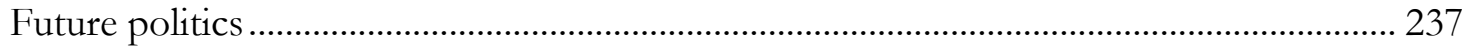


Women's perceptions of attitudinal change among men?

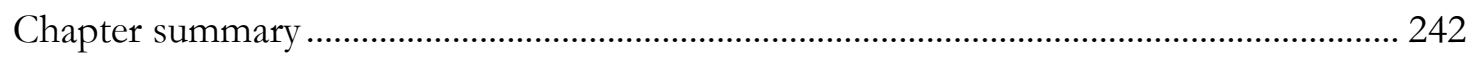

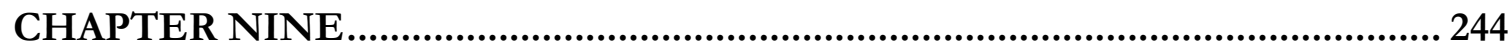

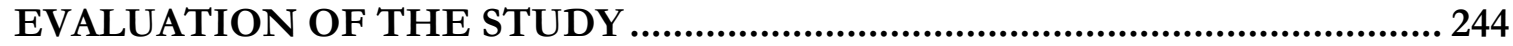

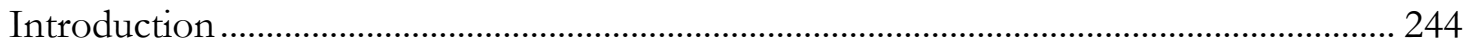

The value of domestic production and women's emergence in the public domain of market labour.

Wasta

Political citizenship and emergence in the public sphere.

Marriage: the principal means of private sphere confinement for adult Kuwaiti women 253

Types of feminism revealed in this study

Power, patriarchy and religion: ownership of the means of production of religious knowledge 255

Reflection on power, obeisance and rebelliousness: Why most obey and some do not. 256

Looking forward: the long road ahead .259

Chapter Summary 263

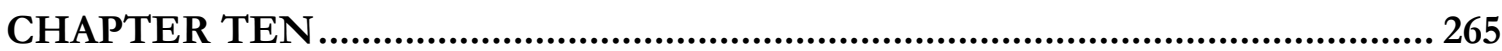

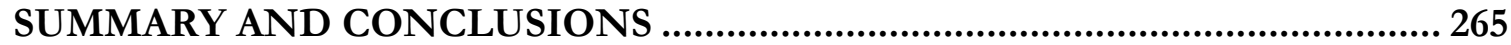

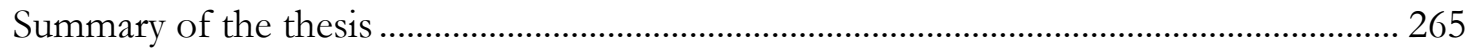

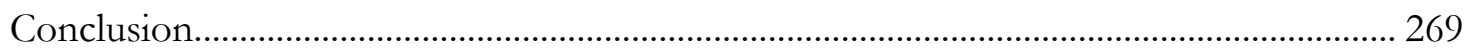

Recommendations for further research................................................................................. 270

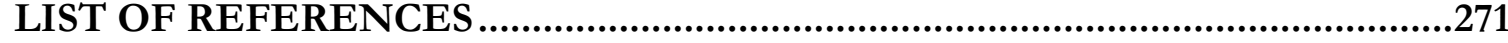

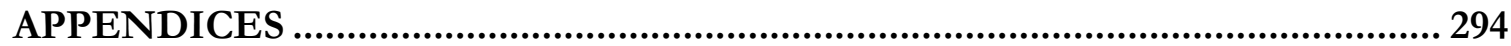

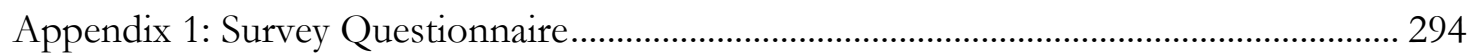

Appendix 2: Participant Information Sheet............................................................................... 297

Appendix 3: Participant de-briefing email................................................................................. 299

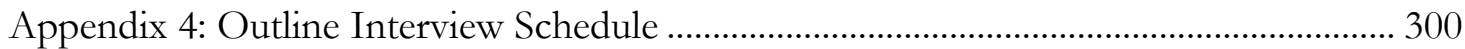

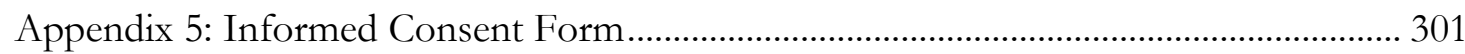

Table of Figures 
Figure 1: Changes in labour force participation in GCC countries $1980-2009$ .73

Figure 2: Labour Force participation by gender (aged 15+) 2003, 2008, 2014 (Kuwaiti nationals only) .74

Figure 3: Women's participation rates in the labour force UK and Kuwait $(1980-2009)$....76

Figure 4: GDP growth and women's participation in Kuwait's labour force 1980 - 2009 .....77

Figure 5: Religiosity and women's representation in European Union boardrooms, by member country. .79

Figure 6: Marital Status of Kuwaiti Women Aged 25 - 44 .89

Figure 7: Sample Analysis - Marital Status 154

Figure 8: Sample Analysis - Employment Status 154

Figure 9: Sample Analysis - Graduate Status 154

Figure 10: Sample Analysis - Age Group 155

Figure 11: Sample Analysis - Voting Behaviour 156

Figure 12: Age and attitudes to equal rights 158

\section{Table of Tables}

Table 1: Women candidates and MPs 2008 to 2013 .62

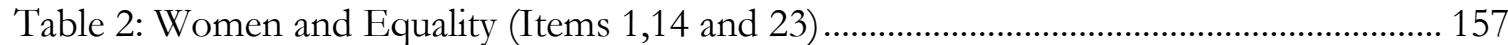

Table 3: Women and Careers (Items 22, 17 and 20) ................................................................... 159

Table 4: Women as Judges and Lawmakers (Items 5, 13 and 18)......................................... 159

Table 5: Women and Political Participation (Items 3,4 11 and 25) ....................................... 161

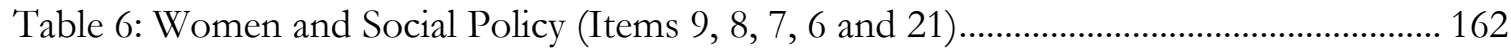

Table 7: Women Equality and Islam (Items 16. 12, 15 and 10) .................................................. 163

Table 8: Perspectives on the Past Present and Future (Items 2, 9 and 24) ............................ 165

Table 9: Demographics of Interview study participants 169

\section{Definitions}

In this thesis less commonly known Arabic words are italicised. The most prominent examples of these are defined below as well as one English term of particular importance. 


\section{Diwaniya}

Diwaniya are social gatherings that usually take place in a person's home and that have long been an important feature of Kuwaiti culture they are characterised by an 'open house' approach whereby in principle anyone was welcome to enter and participate. Long the preserve of men, in recent times women have increasing held diwaniya where women's issues are often the topic of conversation. Most controversially of all, there have been attempts to hold diwaniya with both sexes present, something that has met with great opposition (Toumi, 2010).

\section{Fatwa}

A fatwa is a sharia ruling given in compliance with the Qur'an and the Sunna and result from the scholarly reasoning of Islamic jurists. A citizen can apply to the government for such a ruling to be made on a wide range of issues (Hendrickson, 2013).

\section{Majlis Al-Umma}

The Arabic words 'majlis al-umma' translates as a place of sitting. In its capitalised form it is the name of the national assembly (or parliament) of Kuwait. It was established by the 1952 Constitution.

\section{Talaq}

Talaq is an oral process of divorce whereby the husband may effect a divorce by the utterance of "I divorce you, I divorce you, I divorce you". The wife does not even have to be present which has led to much controversy over talaq by text message or email. The divorce can also be reversed by the husband, once again through a simple verbal indication (Ahmad, 2009).

\section{Ulema}

The ulemas are men of Islamic religious knowledge and hold a senior and vital role in the social, legal and political lives of citizens in Islamic societies and are attributed a prestigious form of authority (Gibreel, 2001). 


\section{Wali}

A wali is a male guardian of an unmarried Muslim woman. The wali is most often the women's father but can also be an uncle, brother or other male relative. The wali exercises certain powers over the woman; for example, she may not marry without the approval of the wali (Nazir and Tomppert, 2005).

\section{Wasta}

Wasta is a tribal Arabic term that far predates Islam. It can be defined as a form of social capital that is derived from personal connections - these connections are mainly among members of the same tribe or relatives within the same extended family. This social capital is commonly used to achieve certain objectives which may be political, financial, social, among other areas of life. It is sometimes negatively associated with corruption and nepotism (Barnett, 2013).

\section{Educated urbanised women}

Perhaps the key English term used in this thesis is 'educated urbanised women'. It is used to describe the target population for the primary research. In conventional terms virtually all of Kuwait is urbanised (98.33\% according to the World Bank (2015); however, in this thesis the word urbanised is used as a rather multi-faceted term to describe more than just living in an urban area. To the basic characteristic of where they live is added access to the public sphere (without being accompanied by a male) access to technology such as the internet and social media and lives less influenced by tribal considerations. So, in the context of this study 'educated urbanised women' refers more to a set of attitudes and standards of education than merely to the location of one's home.

\section{MY PERSONAL JOURNEY}

From a really young age I had asked myself the question of why women did not have equal rights with men. As a young girl I always used to compare myself to my brothers, I saw that however hard my parents tried to treat me equally it just did not make up for the way Kuwaiti 
society was organised in favour of men. Growing up, every day I would see more and more aspects of life that I could not participate in the way that boys and men could. I strongly felt that this infringed against my humanity. However, when I voiced questions about equality people reacted differently to me, as if the questions were unusual or inappropriate. I came to realise that if I wanted to raise these kind of questions I would have to do it from a position of academic strength.

I was certain that there had to be more equality, particularly within the family. As an undergraduate I had read texts on women's issues and I started attending conferences such as the UN's 'Women 2000: Gender Equality, Development and Peace for the Twenty-first Century" in New York between 5- 9 June 2000. For a young Kuwaiti woman just 20 years old to travel alone abroad for 10 days was daunting enough, but to attend a conference that discussed topics which were taboo for Kuwaiti women was more exhilarating than scary.

The value of this study should not be underestimated. Researching women's rights in Kuwait is extremely controversial. There have been obstacles which have made me doubt whether this research study could be completed. Most importantly, the issue of how I could get to hear the voices of women in a society where so much is left unsaid and so many issues and topics are left un-discussed. Unsurprisingly therefore I was extremely worried about my research participants - would women come forward to take part in the research? And, for those women who did come forward - could I ensure that no harm would come to them through participating in the study? However, the fact that the study was controversial and problematic was definitely not a reason to avoid it. In fact, I felt it added to the value of what I was doing. Nevertheless, at the forefront of my mind were the issues of how I could make participation in the study a positive and safe experience for those women who took part. I surmised very quickly that if I engaged with women who were educated and urbanised (as opposed to those un-educated and from more tribal families) in a safe environment that the risks to both the participants and the researcher could be reduced. The realities of access, culture, religion, participant protection and so on were all issues which therefore impacted on how and where I carried out the research as well as who took part in it.

I embarked on data collection initially through a questionnaire. The purpose of which was to collate basic descriptive data but also very importantly the questionnaire I believed would be a vehicle to draw women to the study and encourage women to go on to take part in indepth interviews. Although the questionnaires were distributed by myself at safe 
environments (university campuses for example) to women who either attended, studied at or worked within educational environments, I was quite surprised by the numbers of people who refused to take the take the questionnaire from me. However even from this I learned; women did not simply refuse or walk away but engaged in discussion about why they did not want to complete the questionnaire. In short, women explained in a variety of ways how this kind of research was not appropriate. My presence however generated interest and slowly I found more and more women willing to participate and word of mouth generated momentum - over 400 women completed the questionnaire.

Despite over 400 women completing my questionnaire only 37 women indicated their willingness to be interviewed and ultimately just 20 participated. While I had anticipated a small self-selecting sample, the small uptake is perhaps an indicator of the controversial nature of this study situated in Kuwait. This was my first interviewing experience in a research context and I was painfully aware that I had to be respectful and conscious of cultural sensitivities. I thoroughly enjoyed listening to views of women I had never met before and my learning and understanding of how women perceive women's rights within Kuwaiti society was greatly enhanced.

Not all of the participants were in favour of extending women's rights and with regard to these women I felt that their views were deeply rooted in the past, in their past family history - importantly however, all views were treated with respect. Interestingly, even the women who took part in the study who were disinclined to ask for rights for themselves they happily projected a different set of attitudes and expectations onto the future, for example they were hopeful for children. For some participants, it seemed to be acceptable to talk about greater empowerment for women in the future, as long as they were not seen to be asking for anything for themselves that society has taught them they should not have.

The findings of the research offer much more than a 'snap shot' into the lives and opinions of women in Kuwait - they offer a first building block of knowledge and bring for the first time women's voices into the policy making arena. When I participate with others from around the world, for example at conferences, or when I am speaking with government ministers, or even if I am running for the Kuwaiti parliament in the future I believe that my research will provide me with legitimacy and a solid foundation for my contributions. This research will give me the self-confidence I need to place my chair at the table of any discussion. 
Nevertheless, this study has been an exploratory one, and any change in Kuwait to enhance women's rights in the future will have to be underpinned by further academic work. My ambition is to be an active player in shaping this future, I want to go on to acquire a more comprehensive understanding of women's rights in other countries and bring this knowledge to Kuwait. In summary, it is perhaps appropriate to state that this study represents the beginning of my journey, the rest of it will undoubtedly be focused to a large extent on what works and what does not, when it comes to gender equality.

Finally, this journey could not have been completed without a great deal of support from my family, my husband and my friends. I have the feeling that they think that something positive can be achieved through my work. Even though my research is seen as controversial those around me defend me because they feel I am doing something which needs to be done. And, importantly, perhaps the biggest driver has been my young son. I am trying to raise him in a different way and the thought that when he is older he will come to admire and support my efforts and see them as right and just is a great motivator for me. 


\section{INTRODUCTION}

On the $17^{\text {th }}$ of May 2009, media across the Arab region and beyond were reporting a 'wind of change' blowing a 'female revolution' in Kuwait as four women were decisively elected to the state's National Assembly, one of whom also became a cabinet minister (Al-Jazeera, 2009; Reuters, 2009; Worth, 2009). Already passed and proposed legislation suggested a raised awareness of gender rights but how far this legislative reform affected the daily lives and attitudes of Kuwaiti women had yet to be examined. This study aims to address this lacuna in understanding, which is how the legislative changes that spark discussions among academics, campaigners and politicians are perceived by ordinary citizens, specifically, the women of Kuwait, and what concrete effects they have had, are having and may have in the future.

This chapter aims to contextualise the research, and introduce some of the key research themes which shaped the study. First, very importantly, it begins with a brief summary of Kuwait and in doing so provides much needed context for all further discussions from the outset of the thesis. Thereafter, the justification for the study and its relevance to social policy is explained. The aims of the research are also established in this chapter and the theoretical and methodological approaches that the study has taken are described. Finally, each chapter of the thesis is outlined and each chapter's contribution to the overall aims of the thesis is noted.

\section{Kuwait in Summary}

By way of setting the scene for this study and so as not to assume familiarity with Kuwait this section provides a brief overview of the country.

\section{Geographic}

The State of Kuwait, as it is formally known lies to the north east of Saudi Arabia at the northern end of the Persian Gulf. This low lying country covers an area of $17.818 \mathrm{sq} . \mathrm{km}$ (Kuwait Government, 2013) nearly as large as Wales, consisting mostly of barren, sandy desert land. In addition to its southern border with Saudi Arabia to the east and north it 
shares a border with Iraq. Kuwait's strategic position at the head of the Persian Gulf has had a long standing influence on its history.

\section{History}

Archaeological endeavour in the 1950s proved the existence of an ancient civilisation in Kuwait and historians have traced the travels of Alexander the Great to the lands on the east of the Persian Gulf in 326 BC (Al-Diwan Al-Amiri, 2015). Battles between the Persians and Muslims at the time of the advent of Islam also took place in what is now Kuwait in 633AD (Casey, 2007). The first historical references to the ruling Al-Sabah family indicate their presence from 1613 AD a further fourteen rulers have followed Sheikh Sabah Al-Awwal (Casey, 2007).

Although nominally ruled by the al Sabah family Kuwait and its development were heavily influenced by external forces. Powerful regional merchants dominated commercial activity well into the $20^{\text {th }}$ Century (Casey, 2007). The Ottoman Empire under which the Emirs were effectively provincial sub-governors until its fall after the First World War when it was declared a British Protectorate (Casey, 2007). The $22^{\text {nd }}$ of February 1938 was an important day in Kuwaiti history. It was the day that oil was first discovered four years after the first concession agreement had been signed with the Gulf Oil Corporation and Anglo-Persian Oil Company (now Chevron and BP respectively). Despite the stalling caused by the Second World War, Kuwait's oil production developed quickly and by 1953 was the largest producer in the Gulf. More recently it produces almost 2.5 million barrels a day ranking $10^{\text {th }}$ globally (CIA World Factbook, 2010).

The discovery of oil in 1938 raised Britain's interest in Kuwait and led to it taking full control of Kuwait and its larger neighbour Iraq in 1941. British rule lasted until June $19^{\text {th }}$ 1961 when the two countries exchanged documents asserting Kuwait's independence.

The more recent history of Kuwait has been dominated by the two 'Gulf Wars' disputes over oil production that provided the pretext for the invasion of Kuwait starting on August $2^{\text {nd }} 1990$ described as "the most catastrophic event that ever happened to Kuwait since its inception in the 18th Century" (Olimat, 2009, p.202). Six days later defying international condemnation, Saddam Hussein announced the annexation of Kuwait the ' $19^{\text {th }}$ province of Iraq'. The UN Security Council adopted Resolution 668 
authorising the use of force to reverse the annexation and the Gulf War, or "Operation Desert Storm", began on $17^{\text {th }}$ January 1991 (Casey, 2007). With the invading forces repelled quickly the emir returned from Saudi Arabia. During the second Gulf War, Kuwait was a crucial staging post used by mainly US and UK forces in their invasion in 2003 and subsequent occupation (Casey, 2007). The current emir, Emir Sabah IV AlAhmad Al-Jaber Al-Sabah, began his reign in 2006.

\section{Demography}

The population of Kuwait was estimated in 2012 to be 3.3 million and comprised of 1.12 million Kuwaitis with the remainder being non-Kuwaitis and foreigners (Kuwait Government, 2013b). The sex ratio shows there are 1.41 males for every female (CIA World Factbook, 2015). Life expectancy (est. 2013) is 78 years for males and 79 yrs. for females (World Health Organisation, 2015).

Eighty percent of the population is Kuwaiti or other Arab and 76.7\% are Muslim. Among Kuwaiti citizens, Sunnis are in the majority (70\%) with 30\% being Shi'a. Kuwait has a young population with a median age of 26.4 years compared with 40.4 years in the UK (CIA World Factbook, 2015), though it is in line with the region's average.

\section{Economy}

For centuries the Kuwaiti economy was based on pearl diving but that changed with the discovery of oil in 1938. Today Kuwait is a capitalist-statist relatively open market economy described as high income non-OECD with a per capita Gross National Income of \$52,916 in 2013 approximately 20\% higher than the UK in the same year (World Bank, 2014). Despite this wealth Kuwait has not performed, as an economy, as well as some of its neighbours particularly in terms of its infrastructure and its attractiveness for foreign direct investment. Its government effectiveness as measured by the World Bank lags significantly behind those countries in the region it is most appropriate to compare it to including the UAE, Qatar, Oman, Bahrain and Jordan (World Bank, 2014).

The economy has been described as "government-dominated, bureaucratic, [and] oilcentric" (Wigglesworth, 2010) and in recognition of this and also to counter the negative effect that the global financial crisis has had, the Majlis Al-Umma approved a wide 
ranging ambitious development plan to restructure its economy, increase private sector activity and reduce reliance on oil. The recent dramatic fall in the price of oil has affected exporters like Kuwait, however, the government’s latest 5-year plan features $\$ 155$ billion of investment, much of which will be spent on infrastructure projects and a range of generous subsidies which have reduced the cost of living for Kuwaitis such as those on electricity, water and petrol are set to be cut (Al Arabiya, 2015). The financial investments are complimented by a major legislative programme aimed at building efficiency, increasing competitiveness and improving governance.

Importantly, Kuwait's status as an oil-based economy is highly relevant to any study of the rights of Kuwaiti women and the social policies that affect them. This is because in many ways the legitimacy of the ruling families in the Gulf Region has been supported by a State Welfare system that is funded by oil revenues (Joseph and Najmabadi, 2005). Indeed, Olimat (2009) describes this as a trade-off whereby citizens give up real political power in return for a range of mainly financial benefits such as not having to pay taxes.

\section{Employment}

The labour force participation rate of women in Kuwait is relatively high. In 2011, of the total female population above the age of $1562.5 \%$ were in employment compared to $87.9 \%$ of males (ILO, 2015). This is more than treble the rate of participation in neighbouring Saudi Arabia (20.4\%) and has now overtaken Qatar (53.1\%) (ILO, 2015). Trend analysis also reveals rapid and sustained growth in the level of women participating in employment from 1980 (19.3\%) through 2003 (46.3\%) and on to 2011 (62.5\%) (ILO, 2015).

On $21^{\text {st }}$ February 2010, a new Private Sector Labour Law (No.6 of 2010) came in to force enhancing private sector workers' rights and addressing areas such as end of service compensation, holiday entitlements and maternity leave among others. Section Four focused on the employment of women and introduced equal pay for the same work and also the right to maternity pay. It also required employers to set up nurseries where more than 50 women are employed. The overall aim of the law is to make private sector employment more attractive for employees who may have traditionally perceived state jobs as offering greater security and benefits. In 2015, the government went further and extended these rights and protections to domestic workers not covered in the 2010 law 
(Human Rights Watch, 2015). The effect of women's increased participation in the workforce and the financial independence it offers is a prominent theme in this thesis.

\section{Politics}

The State of Kuwait is a constitutional emirate. The emir (Kuwait head of state, currently Sheikh Sabah IV Al-Ahmad Al-Jaber Al-Sabah) is chosen by a family council of the leading family members: succession is often but not always on a hereditary basis. The legal system is based on the post-Independence constitution of 1962, a constitution that can be amended or suspended by the emir. Executive power is held by the emir who exercises it through the Council of Ministers comprised mostly of male al-Sabah family members and is led by the prime minister who is appointed by the emir (Economist Intelligence Unit, 2009). The constitution guarantees "All people are equal in human dignity and in public rights and duties before the law, without distinction to race, origin, language, or religion". There is no specific enshrinement of gender equality but neither is there of discrimination.

The legislative branch of government consists of the emir and the unicameral National Assembly known as the Majlis Al-Umma the members of which are a combination of elected representatives who are mainly chosen on the basis of tribal interests and the members of the council of ministers. Formal political parties are banned though de facto parties exist in the shape of blocs and members are either associated with one of these blocs or sit as independents. There are, however, active groupings representing Sunni Muslim, Shi'a Muslim and secular interests (Kuwait Politics Database, 2009). Members are elected for four year terms. There has been a recent history of tension between elected representatives and the appointed Cabinet. The emir has the power to dissolve the Assembly, a power which has been used five times sometimes constitutionally with fresh elections held in timely fashion but others unconstitutionally. In March 2008, the Assembly was suspended after the cabinet resigned from it claiming a lack of cooperation from the elected representatives, while another dissolution soon followed after the prime minister refused to face parliamentary questions over his handling of the economic affairs of the country (Economist Intelligence Unit, 2009).

According to Kandari and Hadben (2010, p. 278), "Politics in Kuwait is regarded as a masculine a air derived from ongoing tribal traditions. Men are in charge of political 
matters." However, there have been a number of significant advances in the position of Kuwaiti women in political life in recent years. Now women can vote in and stand for municipal and national elections, they have been elected to the Majlis Al-Umma and appointed as ministers and Kuwait had its first woman sit in the 16-member cabinet from 2005 (BBC News, 2005).

The electorate has demonstrated an ability to express its will both at the ballot box and through political protest. The former is exemplified by the ousting of 21 sitting MPs at the 2009 election and convincing wins for four women candidates, the first to be elected after suffrage was extended to women over 21 in 2005 (Al Jazeera, 2009). The rulers of Kuwait had made numerous attempts to extend voting rights to women but these had been rebuffed by the Assembly. When success finally came women overnight became $57 \%$ of the electorate (Olimat, 2009). An example of extra-parliamentary action was the March 2005 women-led protests in front of parliament against the political exclusion of women. Such was the attention they drew that just two months later the existing legislation was changed to extend political rights to women. This was a clear indication that many Kuwaiti women are politicised, concerned about their rights, want progress and are prepared to take action - despite male patriarchy.

However, while the political dynamic at the heart of the legislative process is repeated throughout the region, Islamist groupings seek the supremacy of sharia law to be reflected in national legislation. Thus, while more liberal interests aim to promote reform across a wide range of fronts including democratisation and gender issues, it remains true to say that two diametrically opposed philosophies face each other in the National Assembly. Given this, it is perhaps unsurprising that the ruling elite of the al-Sabah family see their main interest served politically by economic stability and through modernisation (Rizzo, Meyer and Ali, 2007).

\section{International Conventions}

Kuwait has acceded to a range of United Nations (UN) and International Labour Organisation (ILO) Conventions, two of which are concerned with civil and political rights; The International Covenant on Economic, Social and Cultural Rights (1996) and the Convention on the Elimination of All Forms of Discrimination against Women (1994). However, a series of reservations were made on these Conventions on the basis 
that they were incompatible with sharia; for example, the provision in the former Convention securing the equal rights of men and women would be applied according to 'Kuwaiti law'. In the latter Convention reservations were put in place regarding voting rights (women at this time could not vote under Kuwaiti law but the reservation was withdrawn in 2005 when women were enfranchised) and equal rights in terms of their children's citizenship and equal rights regarding guardianship, custody of children and adoption (United Nations, 2015).

To provide a regional Arab version of the increasing number of global Charters and Conventions, some of which are mentioned above, Arab countries agreed the "Cairo Declaration on Human Rights in Islam" in 1990 and the amended version in 2004, while Kuwait agreed to both there was no formal ratification and it has only 'guidance' status (Arab Human Rights Index, 2013). Article One of the 1990 Declaration asserts that "All men are created equally in terms of basic human dignity, basic obligations and responsibilities without any discrimination on the grounds of race, colour, language, sex, religious belief, political affiliation, social status or other considerations" (Arab Human Rights Index, 2013, p.1).

\section{Women's rights and policy development}

\section{Independence and the Constitution}

As already noted, Kuwait achieved independence in June 1961. The following year saw the adoption of a new constitution that had been drafted by bringing together strands of liberal democratic traditions seen in the US Constitution, the French and British legal frameworks, Egyptian law and Kuwait's Arab - Islamic origins including sharia (AlSabah, 2013). Arguably this paradoxical situation lies at the heart of the discourse on women's position in Kuwaiti society. One the one hand, the Constitution guarantees equality under the law yet on the other it identifies sharia as the primary source of Kuwaiti law. Sharia law sets out the duties and responsibilities that men and women have and these are both different and discriminatory if looked at from the perspective of international Conventions. The most comprehensive code affecting women's position in society is the Code of Personal Status 1984 (no. 51/1984), this is further explained in the next section. 


\section{Kuwaiti Personal Status Law (KPSL)}

The central theme of the discriminatory nature of Kuwaiti law is that women are seen as dependents of men rather than citizens in their own right (al-Mughni, 2010). This is reflected in the KPSL and its 346 articles. Similar laws are in place across the Muslim world though they vary substantially in their detail. The fact that they vary is significant because it effectively confirms that they can be varied further, potentially in the direction of greater gender equality (Musawah, 2015).

Basing the regulation of daily life on a highly conservative interpretation of sharia is seen by many as the main obstacle to developing women's social and cultural rights (Esfandiari, 2004; al-Mughni, 2010). Briefly, women are discriminated against in areas such as marriage, divorce, guardianship, welfare entitlements, nationality rights, housing besides many others. Many of these issues are further discussed in further detail in chapters one and two of the thesis and form topics of enquiry that are explored further with the Kuwait women who took part in this study.

If political rights have developed quite quickly in Kuwait, it is nevertheless arguable that little has happened to alter family and personal status legislation. However, one important example of change came in October 2009 when the Supreme Constitutional Court, whose pronouncements cannot be challenged, ruled that the clause in the 1962 Passport Law (Article 15 of Law 11/1962) requiring women to obtain the permission of their husbands before obtaining a passport or travelling abroad was unconstitutional and it was thereby abolished. The ruling was made after the court had been petitioned by a woman whose husband had refused to let her use her and her children's passports to leave the country (Kuwait Times, 2009). Personal status law is a prominent topic throughout this thesis as it represents an area of life where patriarchy is at its strongest and where changes are most controversial.

\section{Iraqi Occupation and Post War Turmoil}

The invasion and subsequent occupation of Kuwait by its northern neighbour Iraq was a seismic event in the state's history. If women had largely traditional roles within the 
family in the past, from this point they entered the public sphere decisively. The occupation has been described as "catastrophic" (Olimat, 2009) and also "an historical event that brought issues surrounding democratization to the forefront" (Rizzo, Meyer and Ali, 2002, p.647). During this time, women took on roles previously reserved for men and were active in resisting the occupying forces risking imprisonment and even execution (al-Sabah, 2013). There is of course an interesting parallel here with the momentum that was given to women's rights movements in the West after the First World War and repeated after the second (Gottlieb and Toye, 2013). From his exile in Saudi Arabia, Crown Prince Sheik Saad al-Abdullah al-Sabah made a series of promises on political reform to maintain the loyalty of Kuwaiti citizens. Women had established themselves in prominent positions in civil life in both business and academia and were not going to accept returning to their traditional roles once the occupation had been repelled. Again, similarly in Britain after women had taken up positions in the war they resisted returning to domestic roles - however change was very slow - it took the sexual revolution in the 1960s and policy and legal change didn't really begin to take place in earnest until the 1970s.

Similar to Britain, the occupation of Kuwait was a pivotal moment for women but it did not signal an overnight transformation in their rights, far from it. The 1990s was a period of political turmoil. The emir and the executive branch were in conflict with the Islamist dominated National Assembly. The conflict culminated in 1999: frustrated at the lack of progress towards reform the emir dissolved the Assembly and called fresh elections while prorogued the emir issued no less than 63 decrees including one enfranchising women. However, once back in session the new parliament, motivated by umbrage, struck down every one of the decrees (Olimat, 2009; al-Mughni and Tétreault, 2004). Finally, on May $16^{\text {th }} 2005$ a broad coalition of liberals managed to win a vote 35 to 23 in the Assembly, amending the Electoral Law; women had secured voting rights. During the campaign conservative Islamist opponents protested that such a move would distract women from their family duties (Ahmadinejad, 2005).

If women's rights groups had believed that enfranchisement automatically led to representation, then they were to be disappointed at their first two attempts to have women elected to the National Assembly in 2006 and 2008 which failed. An analysis of the 2006 election showed that women overwhelmingly voted for male candidates (Assiri, 
2007). Regardless of these setbacks, women candidates performed better at the May 2009 election and exactly four years after winning the right to vote, four women candidates were elected to the Assembly (Al-Jazeera, 2009).

\section{Current issues}

If the achievement of the right to vote was very significant it was by no means the completion of the journey to greater women's rights in Kuwait. The victory over the Passport Law in July 2009 was declared by one female MP as "a first step in eliminating all laws that are both unconstitutional and a threat to the democratic process in Kuwait" (GulfNews, 2009).

A key issue is the representation of women in the judiciary something for which there is vociferous opposition among conservative lawmakers. Indeed, the lack of women's representation in the judiciary is a key topic of enquiry of this thesis; there are no women judges presiding in Kuwaiti courts and this has been targeted by campaigners as one of the next key changes to aim for. Of course, it is important to note however that lack of judicial diversity is not restricted to Islamic countries. For example, England's first female judge was appointed in 1945: 65 years later less than 14\% of judges sitting in the High Court or higher in England and Wales are women (Centre for the Advancement of Women in Politics, 2010).

\section{Research context}

Kuwait occupies a unique position in the debate on international women's rights. On the one hand, the country exhibits many repressive tendencies in terms of discrimination and inequality; on the other hand, Kuwait is widely hailed as being more progressive than its neighbours in the Gulf region, and is often held up as a model of how Arab states can advance the cause of women without contradicting their basic cultural and religious beliefs. Freedom House, the authoritative US-based NGO which reports on political and civil rights around the world, rated Kuwait 2.6 out of 5 in 2010 (Freedom House, 2010), suggesting that Kuwait is still significantly short of the (western) defined accepted standards found in Western Europe and North America. This said there is considerable discussion over the veracity and legitimacy of these standards, which have been set by those countries almost arbitrarily and from their own perspectives and values. 
Consequently, as Kuwait continues to slowly improve its record in terms of women's rights, there are voices both condemnatory and laudatory, with some believing that the country is an excellent example of non-liberal progressive reform, and other believing that the country is simply not moving fast enough, and is being over-praised for small gains. Drawing on two commentators to illustrate the conflicting messages: Olimat (2009, p.199) reports that Kuwait is "a distinguished model of democratization in the region" and what is more "Currently, Kuwait is freer than any other Arab country in the region, and enjoys a wide range of freedoms incomparable to most Middle Eastern countries." This rosy picture is tempered by Esfandiari (2004) who writes that "equal legal status... is virtually unachievable so long as family law remains based on sharia, and rules derived from particular interpretation of Islam prevail in the social sphere" (p.63).

Despite the changing social environment and the many important issues it raises, there is a lack of research on women's rights/lack of women's rights in Kuwait generally, and a void of empirical research exploring how law and policy has impacted on Kuwaiti women. This thesis sets out to fill some of this void, as it embarks on exploratory research which aims to enhance knowledge in this area and to provide information that can assist policy makers to progress women's rights in a positive way, and importantly, provide women with a voice within the political and policy framework in Kuwait. To date, the author has no knowledge of any previous quantitative or qualitative examination of the attitudes of Kuwaiti women themselves to the rights they enjoy or lack. Academically speaking the voices of Kuwaiti women have gone largely unheard.

Knowledge on women's views and opinions offers much needed light on the sustainability of the 'social contract' between the ruling elite and the citizenry, a citizenry with disparate attitudes and values, ranging from conservative, Islamist, patriarchal, traditionalist and tribal to liberal, social democratic and feminist. Furthermore, women's views and opinions provide a greater understanding of the relationship between greater educational, political and economic empowerment and the desire for formal legally based equality. This is vital if Kuwait is to move to a greater understanding of women's rights and the compatibility of those rights in a modern democracy with tradition-based sharia principles.

Kuwaiti women face a whole range of challenges and disadvantages both in public domains and in the private sphere which are not faced by men and to a large extent have 
been put in place by men. A complex web of traditionalist cultural, religious and civic forces some coded in to law and some maintained by the power of religion and tradition mean that inequality and discrimination and a lack of social, cultural and economic power pervade their lives. Thus this research, while offering some highly prized academic outcomes also presents significant challenges. The challenges include accessing the views of the 'ordinary citizen' and ensuring that the attitudes expressed are those of the respondent in a society where tradition or ancient social codes and mores still prevail. A study of women's empowerment in an Islamic country such as Kuwait also involves compromises on behalf of the researcher. In order to ensure the participation of women it is necessary to set boundaries as to the field of enquiry. Certain topics of enquiry could give rise to harm for both the participants and researcher - for example certain areas such as male violence, sexuality and the direct questioning of Islam or Islamic principles (the latter of which is a criminal offence in Kuwait).

This research project uses direct, primary research methods to determine the views of women in Kuwait, allowing them to explain their concerns, worries and satisfaction with the state of women's rights in the country. This information is contextualised against the backdrop of indirect, secondary research into the history of the subject, looking at the competing arguments and the different interpretations that have been made. The aim is to build up the most comprehensive analysis of women's rights in Kuwait yet made, informed by an unprecedented attempt to uncover and understand the everyday experiences and thoughts of the women themselves.

\section{Limitations to the research}

The study of women's empowerment in an Islamic country such as Kuwait involves compromises on behalf of the researcher. To begin with it is extremely difficult to assess the views of the 'ordinary citizen' - a representative sample of women who are urbanised, not urbanised, educated and not educated, tribal and non-tribal lays far beyond the capacity of this study. Achieving a representative sample in the study was not possible as the participation of certain groups of women (those from the most tribal, traditionalist parts of Kuwaiti society) would have been impossible to secure and even if achieved would have presented unacceptable risk to both participants and researcher. Thus in order to ensure the safety of the women participating in this study, it was 
necessary to set boundaries to the field of enquiry and it was decided that only the views and opinions of women who are urbanised and educated and those in positions of leadership would be sought. Regarding the term 'urbanised', this is used as a rather multifaceted term to describe more than just living in an urban area, after all, according to the World Bank, 98.33\% of the population of the country is classed as urban (World Bank, 2015). To this very basic question of where they live, other characteristics are added such as access to the public sphere (without being accompanied by a male) access to technology such as the internet and social media and lives less influenced by tribal considerations. So, in the context of this study the definition refers more to a set of attitudes and standards of education than merely to the location of one's home. In Kuwaiti society, this group is overwhelmingly educated in the sense they are mainly university graduates or students. Specifically, the survey reported in this study revealed that nine out of ten respondents were indeed university graduates or students. For these reason this thesis refers to educated urbanised Kuwaiti women as being the research population for this study.

As already noted, ensuring that the attitudes expressed are those of the respondent in a society where tradition or ancient social codes and mores still prevail is problematic. Thus, the design of the methods of data collection and tools to gather data as well as data interpretation were extremely important - every step possible was taken to relax the participants and to ensure they felt safe. Also in an attempt to travel beyond the social codes and mores, a conscious effort was made to explore women's hopes for future generations.

Given that the majority of women taking part in the research were likely to be women of faith and some women may have traditional cultural family backgrounds then particular concern had to be given to risks to both the participant and researcher given the controversy of the research topic, cultural sensitivity and the possible adverse reaction to their participation among men. Thus, it is important to note at the outset of this thesis that issues that may or could give rise to heightened risk were discounted, such as male violence, sexuality and the direct questioning of Islam or Islamic principles. Nevertheless, having made these compromises, the research considers the views of Kuwaiti women on other controversial (albeit less controversial) issues such as voting, women's role in the workplace, social policy and so on. This type of research still represents a journey into 
the unknown - the findings of which will enhance an understanding of if and how women in $21^{\text {st }}$ Century Islamic Kuwait are resisting patriarchy and seeking greater empowerment.

\section{Research aims and methods}

This study undertakes a critical exploration of educated and urbanised Kuwaiti women's perceptions of their changing social environment, specifically with regard to gender relations and gender inequality and in doing so builds up the most comprehensive analysis of women's rights in Kuwait yet made, informed by an unprecedented attempt to uncover and understand the everyday experiences and thoughts of the women themselves. To do this the study sought to examine how Kuwaiti women interpreted legal and policy developments across a number of domains. The research had three main aims:

1. To explore the impact of legal and policy reforms made in the recent past (mainly in the last 15 years) in the public domain and the lack of legal and policy reform in the private domain from the perceptions of educated and urbanised Kuwaiti women.

2. To explore the implications of the patriarchal structuring of Kuwaiti women's lives in the private domain, marriage and divorce and the system of justice from the perspectives of educated and urbanised Kuwaiti women.

3. To explore the views of urbanised and educated women with regard to how men are experiencing women's empowerment and to explore their aspirations for equality in the future.

Adopting a mixed methods approach, this phenomenological study discusses descriptive findings from a survey carried out with over 400 educated and urbanised Kuwaiti women together with in-depth interviews carried out with 20 educated and urbanised Kuwaiti women and 5 women in positions of leadership in Kuwait. The study represents a critical 
exploration of Kuwaiti women's resistance to patriarchy in the 21 st century against the background of social policy developments and controversies.

\section{Research questions}

Having established the three-fold aims of the research three research questions can be formulated as follows:

RQ1 How has the recent development of social policy pertaining to women's rights in Kuwait been perceived by educated urbanised Kuwaiti women?

RQ2 How does the Kuwaiti urbanised educated woman in Kuwait view equality in the arena of social justice in Kuwait?

RQ3 How do educated urbanised women in Kuwait view their future empowerment and development of social policy?

The findings of this study are organised into three chapters (six, seven and eight), each addressing one of these questions.

\section{Research approach}

The research approach behind this exploratory study draws on a range of inputs along both its theoretical and methodological dimensions. As discussed in more detail in chapter three, a number of theoretical constructs were considered for use in conceptualising the findings of the current study and indeed many were used in this fashion. However, as this was very much an exploratory piece of research in a research context where there is a dearth of existing work, the theories considered are far from forming a rigid theoretical framework.

Ontologically speaking, the approach required to meet the research aims was relatively easy to identify. As the research attempts to understand the subjective meaning of social action and as the researcher is interpreting the interpretations of the subjects being studied it is clearly based on an interpretivist ontology. 
The epistemology of this paper is phenomenological because it is concerned with how meanings, understandings and assumptions about social phenomena are socially constructed, and the social processes that sustain these meanings. It is a first-person approach to knowledge and the construction of reality, reflecting this study's desire to listen directly to the voices of Kuwaiti women as they interpret what is happening around them.

Exploratory research needs to maintain flexibility at each stage and while the main research approach applied was qualitative, the number of responses received to what was initially intended as a small questionnaire survey aimed at piloting and guiding the subsequent interview-based study was so high (n437) that it would have been a missed opportunity not to use the quantitative data generated in a way not originally envisaged. Thus the descriptive data from the survey is reported on and utilised as complimentary source of findings. To this extent this could be characterise as mixed methods research.

Finally, at this introductory stage another characteristic of the research worth highlighting is feminism. The fact that this research was conducted by a female researcher investigating empowerment of women and collecting data only from female subjects and ultimately making recommendations which are aimed at benefiting women would suggest that this study is effectively feminist research. However, the study did not apply a rigid feminist theoretical framework, or any particular theoretical framework for that matter. The main reason for this is the exploratory nature of the research and uncertainly that theories developed in western contexts would be transferable.

\section{Research importance}

The study provides Kuwait, the Gulf Region and the world at large with an enhanced understanding of the relationship between greater educational, political and economic empowerment and the desire for formal legally based equality. The impact of the socalled Arab Spring of 2011, which saw women protesting alongside men for political change, and the difficulties women are experiencing in maintaining parliamentary representation is difficult to predict (Olimat, 2012) making research giving a direct voice to women both valuable and timely. 
Shedding light on the sustainability of the 'social contract' between the ruling elite and the citizenry, a citizenry with disparate attitudes and values, ranging from conservative, Islamist, patriarchal, traditionalist and tribal to liberal, social democratic and feminist, this thesis makes an original and substantial contribution to knowledge and represents a solid foundation from which policymakers can begin to formulate more specific responses to address women's future role in Kuwaiti society.

\section{Structure of the thesis}

This thesis has four parts comprising ten chapters in total.

\section{PART I Research context}

In Chapter one there is a domain by domain discussion of the developments seen in recent decades covering education, polity, media, housing and divorce. The aim of the chapter is to establish what is already known about the issues being addressed in this thesis. Referring to a range of source types including sociologists from Kuwait and the Arab region; foreign NGOs, interest groups and agencies; official Kuwaiti sources; and new reports, the chapter describes the position of women in Kuwait in a range of domains including polity, the law, the family, education and the workplace. It also describes the role of Islam in women's lives.

Chapter two expands the research context, examining areas of civic life such as education and employment where women have made policy gains in terms of gender equality, and other areas particularly the private/family domain things remain largely unchanged and patriarchy is the dominant factor in gender relations. The twin track examination is important to the thesis because it reflects the central dilemma not just of the move towards women's empowerment but also of the country as a whole which sees it trying to reconcile the need for modernisation with the role of Islam and sharia in both the social fabric and the law of the land. The chapter is divided into two parts to reflect the twin tracks with the public sphere of civil life discussed in the first and the private domain of family and personal status examined in the second. Whereas in the first chapter the constitutional position of women and the basis for this position in Islam as well as the legislative framework governing women's lives is discussed, chapter two 
examines change: the change towards empowerment on the one hand and the change or resistance to change from retrenching patriarchy.

\section{PART II Research approach}

Chapter three presents the theoretical perspectives and concepts that informed the research approach to the study either in methodological terms or in the evaluation of the findings. The aim is to present the ideas of authors whose work was felt to include conceptualisations which may have a relevancy to this study despite its contrasting research setting. Although this is exploratory research, it is still important to consider the theoretical work that has been carried out in regard to women's empowerment, patriarchy and power. Despite these theoretical approaches having been developed in western contexts, it is of value both to the current study and the development of these theories that they are considered in regard to Kuwait as representative of a very contrasting context.

Chapter four is divided into two sections. Firstly, the ontology, epistemology, methodological perspective and research strategy are presented. The second section describes what the researcher actually did in the course of sampling, collecting and analysing the data. This section is divided into sub-sections, one for the quantitative survey and the other for the qualitative interview study. Being a sensitive area of research in a challenging research context a detailed explanation of the ethical considerations involved in the conduct of this research is also made.

\section{PART III Results and findings}

In chapter five the results of the quantitative questionnaire survey of educated urban dwelling Kuwaiti women are presented and the main findings are summarised. The aims are to present the views of the women who responded to the questionnaire and also to illustrate how the results informed the interview study that was to follow. The chapter demonstrates that a significant number of educated urbanised women wanted to participate fully in the public sphere but did not want to be seen to be directly challenging certain principles (mainly drawn from traditions and Islam). The chapter illustrates how the questionnaire survey provided a sound basis for the interviews which followed. 
Chapter six is the first of three chapters in which the findings of the qualitative interviews are presented; these findings are supported where appropriate by the survey study results. While this is not a comparative study, the findings are also contextualised with reference to comparisons between the recent developments in Kuwait and the history of social policy and gender equality in the UK. This is done in order to see whether commonalities in social change could sharpen the analysis particularly when evaluating the trajectory of this change. This chapter is oriented to the recent past (the last 10 to 15 years) and the public sphere (civil life including, education, politics, employments etc.). The chapter reports on how the respondents perceive the social policy changes, political enfranchisement, workforce participation and education attainment that women in Kuwait have experienced in the recent past. The chapter shows that the expectations of women in the domains of employment, politics and education are high and largely shared. The key message is that the participants wanted full participation in civil life on terms based on gender equality.

In chapter seven, the second findings chapter, orientation switches to the present (the time of data collection) and to the private sphere (the family, home and relationships). The aim of the chapter is to discuss participant views on issues of equality, women's role in the justice system, marriage and divorce, patriarchy and sharia. The main message of the chapter reinforces the central theme of 'twin tracks' discussed at length in chapter two. Furthermore, the chapter reveals a lack of majority support for some measures which would appear to be clearly in a woman's interest, such as the right to pass on citizenship to their children.

Chapter eight presents the findings pertaining to the future and the way women perceive the attitudes of Kuwaiti men. The chapter also discusses how women project their hopes onto future generations, how they believe gender relations will develop in the next ten years and how they feel men are experiencing and will experience the possible future empowerment of women in Kuwait. Broadly speaking there is an optimistic tone to the interviews, although the women seemed to have difficulty in verbalising their vision of the future in anything other than generalised hopes for greater equality, freedom and justice for future generations. This may well be attributable to the nature of speculation and the fact that they may have never previously been asked to encapsulate their hopes for future generations in this way. 


\section{PART IV Evaluation, conclusion and recommendations}

Chapter nine evaluates the study. It identifies a series of threads which, with the help of the theoretical approaches discussed in chapter three, are drawn from the study and viewed as taking forward an understanding of women's empowerment in Islam. Kuwait women's emergence from the private sphere into the political and employment domains; the economic value of domestic labour; the role of marriage; power, patriarchy and religion; and the forms of feminism revealed by the study, are each evaluated. The chapter also forms a view of the likely future direction of travel for women's empowerment. Once again, the evaluation suggests there is a division between public and private spheres in the way women express their desire for greater gender equality and the differing strength of patriarchal resistance to women's empowerment with more permissive attitudes within society to political participation, employment and education while at the same time fundamental issues preventing real gender equality, many arising from tradition and religion, remain largely unchanged. The evaluation also reveals interesting comparisons with the UK with similarities in the shifting and permeable nature of patriarchy during a period of change towards women's empowerment.

Chapter ten summarises the study, its findings and analyses and offers concrete conclusions and recommendations. Specifically, it is suggested that the urbanised educated women of Kuwait who took part in the research are motivated to seek empowerment. In doing so they express themselves mainly with the language of 'natural justice' and human rights in a similar way to their western counterparts; that is principally gender equality under the law. Their emergence from the private sphere into the public domains of education, work and politics has been decisive and seems irreversible. The desire of Kuwait's rulers to reach a 'social contract' sees it balancing the interests of women with those of conservative Islam and tribal interests which suggests that progress toward empowerment will not be rapid, but neither was it in the UK.

The study provides a rare insight into the perceptions and interpretations of educated urbanised women in Kuwait with regard to their position in society and the social, legal and political changes they have witnessed in the recent past. It demonstrates that there are clear parallels with the aspirations of women in western contexts and it clearly contradicts the notion that Islamic societies are fixed and unchangeable or that patriarchy 
is an immovable force opposing women's empowerment - even when this patriarchy is rooted in religious doctrine. 


\section{CHAPTER ONE}

\section{REVIEW OF THE KUWATI CONSTITUTION AND THE LEGAL, SOCIAL AND CULTURAL RIGHTS AFFORDED TO KUWAITI WOMEN}

\section{Introduction}

To borrow the words of Webster and Watson (2002: p. xiii) a literature review is important because "An effective review creates a firm foundation for advancing knowledge. It facilitates theory development, closes areas where a plethora of research exists, and uncovers areas where research is needed". Unfortunately, there is very little research literature available on Kuwait, which is after all a primary reason for embarking on this exploratory study. Furthermore, the social and political environment in Kuwait has changed so rapidly in recent years - much of the literature that is available focusing on women's rights in Kuwait has been overtaken by significant events such as the enfranchisement of women and their participation at elections. Therefore, to identify gaps in knowledge a thorough analysis of pertinent parts of the Constitution together with a relatively recent historical analysis of legislation and legislative reforms is undertaken. Furthermore, and understandably given the dearth of contemporary empirical studies on or surrounding the topic of women's rights in Kuwait, the review necessitates the inclusion of those based on sociological analysis as well as more opinionbased contributions from newspapers and websites in order to facilitate an adequate overview.

The initial search terms used for academic databases were 'women rights Kuwait' and 'human rights Kuwait'. However, this was not intended to be a systematic review and the bibliographies of the initial search results were used to identify further relevant sources. Thus, importantly, the selection of literature was mainly filtered by examining texts that focused on Kuwait rather than any wider region. This is wholly appropriate because there are substantial differences even between the countries of the Arabian Peninsula limiting severely the generalisability of studies conducted outside of Kuwait. These differences are manifest in many ways including the rights afforded to women, at the root of these 
variations lies the absence of any clear description of a women's role in either the Q'uran or Hadith meaning that there is scope for interpretation.

For purposes of organisation, the literature review documented here adopts the following five headings used by Freedom House (2010) to rate women's rights in their indices, these are:

o Non-discrimination and Access to Justice;

o Autonomy, Security, and the Freedom of the Person;

o Economic Rights and Equal Opportunity;

o Political Rights and Civic Voice;

o $\quad$ Social and Cultural Rights

These headings were used because they appeared to match the researcher's assumptions as to what the main areas of discussion might be in an exploratory research study, rather than any particular acceptance of the authors' own perceptions or arguments. These headings could also be said to align with the research aims set out in the introduction to this thesis.

Thus, utilising Freedom House's indices to rate women's rights, the chapter begins by discussing the formal legal framework of the country, starting with the Constitution but also covering the legislative process, the judicial system and women's role in it, Islam and women's rights and current legislative sources which are arguably discriminatory. The chapter moves on to consider both legal and informal social and cultural restrictions on women's autonomy, security and freedom of the person. After this, the focus is on the economic domain, particularly economic empowerment of women and access to education. Thereafter the recent history of women's political and civic rights in Kuwait is considered and the chapter finally reviews the social and cultural rights afforded to Kuwaiti women (including access to housing and divorce). A summary completes the chapter. 


\section{Non-discrimination and access to Justice}

As already indicated in the introduction to this thesis, the Kuwaiti state is based on a hybrid of state and legal concepts. According to a United Nations profile, "The legal system of Kuwait is an amalgam of British common law, French civil law, Islamic legal principles, and Egyptian law" (United Nations, 2004, p.7). Twelve articles (162 to 173) of the Constitution provide the framework and principles on which the legal system is based including guaranteeing its independence.

\section{The constitution}

The Constitution is a fusion of liberal democratic traditions seen in the US Constitution and the French and British legal frameworks, Egyptian law and Kuwait's Arab - Islamic origins including sharia. As already noted, the Kuwait Constitution (Article 29) states: "All people are equal in human dignity and in public rights and duties before the law, without distinction to race, origin, language, or religion." but it does not specifically enshrine non discrimination against women or contain articles that enshrine discrimination rights (al-Mughni, 2010). This lack of explicitness has been contrasts with the definition of discrimination in the Convention on the Elimination of All Forms of Discrimination against Women CEDAW (Article 1) which describes it as,

[...] any distinction, exclusion or restriction made on the basis of sex which has the effect or purpose of impairing or nullifying the recognition, enjoyment or exercise by women, irrespective of their marital status, on a basis of equality of men and women, of human rights and fundamental freedoms in the political, economic, social, cultural, civil or any other field.

Kuwait is a signatory to CEDAW adopting it as national law on 30th January 2004 but it also registered reservations to three articles: Article 9 which guarantees equality regarding the nationality of children; Article 16 which covers equality in marriage and the family; Article 29 which required international arbitration of disputes arising under the Convention (United Nations, 2006). It has also so far resisted formalising the wording of the Convention into either the Constitution or relevant laws; though as the Constitution has never been amended (Brown, 2001) the lack of such incorporation is perhaps unsurprising. 
The hybrid nature of the Constitution lies at the heart of many of the issues dominating the discourse on women's rights (al-Mughni, 2010). According to al-Mughni and Tétreault (2000, p. 143) “Kuwait's constitution does not discriminate between women and men with regard to their citizenship rights but a number of laws adopted under that constitution $[\ldots]$ do discriminate against women." The Constitution was the first such instrument adopted by states in the Arabian Peninsula and comprised 183 articles. Its durability is attested by the fact that it has never been amended (Brown, 2001).

As noted in the introduction to the thesis, a range of laws flowing from the Constitution have discriminated against women and al-Mughni (2010) highlights the Social Security Law (No. 22 of 1987) and the Housing Assistance Law (No. 47 of 1993), to demonstrate that Kuwait's laws and policies still treat women as dependents of men rather than individuals enjoying equal rights and responsibilities. As already noted, progress in some areas is indeed evident: the achievement of the right to vote and the ruling of the Constitutional court that the 1962 Passport Law requiring women to gain the consent of their husbands before obtaining a passport was in violation of guarantees of freedom and gender equality in the Constitution.

In reaction to the Universal Declaration of Human Rights, seen by many in Islam as being based on Judeo Christian values (Darraj, 2010) the 57 members of the Islamic conference adopted their own declaration, the Cairo Declaration of Universal Human Rights in Islam (CDHRI) in 1990. Its key article on Women's Rights Article 6 states "Woman is equal to man in human dignity, and has her own rights to enjoy as well as duties to perform, and has her own civil entity and financial independence, and the right to retain her name and lineage" which critics say enshrines the acceptability of denying equal rights to women because rather that stating they are simply equal they are only equal in human dignity (Maltbie, 2010). Critics of the progress made by the government in extending rights insist that governmental pronouncements and the signing of treaties are one thing but in practice they do not necessarily mean an end to discrimination through fully applied laws; as Neuwirth (2002) puts it there is a "substantial gap between the rhetoric and the reality of sex-equality rights" (p.3). 


\section{The legislative process}

Power to legislate is vested in the emir and the National Assembly as enshrined in the provisions of Article 51 of the Constitution. The executive branch in the form of Ministers draft bills to put before the Assembly. In the Constitution it is further stipulated that no law can be promulgated without it being passed by the National Assembly. The quorum for the Assembly is half of its membership. In the event of a two-thirds majority in the Assembly the emir promulgates the bill and it becomes law. If this is not achieved the bill must be introduced in the following session when a simple majority will suffice. The emir is required to promulgate bills into law within 30 days (7 days in an emergency). There is an Official Gazette Al-Kuwait Al-Youm, where all laws are published before they come into effect. As well as codifying laws, the State Official Gazette publishes Decrees, Cabinet Decisions, Ministerial Resolutions and other Administrative Resolutions such as those made by bodies like the Public Authority for Industry (Al-Kuwait Al-Youm, 2011). The legislative process is important to this study as it is so male dominated and women's participation within the process is so marginal that women clearly need to co-opt male sections of society in order to achieve reform and empowerment.

\section{Judicial system}

The Kuwaiti judicial system was effectively set up by the Decree issuing Law Regulating the Judiciary 1959 (no. 19/1959) before formal jurisdictional independence from the British (Amin, 1991). The key influence was the increasing body of Arab civil law emerging in secularized states like Egypt (Amin, 1991). This contrasted with neighbouring Saudi Arabia, never under European colonial rule, where the Islamic sharia legal system remains dominant (Al-Suwaidi, 1993). In what may be one of the most crucial words in the Constitution, Article Two states that sharia is "a" main source of laws in the state rather than "the" main source. Equally relevant, Article 79 states that no law can be enacted without being passed in the National Assembly and sanctioned by the emir. In 2012, 31 of the 50 members of the assembly voted to amend Article 79 by inserting the requirement for all laws to be compliant with sharia. The emir rejected the amendment (Westall, 2012). This move is highly relevant to the current study as it shows that women are reliant to a considerable degree on the government for defence against 
Islamists who would extend the role of sharia closer towards the example of its larger neighbour Saudi Arabia.

There is a three level civil courts system: firstly, courts of first instance or summary courts take cases based on their seriousness; second, is the Court of Appeal and above these is the court of Cassation (Brown, 2001; Khedr, 2010; Encyclopaedia of Nations, 2007; al-Munghi, 2010). The High Court of Appeals is divided into a chamber for personal and civil appealed cases and another handling appeals for criminal and commercial matters. The Court of Cassation reviews appeals from the State Security Court while a separate Military Court hears cases that involve offences committed by serving military personnel (Khedr, 2010).

At the apex of the judicial structure is the Superior Constitutional Court, this court passes judgment on matters of interpretation of the Constitution. The five (male) member court reviews disputes relating to the constitutionality of laws passed. In two recent landmark rulings the court, whose rulings cannot be challenged, has demonstrated its willingness to rule in favour of women. The first, concerning the passport law has already been mentioned. In the second it reversed the decision of a parliamentary committee that two women MPs should be expelled for not wearing a hijab. It was in October 2009 that a debate ignited in some Arab countries regarding whether the wearing of the hijab was mandatory for women. A leading Egyptian cleric Mohammad Tantawi declared it non-mandatory. The Salafist Kuwaiti cleric and MP Mohammed Hayef Al-Mutairi reacted strongly to this Egyptian move and forced through fatwa (a religious edict) with the opposite effect with the Ministry of Awqaf and Islamic Affairs (the official fatwa regulator) ruling that the hijab was indeed mandatory for Kuwaiti women. Most controversially, this meant that women MPs could not carry out their duties including attending the national assembly without wearing the hijab (The Kuwait Times 9th October 2009). After this fatwa, four voters petitioned the Supreme Constitutional Court to have the election of two of the four women MPs nullified for not wearing a hijab. The highly significant ruling rejected the petition and ruled that the Election Law 2005 was too vague on the matter and that the equal rights guaranteed in the Constitution took precedent (McKee, 2009).

As regards family law, religious courts handle cases relating to family law though these courts remain inside the state judicial framework. This law is codified in a number of 
laws the most comprehensive of which is the Personal Status Law 1984. There are separate courts for Shias and Sunnis and another for non-Muslims (Joseph and Najmabadi, 2005; Khedr, 2010). This is extremely relevant to the current study because the Kuwaiti women whose voices it aims to hear may not be subject to the same legal interpretations of family matters. Shia courts tend to be somewhat less traditionalist and conservative than their Sunni counterparts with Shia women being treated more fairly in divorce and some inheritance issues than Sunnis; also, only a Sunni woman in Kuwait requires the signature of a male guardian on their marriage contract (Krause, 2009).

\section{Women judges}

Judges in Kuwait's regular courts are appointed by the emir based on the advice of the Justice Ministry. Those who are Kuwaiti citizens are appointed for life while non-citizens serve on the basis of fixed term but renewable contracts (Encyclopaedia of Nations, 2007). There is no specific legislation barring women from becoming judges in Kuwait. As the Constitution dictates, in the absence of a law passed through the legislative process of the State the principles of Islamic law are applied and these are being interpreted by conservative scholars as precluding women from serving in the judiciary. Elsewhere in the Gulf region, a different interpretation has been applied, leading to woman judges being appointed in Bahrain (2006) the UAE (2008) and Qatar (2010). Even before this, no less than 11 Islamic countries across the Middle East and North Africa had seen women appointed to the judiciary: Afghanistan, Algeria, Egypt, Iraq, Jordan, Lebanon, Libya, Morocco, Syria, Tunisia and Yemen (Colb-Rubin, 2007).

At the time of writing there are no women judges presiding in Kuwait though they can act as investigative judges and have recently been appointed as public prosecutors. Twenty percent of the membership of the Kuwaiti Bar association is female (al-Mughni, 2010). The appointment of female public prosecutors could be significant as after or between 5 and 7 years they would be eligible to be appointed judges.

Across the Middle East the issue of women judges has caused more controversy and proved to be a greater taboo than having women as ministers or MPs (al-Mughni, 2010; Toumi, 2012; Cop-Rubin, 2007). When a woman was appointed a judge in the Shiite dominated town of Najaf, Iraq, in 2003 fatwas were issued by male clergy forbidding such a move and thousands took to the streets to demonstrate against it. The occupying 
American forces had to annul the appointment to restore order (Colp-Rubin, 2007). As both justice and the judicial system are important threads in this research it is important to emphasise that women's participation in this domain represents a 'red line' for Islamists in the Middle East region. It could be argued that as the law, particularly sharia law, is one of the key means used by men to exercise control over women and keep them in the private domain - and arguably, the entry of women into the judiciary would be a serious blow to a patriarchal society.

Undoubtedly, in Kuwait there is a particular resistance to women's possible future involvement as judges in cases in the family courts. Furthermore, the experience of other countries suggests that even should headlines be generated by the appointment of the first woman judge in Kuwait, genuine unrestricted representation will be a long way off. The assertion made here is that the lack of judicial diversity is not restricted to Islamic countries. For example, England's first female judge was appointed in 1945: 65 years later less than 14\% of judges sitting in the High Court or higher in England and Wales are women (Centre for the Advancement of Women in Politics, 2010). From this experience it seems that while the current group of recently appointed female public prosecutors may produce Kuwait's first women judge(s) it may be some considerable time before there is genuine representation of women in the judiciary. A lot will depend on the views of Kuwaiti women on this issue which underline's the importance of exploring women's views on women in the judiciary in Kuwait - an important topic in this current research.

\section{Islam and women's rights}

Women's rights are at the heart of the debate as to whether Islam and democracy are compatible. What becomes quickly evident is that the answer to this question is not a simple negative or positive one but a lot more complex. According to al-Mughni (2010), Kuwaiti women enjoy religious freedom and Muslim women can make personal choices about their own level of adherence to Islamic traditions such as the wearing of the hijab. Having said this Islam has a wide range of influences that affect the day to day lives of women citizens in a way which discriminates against them. Much of Islam prioritises patriarchy and so is a crucial issue with regard to progressing women's rights and also a key theme of this research. 
The most basic and all-pervading influence is the concept that men are superior to women by God's own design. Indeed, Surah: 4 Verse 34, (seen by many as the most controversial of all), pronounces that 'Men are elevated above women, for God has placed them so by nature.' For many Muslims, this encapsulates men's authority, indeed duty, to maintain social control over and even to denigrate women (Maltbie, 2010). However, Keddie (2004) argues that like Christians, many Muslims do not accept the superiority of men. But nevertheless a range of influences guide Muslims towards maintaining traditional doctrines. These influences are listed by Keddie (2004) as: the lengthy history of strictly patriarchal tribes across the Muslim world and the predominance of extended families; a general disillusionment at the lack of social and economic development made by autocratic and usually secular governments that are frequently western backed; the continuing Israeli occupation of Arab land and the failure of other doctrines such as international socialism and secular nationalism. These influences have combined to lead many Muslims in the region to idealise the past and blame today's problems on the way societies have deviated from Islamic traditions (Keddie, 2004). The result according to Keddie (2004) is "a kind of pan-Islamic nationalism that finds solace and support in restating Islamic doctrines” (p.25). A similar point is made by al-Dekhayel (2000, p. 17) who sees much of the opposition to women's rights as arising through their association with western imperialism, stating that "progressive reform is often tied too closely to western agents, with the result that the reform is rejected not because of any inherent qualities it possesses, but simply because anything that hints at western imperialism will automatically be rejected". The success experienced by Kuwait in this area is largely due to "an understanding that these issues can be separated... [and] that the progression of women's rights need not necessarily lead to a further adoption of increasingly western traits and cultural orthodoxies" (alDekhayel, 2000, p. 37).

In terms of the Qur'an itself, Rizzo et. al., (2002) assert that there is an unmistakable egalitarianism that runs through it but that this does not necessarily translate itself into support for women's rights as Islamic religiosity is closely linked to the conservative cultural attitudes of 'traditional' Islam where the woman is viewed as being weaker, more irresponsible and less rational and so they need to live under the protection of men. The current study will go a long way to revealing the prevalence of these attitudes among women in Kuwait not least because their attitudes are rarely researched directly. 
It is not just in Islam that women are assigned a subordinate role, in fact it appears panreligious. As Keddie (2004, p. 27) states:

The status of women in the Bible is subordinate, as it is in Roman Catholic and fundamentalist Protestant doctrine, yet most believers in developed countries do not accept the traditional Christian view of women's subordination to men. Many believing Muslims similarly do not accept traditional views regarding women, but the factors that have increased fundamentalism in the Muslim world have similarly worked to increase male-dominant religious views.

The universal nature of the relationship between religious conservatism and the subordination of women is supported in a study carried out by Rizzo (2005). Her findings reveal a worldwide trend: that religiously conservative people, groups and nations are not supporters of women's rights. Instead the gender roles are patriarchal and tend to favour roles for women as mothers and wives contained within the family rather than in society. Women are subject to the authority of their male relatives and are not encouraged to participate in the labour market or in politics. Nevertheless, clearly the current status of women in Kuwait shows that conservative Islamist influence has not been successful in achieving predominance: Kuwait has high levels of women's participation in the labour force, women's increasing economic empowerment and women have attained the right to vote (something discussed both later in this chapter and expanded upon in the following one). Instead of predominance the picture is one of compromise under with the rulers of Kuwait seek to modernise while making concessions to Islamists in certain areas and to women's rights interests in others. How women perceive this compromise is an important theme of this research and represents a gap in knowledge that needs to be filled.

In Arab countries religion dictates personal status. More specifically, membership of a particular sect (principally Shia or Sunni) is the main factor as it is decisive in placing the individual either in the minority or the majority group in society. Membership is hence the key to the level of opportunity to gaining access to power politically speaking (Meyer, et. al., 1998). In Kuwait the majority (70\%) are Sunnis. Meyer et. al. (1998) focus on establishing whether sect, school of thought and the orthodoxy/ religiousity dichotomy are predicative of support for the extending women's rights. The picture is further complicated by 'schools of thought' within these sects. According to Meyer et. al. (1998) there are four schools of Islamic thought in Kuwait, two for each sect. Regarding 
Sunnis, there are followers of the Najd clergy in Saudi Arabia who take a conservative stance and support a patriarchal social structure that segregates women from wider society. Conversely, other Sunnis adopt the approach of the Alazhar clergy of Egypt and/or the philosophy of the Muslim Brotherhood who advocate a higher level of social integration for women. On the Shia side there are those who follow the teachings of the Qom Iranian clerics whose views led to the extension of political rights to women enshrined in the post revolution Iranian constitution, while many follow Najaf clerics of Iraq who adopt a more traditionalist approach to women. Those in the Sunni political elite, however are, as has been demonstrated, not necessarily opposed to the extension of women's rights as sect membership is less predicative of attitudes and political calculation more so (Meyer et. al., 1998).

Yet another dimension is also introduced by Meyer et. al. (1998); this is the 'Orthodoxy''Religiousity' dichotomy. Orthodoxy describes beliefs based on the Qur'an itself whereas religiosity draws mainly on the hadiths being the reported habits and actions of the Prophet. This is exemplified in Kuwait by the belief in the need for women to dress modestly (specifically mentioned in the Qur'an: hence Orthodoxy) which is widely adopted whereas the growing of a beard among men, reported in the hadiths (hence Religiosity) as Mohammed had a beard is not widely applied. Thus Islam is characterised by differences in interpretation in many areas and this is highly relevant to women's rights. Islamic religiosity is associated with conservative cultural positions and it is influenced by traditional Islam, which sees women as the weaker, irrational, irresponsible sex who need to be under the control and protection of men. The Qur'an, for example, states that while divorce is not ideal it is allowed, leaving Muslims to interpret what this means in practice. Western (2008, p.147) described this interpretation more vividly as Islamic law being "taken hostage by customs and traditions that are clearly not Islamic". These traditions are patriarchal and so work against women's rights. By contrast, he suggests that if Islamic legal principles are correctly interpreted then the system resulting would be one that is beneficially to the rights of women and even advances them (Western, 2008). Clearly, the control of the means of production of religious knowledge is a key element for women's empowerment and so this is a thread that will also be taken forward in this research. Interpretation for power preservation or attainment is not the sole domain of conservatives; across the region women have used a modern interpretation of the Qur'an to advance their cause and counter accusations of 
westernisation under the banner of Islamic feminism (Maier, 2006). The choice whether to challenge patriarchy using holy texts or to opt for secular arguments based on a mainly western human rights discourse is one of the main differentiators between different approaches to empowerment among Kuwaiti women. Is the choice a pragmatic one, based on perceived likelihood of success? It is certainly true that refusing to enter into religious discussion of women's rights puts women into a marginalised position in an Islamic country.

\section{Women as witnesses}

There is considerable debate between modern and orthodox commentators over verse 2:282 of the Qur'an regarding women as witnesses.

O you who have believed, when you contract a debt for a specified term, write it down. And let a scribe write [it] between you in justice. Let no scribe refuse to write as Allah has taught him. So let him write and let the one who has the obligation dictate. And let him fear Allah, his Lord, and not leave anything out of it. But if the one who has the obligation is of limited understanding or weak or unable to dictate himself, then let his guardian dictate in justice. And bring to witness two witnesses from among your men. And if there are not two men [available], then a man and two women from those whom you accept as witnesses - so that if one of the women errs, then the other can remind her.

This verse has been used by orthodox scholars not just to accord a lower value to women's testimony but to effectively lock them out of the judicial system, such as those so opposed to women judges in Kuwait. They have also extended the interpretation beyond financial matters to all matters including theft, rape, adultery, and murder (Engineer, 2008). Engineer (2008) rejects this interpretation and argues that this verse should be treated as contextual not normative and that the verse was referring strictly to financial matters and the requirement of an additional woman to remind the first was due to their inexperience in financial matters at the time, not any inferiority of intelligence. Engineer (2008) also points out that there are seven other verses in the Qur'an related to the taking of evidence and not one makes any reference to a requirement for two women witnesses. Kuwait is a country in which a women's testimony counts for half that of a man across a range of areas. The consequence of this devaluation of testimony is 
arguably a restriction on a women's access to justice which is something that is investigated further in this current study.

Drawing on the work of Rizzo (2003) once again, there is a universal nature of the relationship between religious conservatism and the subordination of women. Her findings reveal another global trend: that religiously conservative people, groups and nations are not supporters of women's rights. Instead the gender roles are patriarchal and tend towards favouring roles for women as mothers and wives contained within the family rather than in society. Women are subject to the authority of their male relatives and are not encouraged to participate in the labour market or in politics. Furthermore, Keddie (2004, p.27) argues that religious conservatism and patriarchal social systems can also be found under interpretations of the Bible made by some Roman Catholic priests and in fundamentalist Protestant doctrines. The existence of such teaching of the subordinate role of women in whatever religion does not, however, mean that such attitudes extend throughout the populations. However, the degree to which it exists among Kuwaiti women has been largely un-researched and this is a gap this current study aims to fill.

\section{Legislative sources of discrimination}

The literature identifies those laws characterised as discriminatory (al-Mughni, 2010; Rubin, 2007; CEDAW 2004; inter alios). The United Nations Committee on the Elimination of all forms of Discrimination Against Women (UN-CEDAW), the body responsible for monitoring progress under the eponymous convention, reserved greatest concern for the Nationality Law whereby women may not pass on their nationality to their children or their foreign husbands while men can (UN-CEDAW, 2004). They also highlight the Personal Status Law (No.51 of 1984) together with the Civil Code both of which include provisions that discriminate in matters relating marriage and the family such as the legal age of marriage, divorce and guardianship can (UN-CEDAW, 2004). To these al-Mughni (2010) adds the Social Security Law (No. 22 of 1987) and the Housing Assistance Law (No. 47 of 1993). This legislation stands out as reinforcing the position of women as dependents of men and inhibits their right to independence. However, despite the discriminatory provisions, a survey of 1376 men and women conducted by the Women's Cultural and Social Society (WCSS) found that the majority of Kuwaiti citizens were in favour of keeping and enforcing the current Personal Status Laws (al 
Sharekh, 2007). Unfortunately, no gender breakdown or methodology could be ascertained.

\section{Autonomy, security, and the freedom of the person}

It has been noted elsewhere that following independence in 1961 Kuwait's rulers looked to more westernized secularist Arab countries to frame its Constitution and laws (alSuwaidi, 1993). This has had a major influence on women's day to day lives with regard to personal autonomy. Unlike in neighbouring Saudi Arabia, in Kuwait women can drive cars and there are few restrictions on their personal movements. Kuwaiti women regularly travel abroad on business or to study and the law requiring them to obtain the consent of their husband or male relative to apply for a passport was quashed by the Supreme Constitutional Court in October 2009 (al-Mughni 2010). For many women however, social norms and traditions mean that in practice a woman should seek permission should she wish to visit a friend at night or go abroad though how strictly this is adhered to varies from one family to another (al-Mughni, 2010). The need for a male relative to be present in social situations is not adopted widely in Kuwait and is largely a matter influenced by the traditions of the family concerned, again providing a contrast with Saudi Arabia where this practice is almost universal (al-Mughni 2010). These family traditions are likely to play a role in forming the perceptions of the women taking part in this study, and it is therefore anticipated that the findings may encompass a range of views.

Despite not usually requiring a man to be present in social situations, a women's personal life is nevertheless governed by a set of family laws - the Personal Status Law 1984. There are two such sets, one for Sunnis and one for Shiites and there are a number of significant differences between them. Because of these differences there are also separate courts for each sect, as already noted. According to al-Mughni (2010 p. 230), this legal framework "formalizes men's superiority and legitimizes discrimination." That personal status and family law follows sharia and a conservative definition of the same is seen by some as a major impediment to women's equality under the law, prompting Esfandiari (2004) to write that "equal legal status [. . . ] is virtually unachievable so long as family law remains based on sharia, and rules derived from particular interpretation of Islam prevail in the social sphere" (p.63). It is therefore suggested that the 346 articles included in this 
law passed in 1984 has an immediate and deep impact on family life in Kuwait, defining the woman's role within the family and prescribing how matters such as engagement, marriage, divorce, financial obligations, custody etc. However, the impact from the perspectives of Kuwaiti women themselves remains unknown. Nevertheless, it is acknowledged that the central theme of the discriminatory nature of Kuwaiti law is that women are seen as dependents of men rather than citizens in their own right (al-Mughni 2010).

From reviewing the literature thus far, it can be argued that there are key points of discrimination that restrict the freedom and autonomy of woman in Kuwait and these can be summarised as follows:

Employment: The Personal Status Law (Article 89) gives some leeway to prevent a wife from working if the husband believes it is against "family interests" a term capable of wide interpretation. Other provisions give incentives for women to stay at home rather than join the workforce and it has become an important Islamist objective to increase these 'stay-at-home' incentives (Kareem, 2013).

Marriage Rights: There are several areas of discrimination regarding marriage. These include: differential legal ages for marriage; the requirement for a woman to have a male marriage guardian (wali) who must agree to any proposed marriage; the right of a man to have more than one wife and that such polygamy is not grounds for divorce; and the right of a man to use talaq (a verbal self-declaration of divorce). Furthermore, a woman's choice to remain single exists in principle but in practice there is substantial social stigma attached to this choice, which grows as they get older (al-Munghi, 2005).

Nationality Rights: A female Kuwaiti citizen is not able to pass on her nationality to either her children of a foreign spouse. Should a Kuwaiti man marry a foreign woman the woman receives residency rights straight away and can become a citizen after 10 years. The situation for a Kuwaiti woman marrying a foreigner is far more restricted and complicated (al-Mughni 2010). According to al-Mughni and Tétreault (2000, p.157) this shows that in Kuwait

[...] women are part of nature rather than civilized society. A Kuwaiti woman has no nationality that belongs to her absolutely. She is a 
Kuwaiti by virtue of having a Kuwaiti father but can lose her status as a Kuwaiti if she marries a foreigner [...].

\section{Economic rights and equal opportunity}

As already noted in the introduction to this thesis, Kuwait is a 'capitalist-statist' relatively open, market economy classified by the World Bank as high income non-OECD with a per capita Gross National Income per capita of $\$ 52,000$ in 2014 compared to a figure of $\$ 42,690$ for the UK in the same year (World Bank, 2015). The wealth of the country is relevant as it enables the ruling elite to reach a social contract with the population which includes significant financial concessions as discussed below.

\section{Oil: A force for autocracy and discrimination?}

Any review of literature regarding the economic rights of Kuwaiti women needs to consider the consequences of Kuwait being an oil-based economy. Because, as Olimat (2009) explains, the role of oil wealth in preserving the ruling elites in the region with financial power being used to push Kuwaiti citizens to acquiesce in return for housing, health care and other benefits. To borrow the words of Joseph and Najmabadi (2005), the legitimacy of the ruling families in the Gulf region has been based on a "state welfare system that provides citizens with rights to free education, employment, housing and health services as well as other grants and state subsidies" (p. 465). Rizzo (2005) supports this by stating that women's healthcare and education has been a beneficiary of the creation of the welfare state only made possible by the oil wealth and overseas investment wealth. Such is the extent of this welfare state that Khalaf and Hammoud (1987) assert that in oil rich states the level of welfare provision actually exceeded those in industrialised economies.

Thus as Olimat (2009) argues, financial power is used to 'buy off certain rights and interests and generally to compensate for the lack of opposition and plurality in political and civic life. However, these huge efforts by the regimes (in the gulf region) to limit civil society have been only partially successful - groups of Islamists, tribalists, technocrats, human rights activists and others are still active and because Kuwait is one of the most 
open of the states in the region their voices are still periodically heard loud and clear. As a result, Kuwait has an enlivened politics that has shown a tendency toward turmoil with the two major protagonists being the ruling elite and government on one side and Islamists on the other. Women, have taken on the role of a 'third force' and yet while they represent a majority of the electorate they have little political power. The question that is largely unanswered is why votes have not translated to power and also whether and through what mechanisms it will in the future. This study aims to cast some light on these issues.

Through empirical analysis, Weiffen (2008) demonstrates that the Gulf region is inherently tended towards autocracy. The twin influences driving this tendency are seen as cultural, in the form of Islamic traditions and economic in the form of oil wealth. The key finding is that "both Muslim cultural influence and oil wealth alone are each correlated with higher levels of autocracy" (p. 259). Weiffen (2008) coins the term "cultural-economic syndrome" to describe the forces at play pulling the Gulf States towards autocracy and keeping them there. The revenues from petroleum exports $(95 \%$ of all exports) have acted as a disincentive to diversify the economy, particularly during times of high oil prices; they are also a dampener on the demands for greater democracy. As Weiffen (2008) explains, oil economies such as Kuwait, are referred to as 'rentier states' because their income is in the form of rents from overseas companies that are paid directly to the government. This has two main consequences; first, only a tiny part of the population is involved in generating the vast majority of the wealth, wealth that is nevertheless widely distributed in the form of the welfare state. Second, in a mirror image of the phrase "No Taxation Without Representation!" that was pronounced in 1750 by Reverend Jonathan Mayhew, a Boston preacher, the Gulf states operate more on a 'no taxation - no representation' basis. Weiffen (2008) suggests that this absence of taxation deflates demands for greater democracy; though clearly as events have shown the economic and cultural forces that have caused Kuwait to tend towards autocracy have not succeeded in removing altogether the pressure for greater women's rights.

If oil wealth is a disincentive to diversify then more recently demographic changes have indeed encouraged diversification (Saadouli, 2010). The capital intensive nature of the oil sector may have historically worked against the extension of women's participation in the workforce or at least slowed progress in this area (Rizzo 2005). Ten years ago the 
Kuwaiti government adopted a Manpower Growth and Restructuring Program (MGRP) in order to encourage the private sector to absorb more of the new young workers, both male and female, who were increasing in numbers quite rapidly. Elsewhere in the literature, studies have pointed to Kuwait's very high level of dependence on foreign workers in many sectors of the economy (al-Enezi, 2002) as a driver of policy. This has not, however, had a negative effect on women progressing their rights as these migrant workers are either in the private sector in low-skilled jobs (in the case of males) or in the household sector as domestic workers (maids and nannies) in the case of female migrants (SKCSB, 2014). Kuwaiti women would not take low skilled positions in the private sector and the availability of domestic labour has made it increasingly possible for women to enter the labour force. Like its larger neighbour and their Saudisation process, Kuwait has adopted "Kuwaitisation" to raise the prominence of its own citizens in the workforce and reduce reliance on imported labour. This has been another reason for Kuwaiti women's increased role in the workforce, which is discussed in the following section and analysed in greater detail in the next chapter.

\section{Women and employment}

Before discussing women's participation in the labour force in Kuwait it is useful to look beyond this country for context, and in particular on the effect of the Second World War on women's role in the workplace in the UK. The Second World War was a game changing point for women's empowerment but in this case in terms of the employment domain. In Britain, women entered the industrialised labour force in vast numbers to satisfy demand for manufacturing labour. However, there was resistance to this move from the private domain. Almost half the child nurseries opened for women during the war were closed as part of the unannounced effort to pressure women to go back to becoming homemakers and leave the world of waged work to the demobilised soldiers (Riley, 1983). Indeed, during the 1950s patriarchal society was alive and strong in the UK and households were headed by male 'breadwinners' married to female 'homemakers'; there was little change for a decade or two after the war but in the 1960s women began to take up new positions in factories etc. (Chapman, 2004).

Such pressure on women to remain in the private domain only delayed or slowed what would become an inexorable rise in women's participation in the labour force. Between 1950 and 1990 the number of female workers in the UK rose from 7.1 million to 22.9 
million (Wrigley, 1999). Instead of providing domestic labour women were now in factories making the appliances that would do that work instead of them. In terms of women's activism this period became known as the second wave of feminism. The relevance of this point concerns the potential for parallels with the Iraqi occupation of Kuwait in 1990-1991, something returned to later in this chapter in the context of the momentum towards women's suffrage.

As already noted, women's participation in the workforce in Kuwait is discussed in more detail in the following chapter. Briefly however, 37.6\% Kuwait women aged 15+ were in the labour force in 2014, compared with 54.2\% for men (SKCSB, 2014). These participation rates tend to understate participation of women because so many are in higher education and furthermore it includes those beyond working age.

The labour force inclusion rate for women in Kuwait is relatively high though the whole private sector employment scene is dominated by a tendency for employers to prefer skilled foreigners, particularly Asians. This is because they are "prepared to work for lower wages, and come single" (Bashar and Khan 2010, p.11). Few Kuwaitis, either men or women, work in the private sector which is seen as a low status form of employment. In the public sector, the ministries of education and health are major employers of Kuwaiti women (SKCSB, 2013b, p. 141). Under the Kuwait Labor Law. No. 6 of 2010, women in Kuwait are protected from employment discrimination on the basis of gender, including with regards to pay under Article 26.

The government of Kuwait, like its Saudi neighbours introduced a range of measures to enhance citizen participation in the workforce with the aim of reducing reliance on imported labour. Consequently, this has reinforced the high employment rates for women in Kuwait. And importantly under Article 26 of the labour law women have the right to equal pay for the same work (al-Mughni, 2010). Women are also highly represented in the civil service, but they rarely reach decision-making managerial positions (UN-CEDAW, 2004). The reason for this is a combination of the Kuwaiti version of the 'old boys' network' and the patriarchal norms that women should not rise above men in the workplace. In addition to a relatively high level of participation in the workforce there is also widespread entrepreneurship among women, something which has enabled many to gain economic independence (al-Mughni, 2010). 
Western (2008) adopts economic determinism in his analysis of the extension of women's rights in Kuwait and the wider Middle East; he presents evidence from early Islamic writing that suggests that Islam supports a high level of participation for women in Islamic society. Despite Islam being perceived in some quarters as repressive it does grant women substantial economic rights and this can be traced back to the very beginning of Islam. Western (2008) lists these Islam given economic rights as: dowry, inheritance and maintenance. It is economic empowerment that has facilitated the extension of women's rights:

Whether the 2005 Kuwaiti recognition of a woman's right to vote is based on this economic progress or on some other international pressure is hard to say, but arguably the trend towards increased women's rights tracks the growth of Arab women's spending power (Western, 2008, p. 82).

Women's increasing economic empowerment has been highlighted by the banking sector which has recognised women as a major business opportunity. Again the theme of contradictions reappears. While women are becoming more economically active and have learned to invest in their own economy, it is still within the overall context of Islamic cultural traditions, mores and ancient social codes; so separate banks are created for them and all women working at them wear the hijab (González, 2013).

Despite the numbers of Kuwaiti women who are employed, women's participation in the workforce still falls short of the aspirations set out in the Convention on the Elimination of all Forms of Discrimination Against Women and the United Nations Committee on the Elimination of Discrimination against Women has expressed concern at the lack of diversified employment opportunities for women in spite of their high level of education (UN-CEDAW, 2004). The committee also noted the persistence of restrictions on women's employment and protective employment laws, benefits and policies which “perpetuate traditional stereotypes regarding women's roles and responsibilities in public life and in the family" (UN-CEDAW, 2004, p.4). Thus, there is a clear limitation placed on women's participation which could be described as greater participation but on men's terms.

\section{Inheritance}


Although women enjoy full and equal property rights and discretion how their income, land and assets are used, when it comes to inheritance sharia dictates that their inheritance rights are half those of male siblings. This is stipulated in the Qur'an and is based on the principle that a male also has duties to use his wealth to support his wife/ wives and other dependent female members of the family (al-Mughni, 2010).

\section{Education}

There has been a wide range of developments in terms of women's economic rights and equality of opportunity. Underpinning this is education. Clearly attitudes to women's education rights vary enormously across Muslim countries with Kuwait at the more liberalised end of the spectrum (despite gender segregation) and Taleban ruled Afghanistan (where education for women was banned) at the other. The education rights enjoyed by Kuwaiti women are perhaps the strongest area of all in terms of women's rights and provided a "showcase" example (Najmabadi, 2005, p. 465). Under Article 40 of the constitution, every Kuwaiti citizen is guaranteed free and equal access to the education system from primary school through to university, and male and female students are provided with equal opportunities to study abroad. In the sphere of education women have made significant gains over recent decades, and the percentage of young literate women in Kuwait is now equal to that of young literate men. According to al-Mughni (2010, p. 236), "Access to education has enabled women to become financially independent and pursue diverse careers. Women are now found in most professions including engineering, architecture, medicine, and law, as well as on executive boards of major banks and private companies."

This largely positive education picture however needs to be somewhat qualified. Until recently, in some disciplines such as medicine and architecture, to be admitted to a course at Kuwait University a woman needed to achieve higher grades than a man and this was justified by the government as positive discrimination in favour of men as they have been less successful in securing university places (al-Mughni, 2010). In 2012, an administrative court ordered Kuwait University to cancel this policy (Human Rights 
Watch, 2015). Enrolment data for Kuwait University shows that female students outnumber male students by more than two to one and dominate most disciplines, including law, (SKCSB, 2013b p.209) something which may be particularly relevant to the battle between liberals who want to see women as judges and conservatives and Islamists who vehemently oppose it.

Also, gender segregation for adult students continues to be a contentious issue, with Islamists pressing for it while liberals are against it (al-Mughni, 2010). In 1996, an Islamist dominated National Assembly passed a law that required segregation within the public university education system; the segregation came into effect in 2001(Olimat, 2009). The lawmakers drew accusations of hypocrisy by opponents who pointed out that the sons and daughters of these parliamentarians were predominantly being educated at western universities which were not segregated. The ferocity of the debate on segregation is amply illustrated by the reaction in 2008 to the introduction of a bill by parliamentarian Ali Al-Rashid that would permit coeducation once again. He received visceral death threats from a retired civil servant who was later arrested by the police (Sheshtar, 2008). In an opposing move in the long running battle over coeducation, conservative lawmakers sought to extend the ban on coeducation to foreign run education outside the state sector but with a more pro-government assembly in place by 2013 moves began again to rescind the ban on co-education (Toumi, 2013b).

Women's access to education in Kuwait and their entry into the labour force are essential to the discussion of women's empowerment. Interestingly, the progress on education and employment has come in spite of resistance from the conservative, traditionalist, Islamist forces; essentially against the forces of patriarchy. This is important as it demonstrates that there are domains over which this patriarchy does not have full control, something which is a recurrent theme throughout this thesis.

\section{Political rights and civic voice}

This section of the chapter reviews the road to women's political rights - their involvement in the democratic process is a crucial element to women's empowerment and another key theme in this study. As Keddie (2004) asserts "Strong correlations can be found between a woman's status in society and that society's likelihood of being 
democratic" (p.27). The level of political rights attained by women in Kuwait is significant (highlighted further in this section). What is more and particularly noteworthy is that the attainment of political rights by Kuwaiti women exemplifies democratic progress occurring in a largely non-democratic political system (Shultziner, 2008). Kuwait's National Assembly is, nevertheless, viewed as unique in the Gulf as it has a parliament with genuine power and which is democratically elected. Still, by generally accepted standards the State of Kuwait still falls short of the label 'democratic' (Shultziner and Tétreault, 2011). To describe the road that eventually led to women's suffrage, it is necessary to start with the Iraqi occupation of Kuwait which took place fifteen years earlier.

\section{Iraqi occupation adds momentum}

In a possible parallel with the partial extension of suffrage to women in the UK after the First World War and the wider development of women's rights across the western world after the Second World War, a repeated theme in the literature is the impetus given to the Kuwaiti women's rights movement by the occupation of the country by their northern neighbours Iraq in 1990-1991 (Tétreault, 2001; Rizzo, Meyer and Ali, 2002; Olimat, 2009; al-Mughni, 2010), an occupation described as a "catastrophic event for the State of Kuwait" (Olimat, 2009) while Rizzo et. al., (2002) refer to "an historical event that brought issues surrounding democratization to the forefront". Al-Mughni (2010) argues that the Occupation may have been a trigger to more liberal policies as a payback for their role during this period. From his temporary exile in Saudi Arabia during the Occupation, Crown Prince Sheik Saad al-Abdullah al-Sabah made a series of announcements to sustain loyalty to the ruling family and maintain morale. He promised that the rights of citizens, including women, would be strengthened should the occupation be ended. The Crown Prince stated Kuwait would "rise in the shadow of the Constitution of 1962 to solidify democracy and deepen popular participation, which was and remains a goal we all strive to realize and struggle to achieve" (Ibrahim, 1990). Kuwaiti women demonstrated their persistence and determination during the invasion and subsequent occupation by organising demonstrations, confronting both machine guns and tanks and saying 'No' to the invading forces. Furthermore, they clandestinely published pamphlets, some were taken prisoner while others were executed (al-Sabah, 2003). As an inadvertent consequence of the invasion the women's rights movement in 
the state finally made a breakthrough in terms of national representation. The siege mentality that necessarily existed in Kuwait during this period led women to assume a number of positions of responsibility that they would never have been allowed to take on under the former, peacetime regime (Boghardt, 2006).

War brings necessity including the need to draw on all available resources. It is no time to deny half the population the opportunity to contribute. This has been demonstrated time and time again. In the American Civil War women took on new roles even working as spies, they earned their own money and gained greater independence as a result. After the war newly emboldened the women's suffrage movement started building momentum (McElroy, 1991). The First World War is also recognised as leading to a step change in women's rights in many countries. Historian Gifford Lewis (1986) suggested that "The highly skilled and dangerous work done by women during the war was probably the greatest factor in the granting of the vote to women" (p.165). It also heralded what became known as the first wave of feminism. It was only during and after the First World War that women's suffrage was widely realised and between 1914 and 193958 nations, US states, provinces and territories granted women the right to vote including Britain in 1928 (Daley and Nolan, 1994).

The Iraqi invasion of Kuwait took place on 2 August 1990 and the occupation lasted under the country was liberated on 27th February 1991. During this seven-month period women were taken as prisoners of war and took part in the fighting as formidable resistance fighters. As the war ended women were encouraged to play a full role in the reconstruction of the country, they started gathering at women only social meetings, diwaniya. Women's rights issues were openly discussed. This was very different from the UK where, as already stated, in the immediate aftermath of the war thousands of men returned home from fighting and women were looked upon to give up their jobs to ensure employment for the homecoming men.

Whether war produces long lasting empowerment for women is disputed. Juliá and Ridha (2001, p.583) argue, “Once the armed conflict is over and peace returns, women's choices, rights, and lives once again tend to become circumscribed by tradition, religion, and male prerogative." Similarly, Cooke (1994) observes that in the case of Arab women role reversals and time of war are temporary and not transformational. Indeed, in Kuwait before the war women could not join the armed forces. This was set aside for the period 
of the war and then reinstated once the fighting had stopped. Julia and Ridha (2001) interpret this as religion (under which defending your country is obligatory) usurping tradition at times of war.

In the UK, war, particularly the Second World War, does appear to have been a transformational event although at all times women's rights were gained gradually. It is possible that in Kuwait's case and perhaps in the Arab region that war only suspends patriarchy. However, in all cases, including Kuwait the momentum war gives to women's activism is deep and long lasting.

Once the Iraqi forces had been forced out of Kuwait in 1991, the new government found that it was unable to simply force women to return to their old roles (Ibrahim, 1990), and over the following five years, women reached a number of previously unthinkable positions within Kuwaiti life, including powerful academic and business roles. Kuwait was widely applauded for this change in women's rights, particularly as it contrasted so heavily with more repressive regimes in the region. However, while women started taking positions of influence in civic life in the business and educational spheres their political rights as defined by the 1962 Election Law remained virtually non- existent (al-Mughni, 2010). The advances made by women's organisations did not go unopposed and the decade afterward the Occupation was characterised by political confrontation and turmoil. Liberals and Shia Muslims pressed for increased Women's rights including the right to vote, while opposing them Sunni Muslim MPs and traditionalist tribal representatives sought to introduce highly draconian laws that would have led to a kind of gender based apartheid; a law requiring university level education to be segregated was passed in 1996 and came into effect in 2001 (Olimat, 2009).

\section{The November 1999 parliamentary votes and increasing militancy}

The lack of progress in modernising Kuwait and extending civic rights led to the National Assembly being intermittently dissolved by the Amir ahead of term. It was not just the strength of Islamist and tribalist opposition that prevented progress but also the weakness of the secularist support for the extension of voting rights, indeed some secularists were mobilised against it. This position was based on the calculation that because Islamist and tribal MPs had more wives than the secularists they would benefit disproportionately from the change in the law (Olimat, 2009). This may have led the 
Emir to conclude that a royal decree was the only way to extend voting rights in the foreseeable future. The final dissolution of the decade took place on May 3rd 1999 and while it was not sitting, awaiting fresh elections the Amir issued 63 decrees one of which gave women the right to both stand for and vote in elections (Reeves, 1999). When the new parliament assembled it struck down all 63 decrees. After the vote on voting rights for women one man exclaimed; "Kuwaiti people don't want women's rights. Why do you want to force it on them?" (Reeves, 1999). The man in question's conclusion was clearly his own as women had never been asked about their rights and aspirations for them, one of the main gaps that this research study aims to fill.

Umbrage at the actions of the Emir guided the parliamentarians rather than any rational debate over whether voting rights for women were part of the overall human rights that all Kuwaitis should be entitled to (Olimat, 2009). Al-Mughni and Tétreault (2004) argue that the scale of the defeat was exacerbated by it being submitted at the same time as decrees relating to major economic and social policy changes including permitting foreign direct investment in oil production a highly contentious matter. A replacement bill, this time framed by liberal parliamentarians was put again to the Assembly in the subsequent days (al-Mughni and Tétreault, 2004).

The division in Kuwaiti society regarding the extension of voting rights to women was never clearer than in late November 1999. In the National Assembly a proposition supporting the extension of voting rights to women was being voted on. The vote had been triggered by the decree issued by the emir, Sheik Jaber al-Ahmed al-Sabah, in July that year after May's dissolution of the Assembly resulting from his frustration at the lack of progress it was making on this and other issues. News reports such as the one below published in the New Straits Times refer to the sharp differences between on the one hand the modernists and the other Islamist and tribalist conservatives.

[...], scores of women in bright orange T-shirts cheered every vote in favour of a historic proposition that would have made this tiny Persian Gulf country the first among its close neighbours to grant full political rights to women. But in the next gallery over, an even larger group of men wearing traditional dishdasha robes cheered even louder every time a member of the all-male Parliament announced that he was voting no (Jael, 1999, p.14). 
While the vote count was 32 to 30, of the 50 elected members of Assembly only 15 voted in favour with 32 against, revealing the scale of the task still facing the modernizers. Al-Mughni and Tétreault (2000) identify the defeat of the royal decree in November 1999 and the subsequent failed attempt to pass legislation as a transformative event (as the Occupation had been labelled elsewhere) that galvanised the efforts of both men and women campaigners for voting rights.

The male-only judiciary refused to rule the Election Law of 1962 unconstitutional, something which again sparked mass protests that gained international attention (alMughni, 2010). Another proposition to extend the franchise to women was defeated in 2003. During this time Conservatives continued to use the argument that the woman's domestic role with the family would be under threat as a consequence of their involvement in politics (Ahmadinejad, 2005). Increasingly frustrated, women turned to non-violent direct action in the run up to the 2003 election; hundreds of women demonstrated and some stormed registration offices demanding the right to vote (Rennebohm, 2011). The importance of understanding this period and the issue of women's suffrage is that it was a period of struggle in the same way that it was in countries like the UK. Modernising elements of society, which included the ruling elite, were ranged against conservative, traditionalist Islamist interests aiming to preserve a patriarchal social structure. By 2005, the particular struggle over suffrage was won.

\section{Women achieve suffrage and secure representation}

Finally, on May 16th 2005, the parliamentary mathematics saw 14 government ministers and a broad coalition of liberals win a vote 35 to 23 in the Assembly, thus amending the Electoral Law. It brought to an end many years of debate and struggle. Opponents comprising of Islamist and tribal lawmakers did however secure the inclusion in the amendment of a caveat that women candidates and voters must, at all times, act in accordance with Islamic Law something that would be used subsequently in an attempt to exclude two women MPs for not wearing the hijab (as already noted). Nevertheless, Freedom House in its 2010 report 'Women's Rights in the Middle East and North Africa' described women's enfranchisement in Kuwait as the most significant development in women's rights in the Gulf Region during the past five years (Freedom House, 2010, p.2). 
With this vote the political landscape in Kuwait was transformed particularly as women would now comprise $57 \%$ of the enlarged electorate of around 350,000 citizens (Olimat, 2009). But of course, the enfranchisement of women was, however, no guarantee of representation and no female MPs were returned in either the 2006 or 2008 elections. Olimat (2009) puts the lack of success down to deep-seated tribal customs and traditions that do not support women's participation in political life. It is certainly true to state that Kuwait is at its most fundamental a truly patriarchal society and the passing of legislation does not automatically or rapidly alter this. Women voted overwhelmingly for men in the 2006, 2008 elections again largely for cultural reasons combined with a lack of belief that the female candidates would win (Olimat, 2009). On top of this Olimat (2009) points to a lack of strategic working arrangements with other interest groups and shared goals among women's organisations as further reasons preventing greater success at this stage; this was presaged by Tétreault (1993). Analysis of the voting figures shows that women voted mainly for men supporting Assiri (2007) who claimed that failed tactics among women candidates had been based on the misguided assumption that women voters would vote for women candidates based on their gender alone.

In 2007, a research study was undertaken to explore Kuwaiti men and women's perceptions of women in the country's political domain (Sarhrouny and Choukri, 2007). The timing of the study is important. At this point in time women had secured the vote and 27 women had stood at the June 2006 election, in which $57 \%$ of eligible voters were women; none were returned. The study found that among the main women's rights issues of the day were marriage allowances being paid only to men, housing allowances for divorced women, citizenship rights, the unfair treatment of women during divorce. These issues are among those considered in the forthcoming policy review chapter. Turning to perceptions of women and politics both men and women perceived women to be inexperienced in politics, unaware of their personal interests and heavily influenced by husbands and male relatives (Sarhrouny and Choukri, 2007). Women as candidates and potential MPs were on the one hand seen as "tougher", "more practical", "more mindful" "better problem-solvers" and "highly capable" yet on the other were also described as "weaker than men" and emotional. The researchers noted:

Although participants were divided as to whether a woman MP would be as effective as a male MP, many felt that a woman MP would be unable to influence the Assembly, regardless of her capabilities, because 
her fellow legislators would not have trust in her judgment. In fact, some male participants from the Bedouin group expressed disapproval for allowing women to contribute to legislation as they believed it is not allowed under Islam; their perception was that in Islam, women cannot make laws because it would give them control over men. (2007, p.15)

This research from 2007 took place before women had eventually been elected as MPs and so the current study will provide a more up to date exploration of attitudes women have to other women's participation in politics.

There are many reasons one could legitimately argue to explain why women's desire to vote did not translate into more MPs. Perhaps female voters were less accessible than male candidates and so did not hear the women candidates' message; maybe they were inexperienced as voters and still heavily under the influence of their male guardians. Perhaps, the female candidates were perceived as being inexperienced and insufficiently skilled. The Women's Study and Research Center and the United Nations Development Fund for Women, surveyed the basis on which voters choose which candidate to vote for and found that the majority of respondents did not consider gender a factor in their selection though among those who had a gender bias, this bias was on balance in favour of women (WSRC/UNIFEM, 2008). They cautioned though that there was a mismatch between the responses to their survey and what had actually happened in the polling booths where a much more pronounced favouring of male candidates had been demonstrated (WSRC/UNIFEM, 2008). The challenges that lay ahead of the women despite their election were seen in the reports that the legal and legislative committee of the Assembly, attended only by 4 male tribal conservatives ruled that two women cabinet ministers had broken the law by not wearing the hijab during their swearing in ceremonies. This followed a walkout of some conservative MPs when the women arrived at the Assembly to take their seats (Izzak, 2008). It is arguable that although the extension of participation to women was an eye-catching initiative, too little attention was paid to certain restrictions that remain in place: women are still unable to serve in the judiciary or the military, to hold positions within the social security and pensions departments of the legislature, or to have equal marital rights to their husbands.

Finally, exactly four years after winning the right to vote four women candidates were elected on May $16^{\text {th }}, 2009$. To put Kuwaiti women's suffrage and the early results into context, the period from forming a national movement for suffrage in the UK to the 
achieving of equality of franchise lasted 56 years (from 1872 to 1928). It was a further 69 years (1997) before the number of women MPs exceeded $10 \%$ of the total (UKPoliticalinfo, 2015). Clearly there is much precedent to suggest that the suffrage does not necessarily translate into representation in the short term. The importance of women's participation in politics is therefore an important theme that is carried forward through the remainder of this thesis.

\section{Rulers' motivation in extending rights to women}

Tétreaul (2001) describes the aspirations of the rulers of Kuwait as being to create a country that is on the one hand economically developed and modernized while at the same time 'traditional' and tribal in the way it is socially organized and ruled over autocratically. This seemingly impossible dream is full of contradictions, contradictions that are seen in many aspects of political and civil life in Kuwait including women's rights and their position in society. Elsewhere in the literature, there is reference to a 'social contract' between the rulers and the citizenry. Al-Mughni and Tétreault (2000) point to the existence of a 'social contract' in many countries of the region whereby in exchange for ceding power in the economic, judicial and educational spheres religious interests, in this case Islamists, are allowed to retain major influence in the private sphere including 'private behaviour' and personal status. This helps to explain the apparent contradictory nature of developments in Kuwait whereby some aspects of society are liberalising and modernizing and others are not. This is most clearly represented in the judicial system where a more liberalised constitution and legislative framework is juxtaposed with the dominance of sharia law in the family courts but has also been seen in the opposing ideologies present in the National Assembly. Assiri (2007) also refers to a 'social contract' but sees it as an unwritten agreement that the people of Kuwait would give their obedience to the Ruler in return for an appropriate amount of public participation in decision-making (Assiri, 2007), the current embodiment of the participation is the Assembly.

Clearly, the political elite in Kuwait are involved in a delicate balancing act, perhaps even walking a tightrope. The consequences of giving women full equal civil rights are well summed up by al-Mughni and Tétreault (2000, p.161) when they wrote: 
If women had full civil rights the necessity for them to acquiesce to male domination would be attenuated. Women could demand equal rights in marriage, challenging a host of religiously sanctioned practices from polygyny to repudiation that lie at the root of the female subordination in the Kuwaiti family.

They conclude that the driving force behind the discourse on women's rights is neither a religious one nor an economic one but rather is a question of sexual politics (al-Mughni and Tétreault, 2000). Of course, promoting equal civil rights is a direct challenge to patriarchal control which why in Kuwait each aspect of women's empowerment is challenged however minor or symbolic it may be, each one a small battle in a war between conflicting interests. However, women's views across the whole spectrum are rarely heard, something which this current research aims to address.

Rizzo et. al. (2007) examine the politics of political rights and argue that the support of the previous emir and the government as well as the urban elite is the result of political calculation. Women were enfranchised as they were seen as friendly to the regime and because they would counterbalance non-urban opposition and stabilise the political scene. This scene saw upheaval in the 1990s with several dissolutions of parliament ahead of term and threatened the whole progress of the nation. For proof of this calculation they contrast this with the lack of progress towards greater rights for the stateless of Kuwait who may be more likely to vote for Sunni Islamist MPs who represent non-urban tribal interests. With such a small electorate the introduction of any significant bloc of new voters with greater affiliations one way or the other is highly significant. They conclude: "It is essential to examine networks and potential alliances within societies in order to understand the processes of inclusion/exclusion" (Rizzo et. al., 2007, p. 192). This may point to another reason why women's representation has not taken off in the way strength of desire to vote suggested. There are multiple sectional interests within Kuwaiti politics liberals/conservatives, Sunni/Shia, tribal/non-tribal, Islamist/secular and these may be more powerful conflicts and more highly prioritised loyalties than the male/female interests. Gauging whether this is indeed the case will be part of the current research.

Al-Anzi and Gharaibeh (2006) compared the political culture and attitudes of high school students in public schools in Kuwait with those taking a private education. Their findings included the tendency for parents of male children to send their boys to private 
institutions with an international curriculum. Kuwaiti public school students were found to be more politically engaged than private peers. Interestingly, $41 \%$ of public school pupils believed that Kuwaiti citizens had achieved equality under the law (31\% for those in private schools). There is very little gender based analysis in this study, which took place before women gained the right to vote. It did, however, reveal a strong desire among female students to participate in future elections and discuss political issues. In terms of actual political participation such as joining political groups, male students were found to be more inclined than female. The researchers concluded that their findings were broadly in line with the prevailing stereotypes of gender attitudes towards politics.

\section{Social and cultural rights}

Kuwait is a signatory to the International Covenant on Economic, Social and Cultural Rights 1990 with a number of reservations. UNHCR highlighted a number of areas they viewed as requiring improvement. As with the country's performance under CEDAW there were criticisms regarding the "de jure and de facto discrimination against women" (UNHCR Committee on Economic, Social and Cultural Rights, 2004). Beyond the public space of civic society are two 'protected spaces' in Kuwait. These are identified as the mosque and the family home (Tétreault, 1993) both lie beyond the reach of the state. A woman's position in these spaces can be different and contradictory to those in the public space.

"Kuwaiti social practices are defined by laws, mediated by institutions, and shaped by traditional values that include but are not limited to, Islam.” (Tétreault, 1993, p. 282). It is these practices which have a great deal of influence on women's daily lives and account for the fact that despite having education and labour laws which formalise gender equality, discrimination can still exist in these areas. Women have equal rights of access to Kuwait's extensive healthcare, social security and welfare schemes; furthermore, there are no restrictions on forming cultural associations and women are free to play their role in the community (al-Munghi, 2010). 


\section{Reproductive rights}

There are few interferences with women's reproductive rights and use of contraception is widespread especially amongst educated urban women and this has been reflected in falling fertility rates (al-Munghi, 2010). Abortion, however, is strictly controlled on a number of levels under Law no. 25 of 1981. A husband's or guardian's approval is required, it can only take place if there is a pressing medical reason threatening the mother's life or if it known that the child would be born with severe and incurable physical or mental defects. Not following the procedures exactly can lead to a 10 -year prison sentence for the women and anyone involved in assisting her, by providing drugs for example, which further restricts abortions as medical professionals are reluctant to become involved for fear of the penalties should the patient not have been through the correct procedures. The 1981 law was, however, a significant liberalisation compared to the blanket ban on abortions that had been in place under Law no. 16 of 1960. There is no evidence that the most harmful traditionalist practices such as virginity tests and female genital mutilation take place in Kuwait and honour killings do not feature either (al-Munghi, 2010).

\section{Housing}

Al-Munghi (2010) identifies housing as a difficult area for women and is particularly acute among divorced women who are not economically independent. While there are no legal impediments to women owning property the way legislation is framed certainly frustrates it. The Housing Assistance Law (No. 47 of 1993) provides the legal framework under which the government offers subsidised housing. Only married men can apply for such housing while women and unmarried men are excluded. This is intended to reinforce the traditional idea of male headed households.

This tradition is further reinforced by the way government offers low interest loans to facilitate housing purchase. A married man with children and married for four years can apply for a loan of US\$245,356. A divorced or widowed woman with children can only receive a maximum of US\$157,729. Behind this is the law's adherence to sharia which recognises that the man has a responsibility to support the family. The situation is also disadvantageous regarding housing benefits and the state does not recognise or provide housing benefits to female headed households (al-Munghi, 2010). 


\section{Divorce}

Divorce is a growing social concern in Kuwait. Al Munajjed's (2010) study reveals the significant growth in divorce in marriages between Kuwaiti citizens. The divorce rate as a percentage of Kuwaiti marriages rose from 32.59\% in 1994 to $39.05 \%$ in 2007 and subsequent official statistics show it rose again to 46.6\% by 2012 (SKCSB, 2013). In the absence of women judges in family courts women are likely to receive unfair treatment leading to them bearing the bulk of the social and economic consequences leading alMunajjed (2010) to conclude: "Policymakers could improve women's access to justice in divorce by encouraging women to join the legal profession and by appointing female lawyers to judicial positions" (p.26).

\section{The role of the media}

Like education, the media is identified by al-Munghi (2010) as a positive force for women's rights. This is due to the high levels of employment and representations of women throughout media organisations. There is significant coverage of Women's issues although the media are somewhat prone to stereotype women and often portray women's organisations as divided. "Women in Kuwait use the media as a vehicle for bringing gender issues to the forefront of the public debate, and most newspapers devote considerable space to the activities of women's groups" (p.243). Freedom House has described Kuwait's media as being relatively free and among the most open in the Middle East but also pointed to the high levels of fines which can be imposed for criticising Islam under laws introduced as recently as 2006 (Freedom House, 2014). The fact that pro-Islamist laws of this kind were being passed around the same time that women were being granted the right to vote is another demonstration of the contradictory nature of the change that is taking place in Kuwait, a theme that will be explored further in the next chapter.

Unsurprisingly, like all other aspects of life in Kuwait the modernising/ traditionalist dichotomy is seen in the media. Dinkha and Dakhli (2009) point out that there is a high degree of western penetration in Kuwaiti media and that channels such as BBC News, France 24 and $\mathrm{CNN}$ are widely viewed. If this appears modernising, then other developments are more traditionalist. In reaction to the growing popularity of reality TV shows similar to American Idol, Islamist members of parliament urged the government 
to act to ban such shows. In 2004, the government issued a fatwa banning women performers, women could not entertain in public in any way including singing and dancing for example. Earlier a similar ruling decreed that single men and families must sit separately at public concerts. In July 1997, all public concerts and shows that did not adhere to Kuwaiti traditions and Sharia law were banned (BBC News, 2004).

With the exception of foreign channels received by satellite the broadcast media in Kuwait is mainly state owned and financed. In 2004, Al-Rai Alam (Public Opinion) newspaper launched the first privately owned station, it covers controversial social issues including women's position in society and even homosexuality. Its popularity is on the increase and other private channels have followed and media ownership has recently diversified. Regarding printed media there is a good degree of diversity for a small nation with 5 Arab language dailies and two published in the English language. Criticism of the government is observable within self-imposed boundaries. These boundaries were sharply exposed when an angry mob armed with knives and pistols stormed the offices of the private television station Scope TV (Reuters, 2010). The reason was that the 150 strong crowd had taken offence at remarks made about a member of the ruling family; the station was forced off air and its offices ransacked. Criticism of public officials is generally tolerated although constitutionally the emir himself is protected and legal cases to enforce this are commonplace (Reuters, 2010).

With regard to the media's role in the advancement of women's rights, Sakr (2005) sees both positive and negative tendencies. On the one hand, during the periods of intensive debate such as those surrounding the granting of suffrage are described as "disingenuous" (p. 137) yet on the other the number of women in the media (including the $38 \%$ of the workforce at the State News Agency) is seen as a positive development (al-Munghi, 2010). Al-Mughni and Tétreault (2004) conclude, however, that there was a belief among women activists that overall they were treated fairly by the printed media.

Not surprisingly, the Internet has become an area of concern for the governments of Muslim countries mainly in terms of its ability to circumvent traditional values and allow access to content that undermines morality. In Kuwait attitudes are relatively relaxed and al-Munghi (2010, p. 24) states that "the Internet continues to play an important role in women's lives and has enabled women's rights advocates to network with international organizations and share resources." While al-Nashmi et al., (2010) confirm that "The 
government also supports a techno-savvy culture by allowing the sale of and access to high-tech devices" (p.162). In both the media and in the school curricula there has been discussion as to the use of stereotypes of woman that may be used to reinforce their discriminated position in society (al-Shehab, 2008).

\section{Chapter Summary}

This literature review has served several important purposes. It has established the positions and interests of the various actors in the country in terms of women's empowerment: Kuwaiti women (not a homogenous group by any means) the ruling elite, traditionalist-conservative, tribal and Islamist men (and women) and also it should be added global NGOs, human rights groups and organisations such as the IMF and World Bank. Different analytical perspectives have featured in the review from economic determinism (Western, 2008; Khan and Bashar, 2010) to religion (Rizzo, 2005; Engineer, 1999) and from the importance of political networks and alliances of interests (Rizzo, Meyer and Ali, 2007) to the sexual politics perspective (al-Mughni and Tétreault, 2000). Another purpose was to identify gaps in knowledge, there are several gaps and in particular a lack of information about how the reforms or lack of reforms are received by Kuwaiti women themselves. What do women really think of the personal status laws? Why do so many women appear reluctant to support women candidates? What is and will be women's place in the political domain and will the forces within it support or oppose greater empowerment? Are women winning reforms or being granted them? There are many questions to carry forward but a complete and convincing answer to them can only be reached by listening to the interpretations and perceptions of Kuwaiti women themselves, which is what this exploratory study aims to achieve.

It appears that the Kuwaiti government is motivated to improve women's position in society but it is also aware of the potentially existential threat from Islamists who as a result also have their interests reflected in policy. It is certainly a delicate balancing act. Building on this chapter and the contradictory nature of policy developments in Kuwait, some apparently signalling greater gender equality, others reflecting patriarchal control, 
the next chapter focuses on policy and borrows the words of Neuwirth (2002, p.3), who was referring to the situation globally, to ask to what extent is it true to say that there is a "substantial gap between the rhetoric and the reality of sex-equality rights"? And, if there was a gap when Neuwirth was writing, what difference have the most recent policy changes made, if any? Thus the following chapter examines women's position across a variety of key domains including employment, education and other domains in the public sphere and contrasts this policy with what is happening in the private sphere, such as the measures of the Personal Status Law 1984. In so doing the chapter broadens the platform of understanding of the issues investigated in this study and identifies the questions that are taken forward in this current study. 


\section{CHAPTER TWO}

\section{GOOD NEWS AND BAD NEWS: THE TWIN TRACKS OF POLICY DEVELOPMENT IN KUWAIT}

\section{Introduction}

Kuwaiti nationality brings with it many advantages: free education and healthcare, employment in the public sector, and the provision of housing welfare to all Kuwaiti families whose (male) head does not already own real estate when making the application (Public Authority for Housing Welfare, 2011). However, as this chapter aims to demonstrate this apparent abundance is not always accessible to women on equal terms.

In 2001, leading Kuwaiti sociologist Haya al-Mughni wrote:

The constitution of Kuwait declares men and women be equal before the law and guarantees them equal rights to education and paid employment. But equality means guaranteeing not only of equal rights, but also of equal opportunities for both men and women. In practice, the principle of equality has been absent from state policies (2001, p.63).

In the ten years since penning this view many changes have taken place in Kuwait, perhaps most notably, as already emphasised, the political enfranchisement of Kuwaiti women and the subsequent election of women MPs and appointment of two female ministers.

Current policy in Kuwait can be presented both positively and sceptically. An example of the former perspective came unsurprisingly from the Kuwaiti government in its periodic review submitted in February 2010 under the UN Human Rights Council Resolution 5/1. It reported:

Women enjoy the same rights as men in many areas of life, without any discrimination, in particular with regard to civil, political and trade union freedoms, the right to education and health care, the right to own 
property, freedom of expression and freedom of association. (Kuwait Universal Periodic Review Feb. 2010, p.14).

Released a year later in February 2011, the Human Rights Watch (HRW) World Report 2011 stated that "Discrimination against women continues in nationality, residency, and family laws, and in their economic rights, though women gained the right to vote and run for office in 2005" (section 9d). Furthermore, the United States Department of State (USSD) 2009 Country Report on Human Rights published in March 2010 included the observation that:

Women have some political rights; however, they do not enjoy the same rights as men under family law, property law, or in the judicial system, and they continued to face discrimination in many areas. Nevertheless, women attained prominent positions in government and business [1b] (Section 6).

The aim of this chapter is to set out the development of social policy in Kuwait from the perspective of the position of women in this society. It is structured in two parts; part one begins with a critical evaluation of the current state of politics at the moment something important as the political domain and the forces within it will play a major role in determining women's rights in the future. Part one then goes on to set out the positive advancements in women's rights in Kuwait by re-visiting the issues of political enfranchisement, education, workforce participation and the trends towards urbanisation, which has seen the Kuwait population agglomerate into the urban metropolitan area of Kuwait City to such an extent that the country is now reported to be $98.3 \%$ urbanised. The concept of the urbanised citizen, particularly urbanised women is an important one in this thesis as it is this group on which the study is based. In the second part, this positive picture is challenged by the absence of change in key areas affecting the daily lives of Kuwaiti women. These include divorce, housing, nationality and violence and sexual harassment. The latter and to a somewhat lesser degree divorce are highly sensitive issues in terms of research, however, they are important in the context of women's rights and thus worthy of exploration in this chapter and the closer examination of rights and policy it contains which is intended to assist in steering the thesis. The objective is to demonstrate the twin tracks of policy development one of which progresses with some rapidity and purpose while the other is effectively blocked. One track is located in the civil and political sphere while the other is the domain of tribal tradition and Islamic religious law. 


\section{Part One: Women's rights advance on many fronts}

In the short period since 16th May 2009 (the day the first women MPs were elected), a series of substantial changes have been implemented that are a reflection of the government's interest in developing the role women play in Kuwaiti society, taking the country further down the path that developed nations have trodden, a path leading to women's equality and their equal rights being accepted as entirely normal and protected by law. With this in mind, before commencing the policy review there will first be a brief summary of the current state of the various political forces in the National Assembly and the government as this is likely to be a pointer to future policy development.

\section{The current state of politics in Kuwait}

The previous chapter considered the period leading up to and including the enfranchisement of women in Kuwait and their first entry into parliament. Here the attention shifts to what happened next.

It is tempting to view the Gulf region as being broadly homogenous in terms of politics, but this would be to overlook the particular history and features of what has framed politics in Kuwait today. The Sabah family are broadly accepted as rulers but so is the need for reform (Salem, 2007). In contrast to some other Arab countries political opposition is allowed to air its opinions and occasionally it achieves a position to influence policy, however, there is also a very divided opposition. It is also important to understand that women's rights are by no means near the top of the political agenda and reforms mainly mean tackling issues of corruption, economic management and the relations between the ruling family, government, and parliament (Salem, 2007).

There are no political parties in Kuwait because they are banned but MPs are organised into blocs or factions. These are not formal alliances with agreed long term policy platforms but rather 'unofficial' groupings. Progress on policy is largely dependent on the level of co-operation between the ministers largely drawn from the ranks of the ruling Al-Sabah family and the National Assembly with the latter regularly trying to call 
ministers, including the prime minister, to the Assembly for questioning of their activities and decisions while the ministers themselves are highly resistant to this. However, Salem (2007) also points to examples of parliamentary progress in policy areas where Islamist and non-Islamist have worked together, such as fighting corruption.

As stated four women were elected to the National Assembly in May 2009, numerically speaking this has been a high watermark rather than a springboard to greater representation. Table 1 shows the number of female candidates standing and successful at the last 5 assembly elections.

Table 1: Women candidates and MPs 2008 to 2013

\begin{tabular}{|lcc|}
\hline Election Date & $\begin{array}{l}\text { Female } \\
\text { candidates }\end{array}$ & $\begin{array}{l}\text { Number } \\
\text { of } \\
\text { women } \\
\text { elected }\end{array}$ \\
\hline May 2008 & 27 & 0 \\
May 2009 & 28 & 4 \\
February 2012 & 24 & 0 \\
December 2012 & 15 & 3 \\
(opposition boycott) & & \\
July 2013 & 8 & 2
\end{tabular}

(Source: InterParliamentary Union, 2015)

The first four women elected adopted a largely co-operative stance toward the government seeking to make progress on a number of women's issues, however, the political climate in the region was about to change. Regional politics, including Kuwait's own political environment was at this time dominated by the events of the Arab Spring. Protesters, frustrated at a mounting corruption crisis, had stormed the assembly in December 2011 and the 2009 parliament, with its four women MPs, ended when the emir dissolved it and called for fresh elections to be held within 60 days (BBC News, 2011). The outgoing assembly had been mainly government-friendly but when the more rebellious electorate went to the polls in February 2012 they supported opposition factions in large numbers and as a result all four women lost their seats and the political opposition, comprising an alliance of Islamist and tribal factions, took 35 of the 50 seats. 
Women's issues undoubtedly took a back seat as the ruling elite perceived an existential threat. Faced with an openly hostile assembly the government attempted to challenge the voting system which had produced such an unwelcome result for the government. This attempt failed and with politics in limbo the emir again dissolved parliament and new election were held in December 2012. The government decided to unilaterally go ahead with a change to the voting system and opposition factions responded by calling for a boycott of the poll. A government friendly assembly unsurprisingly resulted, including three women MPs. The representation of Bedouin interests fell from 17 MPs to just 1 (Black, 2012). However, while the constitutional court did uphold the legitimacy of the Emir's change to the electoral system it also declared the December 2012 election result invalid with new elections called for July 27th 2013 (al-Atiqi, 2013).

At the time of writing the most recent elections were the July, 2013 ones, as for the previous election an opposition boycott was called but was less adhered to than in December 2012 and tribal candidates did take part leaving only some of the Islamists not standing. The main swing was away from Shiite candidates and towards Sunnis but liberals also gained, leading to speculation that pressure would be brought to bear on the government to move ahead with a more progressive social policy, including women's issues, particularly with the Islamist opposition greatly diminished as a political force (AlQatari, 2013). Two years later and a report published in local media declared that the planning ministry had drawn up a list of 16 government priorities and that women's rights were at the bottom of the list, suggesting progress was likely to be slow (Trenwith, 2015).

\section{The dualism of women's activism: liberal NGOs and Islamic feminism}

In the absence of political parties NGOs play an important role in political life in Kuwait. In Kuwait two women's associations were founded by the merchant class in 1963 - the Cultural and Social Society (CSS) and the Arab Women's Development Society (AWDS) - and remained the only two associations for a decade. Although the two had a brief union, the CSS (today known as the Women's Cultural and Social Society, WCSS) mainly saw its role in terms of providing entertainment for its members and charity for the poor, whereas the AWDS tried to modernise society and raise the status of women (al-Mughni, 
2001). In 1975, a further association was established, made up of individuals mostly from the Al-Qinaie family, called the Girls Club. The AWDS was dismantled in 1980 after its calls for equal rights and equal opportunities (al-Mughni, 2001, p.68). In the early 1980s two Islamic women's organisations were founded - Bayader al-Salam and the Islamic Care Society (ICS) - bringing the total number of organisations to five. The ICS is of special interest here, as it was formed by the wife of the prime minister (al-Mughni, 2001). However, the largest associations today are the WCSS and the Federation of Kuwaiti Women's Associations. The federation is supported and tightly regulated by the Kuwaiti government. It is the only women's group allowed to represent Kuwait internationally (UNDP POGAR, 2006). Many of the organisations, such as the Women Affairs Committee and Kuwait's Union of Women Societies, have organised campaigns and conferences to protest in particular against the exclusion of women from the political arena. The Women's Cultural and Social Society has held Special Consultative Status before the United Nations Economic and Social Council (ECOSOC) since 2004.

Women in Kuwait have also joined Islamist groups, starting in the 1950s with the Social Reform Society and the Cultural Social Society, in their early years they restricted themselves mainly to philanthropy but once an official process of Islamisation was announced in the country in 1978 they became increasingly prominent on the political stage (al-Mughni, 2010b). This Islamisation was viewed as an opportunity to embed women's role in society into this new order. The rapid modernisation from the 1950s through to the 1970s had transformed women's lives, they were now moving around freely in western clothes often driving their own cars. Al-Mughni (2010b) suggests that this may have left some Kuwaiti women disorientated, even alienated, attracting them to the Islamic movement in search of some kind of stability. Al-Munghi (2010b) indicates that having recourse to the traditions and practices of Islam was particularly valued among more affluent women who may have perceived the rapid pace of modernisation as a threat to their social position: “... elite and upper class women [...] searched for new meanings into their lives but did not want any radical transformation of the socioeconomic structures from which they derive considerable power" (para 9). Furthermore, advancing the women's rights agenda had little or no place in the Islamic women's movement of the 1980s who viewed it as an unworthy western pursuit, but gradually things changed and by the early 1990s Islamist women were advocating for women's suffrage (al-Mughni, 2010b). Participation in Islamic feminist groups spread mainly 
through the setting up of women's committees were women developed social agency and learned new social skills.

Among those leading Islamic feminism, as it is now referred to, was Khadîjah al-Mahmîd who set out her position in a paper written in 1994 (al-Mahmîd, 1994). In it she expounded the version of an interpretation of the early teachings and practices of Islam that suggested that women were actively involved interpreting religious knowledge and that if a just Muslim society was to be created then such involvement was a necessity (alMahmîd, 1994). This was unsurprisingly resisted by her male counterparts.

While male-dominated Islamist groups were able to benefit from the increasing sight of the veil and women's greater devotion to religious study as signs of apparent hegemony for their perspective they demonstrated little or no support for the aspirations of Islamic feminists. On the other hand, liberal feminists could deflect accusations of being western influenced by pointing to the hijab wearing women sharing their cause.

To summarise this short discussion of women's organisations, there is a clear dualism in Kuwait in terms of how women have organised and made collective attempts to alter their position in society. On the one hand, the liberal feminists have taken a largely secular approach with an approach having many similarities to women's movements in the West. In contrast, Islamic feminists have sought to argue for an interpretation of Islam that gave women recognition as autonomous beings and a share in what can be described as the ownership of the means of production of religious knowledge something that features later in this thesis as prominent theme. This dualism also reappears later in chapter three's discussion of the key theoretical concepts and perspectives that are drawn upon in this thesis.

\section{Education policy}

Sustaining the favourable employment and economic participation environment are the education rights enjoyed by women, representing perhaps the most robust area of all in terms of women's rights. Article 13 of the Constitution asserts that "Education is a fundamental requisite for the progress of society, assured and promoted by the State." Under Article 40 of the constitution, all Kuwaiti citizens are guaranteed free and equal 
access to the education system from primary school through to university, and male and female students are provided with equal opportunities to study abroad.

The article states:

(1) Education is a right for Kuwaitis, guaranteed by the State in accordance with law and within the limits of public policy and morals. Education in its preliminary stages is compulsory and free in accordance with the law.

(2) The law shall lay down the necessary plan to eliminate illiteracy.

(3) The State shall devote particular care to the physical, moral, and mental development of youth.

Women have made significant gains in education over the past three decades, and (as already noted) the percentage of young literate women in Kuwait is now equal to that of young literate men (Al-Munghi, 2010). Indeed, in the 2003/4 academic year there were 22,691 female university students compared to just 9,387 males (Ministry of Planning, 2005); though this could be partially accounted for by male students being more likely to be able to travel abroad for their university education.

The central place education holds in Kuwaiti life is due to two main factors. Firstly, the state recognises the need to modernise in order to achieve global competitiveness and education is an effective route to this modernisation. Secondly, political and military instability in the region mean binding the citizenry to the State is crucial and something acknowledged by the Minister of Education in her report to UNESCO on education in Kuwait between 2004 and 2008 when she wrote:

Education is entrenching principles of democracy and respect for the constitution, laws and regulations through political education, curricula and behavioural practices [...] and also seeks to strengthen the education concepts of national unity and strengthen the spirit of citizenship, loyalty and belongingness to the homeland (Ministry of Education, 2008, p. 23).

The balancing act being played out in the Gulf countries with regard to development through education sees governments adopting policies that on the one hand teaches the 
"the importance of globalization and information technology and modern communication" while on the other also "building the correct Islamic faith [...] with Arab-Islamic heritage and loyalty to the Arab-Islamic identity" (Ministry of Education, 2008, p. 47). If these are the aims of education policy, one clear side-effect has been the rise of the educated woman in Kuwaiti society. In 2001, al-Munghi recognised that "Education has changed women's perceptions of themselves and their role in society" (2001, p.8). This education was driving women to demand their enfranchisement and expanding their participation in the workforce as well as their expectations for advancement once they joined the workforce.

Government policy has led to female students at Kuwait University requiring significantly higher grade-point averages (GPAs) than men in order to be admitted into certain fields. For instance, female students have to have a $3.3 \mathrm{GPA}$ to be admitted to the engineering department, while male students need only a 2.8 GPA (al-Munghi, 2005, p.132). As women comprise almost two-thirds of Kuwaiti university students the government depicts this as positive discrimination in favour of male students to redress the imbalance, though it could be argued that the reason for the imbalance is the preference of Kuwaiti male students to study abroad in countries such as Bahrain, the United States and the UK. In 2010, 12,350 Kuwaiti's received their tertiary education outside Kuwait, a substantial majority of whom were male (UNESCO Institute of Statistics, 2010).

Education, while an undoubted positive sphere in women's development and role within Kuwaiti society is not entirely devoid of controversy and the conflicting forces of modernisation and tribal tradition. In the period following the liberation of Kuwait in 1991 and then again following the events of September 11th 2001, the curriculum has been a political issue with Islamists concerned at the westernisation of school text books. The government argued that it was seeking to promote values of tolerance and democracy and discouraging extremism while the Islamists including lawmakers saw the changes as creeping westernization (Letsa, 2004).

In 1996, the Islamist dominated National Assembly passed a law that banned coeducation in the nation's universities and technical colleges a ban that was extended to private universities in 2000, primary and secondary schools were already segregated. For example, at the flagship public institution Kuwait University which was founded as co- 
educational male and female students are now entirely segregated using separate classrooms, lecture theatres, libraries, cafes and are even segregated for extra-curricular activities. Most recently, conservative lawmakers have sought to extend segregation to private foreign owned primary and secondary schools the last places of co-educational learning in the country. Segregation is not necessarily a gender issue or something to the detriment of women's advancement as enrolment levels in tertiary education has shown, however it has the potential in terms of resource allocation to be one.

Whatever the short term political battles taking place on the education terrain, the long term consequences are clear. Expectations are being raised among women and the education system is, despite efforts to prevent it, exposing students to a wider range of social experiences than would have been the case when the traditional family relationships were the sole socialising force. El-Hahaad (2003, p.4) sees education as a "new and powerful source of socialization that competes strongly with traditional family roles or functions in this regard." These competing sources of socialisation are fundamental to the current study as it is the views of educated urbanised Kuwaiti women which are to be elicited during the study and so the contrast between the voiced opinions, attitudes and perceptions of those mainly socialised through education and those dominated by traditional family-based socialisation should become apparent.

Education is, of course, strongly linked to employment in many ways. For example, the "reverse gender gap" (World Bank, 2013, p.102) in tertiary education, means that women in Kuwait enter employment later than men and often retire earlier. Also, despite efforts to restrict the numbers of women in certain disciplines there is still a broadening of the range of fields and the potential seniority of women in the workforce, based on their educational attainment. The next section considers how employment policy is evolving in Kuwait.

\section{Employment policy}

The role of women in the labour force was briefly discussed in the previous chapter, however, such is the importance of this economic empowerment to the thesis that the theme is returned to here, though from a more policy-oriented perspective. 
Before discussing employment policy there should be mention made of migrant labour in Kuwait. This thesis has focussed on Kuwaiti women citizens, there are many aspects of migrant women's lives in Kuwait that merit research but these are beyond the scope of this current study. In 2012, no less than 574,765 non-Kuwaitis were reported to be employed in private households providing domestic labour as maids, nannies and drivers of these 213,770 were women (SKCSB, 2012). These migrant workers earn a fraction of what is earned by a Kuwaiti worker (Kareem, 2013). In the context of this study of Kuwaiti women, the significance of the existence of this large pool of domestic labour is that it may have provided the conditions for Kuwaiti women to enter the labour force as they were freed up from their work in the home as by 2010 nine out of ten Kuwaiti households employed at least one domestic worker. The importance of this factor in rising labour force participation rates has not been assessed in empirical studies. Furthermore, the availability of domestic labour suggests that Kuwaiti women have more time for other public sphere activities including politics and activism. It also tends to undermine the 'women's place is in the home narrative'.

Low rates of labour force participation, gender pay differentials and lack of representation of women in senior positions commonly feature among western criticisms of majority Muslim countries, including Kuwait. However, among Muslim nations there are significant differences in the size of this gender gap, even within the countries of the GCC there are disparities (World Economic Forum, 2015). Under the 2010 Labour Act, women in Kuwait are protected from employment discrimination on the basis of gender, including with regards to pay under Article 26. However, as can be seen in many countries including those in the developed West legislating for equal pay does not automatically lead to men and women earning the same.

Despite the existence of women's organisations and a certain amount of activism gender issues have not dominated employment policy in Kuwait. Rather the main policy thrust has been the Kuwaitisation (or localisation) of the workforce, which Salih (2010, p. 169) defines as "the process of replacing expatriates with nationals in several economic roles," firstly by initiating a policy of replacement of non-Kuwaiti workers in the public sector with Kuwaiti citizens then more recently the equalisation of benefits between public and private sectors to encourage Kuwaitis to seek private sector employment in increasing numbers. This is most likely because from 1997 unemployment became a significant 
consideration for economic policy (Salih, 2010). While the government sought to guarantee every Kuwaiti citizen employment this meant an ever growing and ultimately unsustainable public sector, at the same time the private sector was unable to absorb sufficient Kuwaitis to ease the situation, this is perhaps due to the high levels of employment security, benefits and short working hours they have become used to in the public sector (Salih, 2010). Supply to the labour market in the form of educational output was not matched by demand from the labour market in the form of jobs (Salih, 2010). This affected women as much if not more than men as they have been disproportionately represented in the educational output and face discrimination and job segregation leading to a lack of fulfilment of their expectations (Metle, 2001). In the GCC region there has been a historical preference among the workforce for public sector employment which is seen as having greater benefits and being more secure. There is no reason to suggest that this perception is a gender specific one as the desire for reward and security are human motivators. Salih (2010) undertook a study to understand the apparent aversion to the private sector among Kuwaitis and the finding most relevant to the current study was that among the respondents who did go into the private sector after their education males and females were equally represented. While the sample was small the finding is in line with what can be seen in Kuwaiti business life where women are increasingly featuring in the business leadership community.

It is understandable that the government saw localisation as a necessary process as at the time the policy was being developed virtually the entire private sector was dependent on non-Kuwaiti citizens and more than nine out of ten Kuwaitis were employed in the public sector (Business Law Handbook, Kuwait, 2012).

Another aspect of policy that appeared to gain more attention than women's participation in the labour force was privatisation. Since 1992, a long term process of reducing the state's ownership of companies has been ongoing, encouraged by organisations such as the World Bank (World Bank, 2013). In doing so, jobs have been transferred from the public to the private sector helping to meet the aforementioned objectives of localisation, as those being transferred out of the public sector are invariably Kuwaitis.

\section{Gender participation rates}


While localisation and privatisation were the cornerstones of government policy women's participation in the labour force was certainly not opposed by the government and perhaps the reason it was not trumpeted as an official objective was that it may have stirred Islamist and tribalist opposition. Instead it was allowed to occur without fanfare.

The Arab states of the Middle East have the lowest level of female participation in the workforce of any region, however, while for the two decades from 1992 to 2012 global participation of women over 25 grew only slightly from $53.1 \%$ to $54.2 \%$ in the Middle East there was a far greater rate of increase (Gaddis and Klasen, 2014). Nevertheless, countries with conservative attitudes to women's role in society are clearly associated with lower female workforce participation rates.

While there are very significant differences from one country to the next, there are undoubtedly shared factors that have prevented women from playing a full role in the economic development of the region almost certainly to its economic and social detriment. In 2005, the Arab Human Development Report published by the United Nations Development Programme asserted that under these circumstances "society as a whole is deprived of the general good that would result from women's effective participation in production and in the public life of society" (UNDP 2005, p. 85). Male hegemony had sequestered women in the family home as mother, nurturers and carers, the report argues (UNDP, 2005). Arguably the United Nations Development Programme were right to assert that under these circumstances the states of the Middle East had inflicted harm on themselves through their failure to release the potential of women perhaps fearing the economic empowerment which such participation would almost inevitably lead to. International organisations such as the International Monetary Fund have urged the promotion of workforce diversity and in particular encourage women's participation in the private sector in order to stimulate growth (IMF, 2013). While women may not have been protesting in the streets demanding work opportunities, when avenues into the labour force began opening up they were quickly taken up and in large numbers.

Gaddis and Klasen (2014) discuss economic theory in relation to women's participation rates and in particular the link between stages and rates of economic development, specifically the feminization U hypothesis. Briefly, this posits that women's participation goes through a ' $U$ ' form, with a high level in economies with widespread low paid 
agricultural employment, a dip when industrial production becomes the main form of economic activity and a sector-based economy is in place, then a further rise as the economy and society as a whole develops still further. In the West this third phase probably began in the 1960s whereas for Kuwait this may have been two decades later.

The pre-dominant social and cultural values (and, as covered elsewhere, this is reflected in many laws) see women as dependants and men as the providers. Under this, men receive priority in terms of access to employment and economic rights. Wright and Rogers (2010, chpt.15, p.1) explain the universality and longevity of the patriarchal nature of human society:

For the more than 7,000 years of human history since settled agriculture and early states emerged, male domination has characterized the gender relations of these societies and their successors. Even at the beginning of the 20th century, men and women were generally viewed as occupying sharply different roles in society: a woman's place was in the home as wife and mother; the man's place was in the public sphere.

Increasingly, this model of social organisation is detaching from the reality which sees more and more women needing to make significant contributions to family income or even supporting families or themselves alone as a result of remaining single, the rising divorce rate or marriage to non-Kuwaiti men who may lack access to state welfare (SKCSB, 2013). There is also a clear correlation between reproductive rates, age at marriage and workforce participation and there have been substantial changes in Kuwait in these areas with fertility rates dropping and the age first married rising, trends consistent with increased female labour force participation (SKCSB, 2013; World Bank, 2015). The reason that this kind of indicator is significant is that they represent a direct threat to the patriarchal order where women are confined to their role in the home and private sphere while men take their place in the public sphere. More than two thirds of the women who have entered the workforce are married (SKCSB, 2014) underlining the major changes in how family life is organised in Kuwait.

The political, cultural, economic and social influences that created this social structure and its public-private domains have not gone unchallenged in recent decades and there has been an increase in women's economic empowerment in general and workforce participation specifically prompting Kuwaiti sociologist Haya al-Mughni to make this highly positive statement regarding women and the employment market. "Access to 
education has enabled women to become financially independent and pursue diverse careers. Women are now found in most professions including engineering, architecture, medicine, and law, as well as on executive boards of major banks and private companies" (al-Mughni, 2010, p.236).

Women's participation levels in the workforce in Kuwait are not out of step with other countries of the Gulf Co-operation Council. At one end of the scale Saudi Arabia lags far behind at $22.2 \%$ in 2009 while Qatar has the highest level at $50.9 \%$ in the same year; Kuwait showed 46.7\% (ILO, 2011). Figure 1 shows how increased labour force participation by women is a consistent pattern in the Gulf region but also that there are wide variations from one country to another. Consistent with the notion of competing forces (globalisation and economic development on the one side and the inherent patriarchy (enforced by religion) on the other) the entry of women into the work domain has been slowest in those Gulf countries considered the most conservative and traditional.

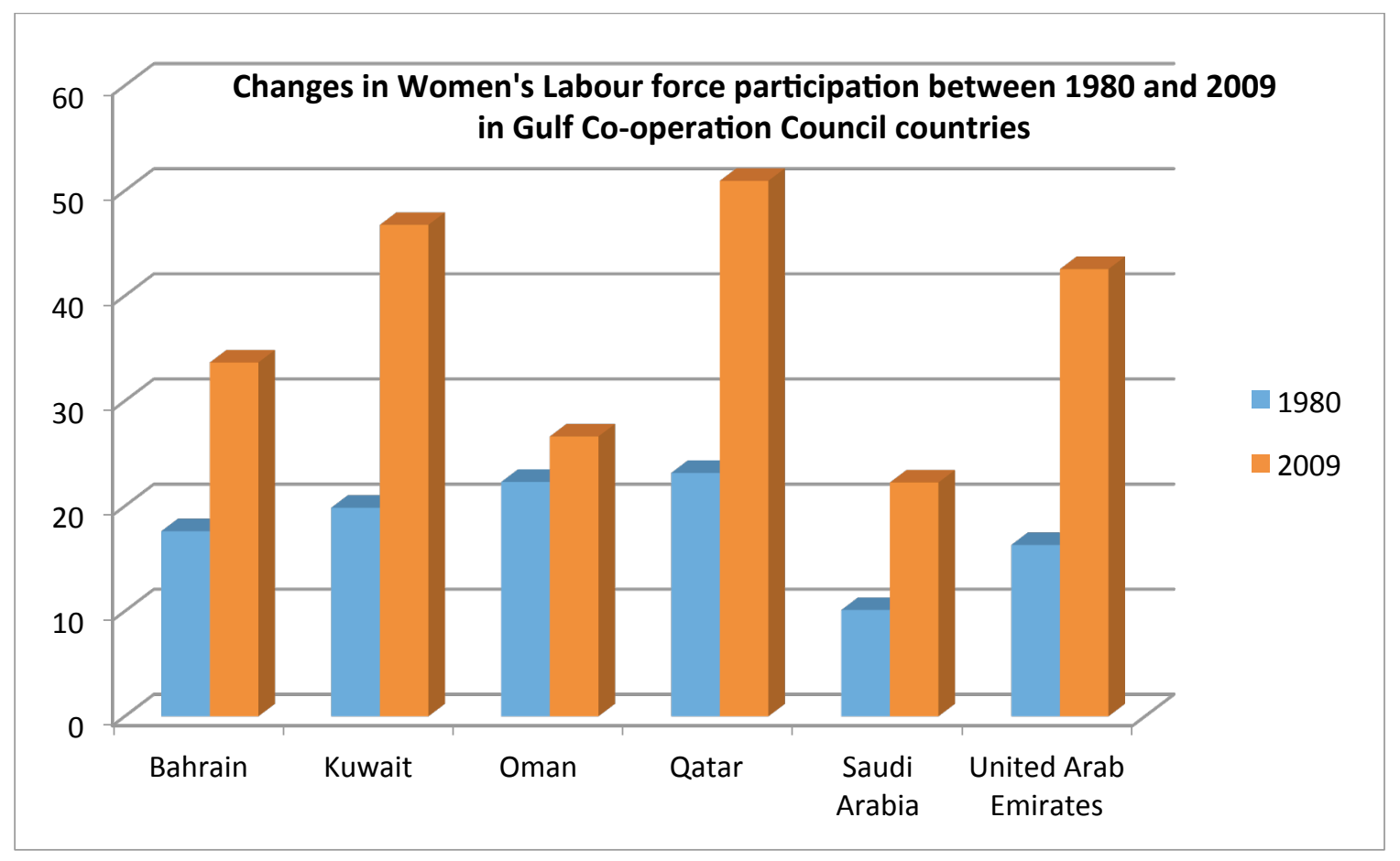

Figure 1: Changes in labour force participation in GCC countries 1980 - 2009

Source ILO, 2010 
However, when considering gender labour force participation rates in the countries of the Gulf region it is important to ascertain which data refers to the Kuwaiti population and which to the population of Kuwait, in other words which show the participation of Kuwaitis and which shows both Kuwaiti nationals and non-Kuwaitis. Participation data which includes non-Kuwaiti women will show higher participation rates because these women have migrated to Kuwait (two-thirds from non-Arab Asian countries such as Indonesia) for the sole purpose of employment. Official government figures tend to make the distinction between nationals and non-nationals: figure 2 shows the growth trend in labour force participation using government data and demonstrates the highly significant increase in women's participation.

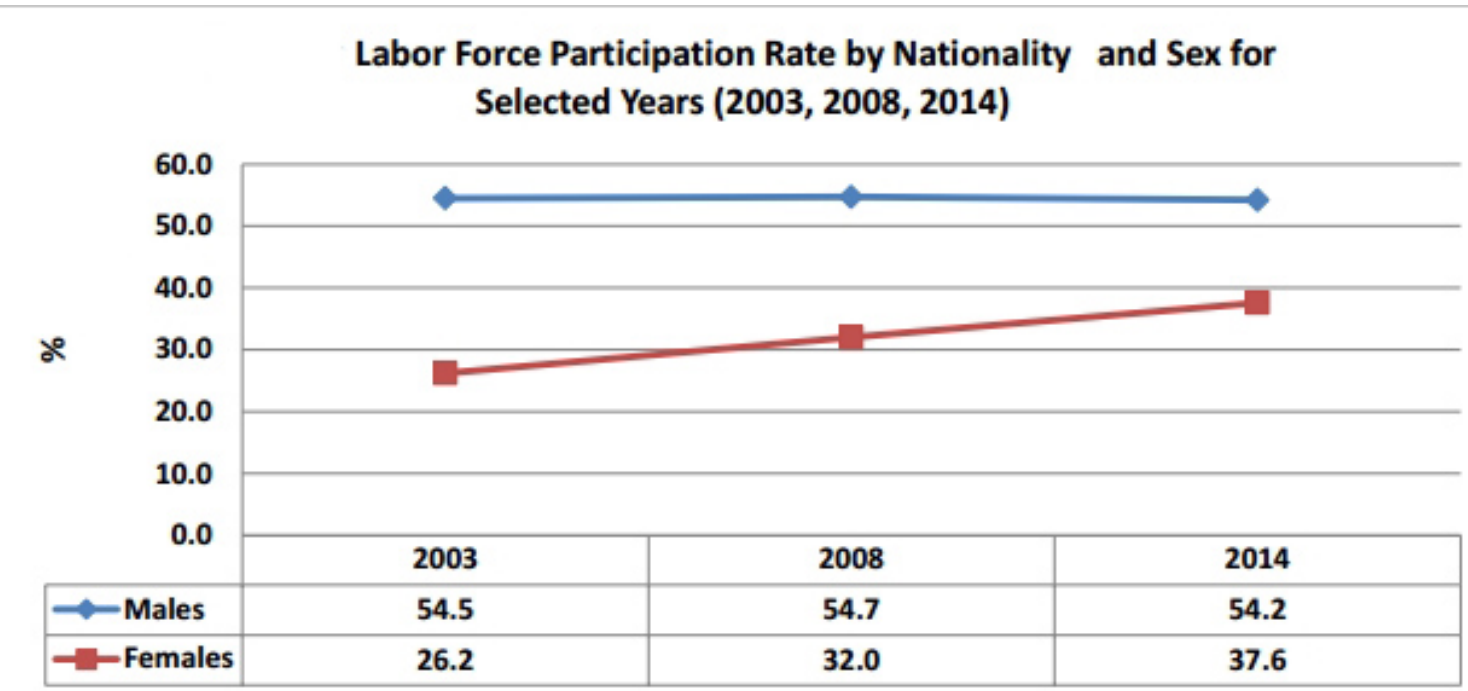

Figure 2: Labour Force participation by gender (aged 15+) 2003, 2008, 2014 (Kuwaiti nationals only)

Source: Labour Force Survey, 2014 SKCSB.

Another consideration regarding participation data is the age variable. Many sources including the Kuwaiti government record data for all those aged 15 or over in their headline participation rates, however, the expansion of women's involvement in higher education would mean that participation in the workforce would not reach its true rate until later. Indeed, the detailed data shows that at ages 15 to 24 only $7.9 \%$ of Kuwaiti 
women are in the labour force whereas from $25-34$ the number is $44.5 \%$ a greater rate of participation than for men (40.4\%) (SKCSB, 2014).

Across the region most governments have been keen to encourage female participation in the formal economy while maintaining their position within the family and their role in bringing up children, a twin role that clear presents both the state and its female citizens with significant challenges. Put another way, women can now offer both productive and reproductive labour (and are encouraged to do so) whereas in earlier stages of development the latter was overwhelmingly the most important. The transformation of women's labour force participation in Kuwait has some similarities but also certain differences with the UK. The similarities are the scale and consistency of the increase in participation and the changing nature of the female workforce as many of the new entrants in both were older married women rather than the younger single females who had entered the workforce prior to getting married and starting a family (SKCSB, 2014: Walsh and Wrigley, 1995). Furthermore, the Second World War in the case of the UK and the Iraqi occupation in the case of Kuwait appears to have prompted women's contribution to the economy and the expectations of women in terms of productive labour. Finally, there is the shared factor of economic growth increasing demand for labour. Concerning points of contrast, the main one relates to the reproductive and domestic labour that women perform. In the UK it could be argued that entry into the workforce was a double-edged sword for women who 'doubled up' rather than being relieved of household duties, assisted to only some degree by the new labour saving devices that came within the reach of working families; whereas in Kuwait the oil-driven economy had sucked in hundreds of thousands of domestic workers starting in the mid1970 and reaching the point where there was an average of one domestic worker for every Kuwaiti household (Shah et al., 2002). One contrast is that while part-time work is very common in the UK it is virtually non-existent in Kuwait for either gender (SKCSB, 2014). Hence while there are parallels between the paths taken to greater participation in the workforce and the economic empowerment which follows, these paths also differ in some ways. Nevertheless, it is possible to conclude that in Kuwait, as in westernised countries, society came to acknowledge that women can offer both productive and reproductive labour (and actively encourage women to take up both work and parenting) whereas in earlier stages of development the latter was overwhelmingly the most important. 


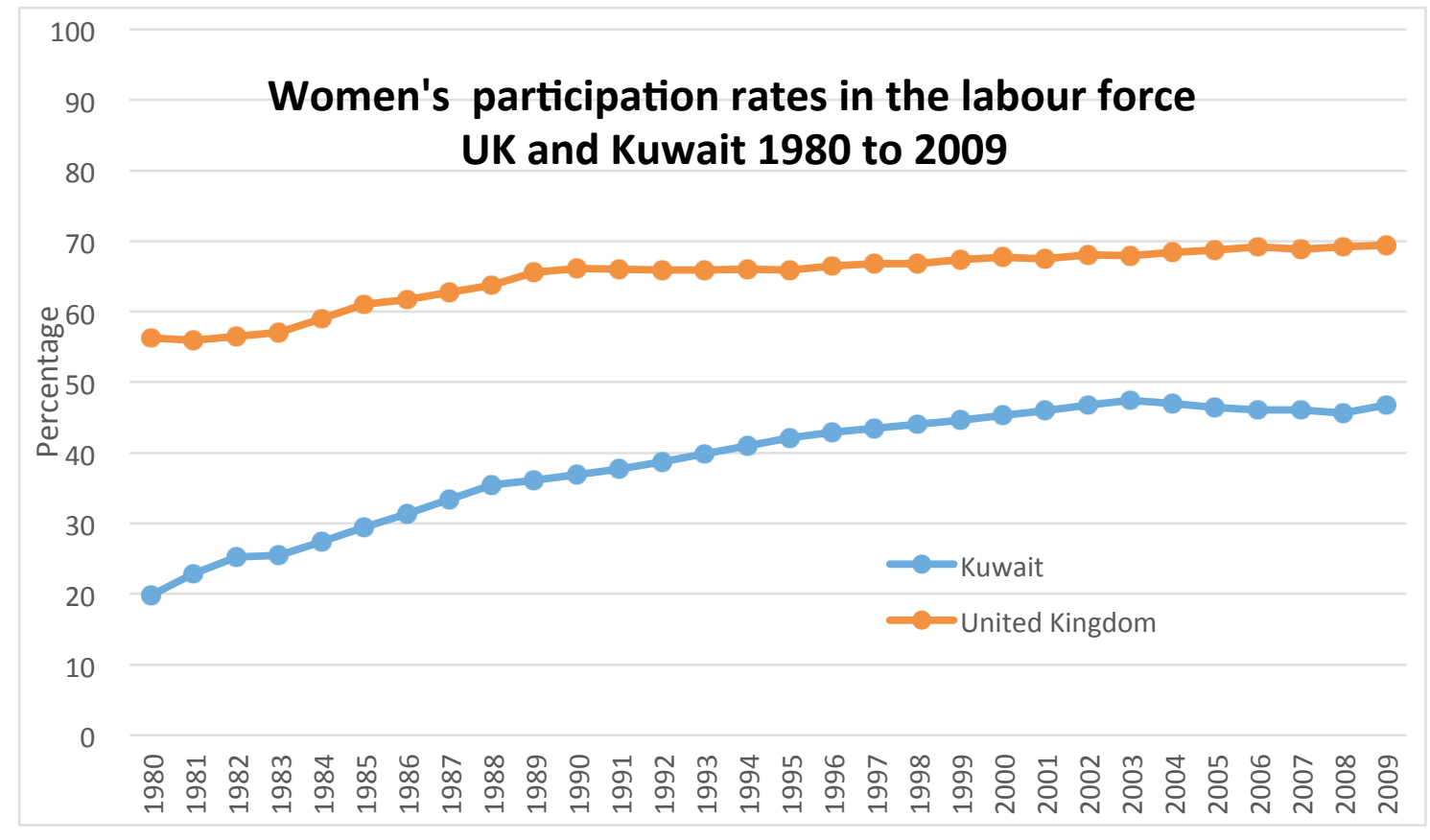

Figure 3: Women's participation rates in the labour force UK and Kuwait (1980 - 2009) Source ILO, 2010

This year by year analysis (figure 3) showed that women's employment has grown significantly over the 30-year period 1980 - 2009 though there is a significant gap between Kuwait and a western economy like the United Kingdom. The data also show that the Iraqi occupation in 1990-1991 or rather the aftermath of it did not rapidly accelerate the level of participation of women in the workforce. Much of the accelerated entry of women into the workforce in the UK had already taken place by 1980, having already started in the post WWII years. 


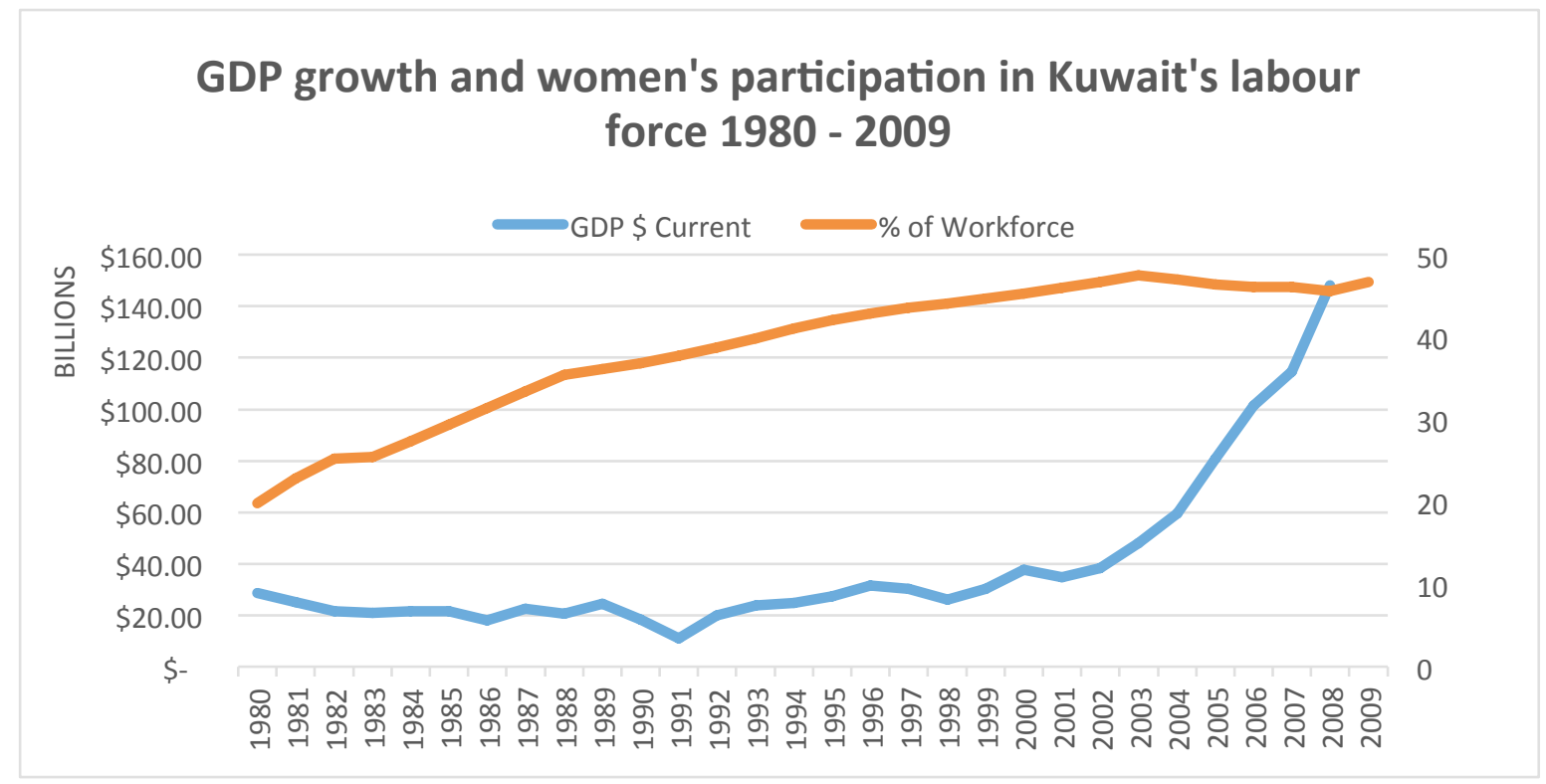

Figure 4: GDP growth and women's participation in Kuwait's labour force 1980 - 2009

Figure 4 clearly shows that rapid economic growth is not a prerequisite for increased women's participation in the workforce. With rather sluggish economic growth in the 1980s and 1990s women's participation accelerated quickly while in the last decade rapid rises in GDP saw women's participation plateauing. The disconnection between economic growth and women's participation in the workforce is most likely due to the employment segregation in Kuwait which sees women largely employed in the service sector or the public sector; a sector which grew in the 80 s and 90 s as the government created the 'oil-welfare state'. Women were taking jobs in health, education and social care as these sectors expanded. By 2004, government statistics were showing that women had reached virtual parity in numbers employed in the public sector (Ministry of Planning, 2005). Furthermore, where economic growth is significantly related to the price of a single commodity (oil) there is a less direct relationship with increased demand for labour as there would be in a broad sector-based diverse economy. In 2014, nine out of ten Kuwaitis worked in the public sector with no significant difference between genders. The view of the private sector as a secondary and inferior means of employment clearly extends to both men and women. Public sector jobs are seen as secure, well paid and having a higher status than private equivalents. However, with the government seeking to reduce its reliance on migrant labour and diversify the economy, some realignment of attitudes is going to be needed. 


\section{Women in the workplace but not in the boardroom}

Women have entered the workforce in large numbers in Kuwait but in most cases the door to the boardroom remains closed. The Kuwait Labor Law. No. 6 of 2010 prohibits discrimination in employment; however, data suggests that just $1.7 \%$ of the corporate board level positions in Kuwait were held by women (Catalyst.org, 2014). This barrier to senior positions which is widely recognised in the UK and other countries as the 'glass ceiling' whereby qualified women fail to rise to the top even in the absence of formal legal impediments (Grout, Park and Sonderegger, 2007; Economist, 2009) is also therefore an issue in Kuwait.

Data published by the European Commission (2012) (see table 1) shows wide variations in women's representation at senior corporate levels between member states who by virtue of their membership of the European Union share similar formal antidiscriminatory legal frameworks. At the one end of the scale 3-4\% of senior corporate executives were women in Malta and Cyprus while the figure rose to 26-27\% for Latvia and Finland. The same data also shows no relationship between participation levels in tertiary education and representation on the boards of the largest companies. It could therefore be argued that cultural factors, principally how religious/ secular a country is appears to be a far greater influence on women's ability to achieve senior positions than a country's formal anti-discriminatory framework or participation in tertiary education. Figure 5 charts the European Commission data on women's representation in Europe's boardrooms alongside a pan-European poll measuring religiosity in the same countries. 


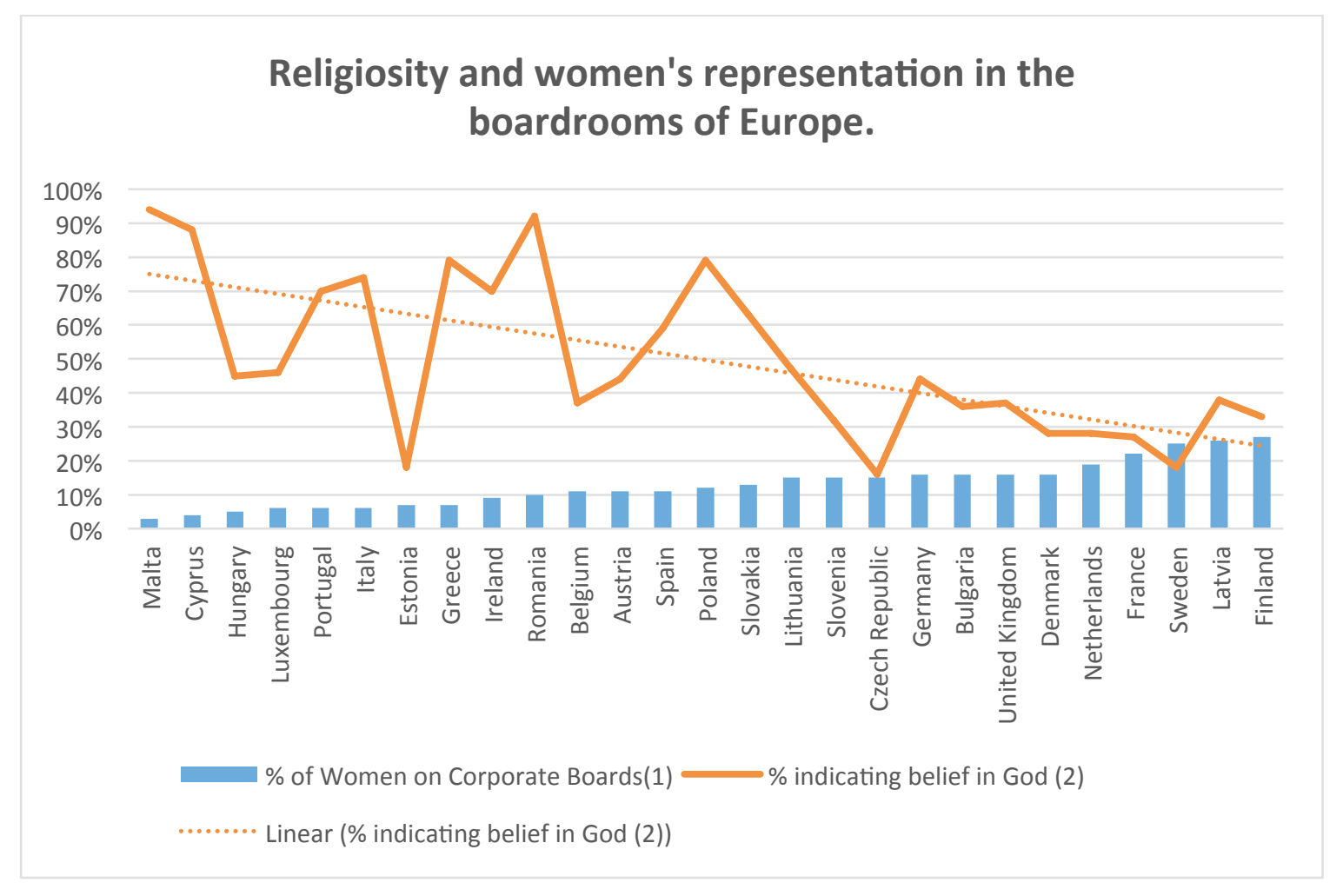

Figure 5: Religiosity and women's representation in European Union boardrooms, by member country

Sources: (1) European Commission 2012 (2) Eurobarometer 2010

With one or two anomalous cases the trend is clear, the more secular a country the greater women's representation in senior positions. A simple average of the 10 most religious countries shows that $8.1 \%$ of senior executive positions are held by women, whereas, in the 10 least religious countries this figure rises to $17.4 \%$.

There is further evidence in the literature to support the link between religiosity and women's labour force participation. H'Madoun (2010) used data from a global survey on religious values to reach the conclusion that "religious women are found to participate [in the labour force] less than non-religious women" (p. 31). This was found to be particularly the case for Hindu and Muslim faith. Yet religion and non-participation may not inevitably be linked, as Weber (1905) pointed out Protestantism presented work as the path to God for women and men. Another interesting way of interpreting the relationship between religion and work is that greater labour force participation means less religious participation. Such a hypothesis was put forward by Hertel (1988) who argues that survey data revealed that lack of religious commitment reduced the likelihood of workforce participation in men but had the opposite effect in women. He did, 
however, recognise that marriage and child rearing were likely to be confounding factors as religious identity was linked among women to marriage and child bearing and among men to working in order to provide for their family (Hertel, 1988).

Turning to Kuwait and the GCC member countries it is possible to consider how it would have performed if it had been included in the above research. Regarding the religiosity poll this would likely have surely shown a 100\% result. Declarations of atheism are harshly treated in the region and Saudi Arabia has recently classified atheists as terrorists. In terms of women's representation at senior executive level, a report puts this figure at less than 1\% for the GCC as a whole (Mckinsey, 2014, p.17). Using a broader category of "legislators, senior officials and managers" official government data reports that $7.1 \%$ of employed Kuwaiti women held such positions while $35.9 \%$ of Kuwaiti men $\operatorname{did}($ SKCSB, 2014, p.54).

There is clearly a correlation between religion and patriarchy and between religion and power, in this example power is expressed through economic influence and specifically influence over major corporations. Thus it can be surmised that global macro-economic theory, as exemplified by the $U$ form theory of the feminisation of the workforce, is pushing in one direction (i.e. greater participation of women in the workforce) against resistant forces of historic patriarchy which remains at its most powerful in religiously conservative societies and most specifically in the Muslim countries of the Middle East. Economic analysis of religion dates back to Adam Smith (1776/1976) and there is also a long established academic interest in the link between religion and workforce participation going back to Weber (1905) and his discussion of the role of Protestantism under capitalism. From this work and others based on it (Feldmann, 2007), it could be concluded that it is not just a question of religiosity versus secularity but of which religion, with both Catholicism and Islam mitigating toward low women's participation.

\section{Participation does not necessarily mean satisfaction.}

Simply being in the workforce does not necessarily mean that a woman can reach a feeling of satisfaction and fulfilment. In Kuwait, women's employment attainment does not match their educational attainment as discussed below. Although there is a lack of information on women's satisfaction and fulfilment as part of the workforce this assertion is perhaps supported by the fact that in Kuwait, women's employment 
attainment does not match their educational attainment. A 2001 study by Metle found that one third of Kuwaiti women perceived discrimination in terms of the position they held related to their educational attainment with this perception increasing the higher their achievements academically. Similarly, the study revealed a widespread feeling of being unfairly treated during promotion processes (Metle, 2001). While not sanctioned by law, women continue to face discrimination in terms of job roles and promotions in the public sector and on equal pay and benefits in the private sector (Krause, 2009). Despite this Krause argues that women or their organised representatives have been co-opted by the government through "large provisions of state funding, operating under the auspices of an individual of the elite or ruling class, and being controlled through the appointment of ministerial employees of the organizations to sensitive and powerful positions" (p. 35). This suggests that the forces for women's empowerment may have been consciously 'deradicalised' by the ruling elite and co-opted as allies against more feared Islamist interests.

Perhaps contrary to the notion of Kuwait as a male dominated society a study by AlWugayan and Alshimmiri (2010) suggested that female university students were more inclined towards entrepreneurial activity than their male counterparts. If such intentions displayed during the final years of their education turn into action, then women should form a significant proportion of the entrepreneurial class in the years ahead. The financial pressures of urban life on couples (especially those with children) have made salary level and job security the overwhelming priorities for both men and women when choosing a job (al-Ajmi and Elhagrasey, 2010). Job security continues to underpin the popularity of the public sector among women, however, in their study al-Ajmi and Elhagrasey (2010) found that of the 912 students participating in their study 57.5\% indicated that they would be seeking work in the private sector, more than the $42.5 \%$ who expressed a preference for the public sector, a finding which suggests that government policies aimed at increasing the attractiveness of the private sector to Kuwaiti citizens by equalising benefits and rights across both sectors seems to be working to some degree.

In the next subsection the Arab phenomenon of wasta is considered, situated within the discussion of employment policy as this is one domain where it has a direct negative effect on the empowerment of women. 


\section{Wasta: social capital and patriarchal glue}

Social capital is a concept that can be applied to all societies whether it comes in the form of the West's 'old boy's network', Chinese guanxi or the Arab world's wasta. Wasta also acts as a link between the public and private spheres offering a pathway into the public domains of work, politics, NGOs etc. from the private domain of the family.

The key unit in Arab wasta is the family but is this social capital available to men and women in equal measure? According to a study by Bailey (2012), Arab women perceive that they have little or no access to wasta in their own right, seeing it as a male phenomenon. That is to say that women do not benefit from wasta but that when they do this social capital is 'borrowed' from their fathers, husbands and brothers (Bailey, 2012). With patriarchy tending to confine (or seek to confine) women to the private sphere, their opportunities to develop their own wasta through social networking outside the home are severely limited (Bailey, 2012).

Wasta can affect not only women's equality of opportunity in the labour market but also an entire economy's performance. One the one hand, wasta-based recruitment is nonmeritocratic being based on family ties rather than ability and, on the other, once someone is hired their performance appraisal and even their termination is not based on any effective management practices but again on wasta (Cunningham and Sarayrah, 1994). According to Bailey (2012) wasta is not solely a gender issue but intersects gender and social class. Hence the socio-economic status of the male husband/ relative will determine how likely a woman is to be able to borrow and personally benefit from this social capital. Also in 2012, a campaign entitled "Kuwaitis Against Wasta" was launched with women featuring prominently. In an example of what might become the new tool of choice for reformers in Kuwait the campaign relied heavily on online social networking (Toumi, 2012b).

If the policy areas discussed so far in this chapter give grounds for optimism in the direction women's empowerment is taking in Kuwait, then this optimism is tempered in the second part. 


\section{Part Two: No progress in key areas of women's rights}

In the first part of this chapter on Kuwaiti social policy the key positive aspects of policy development in Kuwait were set out. These included the gaining of political rights, the access to education and participation in the workforce. Other changes in the law, including the recently amended regulations affecting passports and travel have also been already highlighted as positive indications. Thus far the review has clearly established that significant and consequential changes have taken place in the lives of women in recent decades. This second part, however, contrasts the advances with certain areas of life where clear discriminatory practices still prevail. This is important because in order to progress this study it is necessary to understand in which areas women are treated differently, some would say unjustly, because the study aims to explore how women perceive this injustice or, indeed whether they perceive it as an injustice at all. This part of the chapter demonstrates that there is a contradictory 'twin track' of women's empowerment. Along one track that features public sphere participation including politics, education and employment women are progressing at a good speed, on the other track mainly in the private sphere, things are at a virtual standstill.

For this purpose, nationality and citizenship, the Personal Status Law, divorce, housing and violence and sexual harassment are examined. These areas of policy have been selected for discussion as recent literature has revealed them to be areas on continuing injustice and inequality.

\section{Nationality and citizenship}

The 1962 Constitution has little to say on citizenship or nationality beyond Article 27's assertion that "Kuwaiti nationality is defined by law. No deprivation or withdrawal of nationality may be effected except within the limits prescribed by law". Instead, nationality in Kuwait is governed by the Nationality Law (1959) as amended by Decree Law No. 40/1987, Decree No. 1/1982, Statute No. 1/1982, Decree Law No. 100/1980, and Statute No. 30/1970. Article 2 states that "Any person born in, or outside, Kuwait whose father is a Kuwaiti national shall be a Kuwaiti national himself." Thus, a woman cannot pass her nationality on to her children in her own right. It requires a ministerial decree to assign Kuwaiti nationality to a minor born in Kuwait to a Kuwaiti mother 
where the father is unknown or the paternity is unproven (Article 3). A women's nationality is hence dictated by the nationality of her father. The only exception to the prohibition of women passing on their nationality is in Article 5 of the Nationality Act 1959, wherein it states that a child born to a Kuwaiti mother can —on reaching the age of majority - acquire nationality if the father has either divorced the mother or passed away.

When marrying a Kuwaiti man, a foreign woman immediately receives residency rights and can become a citizen after 10 years. Whereas, if a foreign man marries a Kuwaiti woman, they have the status of a foreign worker and their residency is subject to a stricter regime of permits and fees. With such a large non-Kuwaiti population within its borders and the presence of the 'stateless' Bidoon, marriages other than Kuwaiti-Kuwaiti are relatively numerous (SKCSB, 2013).

Al-Mughni and Tétreault (2000, p. 157) summarise the situation thus

[...] women are part of nature rather than civilized society. A Kuwaiti woman has no nationality that belongs to her absolutely. She is a Kuwaiti by virtue of having a Kuwaiti father but can lose her status as a Kuwaiti if she marries a foreigner....

This chapter of the thesis frequently makes reference to the conflicts and contradictions in Kuwaiti policy and these are exemplified in the area of nationality and citizenship. The tight restrictions on accessing Kuwaiti citizenship seem to result from the small state's feeling of insecurity in economic, political and military terms; hence it is seen as a matter of national security (Tétreault and al-Mughni, 1995). The contradiction is between a premodern, tribalistic way of defining the nationality of women and 'outsiders' and the need to ensure that strategically important positions within the economy and the civil service are filled by competent nationals. The situation is further complicated by the rising expectations of increasingly educated women (Tétreault and al-Mughni, 1995).

In Arab countries the individual is not the basic unit of society, it is the family, and in Kuwait the family is always headed by a male and involves a marriage. This role of the family is constitutionally defined. Tétreault and al-Mughni (1995), while recognising that a woman's subjection is limited by both legislation and the constitution, also see it as a parallel to and consequence of the limited subjugation of the entire population to the ruling family. 
The economics of citizenship should also be mentioned as citizenship and nationality infer a right to share in the generous allowances the Kuwait government provides its citizens. Steps towards equal treatment in terms of citizenship and nationality would put pressure on the amount of resources available for men who may feel reluctant to share the cake among more people (Tétreault and al-Mughni, 1995). A child born to a Kuwaiti mother and non-Kuwaiti father would have severely restricted access to healthcare, housing, education and employment (Glass, 2008).

While women's organisations such as the Women's Cultural Social Society (WCSS) have campaigned on the issue of nationality rights (Glass, 2008) there is no empirical evidence of how Kuwaiti women perceive these nationality and citizenship issues, hence the inclusion of this area of inquiry in the current study. This is important because it shows that there are areas of gender discrimination that have not arisen through the Islamic sharia route but that reflect the political interests of men and the patriarchal state.

\section{The Kuwait Personal Status Law (KPSL)}

As already discussed previously, at the legal heart of discrimination against women in Kuwait is the Personal Status Law (No. 51 of 1984). According to al-Munghi (2010, p. 230) "The personal status law legitimizes male dominance over women." Bhala (2011) describes how the current situation of Personal Status Laws of the Middle East can be traced to the Ottoman Empire. The Ottomans devolved personal status to religious communities in return for acceptance of their sovereignty. "In effect the Ottoman Sultan subcontracted the adjudication of personal status issues to religious courts" (p.258) and this was the case whether they were Christian, Muslim or Jewish communities.

This law, which in Kuwait is based on the Maliki School of Islamic jurisprudence and applies to the majority Sunni population, discriminates against women in, inter alia, giving lesser weight to their testimony; affording them lesser inheritance rights; and assigning spouses unequal rights and responsibilities as to marriage, during marriage and at its dissolution (al-Mughni, 2010). Judges (all male) have wide discretion in applying many provisions of the law, and are free to base their rulings on Maliki texts and doctrine when faced with personal status issues not directly addressed in the law. 
As already noted, Islamic jurisprudence consists of a corpus of principles and specific rules that have resulted from the interpretations of religious texts undertaken by jurists working from the perspective of a number of different schools of thought - the most significant school in Kuwait is the Sunni Maliki School (pps. 17-18) while (uncodified) Shiite family law is based on the Jaafari School interpretation.

The Personal Status Law (no 51 of 1984) (KPSL) establishes a range of rights for women that may not have been available before codification and the assertion of the supremacy of the state legal system in such matters. While women mobilised within Kuwait for the suffrage campaign, the opposition from women to the personal status laws has been less visible and has mainly been channelled through international NGOs and human rights groups (such as United Nations, CEDAW, Human Rights Watch and Freedom House). Women's campaigners often working through these organisations recognise that rights are awarded to both genders but that these rights argue that, such rights as there are, are discriminatory and inferior and different to those afforded to men thus formalising inequality in family relations. Some examples of this inequality, those especially important in the context of women's empowerment, are set out below, though not all as the law extends to 347 articles:

Competence to conclude a marriage: From the age of 15 (the minimum age for women (17 for men)) until 25 a women's marriage must be authorised by her male guardian (Article 29). A woman's choice of marriage partner is restricted by the need for the male guardian to agree to the compatibility between the partners; should agreement be withheld the woman must seek court approval for the marriage (Articles 29, 30). After the age of 25 the woman's ability to choose partner is strengthened (Article 31).

Polygamy: A man may marry four wives concurrently in Kuwait though a woman does have the right to preclude such polygamy through the insertion of a clause in the marriage contract (Article 21). Also the man cannot bring an additional wife or wives to live with the first wife unless the first wife agrees to it.

Financial Support: A married woman is entitled to financial support from her husband whatever her personal means. The law sets out the method of calculation of this maintenance that is determined by a judge (Articles 74 to 83). Under certain limited circumstances the right to payments can be forfeited (Article 87). Either party can return 
to the court to request an increase or decrease in the level of financial support should circumstances change.

Ending a Marriage: The KPSL sets out in detail the conditions and processes which husbands and wives must adhere to in the event of either party wishing to terminate the marriage. Should a man arbitrarily divorce his wife she is entitled to alimony compensation (Article 165). The circumstances under which a woman may seek a divorce are far more restricted than for a man. Divorce is covered in more detail later in this chapter.

Custody: The KPSL establishes the woman's right to custody of children in the event of a divorce and the husband's duty to pay fees to bring up the child. The father remains the guardian in legal terms. A woman loses her custody rights upon remarriage. Furthermore, the temporary nature of the woman's role as caretaker is seen in the fact that the right to custody ends for sons at puberty and for daughters once they reach the age of majority or marry. Shiite family law, however, grants the divorced mother custody of her daughter up to the age of nine and the son until just the age of two.

Bearing witness: The Personal Status Law (No. 51 of 1984) is another example of legislation that formalises women's inferiority when bearing witness (as already noted). Article 133 is another example of codification of women's inferiority, this time when bearing witness "Harm is proved through the testimony of two men, or a man and two women" a direct reflection of the Verse 2:282 of the Qur'an:

And bring to witness two witnesses from among your men. And if there are not two men [available], then a man and two women from those whom you accept as witnesses - so that if one of the women errs, then the other can remind her.

Overall the general tone of the KPSL is a traditional one reflecting the conservative perspectives of its drafters who were opposed to the notion of equality in family relations. Amending the Personal Status Law is a far more difficult task than that required to change other legislation and this is reflected in the lack of movement in this area. Any change requires the confluence of legislative, executive and religious assent to allow such change. Having said this there is a sufficiently wide spectrum of doctrinal interpretation - on the one hand, the principle of obedience to the husband, while on the 
other, the reciprocity of spousal rights to suggest that progress is possible. Furthermore, there have been instances of amendments being made to the Personal Status Law (No. 51 of 1984). In 2003, Article 30 was amended to allow non-virgins to conclude their own marriage contracts without the need for the signature of their male guardian. There has also been a degree of strengthening of women's rights in other areas, for example the right to compensation following divorce. This has come in the form of the General Principles in the Provisions of the Kuwait Court of Cassation which gives sharia family courts additional guidance when applying the various articles of the Personal Status Law. While examples of these reforms in the area of personal status are rare they are not impossible and there are alternatives to amending the primary legislation as in the changes to guidance example or potentially in a particular article being ruled unconstitutional, this was what happened when the Kuwaiti Constitutional Court ruled in 2012 that a 1962 law (which later became an article in the KPSL) requiring a woman's male guardian to grant her permission to obtain a passport was unconstitutional because it violated guarantees of personal freedom and gender equality in the Kuwaiti Constitution (Marinero, 2009). It is suggested that the significant point about these amendments is that they set precedents for further reform and that certain elements of the politico-legal system can be useful in women's empowerment, even as presently constituted.

\section{Divorce}

In essence, under Kuwaiti family law divorce is a male action to end a marriage; a woman's right only exists in the form of specific exceptions to the general principle. Article 97 of the Personal Status Law (No. 51 of 1984) states that "Divorce is the dissolution of a proper marriage bond by the will of the husband or his representative, through a specific verbal statement, according to Article 104." This utterance of "I divorce you" can take place three times, the first two times he has the right to change his mind and rescind the divorce within 90 days, something to which the wife must go along with or go to the court should she not wish to comply. There is no equivalent right for women to divorce through such utterances.

For a woman to secure a divorce from her husband she must do so under a clearly defined and limited number of circumstances: the husband's failure to provide financial support (Articles 120-122); desertion (Article 120); the infliction of verbal or physical 
damage (after a period of pre-divorce arbitration) (Articles 126 to 135) or defects that prevent pleasure (Articles 139 to 142). In a divorce initiated by the woman the decision is final and irrevocable though is much more likely to be given as an absolute last resort. There has, however, been anecdotal evidence that sharia courts are, in some instances, informally levelling the playing field by allowing generous interpretations of verbal or physical damage and defects that prevent pleasure. In Kuwait (Al- Enzi, 2015) and Saudi Arabia (Al- Tamimi, 2012) smoking is a sufficient ground for a petition to be granted. More frivolous grounds can be illustrated by the following examples; one woman, married just one week, who petitioned because her husband failed to use proper etiquette when eating his peas, another woman petitioned on the grounds that her husband failed to squeeze toothpaste from the bottom of the tube (Toumbi, 2013).

Data published by the United Nations shows that for women aged between 25 - 44 (prime family raising age) 36\% were not married (UNData, 2012).

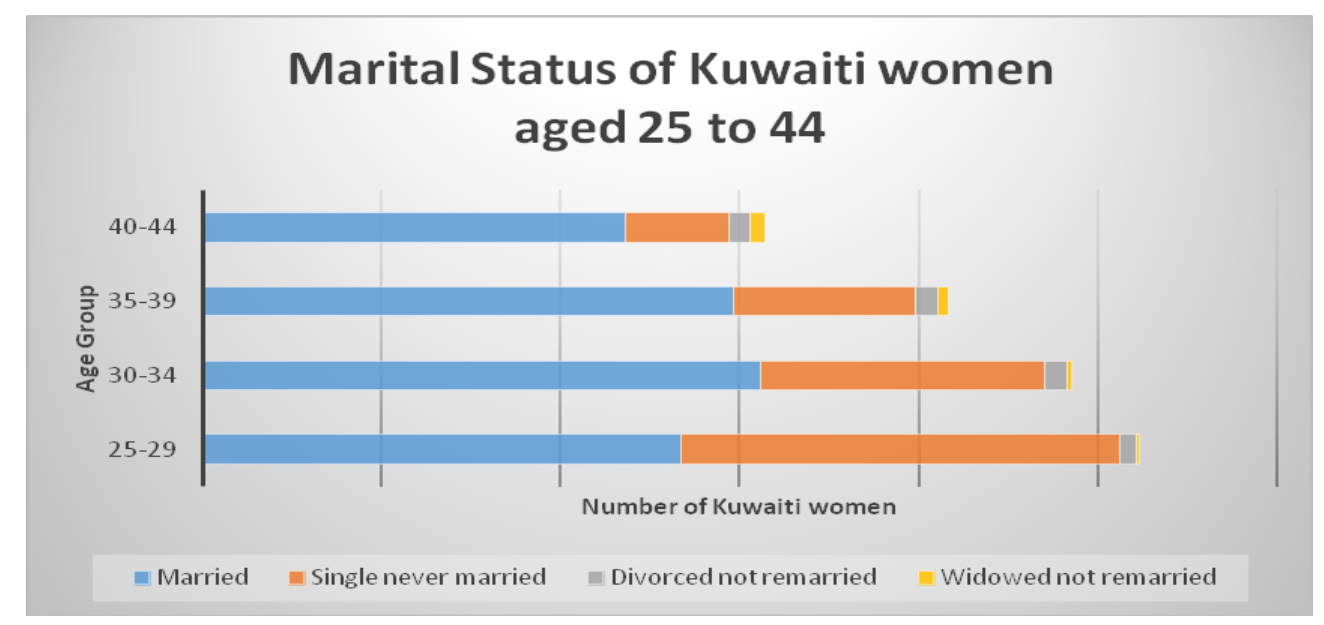

Figure 6: Marital Status of Kuwaiti Women Aged 25 - 44

Source: UNData, 2012

In Kuwait, in the 10 years from 2003 to 2013 the ratio of divorces to marriages as a percentage rose from 32.5\% in 2003 to 46.4\% in 2013 (SKCSB, 2013). The equivalent statistic for England and Wales (for 2012) was 45\% (ONS, 2014). This is interesting because it shows that divorce rates can reach the same levels in patriarchal religious societies as they do in more secular societies where the path of gender equality has extended further. 
Under both Sunni and Shi'a family law women may seek a divorce but their opportunities to do so are vastly more restricted than for men. As noted, a divorce initiated by the wife is final. Under Sunni law, a wife may cite a variety of causes in support of a divorce, including mental or physical impairment of the husband, abuse, lack of performance of marital obligations, non-payment of financial maintenance, or desertion. In Kuwait, neither Sunni nor Shi'a sects permit a woman to divorce her husband because he took another wife, unless this is specifically noted in their marriage contract. In Shi'a family law, the grounds are more restricted and a woman can only raise a divorce case in the event of non-payment of financial maintenance, desertion, missing husband, mental illness, and denial of conjugal rights for a period of four months.

The recent rise in divorce rates in Kuwait and the wider Gulf region is today a major social issue including from the perspective of women's rights. A range of academics and legal commentators as well as politicians have addressed the subject and their contributions are discussed here (al-Kazi, 2008; al-Munghi 2010; al-Munajjed, 2010; Meyer, Rizzo and Ali 2005; Anser, 2009).

Both marriage and divorce fall under the remit of sharia law in Kuwait. This law is codified in Kuwait in the Personal Status Law (No. 51 of 1984). As set out above, the same law regulates other matters such as marriage, child custody and inheritance. There are different versions for Sunni and Shia family courts often with significant differences. Broadly speaking Shiite versions of sharia law as applied to marriage and divorce offer somewhat more support for women than the Sunni equivalent which is highly patriarchal and discriminatory.

A divorce involves certain processes handled through a sharia family court. In the first instance, the couple must notify the Moral and Family Guidance Section of the Family Court and register the case. After this they will receive counselling where they discuss their problems. This is followed by a three month 'cooling off period. If after this period one or both of the parties still want to divorce the case papers are forwarded to the courts where a judge considers them then discusses the issues with the couple at one or two sessions before making his decision (Ministry of Justice, 2015).

A government report covering 2007 set out the reasons that both men and women sought the assistance of the family court. From the man's standpoint the most 
prominently mentioned reasons for an unsatisfactory marriage included: social reasons including the interference of the wife's parents (13.2\%) and negligence (8.7\%): psychological reasons involving non acceptance (51.2\%), change in partners behaviour (23.7\%), easement divorce (18.7\%) and weak conversation (15.9\%): a third key group of factors were religious/ ethical ones and included disobedience (10.4\%), abusive words (7.4\%), desertion (4.2\%) and infidelity (3\%) (Ministry of Justice, 2007). On the other hand, women gave the following factors as those undermining the marriage: social reasons including negligence $(8.1 \%)$, interference of husband's family $(6.6 \%)$ and lack of separate housing (i.e. separate from in-laws) $(2.5 \%)$ : psychological reasons given were non-acceptance $(34.7 \%)$, changes in behaviour (11.9\%), weak conversation $(11.3 \%)$ and violence $(8.6 \%)$. Polygamy was referenced in $7.9 \%$ of cases. Religious and ethical reasons included: infidelity (5.4\%), abusive words (5.1\%) and desertion (3.6\%). Financial frictions were evident in certain cases where women cited non-spending (7.5\%), insufficient spending (3.6\%) and stinginess (1.8\%) (Ministry of Justice, 2007).

The effects of divorce on women can be divided into two categories; those which affect the social and moral standing of the divorcee and the family and those which are economic in nature. Anser (2009) argues that in the Gulf region women experience psychological trauma, pressure from family and the wider community, they can be labelled as having a bad reputation and feel that they have undermined family honour particularly if they are still young. However, al-Munajjed (2010, p. 6) balances the negative factors to some degree by pointing out that for some women, especially those in marriages characterised by physical or emotional abuse, divorce can be "liberating, even life-saving”. Having said this, divorce is, in many cases, a traumatic experience largely as a result of the local customs surrounding marriage and divorce (al-Munajjed, 2010). And, with Kuwaiti nationals being in the minority in Kuwait, it remains true that the government is also keen to encourage high fertility rates. So with fertility rates falling and divorce rising this is widely viewed as a prominent structural problem facing the country (al-Kazi, 2008).

There are conflicting arguments as to why there is a rising trend towards divorce in the Gulf region in general and Kuwait specifically. Some see it as the inevitable result of globalisation and exposure to western values. Al-Munajjed (2010) suggests that the rise in divorce may be a result of a both tradition and modernisation. With exposure to other 
cultures and values through globalisation, expectations of marriage have changed. Arranged marriages and the prominent role of in-laws in a couple's life may according to al-Munajjed (2010) be causing conflicts in this modern era. The traditions and in particular the role of the respective families provide little opportunity for men and women to know and understand each other before entering into marriage and for some who live with the man's parents after the wedding this situation extends into the marriage (El-Haddad, 2003). It seems more likely that deep socio-economic shifts such as higher levels of both educational attainment and participation in the labour market are at the root of increased divorce. Urbanisation and the financial demands of modern life are seeing more and more marriages being based on two incomes (al-Munajjed, 2010). The ability to support themselves and where relevant their children has made divorce a more financially viable option for some women. To some extent policy has also contributed to making divorce financially possible for women. In the wake of the worrying government study (Parliamentary Research Department, 2010) a number of voices could be heard singling out the range of benefits available to divorced women as the main reason for the rising divorce rate. Women divorcees can claim a car, a housemaid and a chauffeur, as well as alimony and housing payments from their former husbands as a result of government policy.

Divorce statistics in Kuwait are not fully reliable as many marriages in rural areas are terminated through tribal 'unofficial' means and may never be recorded by statistic gathering bodies. Furthermore, attributing reasons for the growth in divorce rates is also highly problematic and has been politicised. On the one hand, studies (Parliamentary Research Department, 2010) suggest that factors that are related to traditional or religious influences such as parental interference, polygamy and disobedience appear to be at the root of many divorces while on the other some reports highlight the rise of the financially based divorce as urbanisation and modernisation raise material expectations (Arab Times 2011; al-Kazi, 2008; El-Haddad, 2003). Arguably therefore, divorce laws in Kuwait clearly represent inequality between men and women. Whereas men can divorce easily (even by sending a text message by phone) women's access to a divorce is limited to a strictly defined range of causes and subject to rigorous processes and informal prejudices. It seems that men's ability to get divorced by simply communicating the divorce three times (talaq) to his spouse undermines the desire of the state to maintain the family as the central unit of society. This gives an example of where sharia law runs 
counter to the interests of the state and takes on a purely patriarchal character. It could also be argued that this sends out a message to women that while Islam and the traditions and norms that have led to today's policies present a sharing of commitments and responsibilities in marriage, the divorce laws reveal these to be unbalanced and discriminatory exposing the subservience and subordination of women as secondary citizens.

Understanding the phenomenon of Kuwait's high and rising divorce rate is important. The family is the basic unit of Kuwaiti society and the divorce rates tend to suggest that this unit is under stress. What will the consequences be of having a significant divorced and potentially not remarried population of women in a society where everything is geared towards directing resources to women via a husband? Are there parallels with the alternatives to the nuclear family that arose from the 1960s onwards in the West (Chapman, 2004). To a certain extent this new reality has been recognised by the Kuwaiti government which is starting to make greater welfare provision for divorced women such as the provision of housing allowances. With rising divorce rates capable of being interpreted in so many ways, from the failure of tradition marriage processes including parental 'arrangement' to a symptom of the decline of the nuclear family as the essential social unit of Kuwaiti society it is an important aim of this research to reveal the perceptions of the Kuwaiti women who take part in the study on why the divorce rate is rising in Kuwait and what this means for them.

Attention now turns to housing, an essential resource, the control of supply of which is one of the ways the government influences the empowerment of women and seeks to maintain the male-led family as the norm in Kuwait.

\section{Housing policy}

There is a clear link between rising divorce and housing issues because as the 'model' family declines significant new groups, such as divorced women, have appeared and with them new housing needs. According to an analysis by Maktabi (2015) housing issues were the most frequently raised kind at the Women and Family Committee of the Kuwaiti Assembly, which she argues demonstrates "the economic centrality of access to public housing and rent free loans in Kuwaiti society" (p.11). Hence, it is very important to discuss this policy area in this current study. 
That government is responsible for providing housing to Kuwaiti citizens is one of the most fundamental assumptions of Kuwaiti society seen almost as a constitutional right (Alshalfan, 2013). It is fair to say that there has been some progress for women in terms of their access to housing in their own right rather than by virtue of being married to a Kuwaiti man. What is less easy to determine is whether women's own advocacy, including that of women in parliament, is responsible for these developments (Maktabi, 2015).

With the Iraqi occupation over, Kuwait sought to restore its oil exporting capacity and by 1993 this had largely been achieved. And, as already noted, over the next 10 years the Kuwaiti government put in place a plethora of social and economic programs that subsidised the lives of Kuwaiti citizens and to a lesser extent expatriates working in Kuwait. This came in the form of both consumption and production subsidies. By 2003 more than $20 \%$ of Gross Domestic Product was being deployed in the form of one or other of these subsidies (World Bank, 2005, p. 59). The Housing Assistance Law (No. 47 of 1993) was one such piece of legislation, introducing housing subsidies; it was also a law which codified discrimination against women and reinforced the position of the married male as the head of the Kuwaiti family.

The effect of Kuwait housing policy is to reinforce the traditional idea of male headed households and behind this is the law's adherence to sharia which recognizes that the man has a responsibility to support the family. The official priorities for policy development on housing do not feature gender issues; rather they concentrate on the availability of housing stock in general, the need to access land that is $80 \%$ under the ownership of the Kuwaiti Oil Company and the creation of new cities beyond the metropolitan boundaries of Kuwait City. In order to achieve these objectives, the government is keen to involve the private sector in the construction effort (Public Authority for Housing Welfare, 2015).

The state is legally required to provide housing for married Kuwaiti males but not to female citizens. Even so, a lack of housing stock has meant that fulfilling this duty can take up to 15 years (United Nations Human Settlements Programme, 2010). While waiting, housing assistance is offered to cover the cost of renting or alternatively, interest free loans are available to help married couples buy in the private sector. 
Women have long been denied access to public housing in their own right, in other words other than through marriage to a male Kuwaiti and the state does not recognise female-headed households. This has discriminated against divorcees, widows, the unmarried and those married to non-Kuwaiti citizens. Campaigners for women's rights including the main NGO pressure group the WCSS have prioritised this issue in recent years and in 2010 the public authorities recognised the needs of these groups of women and pledged to set up a public fund to provide loans to them so that they could accommodate themselves. On 23rd of May 2011 the public sector bank the Credit and Savings Bank (CSB) announced that loans of up to KD 45,000 (\$157,000) would be available to women who satisfied certain criteria (Kuwait Credit Bank, 2011). It was doing so to implement Law No. 2 for 2011. In the case of divorced women, they can only apply if their divorce was valid at least three years clearly presenting a problem for many women who were more recently divorced. This stipulation is presumably included to avoid accusations that the new loan entitlements encourage divorce which is seen as a major social problem in the Gulf state.

There was not only progress on access to loans for owner occupation; the provision of rent allowances also improved for certain groups of women. With Law No.2 of 2011 the government opened up access to housing allowances to groups of women outside the 'norm' of a Kuwaiti-Kuwaiti marriage including 27,500 divorcees, 21,200 widows, 11,000 women married to non-citizens, and 8,600 unmarried women over the age of 40 (World Bank, 2013, p. 73).

Two conclusions can be drawn from this short discussion of housing policy in Kuwait. First, policy is directed at maintaining the centrality of the family unit (particularly one in which two Kuwaiti citizens are married). In principle, forming a model family is rewarded by the state with housing or housing loans. Second, societal and demographic pressures such as rising divorce and women marrying non-Kuwaitis has added complexity to this policy area that has seen the government compromise in a way that has benefited certain groups of women.

\section{Violence and sexual harassment}

If many policy areas, including those discussed in part two of this chapter, involve conscious discrimination and injustice to women, often codified into law, then the issue 
of violence against and harassment of women is an informal almost unspoken example of the same. There is little in Kuwaiti policy that seeks to protect a woman's physical integrity. No laws address domestic violence, marital rape, or sexual harassment in the workplace. Furthermore, no government body has been charged with gathering data on these matters. Crime statistics on, for example, theft, are easy to obtain but on a matter as important as rape and other sexual violence no such data exists. In any case, the value of such data would be questionable as incidents involving Kuwaiti women rarely get reported partly because of the lack of support mechanisms in place for those who do and partly because of a largely unsympathetic all male judiciary and a largely dismissive media (Saligram and Moussa, 2013). The lack of legislative protection is mirrored by an absence of support for victims, as Al-Munghi (2010) points out there are no support centres, shelters or legal aid programmes for the victims of domestic violence. The emphasis in cases of domestic violence is firmly placed on family honour and reconciliation. In the rare case of so-called honour killings Kuwaiti law partially justifies them by discounting sentences for those convicted of crimes with the 'honour' label attached, the victims of these crimes are invariably women (Al-Munghi, 2010).

In a rare example of empirical studies into women's issues, Nazar and Kouzekanani (2007) undertook a study of college graduates' attitudes towards violence against women in Kuwait. Using quantitative methods (a questionnaire survey) and a non-probability (self-selecting) sample of 474 students their study showed widespread disapproval of such violence similar to the disapproval of such violence seen in the Qur'an. Statistical analysis did, however, show that disapproval was more pronounced among the young women in the sample than young men. Responses to the questionnaire displayed mixed attitudes towards the position of women within a marriage. Public demonstrations of respect towards women were felt to be important as demonstrated by a $90 \%$ rejection of the public reprimanding of women and an $84 \%$ disapproval of the use of foul language against wives or female relatives (Nazar and Kouzekanani, 2007). Of concern were responses to questions relating to the physical aspects of violence against women. Almost half the total sample agreed that the man has the right to hit the woman if deemed necessary including $62 \%$ of males and $38 \%$ of females (Nazar and Kouzekanani, 2007). 
The media plays an important role in shaping attitudes towards violence against women and this prompted Halim and Meyer's (2010) study of English language newspapers in Bahrain, Saudi Arabia and Kuwait with regard to their coverage of such violence. Their findings showed that newspapers overwhelmingly reflected traditionalist attitudes in that it gave a sympathetic depiction of the perpetrator, tended to lay blame on the women, played down the level of violence, denied a voice to the women involved and failed to portray such violence as systemic. Much of the coverage of domestic violence involved domestic foreign migrant workers and those that did involve married couples did not treat the subject with any seriousness. This lack of concern is, according to Halim and Meyer (2010), reflected by the unwillingness of Gulf Region governments to acknowledge and tackle the problem of violence against women. However, the Kuwaiti government has not entirely ignored domestic violence as an issue. In March 2010, a government study concluded that one-third of Kuwaitis experiences such violence but that the majority of the victims were actually male with $42.1 \%$ having been victims of some kind of domestic violence (including psychological violence) while only $16.8 \%$ of women had been (Ministry of Justice, 2011). This finding is rather surprising to say the least and details of the methodology could not be found though it appears that the data was only collected from couples who had counselling and may have been collected from one in the presence of the other with obvious consequences for its reliability.

A potentially more revealing study was undertaken by Alsafy et al. (2011) who bypassed official statistics and investigated the experiences of primary healthcare nurses regarding domestic violence, thus avoiding the noise and bias of 'official' studies. And yet even among these healthcare professionals there was an apparent weakness in identifying domestic violence as an issue and a sense of denial that it was an issue for public discussion, mirroring much of the media.

The downplaying of domestic violence in Kuwait is worrying, considering that an Egyptian study in 1993 found that domestic violence was responsible for 28\% of all female admissions to trauma wards (Graiteer and Youssef, 1993). In Jordan, 38\% of the sample reported some form of physical and/or sexual violence (Clark et al., 2010). In Lebanon $35 \%$ of women reported experiencing domestic violence by family members (Usta et al., 2007). One possible explanation is hinted at in an article in the Kuwait Times in which Kuwaiti psychiatrist Dr Khaled Al-Muhanadi is quoted as saying that women do 
not report sexual violence because of the societal stigma attached to it while an unnamed Interior Ministry official reportedly said that no records are made of reports of sexual violence and that all efforts are made to solve the issue 'unofficially' (Saligram and Moussa, 2013).

It does appear that domestic violence is an inconvenient truth in Kuwait as it contradicts the various supposed 'contracts' between men and women that are assumed between the genders in Islam. This is because any such violence means that the obligations of the genders under these contracts are not being met by one or either genders, in most cases by men. If there is little legislative attention paid to violence against women, then this is certainly matched by law enforcement agencies. Spousal abuse is seen as a family matter and police are reluctant to intervene (Saligram and Moussa, 2013). If a man is accused of abuse he can normally bring the matter to a close by paying a small fine and sign a declaration of future good behaviour. Spousal rape is not an offence in Kuwait or the wider Arab region.

Analysis of newspaper articles on sexual harassment displayed a similar lack of serious interest in such behaviour and some had tendencies to blame the women's actions, her dress or advocate the need for great gender segregation as a solution to harassment (Halim and Meyer, 2010).

Importantly however, in-country organisations such as the Kuwait Society for Human Rights have called for all aspects of domestic violence to be criminalised and for Kuwait to meet the standards under international human rights instruments such as CEDAW (Arab Times, 2015).

\section{Summary}

This chapter has demonstrated the twin track nature of the development of women's rights in Kuwait. On the one hand the legislative process has been used to remove discriminatory laws and replace them with positive rights. On the other, those aspects of a women's life that are determined by sharia are still riddled with discrimination and inequality. Gender issues have, according to Haya al-Mughni and Mary Ann Tétreault (2000), become a proxy battleground between Islamist and secular political forces; in 
particular, it is an area in which the religiously conservative challenge the legitimacy of secular policy in Islamic terms.

The amendment of laws and the new social policies is not enough to remove discriminatory practices against women. A prime example of this is the representation of women within the judiciary. There is nothing in the Constitution or on the statute books that precludes women judges and yet there is not a single one in Kuwait, something which seriously hampers women's access to justice particularly in areas of family law. The situation has become increasingly unusual now that women are lawmakers and yet not able to sit in application of these laws in a court of law. Leading women's rights advocate Dr Alanoud Al-Sharekh recently highlighted the ongoing challenge "It is just a social bias and lack of awareness. There are many laws that are biased against women and have no value in the Constitution and should be reformed. There are laws of nationality that are biased, housing laws and labor laws that are biased." (Al-Sharekh cited in Ghosh, 2013).

Mass education brings with it higher levels of women's participation in the workforce which naturally leads to their economic empowerment. The education increases expectations and also drives changes in social structure including lower fertility rates and the age at which the key social unit, the family, is formed is raised as Kuwaitis marry later. They also divorce more frequently and earlier in the marriage. These are major structural changes that are surely irreversible and yet full equality seems beyond the horizon. This chapter has also shown how policy areas are linked together. Divorce legislation is linked to domestic violence and also to housing policy: education and employment policy go together while urbanisation leads to changes in demand for housing. This suggests that policy development in terms of women's rights and their role in Kuwait society advance best when they move forward across all fronts; as this chapter has demonstrated this is not happening at the moment; instead the status quo is full of contradictions.

At this point it is important to evaluate what the review of literature and policy in this and the previous chapter has revealed and to identify the important issues to carry forward in the current research. Overall it is clear that there are very few if any reliable empirical studies of what women themselves think of the kind of issues that have been reviewed. This research does not focus on one particular area like divorce or employment but instead aims to present a reasonably comprehensive view across the 
most important domains to arrive at a deeper understanding of what women in Kuwait have experienced, are experiencing and perceive they will experience in the future in terms of their role in society.

The public-private dichotomy appears a clear way to progress. In the public sphere, political participation, women in the workforce, and educational attainment are emerging as important areas. However, in the private domain, the personal status laws, divorce and the role of sharia in reinforcing patriarchal control have all become apparent as detrimental to women during the last two chapters. Women in the justice system arguably straddles both spheres.

Being an exploratory study, these topics which also represent gaps in knowledge in the context of women's perspectives form the basis of the first stage of this research - in a questionnaire. How important do women feel political participation has been? To what extent are the many discriminatory aspects of policy simply unjust or are they seen as inevitable consequences of living in an Islamic country? Should women sit as judges? What do they feel is behind the divorce rates and should men and women have equal divorce rights? These are just a few of the questions that clearly merit exploration. Together with the review of literature and policy in this and the previous chapter, the survey study helps to direct the main qualitative study in term of lines of questioning for one-to-one interviews.

However, before describing the methodology of the current study then presenting its findings, there is first a chapter aimed at putting in place a theoretical framework or perhaps better put, a range of theoretical concepts, which it is felt will be of value in analysing and interpreting the results of this research. 


\section{CHAPTER THREE}

\section{WOMEN'S EMPOWERMENT: SETTING THE THEORETICAL FRAMEWORK}

\section{Introduction}

This chapter charts the methodological framework for the study and outlines the main theoretical perspectives and concepts which informed this process. As research undertaken by a woman exploring women's empowerment through the voices of Kuwaiti women, it is perhaps unsurprising that three out of the four theoretical approaches that have influenced the framework of this study are feminist. Furthermore, given that this study is, in essence, one about power and empowerment theories of power are also very important, particularly with regard to enhancing understanding of the evaluation of the study.

The chapter starts with a discussion of feminist research of which the current study is an example. Importantly however, although this study is concerned with the theoretical application of feminism, a comprehensive discussion of all the forms of feminist theory and their development is beyond both its scope and requirement. Instead this chapter focuses on the concepts of feminism that shaped the study and which assisted in evaluating its results and findings. Nevertheless, adding some much needed clarity, the chapter does begin with a brief discussion on feminism, its main features, its appropriateness to the study and the implications for the researcher in adopting a feminist approach. Thereafter the chapter goes on to discuss in some detail four theoretical perspectives (three of which are feminist) that have influenced the theoretical framework, starting with radical feminism, which is taken to mean to mean a form of feminism which emphasises the patriarchal roots of inequality between genders and the nature of society as one in which women are dominated and oppressed by men. 
In this chapter the radical feminist approach is exemplified by the work of Catherine MacKinnon. MacKinnon is not only a prominent example of a radical feminist academic, but she specialised in law and the way it operates or fails to operate in both the public and private spheres. Her work seems to be particularly appropriate with regard to the question of to what extent public/private sphere change in Kuwait - this is a key issue for this thesis. Furthermore, Kuwaiti rights for women are so far behind western societies in many ways they resemble more closely the period in which radical feminism was the dominant form of feminism (i.e. in the 1970s and 80s). This is not to ignore however the reality that radical feminism has fallen out of favour among many feminists with the limitations of radical feminism as a theoretical perspective being thoroughly discussed for some decades now. The most often cited limitations are its inability to explain why the life experiences of women vary so much and how so much of the change that has taken place in gender relations is possible under their interpretation (Ramazanoglu, 1989; Mandell, 1995; Walby 1995; Walby, 1997). Therefore, in order to provide for a more sophisticated framework of understanding, the cutting edge theoretical work of Sylvia Walby is explored in some detail.

Walby's work on intersectionality and complexity theory (a framework for theorising how the multiplicity of social inequalities intersect) as well as the architecture of gender inequality (the types of inequalities, the strength of vision of equality and the resources deployed to achieve this and the policies and agencies involved) each offer not only interesting theoretical developments but also useful interpretations of gender equality in a variety of domains - for example employment and politics - which are very relevant to this study, albeit that they are from a western context. Thus, her work has the potential to assist in a better understanding of what is happening in Kuwait today. Employing Walby's interpretations of gender equality to the findings of this study might well signal a process of change that is positive just as there are positives in the European context, hence there is the opportunity to identify benchmarks or tools for comparison - the most obvious example being women's suffrage and political participation. However, there is no evidence that Walby's approach can be applied beyond a western context and thus it is important to note that the utlilisation of Walby's work is somewhat experimental and exploratory. 
One strand of feminism that has most definitely been applied to Arab countries and even specifically Kuwait is Islamic feminism. Women who adopt an Islamic feminist perspective focus on promoting an alternative, more gender equal, interpretation of the Holy Qur'an which is arguably seen as less threatening than 'western' inspired feminism in the eyes of moderate Muslim men (Badran, 2008). Islamic feminism is believed to have been behind some of the gains made by Kuwaiti women seeking greater empowerment (González, 2013) and thus it is very relevant to this study because it brings into play important aspects other feminisms do not pay so much attention to, particularly religion.

Finally, the study draws on a non-feminist fourth element to the theoretical framework; Luke's three-dimensional theory of power. Lukes's work on the three-dimensional view of power, thick and thin acquiescence (contrasting states of complicity and resignation) and Objective Interests (a concept similar to false consciousness) has the potential to assist in the formation of an understanding as to why some Kuwaiti women have chosen to accept gender inequality within a strong patriarchal society while others, for example those who protest for equal voting rights, reject conservative forces and hostile opposition to gender equality.

\section{Feminism and feminist research}

As already noted, this study aims to give a voice to Kuwaiti women and in doing so it strives for a better understanding of women's empowerment in Kuwait - thus feminism is adopted as the overarching theoretical framework. Feminist research in its current form can be traced back to the late 1960s and the 70s where it emerged from the increasing belief among women academics and students that there was a significant mismatch between their own life experiences and the existing models of research as well as the findings of contemporary studies (Hesse-Biber and Leavy, 2007). These findings were felt to be invalid in so far as studies undertaken by and/or of men were often being simply generalised into studies of 'people' and hence were presented as including women (Epstein, 1981). At the same time female scholars were questioning scientific methods which they saw as being dominated by patriarchal consciousness which dictated which questions were asked and how they were asked and then analysed and discussed "within male-centred frameworks of explanation" (Holland and Ramazanoğlu, 2002) p. 45). The clear conclusion from this was that both patriarchal methods and theory was not capable 
of addressing gender-based research. As Sarantakos (2005, p. 54) explains "Feminist research is based on the assumption that the world is socially constructed, displays a relative aversion to empirical positivist methodology and rejects the value free nature of research."

Specific criticisms of traditional research methods, mainly made in the seventies and eighties, include "sexist and elitist research topics", "biased research designs" and the existence of an "exploitative relationship between the researcher and the subject" (Fonow and Cook, 1991, p. 86). There was also specific questioning of the validity of quantitative data which was criticised for its simplistic nature and superficiality while findings have been unacceptably generalised (Fonow and Cook, 1991). Opposing this patriarchy, feminist research recognises that women and women's issues needed to be studied in their own right. What is more, such research is normally undertaken from a perspective that takes certain concepts as being fundamental. Millen (2007) identifies two of these concepts as empowerment of women and the equality of the researcher and the researched, and similarly refers to the emancipatory nature of feminist research.

Feminist research is by no means one clearly defined approach to research; rather it is an umbrella under which a range of approaches stand linked through certain common principles. Some would confine the application of feminist principles in research to "epistemological considerations" (Millen, 2007) while others see feminist research as part of the overall feminist struggle and argue that the principles should pervade all aspects of research including the methodology and the analysis of results (Hesse-Biber and Leavy, 2007, p.4).

By documenting women's lives, experiences, and concerns, illuminating gender-based stereotypes and biases, and unearthing women's subjugated knowledge, feminist research challenges the basic structures and ideologies that oppress women. Feminist research goals foster empowerment and emancipation for women and other marginalised groups, and feminist researchers often apply their findings in the service of promoting social change and social justice for women.

Sarantakos (2005, p. 54) describes feminist research as "an emancipatory type of enquiry" that is founded on critical theory and goes on to list the objectives of such research as highlighting the structural causes of current situations, proposing ways in which negative 
consequences can be alleviated, giving women a voice and in so doing empowering them and contributing towards social change through helping to reconstruct society.

Unsurprisingly, feminist research participates in the qualitative versus quantitative discourse among researchers. Supporters of the qualitative approach to research point out that a woman's life experiences, the actions and understanding of the world can only be studied in women's own terms; thus rejecting traditional quantitative methods (Fonow and Cook, 1991, p.85). Concerned about established methods being entirely disregarded, those researchers (including some feminist researchers) who maintain a quantitative approach see the feminist qualitative argument as potentially undermining the scholarly value of the research, mainly as it invites researcher bias in the absence of traditional safeguards (Fonow and Cook, 1991). Having said this, the perception that feminist researchers abstain from all considerations of matters such as objectivity, measurement, reliability and generalisation is not correct (Sarantakos, 2005, p.55). Those feminist researchers who adopt the interpretivist paradigm are still able to adopt principles including validity and objectivity in their studies (Sarantakos, 2005). This is certainly an aim of this study which as the following chapter explains in detail, adopts a mixed methods approach for its data collection.

\section{Radical Feminism}

Accepting the clear evidence of patriarchal dominance across most if not all domains of life in Kuwait, the theoretical framework is broadened out to encompass a variety of approaches - one of which is radical feminism.

Radical feminism in its current form emerged out of the 1960s (Ramazanoğlu, 1989). In its early stages the assumptions on which the theory and practice of feminism were based were relatively straightforward. As Ramazanoğlu (1989, p.3) explains it was underpinned by the understanding that "In general women have interests opposed to those of men, that men generally dominate women, and generally benefit from this domination". Society is organised as a patriarchy where the male class dominates the female class, or as some prefer to define it, dominant males exercise power over other males and all women. 
In the USA, radical feminists such as Ellen Willis claimed great achievement for their particular role in the women's liberation movement starting in the 1960s and culminating in the Equal Rights Amendment in the United States which passed both Houses of Congress in 1972 but ultimately fell into a quagmire of state ratification and never became part of the Constitution (National Council of Women's Organizations, 2013). However, among the successes claimed for radical feminism in America were sexual politics which became a recognised issue, establishing the lexicon of second wave feminism, triggering the movement for legal abortions, and being the first to put the proposition of gender equality in the home (housework, childcare etc.) on the table (Willis, 1992, p. 118). Thus, while the majority of comparative analysis in this thesis draws on the UK experience, there are nevertheless some interesting references to be made to the United States, not least because radical feminism was shaped there and that country has a written constitution like Kuwait.

Radical feminists (in both the USA and UK) were overwhelmingly white and middle class and unfortunately their reluctance to add class and race dimensions to their analysis resulted in diminishing support for their approach which failed to permeate beyond a relatively small social group, leading to the failure to integrate feminism into the wider radical political agenda (Willis, 1992, p.122). However, this suggested demise was hotly contested and indeed history stood testament to the more powerful feminist work to come which could rightly be described as radical feminism.

For example, MacKinnon writing in 1987 applies a radical feminist perspective to the domain of law, particularly the legal treatment of pornography and harassment. While accepting that other inequalities exist within a "general theory of inequality" (MacKinnon, 1987, p.3), MacKinnon asserts the primacy of gender inequality. For example, while class inequalities are self-evident "Women get their class status through their sexual relations with men of various classes" (1987, p.3). For her, male supremacy is a specific politics and social relations are organised in such a way that men dominate and women submit to men and that the nature of these relations is sexual.

Mackinnon's analysis is essentially a classical radical feminist one. In society men hold power over all that has value as well as the power to determine what has value and what has none. This power is consciously and systematically used to define and shape men and women as social beings in a way which enhances the power of the former and maintains 
the subordination of the latter. This in turn shapes the whole of society along hierarchical lines based on sex. This includes institutions, private relations, families and all other domains of social life. According to Mackinnon, only the actions of women to get men's "feet off our necks" and seize power from men can alter this social organisation (Mackinnon, 1987, p.3). Mackinnon saves her sharpest analysis for the relationship between gender differences and domination. She argues that "difference is inscribed on society as the meaning of gender and written into law as the limit on sex discrimination" (Mackinnon, 1989, p.216). In other words, the law is used to define in what domains and in which respects women are granted sameness and in which difference is preserved. She argues that "difference is the velvet glove on the iron fist of domination. The problem is not that differences are not valued; the problem is that they are defined by power" (MacKinnon 1989, p.219). Gender as difference is essentially a male concept, from a woman's point of view "Difference is inequality's post hoc excuse, its conclusory artefact, its outcome presented as its origin ..." (MacKinnon, 1989, p.218).

This treatment of the concept of difference is pertinent to the current study, particularly as difference is so embedded in religion. This is clearly the case for Islam the official religion of Kuwait. Heavenly gender inequality is translated to Earthly gender inequality based on the differences in gender roles described in the Qur'an and Hadith. The fact that a woman may not marry without the permission of her male guardian (father, brother, uncle, etc., or even son); the fact that a woman may not travel outside her home town or city without a male chaperone who is a close relative; the fact that a woman's witness is worth only half that of a man's, in most areas of law; and the fact that a woman's inheritance is normally half that of the corresponding man are all rooted in Islam religious texts. Difference is ordained and so, on socially conservative interpretations, cannot be challenged.

Furthermore, MacKinnon is mainly concerned with the domain of law which is highly relevant to the current study as it is in this domain where much of the activity to empower women in Kuwait has taken place. If the nature and complexity of inequalities in Western societies has reduced the effectiveness of radical feminism, both as a theory and a political movement, in the last two decades, it could be that it is still highly relevant in today's Gulf region. Perhaps the fact that this study listens to the voices of educated urbanised women, with the same ethnic background and similar socio-economic status 
mean that a one-dimensional gender analysis is actually the most appropriate. Chapter four explains why this particular group of women participated rather than a sample representing all women living in Kuwait.

Thus, radical feminist writers (and specifically MacKinnon) offer important insights that can be applied to the current study, particularly when comparing the experiences of western women with those of the women of Kuwait and when seeking to interpret the development of women's empowerment in Kuwait through a feminist lens.

Radical feminist theory plays an influential role in the methods adopted in this study as well as the evaluation of the results. However, as already indicated, it is not used exclusively as the researcher agrees with many other academics over the last one or two decades regarding the gaps and shortcomings in adopting a one-dimensional classic radical feminist analysis. Thus, to fill these gaps additional theoretical tools are required to ensure thorough analysis.

\section{Walby's feminism}

As the corpus of feminist research grew so did the gaps in radical feminism when addressing questions about why some men and women appeared to share the same interests, why some women had power over others and generally trying to represent the full diversity of women's experiences which were clearly not all the same (Ramazanoglu, 1989). It has already been noted how Ellen Willis, a leading figure in radical feminism, expressed frustration at its proponents' unwillingness to consider race and class inequalities and joining what would later be referred to as a "coalition" of progressive social forces battling a range of overlapping inequalities.

Classical feminist theory mainly aimed its attention at critiquing class based analyses of a whole range of social domains. More recently this application of feminist theory and research has tended to lose favour as feminist academics have sought alternative approaches to understanding gender inequality, particularly ones which take account of other forms of social inequalities such as ethnicity, nationality and religion, age and indeed class. Prominent among these is Sylvia Walby. Walby welcomes Mackinnon's contribution to our understanding of issues such as sexual harassment but argues that this radical feminist approach does not help greatly in analysing other aspects of women's 
role in the labour market (Walby, 1997, p. 38). Walby (2007) is interested in developing complexity theory to critique what she sees as the traditional social system theory which has outlived its usefulness.

\section{Walby's Complexity Theory}

Complexity theory offers a framework for theorising how the multiplicity of social inequalities intersect in a way which facilitates a new concept of social system in place of those based on either Marxism or functionalism. She explains, "Complexity theory is a loose collection of work that addresses fundamental questions on the nature of systems and their changes" (Walby, 2007, p. 449). Among the intersecting inequalities Walby seeks to interpret are gender, class, ethnicity, nationality and religion.

One of the key concepts in complexity theory is intersectionality and Walby sets out five approaches to this concept from the literature and takes preference for what she terms the segregationary reductionist approach (Verloo, 2006; Yuval-Davis, 2006) as a useful starting point. She quotes Yuval-Davis (2006, cited in Walby, 2009, p.255) to explain the segregationary reductionist approach:

The ontological basis of each of these divisions is autonomous, and each prioritizes different spheres of social relations ... For example, class divisions are grounded in relation to the economic processes of production and consumption; gender should be understood not as a "real" social difference between men and women, but as a mode of discourse that relates to groups of subjects whose social roles are defined by their sexual/biological difference ... Ethnic and racial divisions relate to discourses of collectivities constructed around exclusionary/inclusionary boundaries.

Walby argues that this is a useful starting point but that it does not go far enough in enabling the theorising of each set of social relations. Here the complexity of the approach starts to become clear. In addition to the multiple sets of social relations there are also a series of domains (she puts forward economy, polity, violence, civil society as four of these). So there are multiple sets of social relations in multiple domains each of which need to be separately understood. Each domain and each relation is a separate system rather than a component part of an overall system (Walby, 2007). But the complexity does not end even there; she continues "it is necessary to theorize more fully the relationship between systems of social relations and how they affect each other 
together with the dynamics of social change." (Walby, 2007, p. 454). For Walby it is complexity theory which facilitates theorising these systems in a way previously unavailable through systems theory. She does not advocate the rejection of systems theory per se as those who have opted for discourse, deconstruction and identity and the prioritisation of agency in human relations.

Walby describes complexity theory as an emerging approach or framework rather than a unified body of theory. It has roots in two theoretical schools, chaos theory and systems theory. She identifies Luhmann $(1985,1990,1995,2000)$ as the first academic to apply complexity theory to social science. However, she points out that this early work dissociates itself with consideration of the power, inequality, economics, and politics domains. Fusing a Marxian perspective with complexity theory has more potential but she believes that it still does not adequately address the issue of the intersection of multiple social inequalities (Walby, 2007).

So what we are left with is Walby's own 'hybridization' of complexity theory which is "positioned within the tradition of social theory inspired by Marx and Weber" (Walby, 2007, p. 58). This states that each set of social relations is a system. Examples of the sets are class, gender, ethnicity, so each of these is a system. Each set of social relations is also a system of inequality "constituted in each institutional domain of economy, polity, violence, and civil society" (Walby, 2009, p. 443).

Walby's complexity theory has undoubtedly evolved out of systems theory, indeed in Theorizing Patriarchy in response to what she saw as shortcomings she highlighted the use of dual-systems theory when analysing women's participation in the labour market - one system being class-based relations and the other being the system of gender relations (Walby, 1997). Alexander (2009, p. 2) suggests that Walby's work "revises sociological systems theory to bring it into a framework compatible with the non-linear dynamical systems analysis of chaos and complexity theory." She explains that complexity theory has a long history across a whole range of disciplines and Walby is developing its use for social research and also using social theory "to bear on the metaphors and images of complexity theory" with the added dimension of social systems which both overlap and compete (Alexander, 2009, p. 12). 
Aside from the theoretical developments, Walby also advocates a focus on policy and institutions, a result of her own position within 'real world' policymaking. It is part of a recognition that women's empowerment can take genuine steps forward even under the conditions of gender inequality. Holst (2012, p. 299) refers to Walby's The Future of Feminism as an "impressive synthesis of her engagement with sociological research, social theory, gender studies and feminism." In regards to Walby's relatively optimistic approach to positive change, Holst sounds a note of caution. Among Holst's critiques are that Walby overlooks a series of gender conflicts by 'sweeping them under the carpet' and reducing the definition of feminism to the pursuit of greater gender balance. Additionally, she argues that Walby sees the feminist theory of hegemonic maledominated culture as something purely for theory while this hegemony is solvable in practice, through developments such as the proliferation of feminist policies and legislation. Holst questions, for example, whether policy moves such as the German government's initiative to achieve a 30\% representation for women in German boardrooms is a feminist move or one aimed primarily at increasing economic competitiveness. In the evaluation of the findings of this current study, there is an attempt to seek to understand to what extent are the policy and legislative changes in Kuwait are similar to this example. In that while appearing to advance women's position and perhaps seeming to arise from the campaigning of women and women's groups, are they part of a different agenda?

Walby does not reject feminism, far from it. The opening lines in The Future of Feminism pronounce feminism is "still vibrant" and "a success" and she rejects the notion that we live in a post-feminist era (Walby, 2011, p.1). Against the background of the much discussed decline of the 'isms' and the vaunted end of ideology Walby seeks to plot the future path of feminism as a vibrant multi-dimensional but somewhat less visible force. Part of the lack of visibility is, according to Walby (2011), a result of its absorption into institutions and issues that are not purely feminist but are concerned with broader agendas such as gender equality, diversity and socio-economic redistribution which has occurred arguably because they are mainstreamed. Rather than standing alone, today's feminism is more likely to be found in coalition with other social forces. This in turn has led to a new nomenclature as those who would not readily label themselves feminists engage in activity and support causes and policy which advance the position of women in society. So today we hear less of feminism and more of 'diversity', 'equal opportunities', 
and 'gender equality' (Walby, 2011). As an example, trade unions may work towards fair treatment, equal pay, improved conditions, ending harassment and other aims all to the advantage of women, but do not do so in the name of feminism. But does that matter? Is it important to narrowly define feminism in a way which may exclude these projects? Walby argues that it is not and that feminists should embrace their role in coalitions and permit a broader definition of working against gender inequality. This research study considers in chapter 9 the extent to which these coalitions exist in Kuwait and whether the experience of feminism in the UK has any parallels in Kuwait. To what extent are women campaigning for rights and greater equality in coalition with other social forces? Walby indicates that these coalitions would exist though would not always involve the same allies, "There is a multiplicity of ways of framing and shaping feminism as a consequence of the various allies and enemies that co-exist in the same political environment; hence these ways vary between countries and over time" (Walby, 2011, p. 146). In chapter 9 the particular shape that feminism in Kuwait takes is compared with the way Walby frames the feminist project in 21 st century Britain.

The theoretical underpinning for this new reality of coalitions and multi-thread equality projects is intersectionality. Walby frames the socio-political world in terms of projects. Feminism (or rather gender equality) is a project as are human rights, social democracy, environmentalism, anti-racism, nationalism and so forth. These projects are not discreet; in fact, they intersect. Walby (2011) points to the intersection of feminism with national projects. There is a tension when creating the national myth (of a common background) about whether the domesticated view of women from eras gone by should hold sway or whether women should be promoted as "full citizens in the public sphere" (p. 128) and the feminist project may support or reject a particular positioning of women in the national project. Likewise, there is an intersection between the environmentalist project and feminism, two projects which have formed alliances on a number of levels and with women often taking the lead in green politics. The human rights project intersects with feminism and it was the claim to these rights which provided legitimacy for suffrage campaigns around the world. The merging of women's rights with universal human rights has been a powerful intersection in creating an organised, transnational project advancing the position of women and perhaps it could be suggested facilitates the rise of feminist projects in countries like Kuwait where patriarchy is perhaps at its strongest. 
The feminist project intersects with social democracy as can be seen by the insertion of women's issues such as equal pay, childcare provision and sex discrimination into the social democratic project (Walby, 2011). Women have gained an increasingly important place in unions and NGOs to some extend replacing support for social democracy among the traditional male working class constituency. Overall this intersectionality is seen in the synthesis of feminism, human rights, social democracy and environmentalism into today's progressive politics in Western Europe. The evaluation of this study considers to what degree Walby's model of intersectionality can be detected in a very different socio-cultural context, that of Kuwait. In a globalised world are the changing realities for feminism and its role as part of a coalition of progressive forces apparent in countries such as Kuwait, or are these countries at a stage where the traditional zero-sum gender-only based analysis is still the most appropriate way of interpreting women's experiences? After all, it may be that feminism in Kuwait is at such an early stage and faces such overwhelming patriarchy supported by religion, which a radical feminist analysis is actually more appropriate as it was felt to be by many in Western countries nearly half a century ago.

\section{Walby's approach to analysing change in gender relations}

In Gender Transformations Walby discusses the changing patterns of gender relations in the UK. For example, she analyses the growth in women's paid employment and the generational gap opening between younger women with their access to employment and, taking a mainly materialist perspective, how this has permeated organisational and institutional change, the law, politics and the distribution of educational opportunities. Whether changes in employment patterns caused changes in gender relations or the changes in gender relations enabled the introduction of woman to the workforce as cheap flexible labour is a key discussion point (which could also be applied to Kuwait). Walby suggests it is the former.

Increased paid employment among women was the result of the way that gender relations had changed in political, organisational and legal terms but also of girls' and women's rising level of educational achievement and the increasing possibility of combining 'domestic production' with such paid employment (Walby, 1997). In other words, paid employment of women has grown through a patchwork of factors and their ordering and relative importance is "controversial" (p. 21). Women are also increasingly 
found in paid employment in Kuwait and after the findings have been presented, the parallels and differences between the UK and Kuwait in the light of Walby's analysis are discussed. When Walby (1997: 21) writes, “The entry of women into the public sphere is most marked in the areas of employment and education", she could have equally been writing about Kuwait. But the debate as to whether increased educational attainment and greater representation in the labour force inevitably leads to reduced gender inequality is also relevant to both the UK and Kuwait.

While Walby expands upon her subsequent development of Complexity Theory, she acknowledges how interwoven the inequalities of gender, class, ethnicity, sexuality, age and nationality are; however, in Gender Transformations, gender and age are the main focus. It may also be that these two sets of relations are the most important in this Kuwait set study. Two of her themes in this book are how changes in gender relations affect the economy as a whole and how seemingly progressive changes in gender relations have in the UK led to a rupturing between generations, something highly relevant to the study of Kuwait where the educated young women of today with their access to universities and the labour market contrast greatly with women of just one generation earlier (Walby, 1999). However, two points of critique are raised by Howard (1999). Firstly, that the book offers no overall conclusion with an overall theoretical statement; secondly, there is no indication of Walby's view on the generalisability of her arguments to other contexts particularly non-Western ones which is something the current study may be able to shed light on.

Walby (1990) also refers to the work of anthropologist Michelle Rosaldo (1974) who argued that women's subordination is universal irrespective of religion and that it is only the degree that changes from context to context. Rosaldo proposed a framework for understanding why relationships between the sexes are universally asymmetrical. Her preferred approach is to look at the way humans are socially and culturally organised, specifically the division of public and domestic (private) spheres. Women are domestically orientated primarily as a result of their reproductive and child-rearing role (Rosaldo, 1974). She argues that the public-domestic division "provides the necessary framework for an understanding of male and female roles in any society" (p.24). Furthermore, women are subordinate to men because of this confinement to the private (domestic) sphere and the low value assigned to domestic labour. Walby interprets 
Rosaldo's indicator of the strength of patriarchy and the level of subordination as being the level of confinement of women to the private sphere and their isolation from their fellow women in society (Walby, 1990, p.175). This approach will be highly transferable to the Kuwaiti context, coming as it does from an anthropological perspective.

\section{Gender Equality Architecture}

In her 2012 paper 'Intersectionality and the Quality of the Gender Equality Architecture' Walby focuses on the concept of intersectionality which is central to her development of Complexity Theory and its application to Social Theory. Walby discusses the merging of equality commissions in the UK and whether this is a good thing for gender equality. She examines the changes to the 'architecture' of gender inequality which she defines as the range of people and inequalities encompassed; the range of policies and domains included; the scope and ambition of the vision of equality; and the scale and depth of the resources available for gender equality. It also refers to "governmental or quasigovernmental agencies and departments that regulate or promote equality" (Walby, 2012, p. 448). This has been referred to in the literature as "women's policy agencies" and also "gender machinery". In the findings chapters of this thesis the gender machinery of the UK is compared with that which is evolving in Kuwait to see what if any parallels can be drawn and how we may interpret such a comparison to plot the likely future path of women's empowerment in Kuwait.

To sum up the role of Walby's work in this research, its primary use will be as an analytical framework for a comparative discussion of the UK and Kuwait's gender equality architecture. Secondly, intersectionality will be a concept used when evaluating the findings of this research in terms of the different sets of social relations and how they function in the various domains in Kuwait (economic, legal, political etc.). In particular, this study concentrates on gender relations with a supplementary interest in generational differences.

Walby's work offers a broader range of tools with which to analyse women's experiences in Kuwait. However, it sits deep in a western European context and itself makes little claim to generalisability. It may be that some of her analysis is over-sophisticated (too complex) for a society where, from a Kuwaiti women's standpoint at least, gender inequality is so dominant over other forms of inequality as to make intersectionality a 
redundant concept and coalitions impractical and unnecessary. Chapter nine will discuss this further.

\section{Islamic Feminism}

The two authors already featured in this chapter are embedded in Western society and apply their theoretical work to their social and political environments. Katherine Mackinnon has been active in legal issues in North America while Sylvia Walby is a significant contributor to policy discussions in the UK and Europe. There are only hints at generalisability in their work and these are largely untested. These authors, as with the great majority of Western feminists, have a secular stance and have not needed to engage in the dialogue between feminists of different kinds concerning whether a more gender egalitarian interpretation of Islam provides the 'space' for an improvement in women's rights. While there are undoubtedly a significant number of liberal, secular feminists whose views would be familiar to feminists in the West, these are not the only type seen and actively pushing for women's empowerment in Kuwait.

The rise of political Islam towards the end of the 20th century and its call for a reversion to patriarchal sharia created a reaction - Islamic feminism (Mir-Hosseini, 2006). Women who had previously to choose between betraying either their religion or their gender consciousness could now avoid this choice in their pursuit of gender equality. Increasingly educated women came to question more and more the textual grounds for patriarchal Islam. The result was "a gender discourse that was and is feminist in its aspiration and demands, yet Islamic in its language and sources of legitimacy" (MirHosseini, 2006, p. 640). Eyadat (2013) confirms that the rise of Islamic feminism was associated with Islamic revivalism of the late 1970s and 1980s and involved "women exerting their own exegesis on the Qur'an, reinterpreting the holy texts through rationale and historical context, and finding that human rights and egalitarian principles exist in the core of Islam's teachings" (p.360). Badran (2008, p.26) sees this as "subverting the patriarchal Islamist project.”

Islamic feminism now represents a growing movement in Kuwait and the wider Muslim world. Margot Badran (2011 cited in Ahmed and Jahan, 2014, p.2) defines Islamic feminism as "a feminist discourse and practice that derives its understanding and 
mandate from the Qur'an, seeking rights and justice within the framework of gender equality for women and men in the totality of their existence." Such women, therefore, seek a religious route to empowerment by challenging the fundamentalist patriarchal interpretation of the holy texts.

Scholars working from this perspective argue that the guiding principles of Islam, far from subordinating women, are in fact more egalitarian than Western religions, such as asserting the spiritual and moral equality of men and women and a women's right to inherit and pass down property. They argue that the threat of modernity has driven men towards the ideas of the most misogynistic religious leaders fearing a challenge to their traditional superordinate role. In practical terms, Islamic feminists use "ways to negotiate for progressive women's rights within the conservative constraints of their culture" (González, 2013, p.2). They accept the legitimate authority of the holy texts but not the way it has been interpreted and applied particularly in areas such as the personal status laws. Badran (2008, p.28) refers to this as "changing the terms of reference of Islamic discourses from within.” González (2013) wrote a book on Islamic feminism, specifically looking at Kuwait. The author tried to understand why intelligent Kuwaiti women were choosing to wear the veil and support Islamic election candidates and why Kuwaiti men were encouraging Islamic feminism not opposing it. The main way these questions are answered is through the concept of legitimate authority. Like other political Islamists, Islamic feminists are "willing to work within the legitimate sources of authority and political structures that have been granted to them by their local governments" (González, 2013, p. 78). They accept the holy texts are one of these legitimate sources and so enlist them in their cause. Furthermore, González also argues that it is this approach that has been most successful in negotiating change in Kuwait. Successful or not, Islamic feminism finds itself opposed on two sides, on the one hand it is seen as unIslamic by the majority of Islamists, and to secular feminists, Islamic feminism is a blatant contradiction in terms (Mir-Hosseini, 2006).

It is of considerable interest to explore to what extent the Islamic feminist perspective emerges from the data, in other words through the urbanised educated women in this study. Is there a clear division between Islamic feminism and secular feminism, and in what ways does this manifest itself in the data? 


\section{Lukes: Power and Obeisance}

In 2005, Stephen Lukes published a new edition of his widely discussed 1974 book Power: A Radical View. In both editions the author seeks to address two challenging questions about the nature of power. Firstly, he wanted to understand how the powerful manage to secure the compliance of those they seek to dominate; secondly, and perhaps even more challengingly he attempted to develop a framework with which power can be both theorised and studied empirically. Regarding the definition of power, Lukes states "I have defined the concept of power by saying that A exercises power over B when A affects B in a manner contrary to Bs interests" (Lukes, 1974: 37). For feminist researchers this definition sees $\mathrm{A}$ as men and $\mathrm{B}$ as women, though from what is written in this chapter it is clear that many, including Walby, have sought to move to a more complex view of power relations.

However, Lukes views power as being achieved through internal constraints imposed upon the subject. Through these constraints the subject acquires beliefs which facilitate their path to domination through consent, a process which can be either coercive or noncoercive (Lukes, 2005). One qualification introduced in the second edition is that the concept of power is the capacity to exercise this domination rather than the actual exercising of it (Lukes, 2005).

Lukes argues that there are three views of power: one dimensional (a pluralist view), two dimensional (critics of the pluralist view) and three dimensional (the view that Lukes advocates). The three-dimensional view offers the best perspective from which to study power, according to Lukes. While the three dimensional view is essentially born of a critique of the one and two dimensional views it also develops a focus on decisionmaking and control of the political agenda, issues and potential issues, observable and latent conflict and subjective and real (objective) interests (Lukes, 2005).

As noted, one of the central elements of the three-dimensional view is the concept of latent conflict which is defined as 
... a contradiction between the interests of those exercising power and the real interests of those they exclude. These latter may not express or even be conscious of their interests, but ... the identification of those interests ultimately always rests on empirically supportable and refutable hypotheses (Lukes, 2005, p. 28).

In other words, for the researcher, it is not the goal to demonstrate that a particular group has recognised and is responding to their perception of actions being taken that are against their interests but rather to be able to empirically demonstrate that the actions of the As are having a measurable detriment to the interests of the Bs, regardless of whether the Bs even recognise or express concern about the situation. Indeed, it is the very fact that the Bs do not promote their interests or are even unaware of what they are which makes this form of conflict 'latent'. Lukes is seeking an answer for why so many apparent clear conflicts of interests go largely unopposed and are not even developed as 'political' issues: he points to the role played by on the one hand individuals' decisions and on the other institutional practices and social forces (Lukes, 2005).

Lukes's third dimension of power is domination and this is the most important and indeed insidious form of power. It requires one party to dominate and another to submit to this domination. This acquiescence can take two forms. Under the 'thick' form the submissive party are in that state because they genuinely believe in the values and belief system that has led to their domination. Contrastingly, the 'thin' form of acquiescence arises not from any conviction but from a state of resignation to the inevitability of their domination (Lukes, 2005). This approach to power and obeisance is extremely relevant to the current study which seeks to explore and understand the reasons why most women in Kuwait obey while some others do not. In particular, this study seeks to observe the 'thick' or 'thin' acquiescence in Kuwait using Lukes' model.

\section{Summary}

This Chapter has discussed the theories and concepts which it is believed may be of use in interpreting and understanding the issue of women's empowerment in Kuwait. As an exploratory study, it would be wrong to employ a single theory and instead a looser framework has been developed based on a review of the literature and given the particular issues impacting on women in Kuwait today. Thus the framework is predominantly feminist, but it includes several distinct strands which offer the potential 
to further an understanding of women's empowerment in Kuwait. Lukes' theory of power represents a fourth, and very important additional element.

The next chapter presents the study's methodological design and subsequent fieldwork process which took place in order to discover women's experiences and attitudes in today's Kuwait. Thus in the next chapter the methods used to conduct the research for the study are detailed and the epistemology underpinning the study and the chosen research paradigm are explained. The successive methodological choices made in arriving at the research design are discussed together with a description of what happened during the field work. 


\section{CHAPTER FOUR}

\section{RESEARCH DESIGN AND METHODS EMPLOYED}

\section{Introduction}

The previous chapters have reviewed the literature on the Kuwaiti constitution, legislation and policy together with literature pertaining to women's rights in Kuwait. Examples of policy contradictions which demonstrate how undeniable advances such as education, employment and suffrage contrast with personal law issues which continue to discriminate against women have been established. Thus far the thesis has argued that labour force participation and political enfranchisement have occurred in Kuwaiti society, however, a woman's personal life is still governed by traditionalist principles based on a patriarchal application of Sharia. Before reporting and analysing the data for this study, the methods used are explained in this chapter.

As a gender-based study this chapter looks not only at the epistemology and the research paradigm but also discusses the specific challenges of feminist research in an Islamic country in order to provide context for the more specific sections of the chapter which detail the research design, describe what actually took place, and set out the ethical considerations involved.

First the chapter contrasts two different epistemological standpoints, positivism and interpretivism and two research paradigms, quantitative and qualitative. This is done to situate the research in epistemological terms. After this the chapter discusses the specific characteristics of conducting feminist social research in an Islamic nation. It is recognised that cultural factors influence the nature of social research in a particular society and can also place limitations on it, so it is important to consider this in the context of the current study. The issue of objectivity in qualitative research is also considered before presenting the research design. Thereafter the quantitative survey utilised in this research and which provided descriptive data is presented and this is followed by a discussion of the 
qualitative interview approach that was developed to ensure that the voices of women were heard in this research. There is also discussion of the use of video recording and the challenges of transcription and translation. Further sections deal with data analysis and ethical considerations.

\section{Knowledge and the approach to research}

Before describing what the methods, the sample, and the data collection and analysis it is important to discuss some of the dimensions to the research which envelope the research process itself. These are the epistemological basis of the research paradigm, the feminist character of the research, the relationship between social research and Islam and in particular feminist social research and Islam. Once this is completed, the chapter moves on to explaining the research design.

\section{Epistemology and the research paradigm}

Epistemology questions the validity of different types of knowledge (Fonow and Cook, 1991). For the purpose of context setting, two epistemological approaches are contrasted - positivism, briefly, and interpretivism at greater length as this is the paradigm taken in this research.

\section{Positivism}

Positivism heralded the arrival of science to replace the role of 'reason' advocated by Enlightenment philosophy and while positivism pre-dates Comte's work it had been previously applied to the natural science. Comte applied it to what he first called 'social physics' and later renamed sociology. According to Sarantakos (2005, p.8) what Comte meant by positive was "phenomena posited or given in direct experience and resulting from scientific observation and scientific method."

Durkheim was less interested in Comte's philosophical approach and focused his positivism on the parallels between social sciences and natural sciences and in so doing essentially founded sociology as an academic discipline and contributed greatly to social research methodology, particularly quantitative method. Durkheim's study of suicide rates and the subsequent criticisms of them, has in many ways come to symbolise the 
positivist-interpretivist debate. One of the main findings of the quantitative study was that suicide was more prevalent among Protestants than Catholics something he attributed to higher social control in Catholic societies and lower integration in Protestant ones (Durkheim, 1951). The main criticism, though not the only one, has been that the data itself derived from the coroners' willingness to categorise a death as suicide (or the pressure on the coroner from the family of the deceased). Critics argue therefore that the validity of the data can be questioned. Positivism sees the role of theory as being the generation of hypotheses which are verifiable through research (Bryman, 2008).

Sarantakos (2005) attributes the rise of positivism in the nineteenth century to changing economic and social conditions, principally industrialisation and urbanisation that brought with them social problems to which the authorities wanted to find solutions. Unable to find them in the metaphysical philosophical approach to knowledge of the Enlightenment the demand for quantifiable data that could be readily translated into policy rose rapidly. Over the next century and more, social research became entirely dominated by the empirical quantitative principles of positivism. Durkheim exhorted researchers to set aside their values and conduct their work entirely value-free. Antipositivist scholars argue that this is simply unrealistic because the researcher's values are inevitable a factor, right from the choice of research, to the drawing of conclusions (Bryman, 2008, p. 24).

\section{Interpretivism}

The hegemony of positivist social research lasted until the second half of the last century when it was challenged from a number of perspectives such as Marxism, feminism, ethnomethodology, phenomenology and symbolic interactionism which are normally grouped and labelled as anti-positivist or interpretevist. With this new pluralism of social research came the diversification of research methodologies with more qualitative research being undertaken (Bryman, 2008). Interpretivism holds that society cannot be observed objectively because it is always experienced subjectively, the methods associated with natural sciences cannot be applied to social research as different people perceive the social world in different ways. Furthermore, rather than seeking to explain human behaviour interpretivism seeks to understand it (Bryman, 2008). Max Weber, the German sociologist saw his discipline as "science which attempts the interpretive understanding 
of social action in order to arrive at a causal explanation of its course and effects" (Weber, 1947 p.88 cited in Bryman, 2008, p.15). In an interpretivist study, the researcher is attempting to understand the subjective meaning of social action; they are interpreting the interpretations of the subjects being studied (Bryman, 2008, p. 17). As Holloway and Jefferson (2000, p.3) state "If we wish to do justice to the complexity of our subjects an interpretive approach is unavoidable". The methodological consequence of this is that methods should be used which are able to capture the quality of people's perceptions, interpretations and definitions, which necessarily means qualitative ones.

\section{Qualitative Research}

Qualitative research is an umbrella term that subsumes a broad range of research methods united principally in the absence of a reliance on numerical data (Bryman, 2008). The qualitative researcher is attempting to see the world through the eyes of those being studied and to uncover the meanings they attach to the events, experiences and environment around them. To achieve this, a flexible approach is taken to research design without the rigid structure associated with quantitative research (Bryman, 2008). In the case of this study, this flexibility will enable the research to pursue themes of interest that arise during the course of the data collection. Indeed, as explained later in this chapter, it was important to show an example of this flexibility when adjusting the research design to accommodate unanticipated opportunities which arose mid-process. This led to a supportive quantitative study being added to the main qualitative study in circumstances described later in this chapter.

\section{Objectivity in qualitative studies}

The principle of objectivity in research requires a researcher to remove any traces of personal values and prejudices from every stage of the research process. Clearly such a principle cannot fit within the sphere of feminist research or indeed with any qualitative research. Opposition to objectivity comes from normativism which argues that not only is objectivity impossible to achieve, it is not even a desirable principle (Sarantakos, 2005, p.93). Social research is inevitably normative and the researcher unavoidably biased. However, disclosing bias or personal viewpoints has less potentially damaging consequences for research than presenting it as value neutral (Sarantakos, 2005). Not all feminist researchers see the problematic nature of objectivity as meaning that subjectivity 
should pervade all aspects of research. Safeguards against bias are still possible within a feminist context, for example in sample selection (Fonow and Cook, 1991, p.98). The safeguards applied in this study are detailed in the research design part of this chapter. It is considered important that the benefits of objectivity, foremost of which is its ability to change political opinion, should not be lost altogether (Fonow and Cook, 1991). Thus, this study rejects objectivity as an absolute concept, discloses subjectivity when appropriate yet adopts certain research practices that are designed to underpin the quality of the study including the analysis of data, reporting of the results and interpretation of findings.

The research paradigm adopted for this study is a qualitative interpretivist one. According to Sarantakos (2005, p.134) a qualitative approach is indicated if "There is a need to study reality from the inside, that is, to understand it from the point of view of the subject". In a study which has both a gender and religious context using positivist quantitative methods is considered to be highly problematic as are quantitative instruments such as questionnaire surveys. Part of the value of this study is its attempt to understand the perceptions and attitudes of Kuwaiti women towards their rights and their position in Kuwaiti society, and therefore it is important to take every opportunity to remove direct outside influences, such as the presence of a husband of male relative. Indirect influences like social, religious and patriarchal expectations are too embedded to hope to remove but their presence can be considered when analysing the results. At the same time in order to produce valid, reliable and generalisable findings the issue of researcher bias also needs to be consciously considered and countered in the research design. By adopting a qualitative approach using in-depth interviews the researcher is able to better interpret the data, i.e. the respondents' words, more holistically.

\section{Critique of Qualitative Research}

Bryman (2008, p.391) identifies four main sources of criticism of the qualitative approach to research. Firstly, it is seen as lacking objectivity and being too reliant on the subjective views of the researcher, views which may be affected by the personal relationship between the researcher and their subject. The second critical theme is that of irreplicability. In qualitative research the data collection is highly related to the person of the researcher themselves and their own decisions as to what is of importance; this makes it difficult for the study to be repeated by another researcher in a different setting 
or in the same setting at a different time. Similarly, the third critique concerns generalisability. Qualitative methods such as unstructured interviews, case studies and participant observation generate data that is very difficult to generalise to other settings. Finally, Bryman (2008, p. 392) highlights the lack of transparency inherent within qualitative methods as a source of criticism. In contrast to quantitative studies where the evidence is numerical it can be more difficult to understand what a researcher really did in the course of their study, for example how they arrived at their sample and how they reached their conclusions. Sarantakos $(2005$, p.46) adds that qualitative data is relatively expensive, time consuming and, due to the close contact between the researcher and respondents, can lead to ethical problems. Ethical considerations are explained later in this chapter.

The importance of epistemology and the research paradigm become increasingly clear when considering the particular characteristics and challenges of researching in Islamic context as discussed below.

\section{Social research and Islam}

Feminism is a particularly revolutionary concept in the Islamic gulf region but that is not to say it does not exist. Indeed, Islamic feminism as a theoretical perspective was discussed in the previous chapter. Siddiqui (2006) argues that while western feminists, deflected by concern at accusations of imperialism and crusadism, may have been reluctant to engage in the discourse on women and Islam a growing number of Muslim feminists are engaging by firstly seeking to protect women against practices such as forced marriages and genital mutilation then secondly to advocate women's empowerment. For Siddiqui (2006) this poses a particular challenge as it involves negotiating issues of freedom and autonomy with women who are struggling to reconcile their religion, their cultural traditions and their immediate familial contexts with a feminism motivated by a desire for self- autonomy.

Feminist scholars working in Muslim societies also reflect on the uneasy relationship between feminism and Islam. Sholkamy (2011) identifies two strategies adopted by feminists and these were also discussed in the previous chapter. Firstly, there are those that reject the largely secular principles of western feminism and argue that religion can 
provide a platform from which issues of justice and equality can be addressed and empowerment achieved. This is achieved through urging a reinterpretation of Islam away from its anti-female biases toward what they believe to be the natural justice and equality of the religion. Such feminists adopt the approach that "If people are driven by faith, then let us use faith to drive them towards social and political change" (Sholkamy, 2011a, p.47). Sholkamy (2011b) highlights a problem with this approach in that it perpetuates the notion that gender justice requires a religious justification which in turn adds legitimacy to religion-based justifications of policies and practices that are inherently patriarchal and discriminatory. As Sholkamy (2011b) explains "if feminists appeal to faith to justify their demands they may be faced with a different but equally authentic religious interpretation that rejects gender justice" (p.3). The alternative strategy is to pursue the aims of feminist research outside the context of religion without denying that they are Muslims or undermining anyone's faith. This approach characterises the discourse as one of justice and citizenship that transcends any particular religion. In this study, the researcher shares many characteristics with the participants (i.e. a woman, a Kuwaiti, urbanised and educated) and therefore had the benefit of empathy to negotiate the way along a sensitive and controversial research path.

This study, because of its area of investigation and its setting, raises a number of important methodological issues that merit further discussion, beyond the brief comments in the previous section. Hence the matter of research interviewing in 'exceptional' circumstances involving both researcher and subjects under sociopsychological stresses is considered now in the context of the current study.

\section{Researching sensitive issues with Muslim women subjects}

Researching sensitive issues in Muslim settings presents challenges to the researcher, a point made elsewhere in this thesis. However, there is a small but growing body of such research. For example, Reema et al. (2013) conducted an inquiry into domestic violence in Jordan in which they elicited the life narratives of 12 Jordanian women who had experienced such violence. Despite having to endure undoubtedly immense cultural pressure the participants were able to verbalise their experiences and even offer their own understanding of how cultural assumptions had affected their lives which supports this researcher's own belief that women in Islamic countries have an interesting story to tell and are more than capable of critiquing long-held and powerful cultural beliefs when 
doing so. Also, in a US study of Somali immigrants, Clarkson Freeman et. al. (2013) investigated Islam and health in order to understand the way religion and specifically the Qur'an influenced health beliefs and practices among this population. The researchers gathered data from 20 semi-structured hour long interviews and once again found that despite the sensitivity surrounding the subject matter and the specific questions few if any barriers to meaningful analysis arose. Widdicombe (2011) had both male and female subjects for her study of religion and the subject's interpretation of their own religious beliefs. There is no difference reported in the willingness or ability of Muslim women to answer the questions and men's; and indeed no difference between the Muslim part of the sample and the Christian one.

Also, in Iran, Mehdizadeh (2013) researched women's employment and its relationship to childcare. Again, interviews were used as part of a mixed methods approach with 14 mothers and 15 people in leadership (including some men). The researcher was able to collect the data and draw substantive conclusions regarding the women's role in the employment market and their role as mothers.

These recent examples of academic research involving Muslim women have been described with a view to demonstrating that there is an established (although perhaps a somewhat recent) tradition of research involving Muslim female respondents answering questions and offering narratives on sensitive and culturally bound topics. The current research is very much in this tradition.

Having considered some of the dimensions of this research which influence the research process and the actions taken as a researcher, the chapter now moves on to describe what research methods took place and why.

\section{The research design}

\section{Adjusting the design}

As already noted, in the course of the research there was an important adjustment made to the research design. The original intention was to conduct a small scale survey to pilot potential questions for the main qualitative in-depth interview study and possibly as a secondary benefit use the survey to make initial contact with women who may be willing 
to be interviewed. This original intention seemed less appropriate when increasingly large numbers of women responded to the questionnaire a number which ultimately reached n437, far beyond any expectation. The survey thus became an effective way to garner descriptive data, when actually it was originally intended as a pilot which would inform the topics that would be considered in later in-depth interviews and on that note, it also represented a powerful tool of access through which the women who took part in the survey could be invited to go on and take part in in-depth interviews. Utilising the survey in this way resulted in the survey respondents forming a self-selecting sample - a sample that came from a specific cohort who were urbanised and educated women attending educational institutions or women's gatherings known as diwaniya. These diwaniya are discussed later in the chapter. There was no filter to prevent women from responding to the questionnaire or indeed participating in the interview study who did not fit the description of educated and urbanised as described in the first chapter. However, the precise research methods used (points of distribution of the survey questionnaire, ability to attend an interview outside their home etc.) would, arguably, have led to a mainly urbanised educated sample.

\section{Research Objectives}

The research needed to be designed in the manner most likely to satisfactorily address the overarching research topic areas which (were set out at the end of chapter 1) and are as follows:

- The development of social policy pertaining to women's rights in Kuwait

- The potential for social policy in Kuwait to be contradictory in its nature

- The future development of social policy in Kuwait and the future empowerment of Kuwaiti women.

\section{The quantitative study}

The quantitative research tool was a self-completion questionnaire (sometimes referred to as a self-administered questionnaire). In essence this means that the respondents answer the questions by themselves without assistance from the researcher or other 
respondents (Bryman, 2008). This type of data collection instrument is a quick and low cost method of collecting quantitative data and is also free from 'interviewer effects' including 'social desirability bias' under which respondents may under report views that are controversial or are perceived as being potentially unacceptable to the interviewer (Bryman, 2008). Furthermore, with a self-completion questionnaire the possibility of interviewer variability such as asking questions differently or in different order is removed (Bryman. 2008). Finally, one of the reasons for the high numbers of respondents and the high response rate achieved in this study was undoubtedly the convenience of the survey and the greater assurance of anonymity of this method compared, for example, to interviews (Sarantakos, 2005). This later point is particularly important where sensitive topics are being researched.

Against these advantages the self-completion survey has a number of limitations. The researcher cannot prompt or probe for deeper information so the data collected is limited to the specific questions asked (Bryman, 2008). The researcher is also unable to provide clarification of questions (Sarantakos, 2005). The items on the questionnaire can be read as a whole which can give rise to 'question order effects', in a structured interview they are asked one by one. Additionally, the researcher has no control over missing data, i.e. skipped questions (Bryman, 2008).

However, the survey employed in this research fulfilled a significant set of functions. It was used to ascertain women's willingness to participate in research of this nature as well as a tool of engagement with women. Additionally, it was intended that the survey would provide some basic descriptive data and that after analysing these data the interview specific questions could be set in light of the findings which really brought in women's voices from the survey - this was important because of the exploratory nature of the study and also it helped to keep the research as unbiased as possible.

The survey first collected demographic data including age group, marital status, employment status, education and whether women voted at the most recent election. Following these demographic items. the rest of the items were in the form of statements to which respondents indicated their agreement or disagreement on a five-point Likert scale (Strongly agree: 5; Agree: 4; Not sure: 3; Disagree: 2; Strongly disagree: 1). In order to establish whether a general sense of a desire for equality existed among Kuwaiti women there were statements enquiring about attitudes to general principles of equality. 
For example, item 6: 'Women should have equal rights under the law.' To understand women's views of their role in the public sphere in politics, employment and in the judiciary there were statements such as Q 10 "Women should be allowed to become judges.' Furthermore, other items sought views on specific policy areas as discussed in chapters one and two: Q14 'Women should have the same right to public housing funds as men.' There were also items aimed at exploring sharia-based practices and policies: Q17 'Women should obey their husband and male relatives.' There were items related to economic empowerment: Q27 'Women should have just as much chance to build a successful career as men.' Additionally, there were items requiring reflection on the recent past and anticipating the future: Q24 'Women's position in Kuwaiti society has improved in the last ten years' and Q29 'In ten years' time there will be more women MPs and more equality for women.' Some questions were paired with questions which tested the consistency of responses, these question were not asked consecutively. An example of a pair was, Q10. 'Women should be allowed to become judges' and Q18 'Only men should work as judges'. Questionnaire findings which highlighted specific areas of agreement and disagreement in women's perceptions could then be explored through questions at the in-depth interviews.

The questionnaire was distributed at female only cafeterias at three Kuwait University campuses (Kaifan and Shuwaikh and Khaldia). Over a period of 5 days I located myself in these cafeteria and asked visitors to participate as they walked past me. In addition, I attended seven women only gatherings at various locations. These gathering are known as diwaniya. While the cafeteria at university campuses may be somewhat similar to those in other countries, it is worth considering the nature of diwaniya and their role in Kuwaiti society a little further at this point as they have a particularly unique role in Kuwaiti society.

\section{Diwaniya}

Diwaniya are social gatherings that have long been an important characteristic of Kuwaiti culture. We can translate the term Diwaniya as 'open house' and one of its key tenets is that in principle it is open to all. It was this principle that enabled the researcher to attend seven of these meetings without difficulty or prior arrangement. As with all aspects of social life in Kuwait, gender plays a vital role. Traditionally, these gatherings have been a male event. Toumi (2010, para. 2) characterises them as: 
A men's realm with those present sitting around on soft benches or cushions, conversing casually, smoking, nibbling light food and drinking tea or coffee. Relatives and friends come and go throughout the evening while the host offers hospitality to all his guests and entertains them.

However, women have increasingly held their own version of these gatherings and there have even been attempts to hold diwaniya with men and women together to discuss women's rights and related issues (Toumi, 2010). These have met strong resistance from the local community who view it as an affront to local traditions. Women have also expressed discomfort at the thought of discussing things of importance to them in the presence of men (Toumi, 2010).

Al-Jassar (2009) studied diwaniya as part of the built environment - the study related the growing importance of the diwaniya to the social status of the household, particularly the male head. Al-Nakib (2014) provides a historic account of diwaniya and other public and semi-private places in the context of protest in Kuwait. While there is little reference to women's use of these gatherings al-Nakib (2014, p.730) provides insight into diwaniya "a forum for political expression and public debate". For example, when the Assembly was prorogued through dissolution in the late 1980s the ousted lawmakers would take turns in holding diwaniya to discuss and plan for the reinstatement of the Assembly al-Nakib (2014).

In a study which did focus on women's diwaniya Stephenson (2011) explains that men have come to own the very term diwaniya with women seeming reluctant to apply it to their own gatherings. They are even referred to as a man's second wife in the same way that in the UK there are 'golf widows'. Having said that, she also casts light on the role of diwaniya as sanctuaries of free speech for both genders citing one women who had told her, "The d w niyya is a free place. We can say anything we want in the $\mathrm{d} w$ niyya. They might take away free speech in the media or on the streets, but not the d w niyya" (Anonymous cited in Stephenson 2011, p. 189). Stephenson (2011) concludes that following women's political enfranchisement the importance of diwaniya to women's is developing: "Women's interaction with and conception of the diwaniya as both a space and institution are transforming and, with that, new ideas about how 
women can spend their time are emerging." (p.198). She continues, arguing that "the d w niyya is a vital microcosm, and medium for the new changes." (p.199).

So, in summary and returning to the current study, women's organising and attending of their own diwaniya, is in some ways an act of defiance in itself. They are more likely to be attended by urbanised educated women with an interest in women's issues. It is for this reason that the researcher attended, briefly introduced herself, and then distributed the survey questionnaire at the end of the gathering and received completed questionnaires from those who had decided to fill them in. The women attending these meetings were essentially from the same cohort of urbanised educated women as those attending the university campuses although the average age was somewhat higher.

\section{Survey data analysis}

Statistical analysis was conducted on the survey data. First the results from individual questionnaires were aggregated into a spreadsheet using Microsoft Excel and then this file was imported into the SPSS program for analysis. Descriptive statistics were generated and these are presented in chapter five. Where appropriate to do so, the findings are also referred to in later chapters in order to strengthen analysis, to compare findings and to provide context.

From the 437 completed questionnaires only 20 women ultimately took part in in-depth interviews, although it had always been anticipated that far more women would be willing to participate in an arm's length anonymous survey than in face-to-face interviews. The results of the quantitative analysis are presented in chapter five.

\section{The qualitative study}

Achieving an in-depth understanding of women's perceptions and interpretations of their role in Kuwaiti society, their attitudes to specific policies and their aspirations for the future was always going to require the collection of qualitative data but a choice had to be made as to precisely how this data would be collected. Focus groups were considered potentially suitable for this study and they are widely used in feminist research. They would have offered the opportunity for the subjects to voice their meanings collectively in a non-hierarchical environment which the interviewer facilitates but does not control 
(Creswell, 2012). However, on reflection, this instrument was rejected primarily due to concerns that being in a group may lead some participants to conceal their opinions or follow more dominant participants. In addition to this, practical considerations such as co-ordinating attendance, finding a suitable location and ensuring that the data is properly recorded were seen as potential problems.

Research interviews are often put into three categories; structured, semi-structured and unstructured. It is actually more accurate to describe it as a spectrum or continuum with formal at the one end and informal at the other (Hesse-Biber and Leavy, 2007, p.115). The further towards informality the lesser the degree of control the researcher has over the course the interview takes while the further towards formality the less the subject has opportunity to expand upon their answers or deviate into other potentially interesting areas. Both semi-structured and unstructured interviews have become popular ways of gathering data within the context of feminist research (Bryman, 2008). The interviewer needs to project sufficient knowledge of the topic and professional maturity to gain respect and trust but without giving the subject a feeling of inferiority. Indeed. a qualitative/feminist interview needs to be respondent-centred and non-controlling (Bryman, 2008, p.271).

In a qualitative feminist study such as this one the interview questions are mainly openended, meaning they cannot be answered with simple yes/no responses. This is done to encourage more in-depth responses and give the respondent the opportunity to answer in their own way free of control. The order in which questions are asked is not important though they should be logical in order to resemble a conversation. An outline interview schedule was prepared and this functioned more as a checklist to ensure that the desired topics were covered at each interview.

In-depth interviewing is a well-established technique for collecting qualitative data. For some this method has become paradigmatic with feminist research (Kelly et al., 1994, p. 34 cited in Bryman, 2008 p. 463). The interview can be classed as in depth if it is intensive, extensive and largely unstructured. For practical reasons the technique is normally associated with small samples. Such interviews are an appropriate alternative to focus groups when the researcher is concerned that being in a group may alter the behaviour of the subjects. The main advantage of this technique is that it enables very detailed data to be collected in the case of this study that means a detailed understanding 
of the perceptions Kuwaiti women have of the contradictions inherent in the development of women's rights and social policies in Kuwait. There is a far greater likelihood of creating a relaxed atmosphere in an in depth interview than would be the case with a shorter more structured interview where the researcher exercises a greater level of control. Having said this, it is equally important to recognise the potential disadvantages of this method of data collection. This technique is time intensive; the interview, the transcription and the translation combine to mean each interview involves a significant time commitment and this needs to be built into the time plan. As with any interview with a low degree of structure, there is a potential risk that the data collected will not address the research question(s) and a high degree of interviewer skill is therefore required to combine loose control with the collection of appropriate data (Sarantakos, 2005). Furthermore, in-depth interviewing is not appropriate for researchers seeking to generalise their findings.

Within the scope of in-depth interviewing there are still options that need to be considered regarding the precise nature of the interview that principally revolves around the degree of standardisation the researcher wishes to achieve across each interview. In this study, a guided interview approach was selected which offered a medium level of standardisation in that a checklist of items that need covering to address the research question was devised in advance but this still allowed for a high degree of flexibility for both the interviewer and the subject.

\section{Sampling for the qualitative study}

Having established the research paradigm as dictating an interpretivist/feminist qualitative study, chosen the in-depth interview as the instrument, then next step was to consider sampling. The nature of the research design suggests strongly that the importance of generalisability in this study is low and this is reflected in the sampling technique.

The sample for the qualitative study was selected once the collection of data through the survey questionnaire was complete. This was because the survey included an item where the respondents were asked to indicate whether they would be willing to participate in an interview. 
There are three main strategies used in qualitative research where representativeness is not sought: convenience sampling, judgement sampling and theoretical sampling. Convenience sampling lacks rigour but is the easiest as it involves using subjects who are the most accessible such as personal friends or work colleagues. Judgement sampling (also known as purposive) involves the researcher using their knowledge of the topic to select subjects most likely to help address the research question, for example those known to be knowledgeable of the topic or have a reason to have formed a personal view. Theoretical sampling is associated with grounded theory (Glaser and Strauss, 1967) and involves the researcher in a recurrent process of sampling as each subject may contribute to redefining the next step on the path to demonstrating a particular theory. In practice there is frequently an overlap between these three types of sampling strategy.

In this study, to reduce risk, educated urbanised Kuwaiti women were purposively targeted for participation as the researcher strongly believed that they would be much less likely to suffer negative consequences from participation than those women from more traditional, tribal family backgrounds where participation in research such as this would be frowned upon. The sample was self-selecting, all women who completed the survey questionnaire were invited to indicate their willingness to be interviewed and so each had an equal chance of participating. This was complemented by judgement sampling to offer the perspectives of women in positions of leadership and five such women were selected, each of whom took part in an in-depth interview. In total therefore, there were 20 interviews with the urbanised educated women cohort.

\section{Women in leadership interviews}

Five interviews were conducted with participants selected on the basis of their demonstrable knowledge of the topic, seen in their writings or their membership of a particular organisation. At the outset of the study it was felt that NGOs would be the most likely source of women in leadership. However, despite efforts to engage with women in senior positions at NGOs the researcher met with significant resistance to any form of participation in the study (as can happen with this kind of exploratory research when in the field, those routes anticipated to be the most favourable, in this case women's NGOs, proved unfruitful). 
Ultimately, however, five women at the time of the interviews were in key leadership positions in Kuwait holding a range of senior roles: government minister, lawmaker, lawyer, senior media figure, parliamentary consultant. Although each of these women did give their consent to publishing their names, in order to stay within the principles of ethical social research their participation and the reporting thereof has been completed on an anonymous basis. The themes discussed at the interviews were the same as the other 20 interviews, though the wording of the questions were altered to avoid asking things that were self-evident from the work of the particular participant: for example, asking an MP if women should participate in elections would have been naïve. However, it was important to hear how these empowered and well informed women perceived the developments that had been taking place in Kuwait and how they felt women's role would change in the future. It is important to note that the five women were selected from both the public and private sectors and with known liberal and Islamic feminist leanings. This was in the hope that they could add a deeper analysis to the question of women's participation in elections and provide some insight into why some women do not, or why they vote for men, or what women's participation may lead to in the future and make these comments from a highly informed position.

The sampling chosen for the women in leadership study can be described as a judgement based strategy applied to a small sample. It is judgement based in the sense that they were deliberately selected in order to best address the research questions. To make the best use of the researcher's time in setting, the process of sample selection for the women in leadership interviews began by means of email/ online contact with potential participants in order to filter the potential respondents. The aims of the study were described to potential respondents in addition to the data collection process and the nature of the filtering process. In response to initial indications of willingness to participate a more detailed explanation of the study and the data collection method was sent along with the filter questions; at this point it is important that the time commitment is set out clearly. Once the sample was identified a further communication was sent outlining interview timings and giving a full description of confidentiality assurances.

\section{Setting based considerations}

Earlier chapters in this thesis have already established the three main perspectives on women's rights in Kuwait: the liberal modernisers, the Islamic traditionalist and the 
tribalist conservatives. Aiming to balance these first two and maintain social stability and the position of the ruling elite is the pragmatic approach of the government. No further study is required to prove the existence of these three main perspectives. It is also established that women living in traditionalist households are still restricted in their own movement without the presence of their husband or male relative. Such women would be largely inaccessible, may be reluctant to participate in the kind of discussions needed to provide valuable data (or be prevented from doing so) and if they did participate their responses may not reflect their own opinions. This latter issue is heightened by the reality that they would be discussing issues with a researcher who dresses in 'western' clothes and from her appearance alone this would suggest that she held liberal views. Western dress is perceived as an indication holding 'western' views in the same way that wearing tradition Islamic clothes is interpreted as an indication of 'traditional' views. The researcher considered adjusting her dress but this was highly problematic, involving as it would trying to adjust clothing to the possible expectations of someone who had yet to be met and with only had a set of questionnaire responses to evaluate this could easily have led to misjudgements. A decision was taken to be consistent and wear business dress for each interview.

\section{Video recording in social research}

The presence of video in our lives has grown dramatically since the early years of the technology. Video has become an increasing feature of social research, something also driven by the substantial drop in the cost of video recording equipment (Jewitt, 2012).

Jewitt (2012) identifies participatory video, videography, the use of existing videos, video elicitation and video-based fieldwork. Video recording has been used to collect primary data in observation studies at a range of settings including in the home, at the workplace and in the classroom (Goldman et al., 2009; Heath, Luff, Hindmarsh, 2010; Norris, 2004; Goodwin, 2000). In addition, videos have been used as secondary data, repurposed and analysed as documentary evidence (Adami, 2010; Chouliaraki, 2006).

As with all methodological choices there are advantages and disadvantages in opting to video record interviews instead of only audio recording. Video-recordings have the advantage of capturing facial expressions and body language for subsequent interpretation which was believed to be useful in this study. Where a video camera is 
used to record the visual aspects of the interview, informants are able to use the visual to communicate their meanings during the interviews and for the research it provides an audio visual record of the interview for subsequent analysis. As Jupp (2006) explains, "Videotaped interviews offer the powerful advantage of capturing body language, proxemics, kinesics, and other temporal-spatial dimensions of human behaviour and social meaning" (p. 319). It is well known that in Arab culture and communication the use of gestures is very prominent and knowing this, it was thought to be very important to capture this non-verbal data.

On the other hand, a series of potential pitfalls were also considered. It was possible that women would be less likely to agree to participate, or indeed less willing to reveal their feelings if they did participate. Or, there might be a tendency to save their most sensitive comments until the camera was switched off. The presence of a video camera is believed to alter the behaviour and responses of participants, at least temporarily. This has been shown not just in a social research context but elsewhere such as in counselling interviews (Gossman and Miller, 2012) and police interviews (Kassin et al., 2014). Even when the interviews are completed there is another challenge to consider and that is the difficulty involved in coding and analysing the visual data as the procedures for doing so have yet to be thoroughly established.

This study aimed to conduct research into sensitive issues which could cause defensive reactions in some of the participants, and thus it was thought necessary to collect data above and beyond the bare spoken, then transcribed words of the Kuwaiti women interviewed. Understanding which issues caused which particular reactions was valuable data collection in itself and as an urbanised Kuwaiti woman the researcher was well equipped to decode.

Ultimately, the importance of being able to record the visual side of the communication taking place during the interviews, combined with the knowledge that the women interviewed would be educated and potentially less vulnerable to the hesitancy toward the 'third person in the room' led to a decision to use video recording.

Having a video recording of the interview meant that as well as transcribing the spoken words, the researcher was able to record observations on body language and gestures as 
well without having to rely on notes taken during the interviews themselves. Transcription is considered next.

\section{Transcription}

The interviews were recorded using a digital video camera enabling the recordings to be played back on a computer. That the interviews are recorded was made clear on the informed consent statement. The collected data was transcribed using the denaturalised approach. While seeking an accurate representation of the interview, this approach does not include the pauses, incomprehensible speech and response/non-response tokens (e.g., yeah, um, huh, or their Arabic equivalents) as would be the case in the 'natural' approach. All of the interviews were transcribed by the researcher. As is common with interview data some interviews or parts of them failed to produce any interesting or relevant data that either address the research questions or raise promising new themes (Bryman, 2008 p.455).

Both audio- and video-recordings are an important source of data in qualitative research today relegating the use of field notes to an inferior status. However, researchers need to step back and ask themselves the question that Hammersley (2010) poses - when we set about transcribing the audio or video recorded material, are we reproducing or constructing the data?

Part of the attraction of electronically recorded research evidence was the fact that it was seen as offering a fuller and truer representation of what was happening or being said (Hammersley, 2010). Nevertheless, the process of transcribing involves mediating the data involving a degree of inference, meaning that while audio or video recording may superficially appear to be a pure reproduction of the data, the research process which involves transcription means that the data is being constructed. Arguably, as in the case of the current research the subsequent translation and analysis steps are also points at which construction is taking place.

Hammersley (2010) presents a series of decisions that a researcher must make when developing their approach to transcription. There are set out along with the relevant decisions made during the research process that took place. The first decision is whether to transcribe at all and then how much should be transcribed. In this study it was decided 
to transcribe the interviews in their entirety to facilitate fuller analysis. Secondly, it needs to be decided whether it is words that need to be captured or other dimensions of the data which include pitch, intonation, amplitude, and pace of speech and in the case of video recording as used in this study, body language. It was decided that the transcription of the video recordings made for this study would include noticeable body language and the dispositions of participants. Rather than recording and evaluating each and every such occurrence an overall impression would be presented within the findings. In a multi-party recording such as a focus group it may be necessary to choose to monitor direction of gaze but in this study it can be assumed that gaze was researcher to interviewee and interviewee to researcher, although avoidance of eye contact is a possibility. A further decision relates to whether 'back-channel' noises should be transcribed. These include utterances such as 'Uhuh', laughter, intakes and outtakes of breath and other sounds which may be significant in some way (Hammersley, 2010). There are also silences and pauses which can be particularly revealing. For this study it was decided to transcribe any such items which were considered to have significance as judged by their length and timing.

\section{Body language}

The video recording of interviews brings the question of body language or non-verbal communication into play. According to Mariampolski (2001), the ability to understand body language is a required tool for interpreting the respondents' feelings and attitudes. Body language, according to Wade (2013) is gendered. The construction of femininity includes the use of body language which is submissive and compact rather than the expansive posturing that is associated with masculinity. Bartky (1988) sums this up when stating that "Woman's body language speaks eloquently, though silently, of her subordinate status in the hierarchy of gender" (p.74). Wade's work is of a western context; however, in the current study the gendered nature of the body language used in the interviews will also be discussed. Of particular interest is whether the body language of the participants can be seen as gendered in an interview between a female researcher and female subject or whether they result from perceived power differentials whereby the researcher is perceived to be in a position of power over the participant (which as discussed later in this chapter the researcher sought to diminish), or whether they could be accounted for by "the third person in the room", the video camera. 
Agliati et al. (2006) undertook an observational study to investigate the relationship between non-verbal communication and culture using Italian and Icelandic subjects. The study was based on the premise that human behaviour is determined by a complex set of factors many of which are cultural, "culture provides an overall template for behaviour in general, since it has been established that not only language, but also gestures and nonverbal communication systems in general are learned and developed through the socialization process." (p. 364). Of course this is not to discount the gendered nature of non-verbal communication as gender intersects with and forms a significant part of the all-embracing term 'culture'. Furthermore, there are individualistic elements determining behaviour which we can refer to as 'personality' (Cesario and Higgins, 2008). Finally, there is the question of adaption by which is meant how we adapt our behaviour and communication based on the situation, "people display a consistent tendency to adapt their behaviour to their interlocutor and to the interactive situation" Agliati et al. (2006, p. 364). During the interviews the researcher was conscious of this potential for adaptation, for example it was felt that those women wearing traditional Islamic dress may adapt their language and opinions when facing a researcher wearing what they would consider to be 'western' dress. The video recording of the interviews enabled the researcher to consider in detail whether adaptation was occurring, something which would have been for more problematic with an audio recording. The issue of dress is now considered.

\section{Dress and the researcher-participant relationship}

The participants in this study were all Kuwaiti females aged between 18 and 65 and they possessed a higher than average level of education. Of the 20 interview participants, 3 wore the most traditional/modest dress comprising a black abaya at interview, 9 wore a bijab with dresses of different colours, while the other 8 wore non-Islamic clothing ranging from smart casual clothes to business dress. As noted, the researcher was wearing business dress. Broadly speaking in Kuwait, clothing is a reflection of a family's religious and cultural attitudes. The steps taken to reduce the risks to participants are discussed in the ethics section later in this chapter. If this is added to the 'third person in the room' dimension of the video recording which as discussed also influences human behaviour then a highly complex, almost kaleidoscopic set of influences existed that potentially affected the participants in this study, all of which were considered when analysing the data and drawing out findings. 


\section{Translation}

This study is being reported in English but the data collected is in Arabic, this presents another challenge though not as major as would be the case if the researcher and respondents did not share a common mother tongue. Sutrisno et. al. (2014) emphasise the importance of explaining the translation process and being mindful of the potential for translation to negatively affect the validity and reliability of the data. Nevertheless, understanding and reporting the respondent's perceptions and opinions is at the heart of qualitative research so both time and care had to be taken in translating the transcription. Responses including colloquialisms and idiomatic speech that may not translate accurately were omitted.

Translation has become a common feature of research as more and more researchers are conducting their work at institutions in countries with languages other their own native tongue. It is not uncommon for these researchers to conduct their fieldwork in their own country and in their own language and then complete their research in another country and another language, in the course of reading for this research, many examples of studies undertaken by Arab students and researchers in their home countries were identified, but while attending a university elsewhere, often the UK and the USA. This was the case for the current study; the researcher is based in the UK but comes from Kuwait and has Arabic as a mother tongue and English as a second language. The quantitative data from the survey questionnaire was collected using questionnaire items that had been devised and refined in English and then translated into Arabic for the actual questionnaire that was handed to respondents. As the data collected was numeric the question of translation did not arise at the analysis stage. However, the verbal qualitative data from the video-recorded interviews was in the form of Arabic words. These words were then transcribed and translated into English.

\section{Qualitative data analysis}


Qualitative analysis involves dealing with words rather than numbers. Despite the absence of standardisation and the statistical techniques associated with quantitative analysis, interpretation of data still needs to be conducted in a scholarly and rigorous fashion (Sarantakos 2005, p. 344). Having said this there is no consensus on a definitive approach to quantitative data analysis with the literature suggesting perhaps 20 or 30 different strategies (Sarantakos, 2005). Broadly, analysis can be assigned to one of two groups: grounded theory and analytic induction (Bryman, 2008 p. 539). Grounded theory is a strategy for generating theory from data rather than using data to prove or disprove a hypothesis which occurs in traditional research. Described briefly, there are four stages in the analysis: qualitative data is first coded to identify key points, concepts are then formed from the key points and these concepts are then grouped into categories. From these broad groups of similar concepts theory is generated aimed at addressing the research questions. Under analytic induction researchers take four steps: 1) phenomena are defined in an outline manner, 2) a hypothesis is developed about it, 3) a single initial instance is considered to determine if the hypothesis is confirmed, 4) if the hypothesis fails to be confirmed either the phenomenon is redefined or the hypothesis is changed so as to include the instance examined, 5) additional cases are examined and, if the new hypothesis is repeatedly confirmed, some degree of certainty about the hypothesis results, and 6) each negative case requires that the hypothesis be reformulated until there are no exceptions, in other words until no data is found that contradicts the hypothesis (Bryman, 2008).

While Grounded Theory and analytic induction are the two main groups of data analysis strategies with the longest heritages, other approaches and variations are widely used. One of these is thematic analysis and it is this approach that has been chosen for the present study; it bears some of the characteristics of grounded theory. Put at its most simple the researcher looks for themes in the data similar to coding. To give structure to the data analysis a matrix can be used to order and synthesise the data creating an index of main themes and subthemes (Bryman, 2008). The researcher decides what the main themes are after listening to the interview recordings or reading the transcripts and these themes should address the research questions. Taylor and Bogdan, (1989, p. 131) have defined themes as units generated from patterns including "conversation topics, vocabulary, recurring activities, meanings, feelings, or folk sayings and proverbs." Certainly, there is a sense of inevitability about some of the themes that emerged from 
the research given the prominence of the issues raised in the literature review chapters informing the topics of enquiry, the findings from the quantitative survey and that this steered the overall direction of the interview. The result was document that resembled a spreadsheet consisting of rows for each interview and a column for each of the themes. The cells contained interview fragments pertinent to the theme.

There have been a number of criticisms of thematic analysis. Firstly, by extracting fragments from the transcript the researcher may be taking it from its context, a context which may well have a significant influence on its true meaning (Bryman, 2008, p. 552). In this sense there is a danger of seeking to take qualitative data and give it a quantitative appearance which could undermine the research paradigm (Holloway and Jefferson, 2000 cited in Marks and Yardley 2004, p. 66). The goal of researchers using thematic analysis should be to introduce a systematic process of data analysis without losing the complexity of the data (Marks and Yardley, 2004).

A researcher handling a large body of quantitative data has the option to use computerassisted qualitative data analysis (CAQDAS), for many this has specifically meant the programme NVivo which is now widely used in social research. CAQDAS has several advantages. These include the computerisation of otherwise time-consuming manual tasks: coding, retrieving fragments, copying transcripts, assembling similarly coded fragments etc. (Bryman, 2008, p.565). In addition to being quicker and more efficient, using CAQDAS makes the process of coding and identifying themes more transparent and lessens the tendency towards anecdotalism - where quotes can be taken as fragments from transcripts without sufficient regard to how prevalent the attitudes or perceptions they contain are in the overall body of data (Bryman, 2008).

There are, however, disadvantages arising from the use of CAQDAS. At the highest level, it may be said to undermine the very principles of qualitative research with its interpretivist paradigm as it seeks to mimic quantitative research. There may also be a loss of narrative flow as data treated more like numbers (Bryman, 2008, p.567). The researcher felt that placing too much emphasis on quantifying qualitative data may be less appropriate where the data had been translated. The number of times a particular word or term appears could simply reflect the translators preferred lexicon rather than being a reflection of the prevalence of the attitude or meaning represented. It is also difficult for NVIVO to capture customary gestures/body language etc., and the fact that the data 
came from videos was also a reason that CAQDAS was unsuitable for coding and analysis.

Following a test on a part of the data it was found that using the tools available in Microsoft Word would enable a satisfactory level of transparency to be introduced to the data analysis stage so it was this path that was taken.

\section{Ethical Considerations}

Ethics are an important aspect of social research as demonstrated over the last few decades by the priority given to them by academic institutions and professional associations. There is a distinct feminist approach to research ethics based in its rejection of male-biased traditional Western ethics that had hitherto dominated research. The approach can be characterised as interdependence not autonomy, community not independence, body not mind, emotion not reason (Thomas, 2007). Relationship, empathy and particularity are seen as more important than universal rules and principles and impartiality (Thomas, 2007). Whether adopting a feminist research approach or not, ethical issues appear at a number of stages during social research and must receive due consideration as they are directly related to the integrity of any study (Bryman, 2008).

In qualitative research, the researcher must consider how the participants are treated by the researcher. This includes asking some very important questions: Have the participants given the appropriate informed consent? What are the potential risks for the participant who takes part in the research? Can any harm result to the participants? Is there any invasion of privacy? And finally, is there any deception involved (Bryman, 2008).

In certain circumstances, participation in a study on Kuwaiti women's perceptions of their rights could be resisted and opposed by husbands and male relatives of the potential respondents. That this opposition could be expressed by emotional, sexual and physical violence could not be definitively ruled out. Steps had to be taken to ensure that in the first instance risks to the participants were minimised and secondly to ensure a framework of support was in place should any participant need additional support. Firstly, in framing the population for the study the inclusion of women from a strictly tribalist/ traditionalist Islamist background was ruled out as unviable. Nevertheless, even 
for those women who did take part, the risk of distress or even intimidation was taken very seriously. As a support mechanism for women who might become distressed at the sensitivity of the research, or who may fear family reprisals an agreement was made with a female lawyer to offer support and advice to participants faced with an issue of a potentially legal nature. For less serious issues, participants were provided with the details of a female counsellor known to the researcher for non-legal support and advice.

Secondly, the rigorous application of informed consent was paramount. The consent statement properly identified the researcher and the institution which granted the ethical approval. The respondent was advised how they were selected together with the anticipated size of the study. The exact purpose and nature of the study were explained together with the level of commitment in terms of time and the location of the interview. The potential benefits that might arise from taking part in it were also explained. Anonymity and confidentiality regarding the data were emphasised. Respondents were advised that they could withdraw from the study at any time and finally the details of the person to contact in the event of a complaint also appeared on the statement (Sarantakos 2005, p. 20; Bryman, 2008 p. 123). Specifically, signed informed consent was received from each respondent.

Throughout the whole research process, the researcher took all appropriate steps to protect the anonymity of the participants and the privacy and confidentiality of the participants was also protected (Sarantakos 2005, p.21). Anonymity was achieved through the use of pseudonyms on transcriptions and by ensuring that informed consent forms that carried the real names of respondents were kept separately from the research instruments so that no link could be made between them. Confidentiality was ensured partly through data security measures and partly by restricting who received the data during the transcription and translation process (with the researcher completing the transcription and translation herself thus restricting the possibility of data loss or misuse). As for privacy, this was maintained by the researcher avoiding lines of questioning that may be sensitive or personal which may have made the respondent feel awkward. And, even though certain lines of questioning were avoided it was still made clear at the start and throughout the interview at regular intervals that participants could refrain from commenting on any question without feeling that they had to provide any reason. 
The interviews were also conducted in a place that provided a suitable degree of privacy so that the discussion could not be overheard and in this way the respondents were made to feel less nervous, cautious or worried. The main interview venue, a private house, was well known as being a women-centred place where women gathered and was perceived to be a safe place where women came together to discuss issues of the day.

While little could be done about differentials in clothing and the inevitable assumptions that would be made based on them (there were no entirely neutral clothing options that could be conceived) every possible step was taken in terms of what was said, how the researcher positioned herself during the interviews and the researcher's own body language, to reduce any researcher-participant power differentials that may have been perceived by the participant.

As alluded to already, this research was always anticipated to be sensitive, even controversial. There is considerable self-censorship when it comes to the discussion of women's empowerment, particularly among women from more traditional tribal backgrounds. Feminist research aims to overcome this very kind of potential limitation.

The survey which was originally intended to act as a pilot for the kind of questions that would feature in the one-to-one interviews turned out to be far more important than anticipated. The number of completed questionnaires ( $\mathrm{n} 437$ ) exceeded all expectations and gathered a large amount of descriptive data, but more than this it also provided a means to engage women in the study anonymously with the option to decline to take part in the in-depth interviews and this option is very important in a study that seeks to give space to women's voices but also takes the risks of its participants very seriously.

The in-depth interview, the instrument chosen for the main part of this study, is one of the most commonly used in feminist research (Sarantakos 2005, p.61). Hesse-Biber and Leavy (2007, p.113) describes the task of a feminist interviewer as being "getting at the subjugated knowledge of the diversity of women's realities that often lie hidden and unarticulated." This is achieved by adopting a reflexive mutual approach during the interview in order to remove the hierarchical power relations which, many feminists believe, is characteristic of traditional research interviewing. Reflexivity is an important concept in feminist research; it describes the process by which the researcher gains an understanding of what biases they may bring to the research and other "situational 
dynamics" that can affect the interview data) (Hesse-Biber and Leavy (2007, p.130). This involves the researcher in recognising their own values, experiences, interests, beliefs, political commitments and wider aims in life and how this may contaminate the data. One dilemma that is not easy to resolve is the question of how a feminist researcher should respond when their own perspectives and interpretations of women's accounts are not shared by the respondents in a study. For example, if the researcher interprets a participant's life experiences in gender terms while the participant expresses them in religious or class terms. Bryman (2008, p. 465) states that this "Raises moral questions about the appropriateness of imposing an interpretation that is not shared by the research participants themselves." In this study, opinions were encountered which the researcher did not agree with, perceptions were heard which the researcher felt were illconceived and attitudes offered which contrasted greatly with those of the researcher. Likewise, the researcher heard from women whose world view seemed to replicate her own completely. The researcher applied her own reflexivity to minimise the potential for bias and selectivity whilst acknowledging that subjectivity could not be removed altogether. Once again the video recording of the interviews enabled more detailed selfmonitoring than would have been the case with audio recording.

\section{Ethical approval}

Ethical Approval for the study was granted by Centre for Criminal Justice and Criminology Ethics Board, Swansea University on 30 ${ }^{\text {th }}$ March 2012.

\section{Chapter summary}

This chapter has set out the epistemology and research paradigm underpinning this study. It explained the specific challenges conducting of feminist research in an Islamic country and provided examples of recent studies of in Islamic settings covering sensitive topics which involved an all or partial female sample in order to demonstrate that high quality data can be obtained in such studies despite many challenges. After discussing the dimensions which form the envelope in which the research took place, the chapter moved on to describe and discuss the data collection process, as well as providing details of data analysis. This provides a foundation for the presentation of the findings which can be found in the following four chapters. 
A quantitative questionnaire survey was described which fulfilled a number of informative functions, as well as offering a broader if less detailed overview of the themes highlighted in chapters one and two. It was illustrated how, as an example of flexibility of approach, this presupposed small-scale pilot survey turned into a significantly large provider of statistical data on the views of women in Kuwait.

The interview-based qualitative study was designed to collect rich in depth data from a small sample of urbanised educated Kuwaiti women. Thus the study is of two parts, one in which women identified from the survey were interviewed and the other which heard the views of a small cohort of Kuwaiti women in positions of leadership and explained what they added to the research overall. Issues relating to the interviews themselves were discussed, including video-recording, body language, dress, transcription and translation. The researcher's considerations of how the qualitative data should be analysed were also explained.

As this research was potentially sensitive in nature the ethical considerations were outlined. The final section of this chapter also discussed how the feminist nature of the research helped in maintaining the required ethical standards.

In the next chapter the descriptive results of the quantitative study comprising a large sample questionnaire survey of Kuwaiti women are presented and analysed. 


\section{CHAPTER FIVE}

\section{QUANTITATIVE RESULTS AND ANALYSIS}

\section{Introduction}

This chapter presents key descriptive findings from the results of the quantitative questionnaire survey which was carried out in Kuwait between April 2012 and July 2012. The survey was conducted as the first component of data collection. It was designed to gather basic descriptive data but it was also an engagement tool - to test the themes of the interviews and in doing so bring women's voices into the research process. As already noted, it was important to gauge reaction to this potentially controversial piece of research and test the lines of questioning that would later be used in the qualitative interviews. Via the survey women were also invited to take part in an interview and thus the survey also assisted in achieving a self-selecting sample for the qualitative element of the research.

It was both surprising and encouraging how many women took the time to fill in the questionnaire. Having said that it was also then a little disappointing how few went on to self-select for interview - while it is impossible to state with any degree of certainty why so many women took part in the survey only 20 went on to be interviewed - there are several possibilities that do raise their heads. Surveys are self-evidently anonymous and can be undertaken quickly and at a convenient time and place, whereas physically presenting oneself for interview may be perceived as somewhat less simple and riskier considering the controversial nature of the research. Nevertheless, the questionnaire certainly worked as a tool of engagement and the eventual number of women who came forward for interview (n20) was satisfactory for a $\mathrm{PhD}$ thesis.

The survey, entitled "Women and Social Policy in Kuwait", comprised of five profiling questions on age, marital status, employment status, graduate status and voting history plus 25 statements on issues related to the role of women in Kuwaiti society. Some 
questionnaire items were checking items in that they were aimed to confirm the responses to an earlier item. The themes around which the items were formulated derived from a combination of literature review and the assumptions of the researcher as to what the most relevant lines of enquiry were and which were most likely to be taken up in the interviews to follow. Analysis was undertaken with the help of the SPSS software programme.

The results of the survey are outlined in this chapter. The chapter begins by evaluating the response rate before presenting the demographics of the sample. It goes on to present the findings by clustering groups of items which share a common them and then presenting and discussing the results. A summary of the findings and the main implications for the quantitative study are set out at the end of the chapter.

\section{The number of responses, response rate and possible reasons for it}

Before presenting the results of the survey item by item it is worth considering how and why such a large response and high response rate was achieved as this in itself may constitute an important finding. The high number of completed questionnaires, in the absence of any form of reward, seems to reflect willingness, even an enthusiasm, for participation in social research into women's empowerment. Without entering into speculation it is highly possible that an opportunity to participate in research on women's issues was uncommon and so had a novelty value. Depending on the motivation of the individual respondents, for some it may have even been perceived as a rebellious act, having the opportunity to speak about unspoken issues. Also, given the method of distribution and collection within secure locations, the explanation of the research and emphasis on informed consent and particularly anonymity, it could well be that the participants perceived participation to be low risk - as the methodology sought to achieve.

The method of distribution and collection (not requiring any posting to be done) would have also been a factor in the high response rates. Respondents could receive and return their questionnaires with minimal inconvenience.

\section{The sample}


The self-selecting convenience sample was comprised entirely of women. It is characterised as a convenience sample as it is one that is available to the researcher as a result of its accessibility. Specifically, questionnaires were distributed to women at Kuwait Universities at cafeterias, and at all women's gatherings known as diwaniya. As already explained in the previous chapter, diwaniya were also considered a 'safe' environment to conduct data collection. Firstly, there is a women-only convention at such meetings, and secondly the women attending these gatherings are more likely to come from less traditionalist backgrounds. A total of 437 questionnaires were returned completed and were used for analysis.

The locations for distribution of the questionnaire undoubtedly affected the sample; specifically, the sample reflected the student population to a greater extent than the Kuwait female population as a whole as reflected particularly in their age, graduate status and employment status. However, the distribution at diwaniya enabled the inclusion of women outside academia. The researcher's own understanding of 'educated' and 'urbanised' have already been outlined in the introduction to this thesis.

\section{Demographics of the sample}

The first five items on the survey aimed to gather some basic descriptive data on the sample.

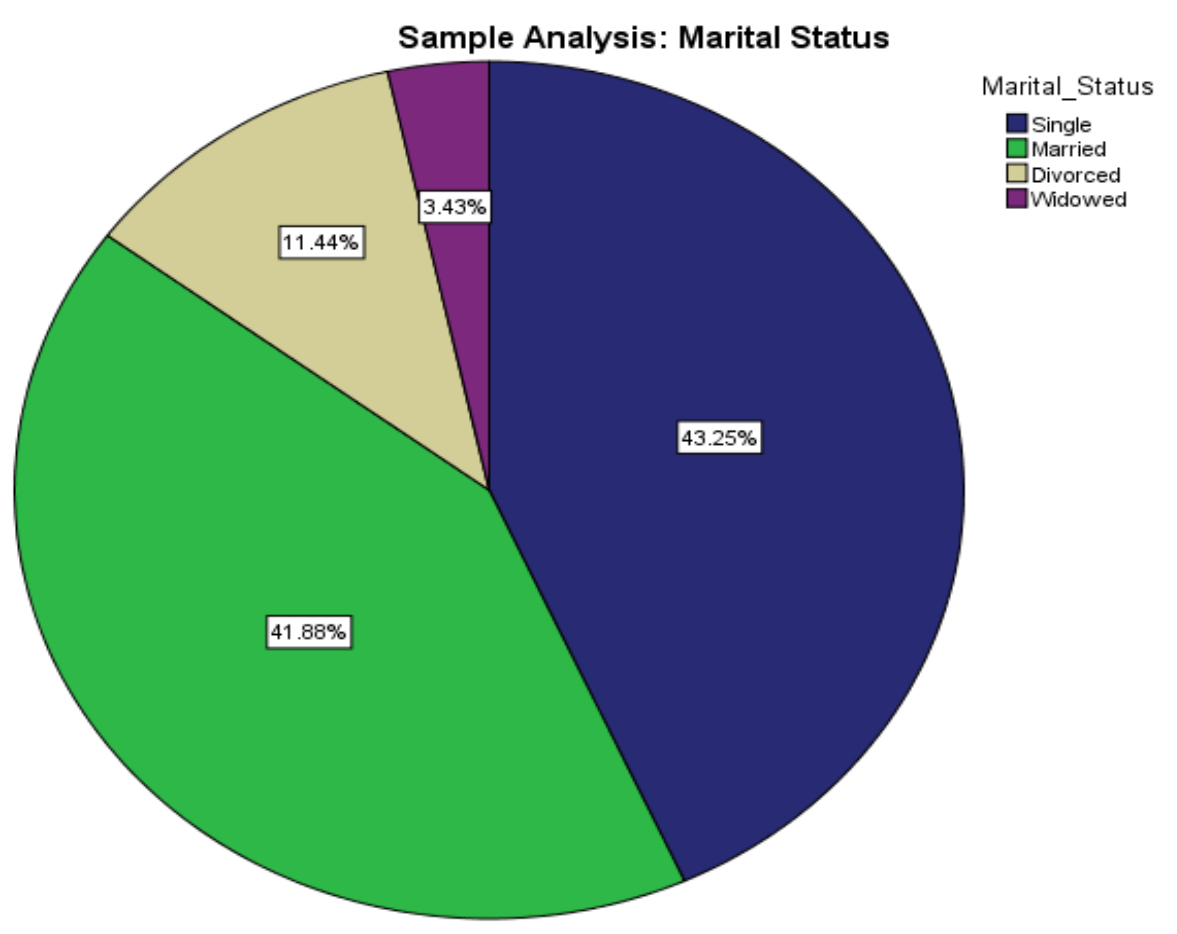




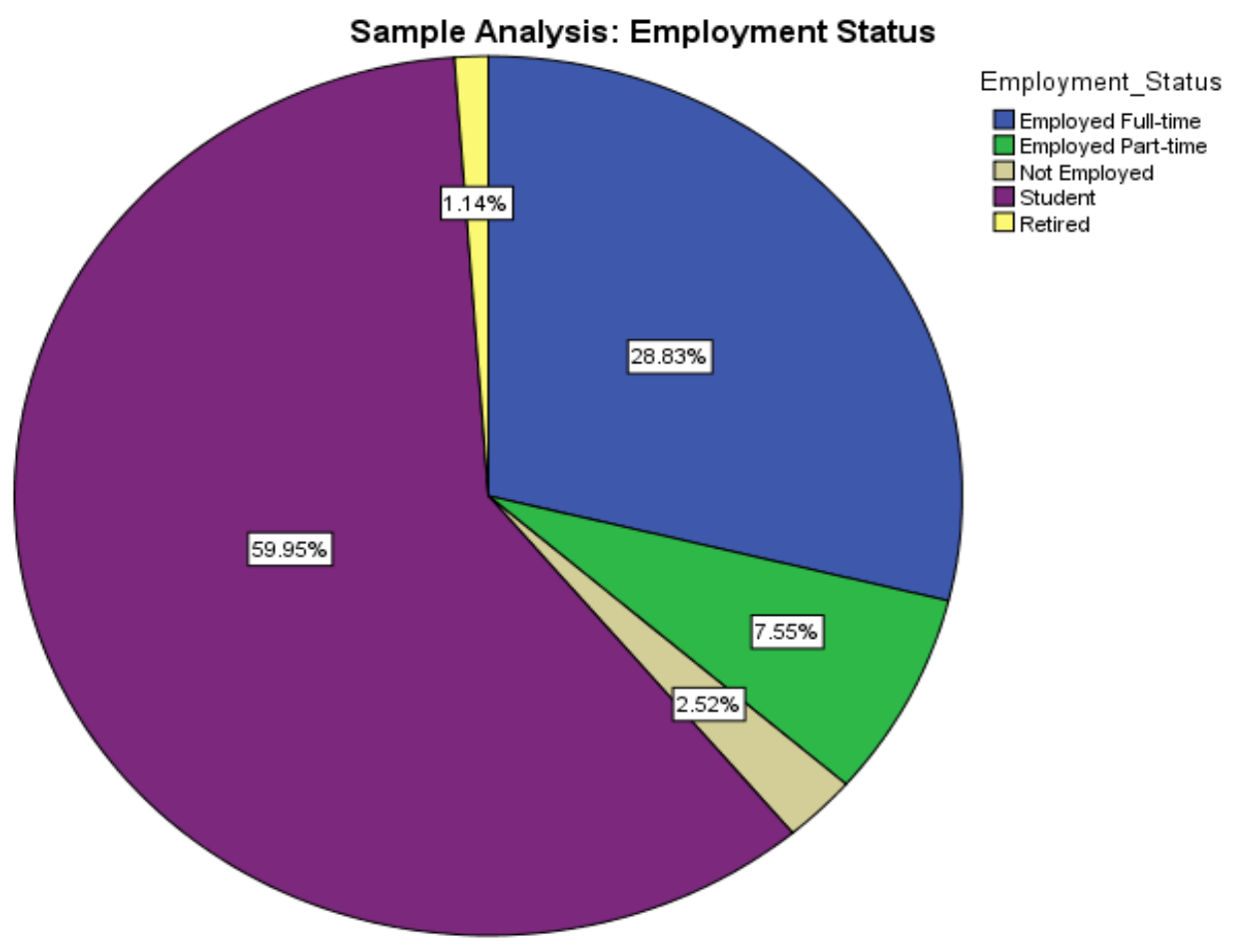

Figure 8: Sample Analysis - Employment Status

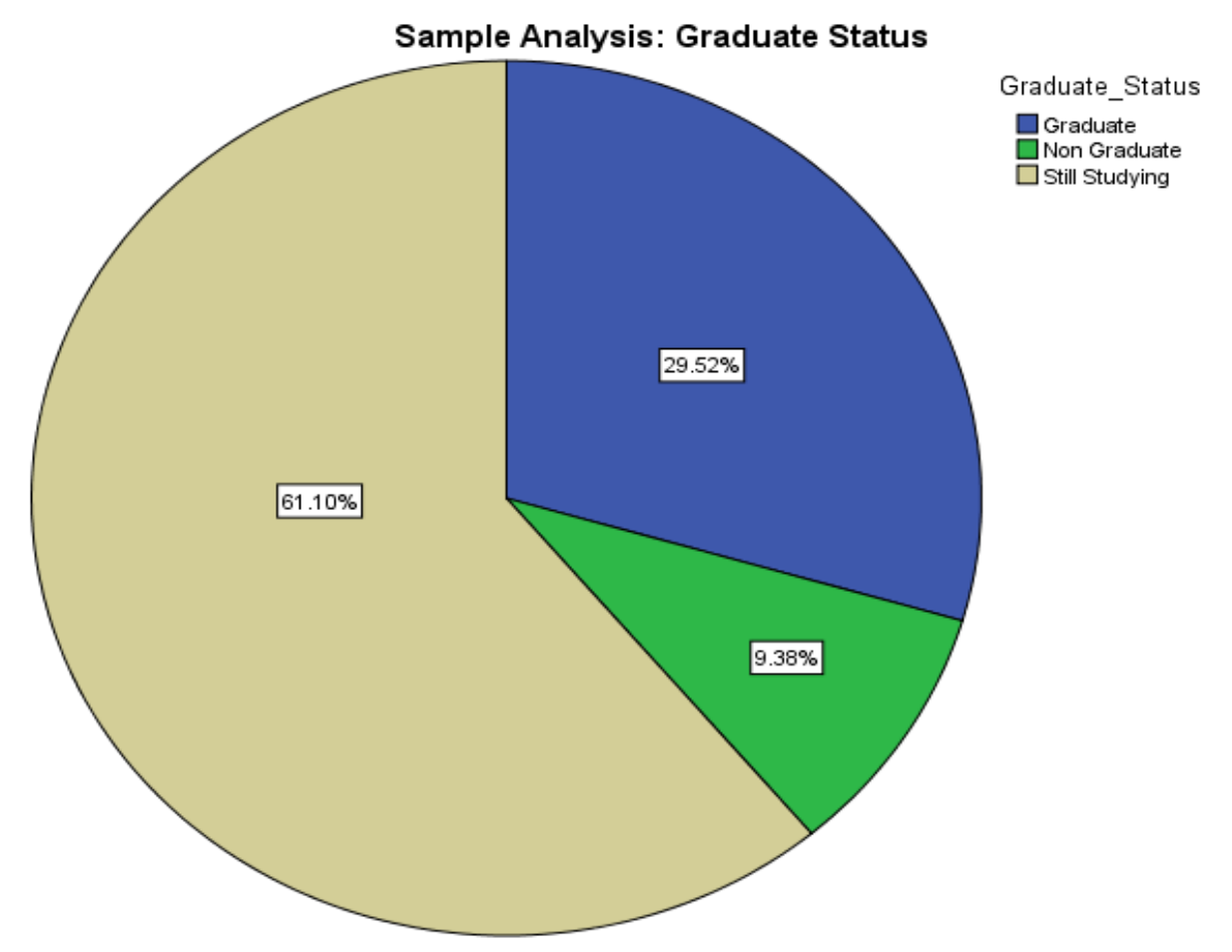

Figure 9: Sample Analysis - Graduate Status 


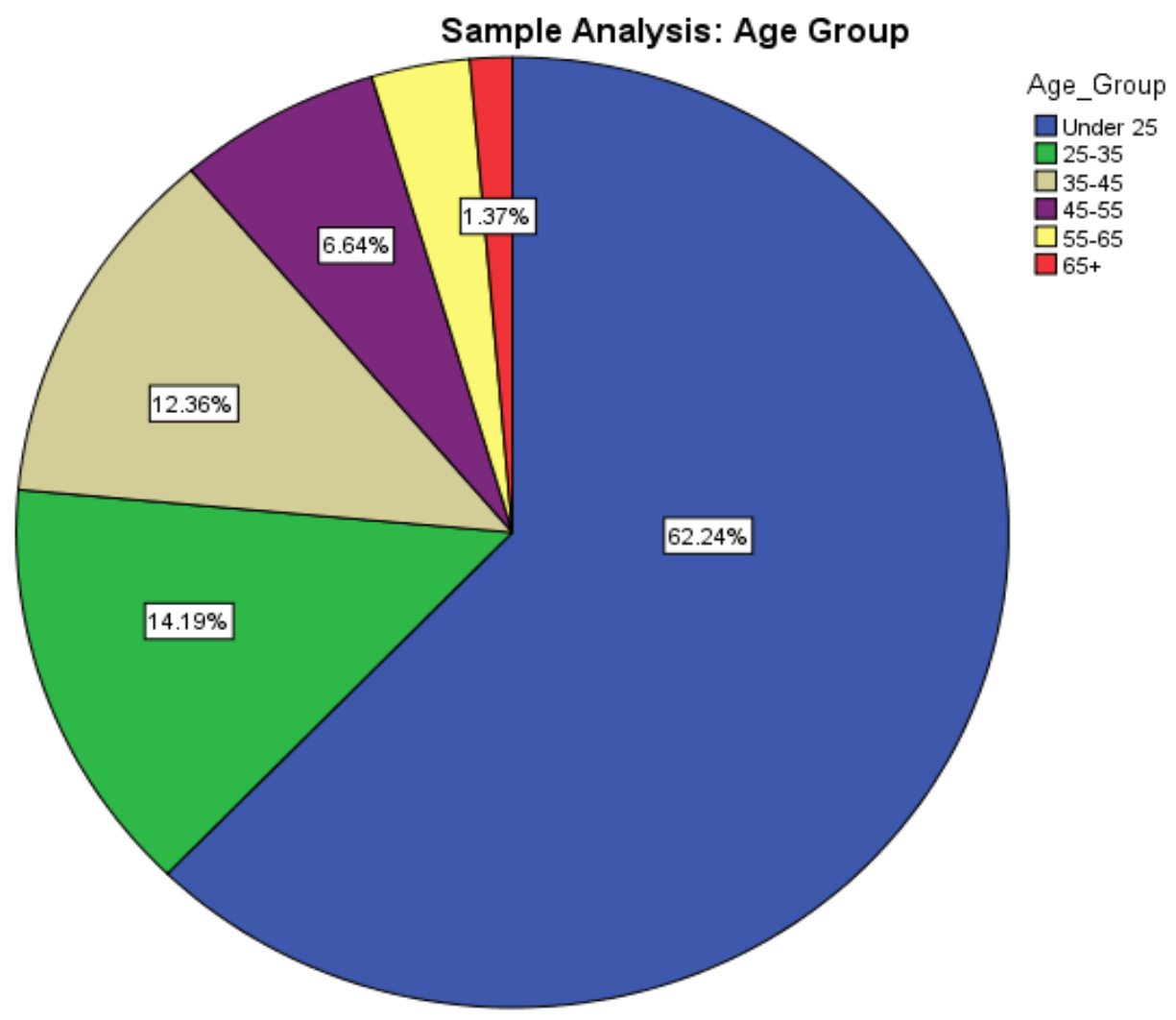

Figure 10: Sample Analysis - Age Group

Kuwait has a young female population with an estimated median age of 26.6 years. Hence, while the self-selecting convenience sample may include a disproportionate number of students, in general terms the relative youth of women in Kuwait was reflected well considering it was a non-probability sample. Distributing the questionnaire at female only cafeterias at university campuses accounts for the high representation of those women who are still studying (61.1\% of the total (n267), while it should be noted that many of these were also working either full or part-time. In terms of women who are neither students nor employed either full or part-time, nor retired, the sample reported only $2.5 \%$ (n11) of the sample as being in the not employed group. Clearly this understates the number of women in the general population who are not in the labour force as discussed in chapter two. 


\section{Sample Analysis: Voting behaviour at most recent election}

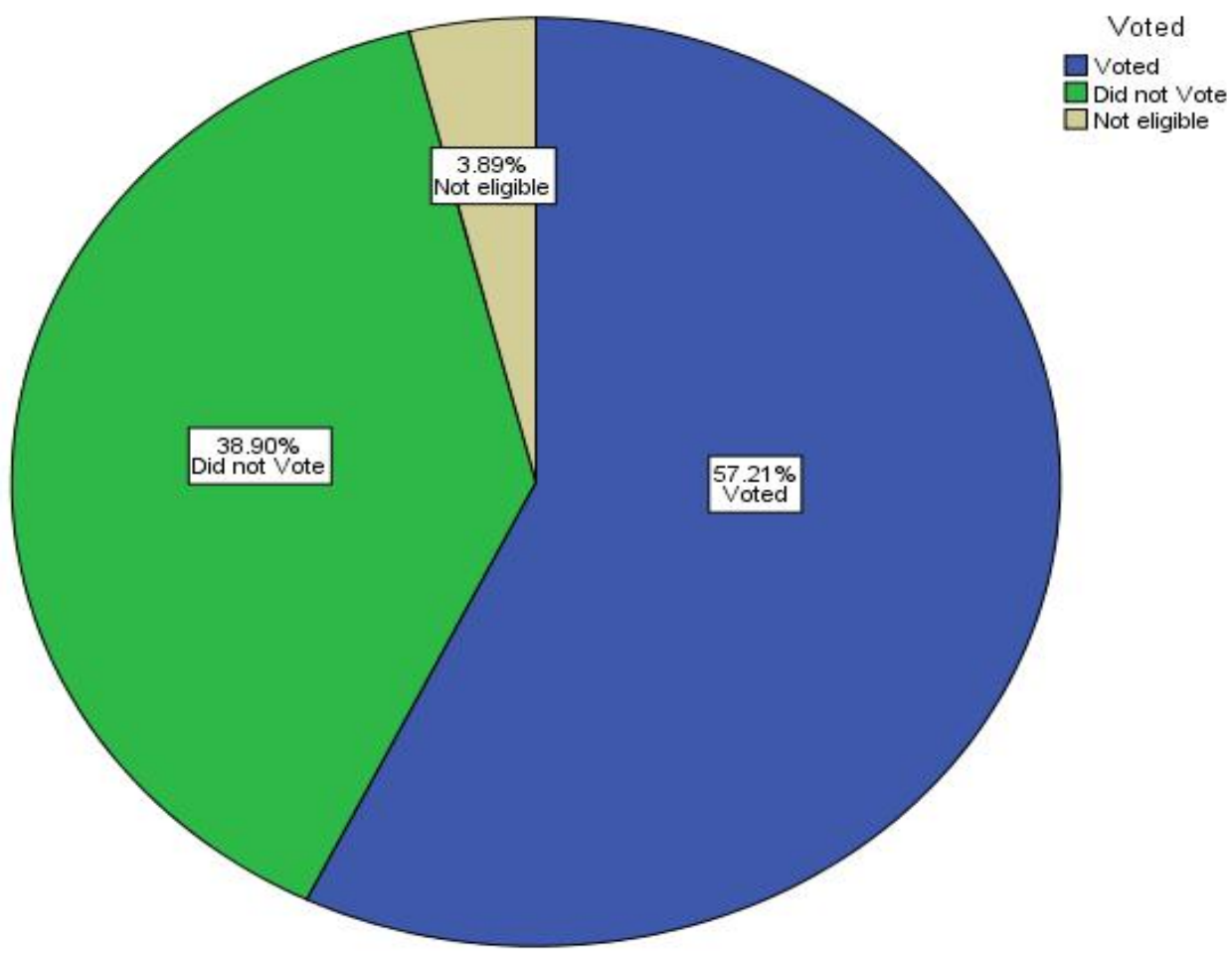

Figure 11: Sample Analysis - Voting Behaviour

Respondents were asked to indicate whether they had voted at the most recent election which at the time of the data collection had been held on the February $9^{\text {th }} 2012$ election (as noted the data collection for the survey took place between April 2012 and July 2012). This was included in order to assess the level of interest in policy issues. Almost $60 \%$ of those eligible to vote participated in the election which was in line with the overall turnout for that election suggesting that this sample was broadly representative of the Kuwaiti female population in terms of political participation levels, bearing in mind it was a non-probability sample.

Before discussing the results of the survey it is important to note that the unexpectedly high number of respondents who self-selected to participate in the survey is in itself a significant finding. It does indicate that Kuwait women are engaged with social policy issues and willing to state their views, although the fact that ultimately only 20 women took part in the one-to-one interviews may also be an indication that they prefer to express themselves in research that does not involve face to face data collection techniques. 


\section{The findings}

\section{The principle of gender equality}

The group of three statements shown in table 2 were aimed at exploring views on the general principle of gender equality. The results show that support for gender equality in terms of the law was indicated by a large majority of respondents but this majority turned into a minority when the statement was rephrased as equal in society', where a large number of women (n128) expressed uncertainty on the issue. Just over half (50.1\%, n211) rejected the idea that equality was impossible but still a significant minority did view equality as impossible.

Table 2: Women and Equality (Items 1,14 and 23)

\begin{tabular}{|l|l|l|l|l|l|l|l|l|l|l|}
\hline & \multicolumn{2}{l|}{$\begin{array}{l}\text { Strongly } \\
\text { Agree }\end{array}$} & \multicolumn{2}{l|}{ Agree } & \multicolumn{2}{l|}{ Not Sure } & \multicolumn{2}{l|}{ Disagree } & \multicolumn{2}{l|}{$\begin{array}{l}\text { Strongly } \\
\text { Disagree }\end{array}$} \\
\hline $\begin{array}{l}\text { Q1. Women should } \\
\text { have equal rights } \\
\text { under the law }\end{array}$ & 127 & $29.1 \%$ & 210 & $48.1 \%$ & 20 & $4.6 \%$ & 32 & $7.3 \%$ & 48 & $11.0 \%$ \\
\hline $\begin{array}{l}\text { Q14. Women should } \\
\text { be equal to men in } \\
\text { society. }\end{array}$ & 47 & $10.8 \%$ & 94 & $21.5 \%$ & 128 & $29.3 \%$ & 108 & $24.7 \%$ & 60 & $13.7 \%$ \\
\hline $\begin{array}{l}\text { Q23. It is not correct } \\
\text { to say men and } \\
\text { women should be } \\
\text { equal in society } \\
\text { because that is } \\
\text { impossible. }\end{array}$ & & $12.6 \%$ & 84 & $19.2 \%$ & 78 & $17.8 \%$ & 128 & $29.3 \%$ & 91 & $20.8 \%$ \\
\hline
\end{tabular}

In figure 9 a trend can be seen stepping away from supporting equal rights for women under the law among for those aged 45 and over while the three age groups under 45 were almost uniformly in favour of such equal rights. 


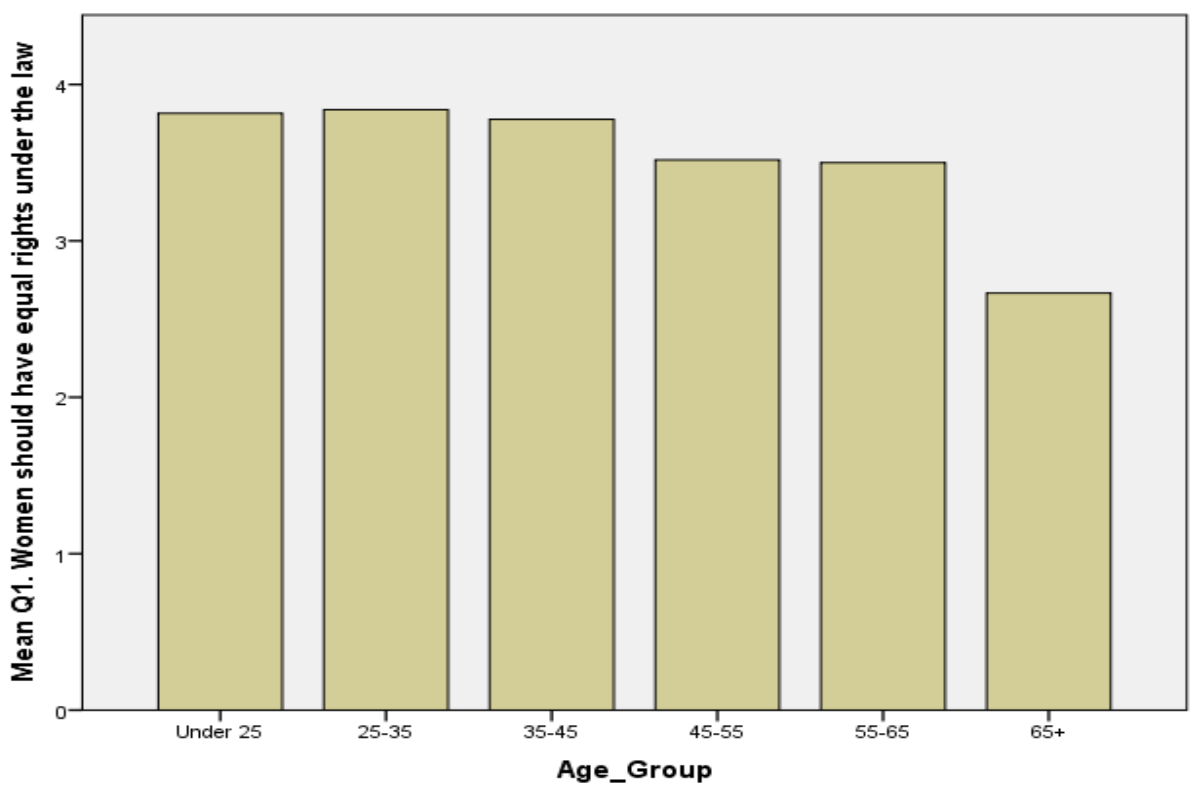

Figure 12: Age and attitudes to equal rights

Overall only $18.3 \%$ (n80) of women disagreed or strongly disagreed with the principle of equality under the law. Employment status and marital status were not found to affect responses to this statement significantly. Hence with the exception of somewhat more conservative views among older age groups (something which would also be expected among western populations) there is a high degree of consistency across the sample.

As to why equality in law and equality in society drew conflicting responses, it could be that equality in law is a less controversial thing to demand as many interpret the Kuwaiti Constitution as giving this equality. Overall this triad of statements showed that while a pro-equality stance drew majority support there were also a significant number of women in the sample who rejected this view. Rejection of gender equality increased with age which is unsurprising, if the widely held perception that older age groups harbour more conservative opinions is true.

\section{Women and work}

Women's increasing participation in the labour force was discussed in some depth in chapters one and two. The three statements shown in table 3 were aimed at eliciting views on the desirability of building a career, women taking senior positions at work and the strength of the traditional notion of women as wives and mothers. In Kuwait, as in other Islamic countries, careers are traditionally seen as the preserve of men. That $56.6 \%$ (n247) of the sample either agreed or strongly agreed that women should have just as much 
chance to build a successful career as men is a clear statement that increased labour force participation among Kuwaiti women is a welcome development. There was a slightly less decisive result for women taking more top positions, with $42.7 \%$ (n187) agreeing or strongly agreeing. Opinion was evenly divided on the question of whether women's main role was in the home as mother and wife with 35.9\% (n157) indicating it was and 38.3\% (n167) not supporting this view, while $25.9 \%$ (n113) were unsure.

Table 3: Women and Careers (Items 22, 17 and 20)

\begin{tabular}{|l|l|l|l|l|l|l|l|l|l|l|}
\hline \multicolumn{2}{|l|}{$\begin{array}{l}\text { Strongly } \\
\text { Agree }\end{array}$} & \multicolumn{2}{l|}{ Agree } & \multicolumn{2}{l|}{ Not Sure } & \multicolumn{2}{l|}{ Disagree } & \multicolumn{2}{l|}{$\begin{array}{l}\text { Strongly } \\
\text { Disagree }\end{array}$} \\
\hline $\begin{array}{l}\text { Q22. Women should } \\
\text { have just as much } \\
\text { chance to build a } \\
\text { successful career as } \\
\text { men. }\end{array}$ & 92 & $21.1 \%$ & 155 & $35.5 \%$ & 90 & $20.6 \%$ & 62 & $20.6 \%$ & 38 & $8.7 \%$ \\
\hline $\begin{array}{l}\text { Q17. There should be } \\
\text { more women in senior } \\
\text { management positions } \\
\text { in Kuwait. }\end{array}$ & 64 & $14.6 \%$ & 123 & $28.1 \%$ & 105 & $24.0 \%$ & 92 & $21.1 \%$ & 53 & $12.1 \%$ \\
\hline $\begin{array}{l}\text { Q20. Women's main } \\
\text { role in society is to be } \\
\text { a wife and mother. }\end{array}$ & 62 & $14.2 \%$ & 95 & $21.7 \%$ & 113 & $25.9 \%$ & 106 & $24.3 \%$ & 61 & $14.0 \%$ \\
\hline
\end{tabular}

Overall these three results indicate that there is substantial support for women entering the employment domain.

Table 4: Women as Judges and Lawmakers (Items 5, 13 and 18)

\begin{tabular}{|l|l|l|l|l|l|l|l|l|l|l|}
\hline & \multicolumn{2}{|l|}{$\begin{array}{l}\text { Strongly } \\
\text { Agree }\end{array}$} & \multicolumn{2}{l|}{ Agree } & \multicolumn{2}{l|}{ Not Sure } & \multicolumn{2}{l|}{ Disagree } & \multicolumn{2}{l|}{$\begin{array}{l}\text { Strongly } \\
\text { Disagree }\end{array}$} \\
\hline $\begin{array}{l}\text { Q5. Women should } \\
\text { be allowed to become } \\
\text { judges. }\end{array}$ & 55 & $12.6 \%$ & 73 & $16.7 \%$ & 85 & $19.5 \%$ & 124 & $28.4 \%$ & 100 & $22.9 \%$ \\
\hline $\begin{array}{l}\text { Q13. Only men } \\
\text { should work as judges }\end{array}$ & 54 & $12.4 \%$ & 91 & $20.8 \%$ & 116 & $26.5 \%$ & 100 & $22.9 \%$ & 76 & $17.4 \%$ \\
\hline $\begin{array}{l}\text { Q18. Men are better } \\
\text { suited to making law } \\
\text { than women. }\end{array}$ & 34 & $7.8 \%$ & 74 & $16.9 \%$ & 111 & $25.4 \%$ & 113 & $25.9 \%$ & 105 & $24.0 \%$ \\
\hline
\end{tabular}

Less than 3 in 10 women (29.3\%) in the sample agreed or strongly agreed that women should be allowed to become judges. On the checking statement that only men should work as judges just over 4 in 10 (40.3\%) disagreed or strongly disagreed. This is a somewhat inconsistent result but taken together it is an indication that the majority of sample were 
not in favour of women becoming judges. When it came to the statement that men were better suited to making law than women a different picture emerged in which only $24.7 \%$ (n108) agreed or strongly agreed, with almost half $(49.9 \%, \mathrm{n} 218)$ disagreeing or strongly disagreeing. Why this apparent support for women making laws did not translate fully into support for women judges may be because Islamic scholars have presented arguments based on holy texts that women should not be judges (highly disputed arguments it should be said) whereas women as lawmakers (i.e. as MPs) is an already established reality in Kuwait.

The contradiction can be seen that while nearly 4 in 5 advocated women as lawmakers (MPs), less than a third advocated women as judges interpreting and explaining those laws in court proceedings. Again this inconsistency merits further investigation but one could hypothesise that women are more likely to support a policy that has already been established (though not without a long period of struggle) than they are to support one where counterarguments are based in the Qur'an or at least in the majority of Muslim scholars' interpretation of the Qur'an.

\section{Women and the political domain}

Four items on the survey covered women and the political domain as shown in table 5 . The results showed a strong majority of women in favour of women's engagement in politics. As for women supporting female candidates, this was agreed to by $73.5 \%$ (n321) while participation at elections was supported by a similar number $(73.4 \%, \mathrm{n} 321)$. When faced with the suggestion that politics was something to be left to men $57 \%$ (n249) disagreed or strongly disagreed. When it came to women actually participating in government 53.1\% (n232) saw this as important. It is perhaps surprising that this last figure was not higher because at the time of the survey there was already a serving female government minister. Nevertheless, this group of questions still gave results which indicated that the women who took part in the survey were keen to engage in politics. The high number agreeing with the idea that women should positively discriminate in favour of female candidates appears inconsistent with actual voting behaviour which has failed to produce growing numbers of women MPs as discussed in chapters one and two. 
Table 5: Women and Political Participation (Items 3,4 11 and 25)

\begin{tabular}{|l|l|l|l|l|l|l|l|l|l|l|}
\hline \multicolumn{2}{|l|}{$\begin{array}{l}\text { Strongly } \\
\text { Agree }\end{array}$} & \multicolumn{2}{l}{ Agree } & \multicolumn{2}{l}{ Not Sure } & \multicolumn{2}{l|}{ Disagree } & \multicolumn{2}{l|}{$\begin{array}{l}\text { Strongly } \\
\text { Disagree }\end{array}$} \\
\hline $\begin{array}{l}\text { Q3. At elections } \\
\text { women should vote } \\
\text { for female candidates } \\
\text { whenever possible }\end{array}$ & 142 & $32.5 \%$ & 179 & $41.0 \%$ & 49 & $11.2 \%$ & 35 & $8.0 \%$ & 32 & $7.3 \%$ \\
\hline $\begin{array}{l}\text { Q4. It is important } \\
\text { that women } \\
\text { participate } \\
\text { elections. }\end{array}$ & 130 & $29.7 \%$ & 191 & $43.7 \%$ & 64 & $14.6 \%$ & 30 & $6.9 \%$ & 22 & $5.0 \%$ \\
\hline $\begin{array}{l}\text { Q11. It is important } \\
\text { for women to be } \\
\text { represented in the } \\
\text { government. }\end{array}$ & $20.6 \%$ & 142 & $32.5 \%$ & 110 & $25.2 \%$ & 59 & $13.5 \%$ & 36 & $8.2 \%$ \\
\hline $\begin{array}{l}\text { Q25. Politics is better } \\
\text { left to men as it is } \\
\text { their role. }\end{array}$ & & $11.9 \%$ & 68 & $15.6 \%$ & 68 & $15.6 \%$ & 122 & $27.9 \%$ & 127 & $29.1 \%$ \\
\hline
\end{tabular}

As table 5 above shows, the women surveyed expressed an overall desire for greater levels of participation in the political domain including lending their support to female candidates.

\section{Women and social policy}

There were five items on the questionnaire which sought responses to statements about five different policy areas: public housing provision, child allowances, nationality rights, divorce and unemployment allowances. These were selected as they had been high profile issues in recent years (as illustrated in the review of the literature documented in this thesis) and frequently raised in the assembly. Table 6 presents the results. 
Table 6: Women and Social Policy (Items 9, 8, 7, 6 and 21)

\begin{tabular}{|l|l|l|l|l|l|l|l|l|l|l|}
\hline \multicolumn{2}{|l|}{$\begin{array}{l}\text { Strongly } \\
\text { Agree }\end{array}$} & \multicolumn{2}{l|}{ Agree } & \multicolumn{2}{l|}{ Not Sure } & \multicolumn{2}{l|}{ Disagree } & \multicolumn{2}{l|}{$\begin{array}{l}\text { Strongly } \\
\text { Disagree }\end{array}$} \\
\hline $\begin{array}{l}\text { Q9. Women should } \\
\text { have the same right to } \\
\text { public housing funds } \\
\text { as men. }\end{array}$ & 74 & $16.9 \%$ & 118 & $27.0 \%$ & 82 & $18.8 \%$ & 93 & $21.3 \%$ & 70 & $16.0 \%$ \\
\hline $\begin{array}{l}\text { Q8. The 50 Kd } \\
\text { Children Government } \\
\text { Allowance should be } \\
\text { divided among both } \\
\text { parents }\end{array}$ & 48 & $11.0 \%$ & 86 & $19.7 \%$ & 109 & $24.9 \%$ & 124 & $24.9 \%$ & 70 & $16.0 \%$ \\
\hline $\begin{array}{l}\text { Q7. Women should } \\
\text { be able to pass their } \\
\text { Kuwaiti nationality on } \\
\text { to their children. }\end{array}$ & 44 & $10.1 \%$ & 84 & $19.2 \%$ & 92 & $21.1 \%$ & 129 & $29.5 \%$ & 88 & $20.1 \%$ \\
\hline $\begin{array}{l}\text { Q6. Women should } \\
\text { have the same rights } \\
\text { to divorce as men. }\end{array}$ & 74 & $16.9 \%$ & 118 & $27.0 \%$ & 82 & $18.8 \%$ & 93 & $21.3 \%$ & 70 & $16.0 \%$ \\
\hline $\begin{array}{l}\text { Q21. One of the most } \\
\text { important rights for } \\
\text { women is to get a } \\
\text { monthly allowance } \\
\text { while her job is taking } \\
\text { care of her family. }\end{array}$ & 58 & $13.3 \%$ & 86 & $19.7 \%$ & 98 & $22.4 \%$ & 117 & $26.8 \%$ & 78 & $17.8 \%$ \\
\hline
\end{tabular}

Overall, there were broadly similar numbers supporting policies that could be characterised as promoting gender equality to those opposing them, and throughout approximately one in five women took the neutral 'Not Sure' option. There was not a single item where a majority of women agreed to or strongly agreed to a policy proposition that promoted gender equality. Access to public housing funds received $43.9 \%$ (n192) support (agree or strongly agree); paying part of the child allowance to the mother was supported by $30.7 \%$ (n134); having the right to pass on their nationality to their children gained 29.3\% (n128) support; equal divorce rights drew 43.9\% support; and a 'stay-at-home' unemployment allowance 33\% (n144). Though in the case of the last item, this is a policy supported by Islamist groups who would prefer women to stay at home rather than participate in the workforce (as discussed earlier in this thesis at chapter two). These results are interesting for two main reasons. First, they show that even among the sample of urbanised, educated Kuwaiti women drawn mostly from younger age groups, pro-gender equality policies could not gain majority support. This could suggest the power and influence of patriarchal ideology delivered through traditions and religion is capable of convincing large numbers of women that policies, 
which on the face of it appear to be against their interests or against the interests of their daughters, are in fact desirable. Second, the results regarding the nationality rights item is particularly interesting as this is more a secular policy area controlled by the government who are keen to preserve access to citizenship. Women marrying non-Kuwaiti's cannot pass their Kuwaiti nationality onto their children which can cause those children considerable disadvantage. Therefore, it is perhaps surprising that this injustice failed to arouse majority support for a change in policy because it is a largely secular area of policy.

From the findings it can be suggested that an expressed belief in the overall principle of equal rights for women under the law did not fully translated into specific policy areas such as divorce and nationality rights where opinion was divided and conservative views commonplace. The contradiction can be seen that while nearly 4 in 5 advocated women as lawmakers (MPs), less than a third advocated women as judges interpreting and explaining those laws in court proceedings. Again this inconsistency merits further investigation.

\section{Women, equality and Islam}

This set of four items aimed to go right to the heart of the relationship between the genders in Kuwait and present respondents with the opportunity to oppose or support the status quo under which women have a clearly subordinate role. Table 7 presents the results.

Table 7: Women Equality and Islam (Items 16. 12, 15 and 10)

\begin{tabular}{|l|l|l|l|l|l|l|l|l|l|l|}
\hline \multicolumn{2}{|l|}{$\begin{array}{l}\text { Strongly } \\
\text { Agree }\end{array}$} & \multicolumn{2}{l|}{ Agree } & \multicolumn{2}{l|}{ Not Sure } & \multicolumn{2}{l|}{ Disagree } & \multicolumn{2}{l|}{$\begin{array}{l}\text { Strongly } \\
\text { Disagree }\end{array}$} \\
\hline $\begin{array}{l}\text { Q16. It is harmful for } \\
\text { women to be under } \\
\text { the guardianship of } \\
\text { their in-laws. }\end{array}$ & 56 & $12.8 \%$ & 116 & $26.5 \%$ & 120 & $27.5 \%$ & 100 & $22.9 \%$ & 45 & $10.3 \%$ \\
\hline $\begin{array}{l}\text { Q12. Women should } \\
\text { obey their husband } \\
\text { and male relatives. }\end{array}$ & 31 & $7.1 \%$ & 57 & $13.0 \%$ & 80 & $18.3 \%$ & 135 & $30.9 \%$ & 134 & $30.7 \%$ \\
\hline $\begin{array}{l}\text { Q15. Women should } \\
\text { be completely } \\
\text { independent in their } \\
\text { personal life. }\end{array}$ & 32 & $7.3 \%$ & 48 & $11.0 \%$ & 119 & $27.2 \%$ & 140 & $32.0 \%$ & 97 & $22.2 \%$ \\
\hline $\begin{array}{l}\text { Q10 Both husband } \\
\text { and wife should be } \\
\text { equally responsible for } \\
\text { paying their living } \\
\text { expenses }\end{array}$ & 28 & $6.4 \%$ & 67 & $15.3 \%$ & 109 & $24.9 \%$ & 143 & $32.7 \%$ & 90 & $20.6 \%$ \\
\hline
\end{tabular}


Overall it is notable that a large proportion (between $18.3 \%$ and $27.5 \%$ ) took a neutral view when addressing these more controversial statements. The idea of obedience to the busband or male relatives was soundly rejected, only $20.1 \%$ (n88) agreed or strongly agreed. However, 33.2\% (n145) of women did not feel it was harmful for women to be under the guardianship of their in-laws with another 27.5\% (n120) unsure. Personal and financial independence was also rejected by the majority of women. The idea of men and women taking equal responsibility for living expenses only found support or strong support from $21.7 \%$ (n176) and the notion of independence in their personal life had only 18.3\% (n167). It would of course be unusual for married respondents or those planning to marry soon to advocate for total independence for women, while those who are divorced may be more likely to take this position.

Of great interest here is the rejection of the classic subordinated role as expressed through obedience to men which was so widespread and contrasted greatly with the previously discussed results on specific social policies. It could be suggested that the sample indicates that in the urbanised educated women's households there is less prevalence of the idea of obedience, and also that the substantial numbers of younger women who are still studying may simply reject the notion of obedience. It appeared from the findings that Sharia based inequalities were less opposed than those within the realm of the state. These issues are worthy of further investigation and the qualitative phase of the research aims to achieve this.

\section{Perspectives on the past, present and future}

This cluster of three items sought different reflections on progress in women's position in Kuwait. The first item was a 'devil's advocate' type statement suggesting that there was no need for further campaigning now that women had the right to vote. The second asked women for a general view of whether women's position had improved in the recent past and finally tried to quantify the level of optimism concerning further progress in the future. 
Table 8: Perspectives on the Past Present and Future (Items 2, 9 and 24)

\begin{tabular}{|l|l|l|l|l|l|l|l|l|l|l|}
\hline & \multicolumn{2}{l|}{$\begin{array}{l}\text { Strongly } \\
\text { Agree }\end{array}$} & \multicolumn{2}{l|}{ Agree } & \multicolumn{2}{l|}{ Not Sure } & \multicolumn{2}{l|}{ Disagree } & \multicolumn{2}{l|}{$\begin{array}{l}\text { Strongly } \\
\text { Disagree }\end{array}$} \\
\hline $\begin{array}{l}\text { Q2. Now that women } \\
\text { have the right to vote } \\
\text { in elections there is no } \\
\text { need to campaign for } \\
\text { any further rights }\end{array}$ & 23 & $5.3 \%$ & 47 & $10.8 \%$ & 25 & $5.7 \%$ & 144 & $33.0 \%$ & 198 & $45.3 \%$ \\
\hline $\begin{array}{l}\text { Q19. Women's } \\
\text { position in Kuwaiti } \\
\text { society has improved } \\
\text { in the last ten years. }\end{array}$ & 75 & $17.2 \%$ & 130 & $29.7 \%$ & 125 & $28.6 \%$ & 70 & $16.0 \%$ & 37 & $8.5 \%$ \\
\hline $\begin{array}{l}\text { Q24. In ten years' } \\
\text { time there will be } \\
\text { more women MPs } \\
\text { and more equality for } \\
\text { women. }\end{array}$ & 94 & $21.5 \%$ & 110 & $25.2 \%$ & 82 & $18.8 \%$ & 92 & $21.1 \%$ & 59 & $13.5 \%$ \\
\hline
\end{tabular}

Regarding the ceasing of campaigning because of women's suffrage, this was rejected by a large majority of women who either disagreed $(33.0 \% \mathrm{n} 144)$ or strongly disagreed $(45.3 \%$ n198). Those agreeing to the cessation of campaigning are likely to be those who do not believe women should be involved in any campaigning in the first place and so the fact that they numbered so few $(\mathrm{n} 70-16.1 \%)$ is interesting. It suggests that those seeking gender equality far outnumber those who reject it in the sample but this decisive result is not consistently repeated throughout the data. The more in-depth investigation of the qualitative research aims to shed further light on this.

Concerning progress over the last ten years the balance was a positive assessment of this with $46.9 \%$ (n205) agreement or strong agreement to progress having been made and $24.5 \%$ (n107) indicating either disagreement or strong disagreement. With the last ten years including women securing the right to vote it is understandable that this is recognised in the data, however, those denying progress could be indicating an opinion that despite this breakthrough little had changed. With regard to looking to the future, optimism was rather more prevalent that pessimism; 46.7\% (n204) of respondents agreed or strongly agreed that in ten years' time there will be more women MPs and more equality for women. There was disagreement or strong disagreement from 34.6\% (n151). Overall there appears to be a positive assessment of both past and future but with a healthy number of sceptics. As discussed in chapter two this scepticism applies to politics as a 
whole and women MPs specifically who are not viewed as a cohesive group acting in the interests of women. Furthermore, at the most recent election prior to data collection (February 2012) no female MPs was elected.

\section{Summary and implications for the qualitative study}

While this survey was completed by a non-probability sample it had significant similarities to the overall female population of Kuwait, in particular in terms of age and political participation at elections. So while statistical representativeness is not claimed there is no reason to believe that the views expressed through the responses to the survey are significantly different to those that would be obtained from a random probability based sample of educated urbanised Kuwaiti women. However, the sample size is large, being equivalent to a survey of nearly 20,000 women in the UK.

The survey produced some interesting results and also some which appeared somewhat contradictory. The greatest degree of unanimity was shown in the rejection of the idea that now women have achieved suffrage there is no point in women campaigning for further rights, and also for the importance of political participation and support for women candidates. There was also strong majority support for equality under the law. Beyond these the results are less decisive and reveal a highly divided sample in terms of attitudes to gender roles, to specific policies and perceptions of how women's lives have changed and whether they may change positively in the future.

The survey found that the majority of women favoured greater levels of political activity and representation in Kuwait. Opinion was more divided on specific policy issues that are prominently discussed today in Kuwait. Furthermore, there appeared to be a greater willingness among the sample to enter responses that could be classified as political policy issues as opposed to being more associated with sharia, the Qur'an and the associated cultural assumptions. A significant minority of the sample gave responses that can be broadly characterised as conservative with nearly four in ten rejecting the idea of gender equality. Conservative views were somewhat more common in older age groups. This was not a sample comprising only liberal feminist women clearly stating their desire for greater empowerment, however the overall impression left is that a significant proportion of the women who took part in the survey wanted change and wanted to participate fully in the public sphere but did not want to be seen to be directly challenging certain principles (mainly drawn from traditions and Islam). It may be that as 
the Kuwaiti Constitution itself states in Article 29 that "All people are equal in human dignity, and in public rights and duties before the Law" an assertion of equality before the law is easier to support openly, while specific and current legal controversies are less easy to take a position on which could be deemed rebellious or challenging to prevailing cultural assumptions. This would also help to explain why political participation and voting for female candidates received high scores as these are already established as rights and so are less controversial. These particular strands are further investigated in the qualitative research, the findings of which are presented in the next three chapters.

The key findings of the survey were used to inform the lines of enquiry to be pursued during collection of the qualitative (interview) data. A total of 37 women used the questionnaire form to indicate that they would be willing to be contacted regarding participation in qualitative interviews, 20 finally took part (some women simply changed their mind or could not find a convenient time). The next chapter is the first of three findings chapters - each of which draws on the findings of the qualitative interviews with the Kuwaiti women identified from the survey responses and the five women in leadership who agreed to be interviewed. Where appropriate, the results of the quantitative study described in this chapter are also re-visited with the aim of supporting the findings of the qualitative study. 


\section{CHAPTER SIX}

\section{STEPS TO EMPOWERMENT? EXPLORING THE PERCEPTIONS OF EDUCATED AND URBANISED KUWAITI WOMEN ON SOCIAL POLICY DEVELOPMENT}

The data collection on which the coming three findings chapters are based took place between July and December 2012.

This chapter is oriented to the recent past in Kuwait, mainly the last decade during which time some changes have taken place which are associated with women's empowerment as discussed in chapters one and two of this thesis. The aim of this chapter is to explore and analyse the data collected from the 20 interviews with educated urbanised Kuwaiti women and five women in leadership (WiL) interviews. The focus is on how women perceive the recent past in terms of changes affecting their lives across a number of different public domains including polity, civil participation and campaigning, employment and education. The chapter addresses the first research question - "How has the recent development of social policy pertaining to women's rights in Kuwait been perceived by educated urbanised Kuwaiti women?"

As already noted in the previous chapter, when asked whether women's position in Kuwaiti society has improved in the last ten years $46.9 \%$ respondents to the survey questionnaire either agreed or strongly agreed, with a further $28.6 \%$ not sure. This suggests that the majority of the sample of women who participated in the survey believed that some positive change had taken place. The interviews with educated, urbanised Kuwaiti women (n20) and women in leadership (n5) offered the opportunity to the researcher to give voice to articulations of this change, its benefits and its limitations.

The chapter is organised around the following themes: empowerment through political participation, empowerment through employment, emotions as a perceived weakness in women, and lastly empowerment through education. First the chapter considers the participants' perceptions of politics and particularly the recent right to vote. Then it 
explores how the participants perceive their role in the public domain of work and the greater financial independence this brings. Next, following up on a strong theme that emerged from the interviews, the issue of 'women as weakened by their emotions' is also included. The final section considers women's access to higher education and how the participants perceived that. Throughout the findings chapters, descriptive data from the survey questionnaire as well as comparisons with the role of women in 'Western' countries, particularly the United Kingdom is incorporated in an attempt to contextualise the findings where it is considered appropriate to do so.

Table 9: Demographics of Interview study participants

\begin{tabular}{|l|l|l|l|l|l|}
\hline$\#$ & $\begin{array}{l}\text { Participant } \\
\text { Name } \\
\text { (pseudonym) }\end{array}$ & Age Group & Employment Status & Marital Status & $\begin{array}{l}\text { Voted at } \\
\text { Last } \\
\text { Election }\end{array}$ \\
\hline 1 & Huda & $25-35$ & Not employed & Single & Yes \\
\hline 2 & Mona & $25-35$ & Employed full-time & Married & Yes \\
\hline 3 & Hanan & $25-35$ & Employed full-time & Married & Yes \\
\hline 4 & Farah & $<25$ & Student & Single & Yes \\
\hline 5 & Samar & $25-35$ & Employed full-time & Married & Yes \\
\hline 6 & Maha & $25-35$ & Employed part-time & Single & Yes \\
\hline 7 & Mai & $45-55$ & Employed part-time & Divorced & No \\
\hline 8 & Khawla & $35-45$ & Employed full-time & Widowed & Yes \\
\hline 9 & Shahad & $45-55$ & Employed full-time & Married & Yes \\
\hline 10 & Shaima & $<25$ & Student & Single & Yes \\
\hline 11 & Munira & $55-65$ & Student & Single & Yes \\
\hline 12 & Kawther & $25-35$ & Employed full-time & Divorced & Yes \\
\hline 13 & Areej & $45-55$ & Employed full-time & Married & Yes \\
\hline 14 & Reem & $25-35$ & Employed full-time & Married & Yes \\
\hline 15 & Fai & $25-35$ & Employed full-time & Single & Yes \\
\hline 16 & Fouz & $55-65$ & Retired & Married & Yes \\
\hline 17 & Afaf & $35-45$ & Retired & Widowed & Yes \\
\hline 18 & Dalal & $35-45$ & Employed part-time & Divorced & No \\
\hline 19 & Sawsan & $55-65$ & Retired & Married & Yes \\
\hline 20 & Manar & $25-35$ & Employed part-time & Married & No \\
\hline & & & & & \\
\hline 12 & & & & \\
\hline
\end{tabular}




\section{Demographics of the women who took part in the interviews}

Table 9 shows a summary of the demographic data collected from the survey questionnaires of those respondents who went on to participate in the interview study (the participant's names have been changed). The demographic breakdown of the sample does not reflect the demographic breakdown of the respondents to the questionnaire survey. In particular, there was a greater prevalence of students in the quantitative study than in the interview study. The women interviewed were more likely to have voted at the previous election than questionnaire respondents (presumably related to the prevalence of students who may not have been old enough at that time). In terms of marital status, the quantitative and qualitative samples were broadly aligned. The average age of the interviews was also somewhat higher than the survey sample. In particular, students had a far greater representation in the survey sample but did not put themselves forward in proportionate numbers for the interview stage of the research.

\section{Empowerment through political participation}

\section{Participating and positively discriminating}

The questionnaire survey showed a strong belief in the importance of women exercising their new right to vote and also a positive reaction among many to the idea of women supporting female candidates when possible. Indeed $73.5 \%$ of the sample agreed or strongly agreed with the idea of positive discrimination in favour of female candidates. Similarly, overall women's political participation was viewed as important or very important for $73.4 \%$ of respondents. Arguably, if this motivation was repeated in actual elections this would result in more women in the Kuwaiti assembly than has actually been the case.

The one-to-one interviews with educated urbanised women revealed a more nuanced view whereby many made it clear that supporting a woman because she was a woman was not appropriate. Interview participants were asked whether they thought it was important for women to participate in elections: some (n8) preferred a more meritocratic approach with support going to the best qualified candidate. Politics is seen as a serious 
profession requiring the right credentials. For example, Huda explained this was necessary:

...because the new generation will have more knowledge and since they have the chance to enter politics they will know their degree will go in the right direction and they will be more interested in studying [politics]. If they study political science, they know they will have chance to run for election. Basically their voice will be heard, [the degree] will not be just a piece of paper.

Most of the educated urbanised women (n16) who took part in the interviews supported positive discrimination in favour of women. For example, Mona was in favour of supporting female participation in politics and other civic occupations and commented:

The situation is much better now for women. They are participating in many new walks of life and entering politics. Before she was limited and now you can find women everywhere. There is no place that women cannot go, even in the army.

Overall the majority of women (n16) appeared in favour of supporting female candidates where possible but for some this should not be at the expense of candidate quality. However, only one participant ruled out positive discrimination in favour of women candidates completely. In circumstances where there was a choice between equally qualified male and female candidates the women in this study gave an indication that they would support the woman. Still, this would be less likely to happen if the female candidate was seen as unqualified. Participants were asked whether they thought it was a good idea for women to vote for women candidates, the following responses highlighted the majority position:

Hanan: I only vote for women and I wish all women would only vote for women candidates.

Mai: Why not? Women vote for men so why not vote for women.

Khawla: Not necessarily, but sometimes yes it's preferable. Yes, because the chance of a woman winning is really low so we have to choose the best women and help her over the line.

Shahad: Why not? It's a really beautiful idea, I support this idea strongly. Women are increasingly dealing with female bosses at their 
workplace so it's fine to vote for women in politics. There is no problem with that at all.

Against this there was a firm rejection of positive discrimination by Huda who rejected the concept of women giving their vote to female candidates simply on the basis of their gender:

Definitely not, because we just recently got our voting rights so we need to give our support to the right person and not give the wrong person our vote just because she is a woman.

In practical terms many women would not have a female candidate to vote for; however, based on this study, female candidates can clearly not rely on the unqualified support of fellow women in all circumstances. Participants were asked whether they felt it was a good idea for women to vote for female candidates on the basis of their gender. Maha saw this as a form of sexism:

No this is not necessary. She should vote for the one who she believes is the best candidate. Not being sexist for women only.

Given the mixed views about positive discrimination in favour of women, it may well be that change has to come from government. Drawing on the UK example in February 1918 the Representation of the People Act gave married British women over the age of 30 the right to vote. The first woman to be elected to the House of Commons won her seat in 1918 (although as an Irish Republican she did not take her seat). In 1919, Nancy Astor became the first woman to take her seat; this was prior to women being given full equal voting rights although as mentioned married women over 30 had been able to vote since 1918. When these rights came though the Equal Franchise Act 1928 a long period of slow growth in the number of female MPs began with 16 women returned in 1929; remarkably 50 years later at the 1979 election this number had only grown to 19 (Parliament.co.uk, 2015). Frustrated at the slow progress one of the major parties, the Labour Party, introduced all women candidate short lists, a move which gave an immediate boost to women's representation in 1997 when 120 women were elected compared with 60 at the previous election. In 2015, 191 women were elected comprising $29 \%$ of the total (Parliament.co.uk, 2015). Reflecting on the UK experience is important because it may give clues as to the likely trajectory in Kuwait. In Kuwait there are far 
fewer parliamentarians with 50 elected MPs and a further 16 non-elected cabinet members who also have a vote in the chamber.

\section{Has elation turned to disillusion?}

It has been noted earlier that the enfranchisement of women was a widely acclaimed moment for women in Kuwait and despite the fact that only two women were returned at the most recent general election (July 2013) there was relatively little cynicism to be found among the women interviewed. There were, however, some exceptions. For example, Munria explained:

Not many women are really participating. That's why there are few people who want to vote for them, they still don't trust women. And still they don't think if women enter parliament that they will do anything. The majority of society are Bedouin, they came from the desert so they can't trust women and they believe women should stay in the home. Today there is a good example in the election with Mrs. Fajer Al Saaed. Many women said they would support and elect her but in reality she didn't win. Her speeches and her CV are perfect but she couldn't get the votes.

Shahad reflected the disillusion that having women in the assembly did not necessarily translate into attention being paid to women's issues:

Women are participating, but in the area that I care about I didn't see any evidence of accomplishment. I don't see that these women [MPs] offer much to women who are divorced or widows or those who are not married - they didn't do anything for these groups. There is no help on housing or salaries or when they want to give nationality to their kids when their husband is non-Kuwaiti. There is no strong voice for her.

For Khawla it was all too little too late and Kuwait was left lagging behind in international terms:

Women should have been participating in politics for centuries... I think it's too late that they have now allowed us to enter the political sector. It's a shame that we are talking about recently gained women's rights when in other countries they have had them for a long time. I don't want to use the worst countries as a benchmark I want to use the better ones, that is the way to go forward and not stand still. 
Again the principle of women's enfranchisement is supported but the outcomes from the political process are not seen as particularly favourable to women and there was no mention of an achievement arising from the return of a female MP, just a satisfaction for the principle itself. Fouz stated:

We were all happy when women got their political rights but in the real world women weren't really affected by it. The most important topics that women want to talk about are not being discussed. Especially about Kuwaiti woman who get married to non-Kuwaitis. Women politicians didn't even talk about it in the parliament. They talked about it when they needed votes before the election. Women still didn't get any of their rights from the Kuwaiti National Assembly. Her kids didn't take the rights from the workplace and on nationality.

One of the women in leadership (WiL1), who is a senior female politician in Kuwait made a number of suggestions as to why, in terms of representation in the assembly, women had not made further advances, pointing to the quality of the candidates being attracted and their motives for standing. According to this participant, women had not co-ordinated, or voted together and she suggested that this could be due to women not having yet developed the right skill set required by a successful politician. This is an interesting point given that since women were first able to vote and stand in parliamentary elections their representation in parliament has not really grown. When asked why she thought that this was the case she explained:

One of the main reasons is that she has not grown politically yet... Also the aims and priority for women who run themselves are different, there are women who only want to be famous or women who want to get some money from the government or who run herself because she wants to get married.

Thus, there is the suggestion that women MPs are not necessarily going to stand for election or be supported because they are going to focus mainly on advancing a women's rights agenda. They could for example identify with their sectarian background more than their gender.

The issue of candidate quality was also raised by WiL2 a consultant to the Kuwaiti assembly who observed that there is a perception that men are more likely to deliver 'favours' in return for support. They invariably have more social capital and so make more convincing business partners in this transactional style of politics. It is a politics 
which in common with many other countries is 'a dirty game' and one which women may be ill-prepared for. WiL2 explained:

We found that the number of the women candidates is a lot lower for every 100 men there are only 10 women. This [low number of female candidates] is based on many factors such as the campaign for the election is really expensive and when running for parliament there many bad things which can follow, harming the reputation of the candidate. Society will talk about them in a bad way so not many women have the ability to get on in this kind of dirty game.

Nearly a decade after women regained the right to vote and to stand as candidates Conservative traditional forces opposed to this in principle are still present and powerful, this participant went on to state:

After 9 years there are many who don't believe that women should be in the Kuwaiti parliament and this is wrong. Even if this idea is becoming less prevalent now it is still there and that is undoubtedly a barrier to her getting into parliament.

Another woman in leadership participant WiL5, speaking when she was still an MP, suggested the concept of 'the unity of men' as the reason while woman have yet to make a significant breakthrough in the political domain:

Women are still new to the political world and the voting process and they do not use the power of their votes to the same degree as men. Women have not reached that level yet in the same manner as men. The unity of men boosts its influence on the government in the selection of leadership positions, and the government grants them to the MPs as a reward, and in general women do not have a strong influence on the government.

\section{Women 'drowned out'}

The parallels between men's behaviour in the Kuwaiti Assembly and their counterparts in the House of Commons in the UK are intriguing. There are regular reports of macho, and sexist behaviour in the UK's parliament perhaps as part of an attempt to intimidate women. Helen Grant MP, the UK equalities minister was quoted in media reports saying "It's a male dominated area. I guess [women MPs who have ended their time in parliament] felt it's hard to make things happen in the system" (cited in Sanghani, 2014). And, although the setting of Kuwait is vastly different in its culture and political 
history to the UK, starkly similar themes emerge through the words of a former MP, WiL5, who took part in the interviews:

Last year ... I was defending a law on the podium, and there was unnatural disorder in the Assembly. Our behaviour as women has surprised the MPs due to our observance of good order and the methods used in our work.

A certain kind of behaviour performed by male members of legislatures appears designed to 'drown out' the voices of women, something reminiscent of classroom behaviour.

Of course, political enfranchisement and participation are not the equivalent of empowerment. While the election of four women MPs in May 2009 was seen as an important landmark in Kuwait it was not the start of a growing presence for women in the national assembly. Indeed, in the most recent elections in July 2013 out of 306 candidates there were only 8 women standing, however, two of these were elected. Again, turning to the UK, Helen Jones (2000) sought to understand to what degree did the achievement of the vote in the UK and women's entry to a range of professions, hitherto largely closed to them, actually increase their ability to influence public life and social policy during the period 1914 to 1950 . She concluded that the two world wars did present new opportunities for women particularly in professional terms as doctors, teachers, nurses and as social welfare campaigners. However, when it came down to direct influence on policy, Jones argues that the period after the First World War saw middle-class women gain influence over working class women but none over men who continued to decide policy. After the Second World War, women's influence rose to a higher level but still only a very small number of women were involved in governance. Women MPs and government civil servants struggled to make an impact on women's issues and were left isolated in the 'man's world'; others had little or no interested in pursuing a gender based kind of politics and the British political system was overwhelmingly class-based (Jones, 2000). In most cases, it is suggested that party loyalties trumped gender interests. Where campaigners appeared successful such as in the establishing of nursery schools, family allowances and free birth control advice the gains were only achieved as the goals coincided with the government's own agenda which was one not based on a desire for gender equality for its own sake. 
Jones (2000) further explains how women's issues tend to get side-lined during periods when the agenda is dominated by crises such as the rise of Fascism in the 1930s. In Kuwait, in recent years the Arab Spring may be another such example of a crisis which relegates women's issues, where the ruling elite perceive an existential threat which takes precedence over making progress on women's rights. The situation and history in Kuwait although very recent in terms of political enfranchisement has several similarities with the UK - slow progress, lack of impact on women's issues and positive policy reform coming from a perspective that change is needed but not a gendered perspective. In this research study one of the most often cited reasons for this lack of progress was wasta a phenomenon which was discussed in chapter two. Eight of the interviewees raised the issue of wasta unprompted.

\section{Wasta: social capital mostly possessed by men}

As already explained in chapter two of this thesis, wasta is a reference to the nepotism and favouritism that means all too often in Kuwait your life chances are based more on who you know than what you know. Britain's own form of wasta 'the old boys club' was particularly dominant in first half of the $20^{\text {th }}$ century and as Jones (2000) reminds us women lacked the networks which "could effectively challenge and dislodge structures and cultures which operated to women's disadvantage" (p. 7). Similarly, the majority of Kuwaiti women who took part in the interviews were frustrated with wasta and the frequency of the term used by the women was quite surprising with the participants viewing it as negative force and by many as a patriarchal weapon. When asked what the single most important gap or limitation was in the reform process more participants mentioned wasta than any other single issue. It is seen as an all-pervading influence which men use to advance and protect their social and economic position. In the political and employment domains wasta is perceived as working against women's interests as well as acting as a degrading influence on social, political and economic progress. Huda highlighted that it was a particular problem in the public sector:

In Kuwait, the public sector is based on wasta which works against women in most cases. If it is not wasta then progression is just based on length of service with promotions given simply because someone has been in their post a long time. Heads of ministries and other senior officials are rarely there because of personal achievements. 
Wasta is seen as anti-meritocratic with family and social connections being used to replace formal qualifications and/or relevant experience. When asked, What was the one thing they would change? Mona replied:

Wasta! I would personally change that because I believe that wasta is a disaster in the country, if we change that we will be in a better country. If I put the right man [sic] in right position the country will improve and the society will be better. Many people are in high positions but are not qualified for this position - how can that happen?

Similarly, Halaa states the case for more meritocracy and less wasta:

Putting the right person based on the qualification and the majors that are required. Personal interest is preventing legislative reform while wasta just ignores the law.

Huda brought together the themes of wasta, education and employment demonstrating their interconnectedness. Wasta, it seems, was responsible for many women being placed in roles that do not match their qualifications:

In the future I hope that it will no longer be the case that people will think or be conscious that her qualification is in graphic design but she will be placed in a bank. Or if her qualification is in marketing that she will work in a newspaper. Why? Because of wasta which dominates many areas of life at the moment. However, I believe that will decrease in future and then people will work in a role where they are most suited.

Interestingly, there was nothing in the words of the participants to suggest that wasta is inherently patriarchal and one can imagine that the wives and daughters of men wellpossessed of wasta may use it or benefit from it themselves; however, from the data it is clear that among the sample of urbanised educated women it is seen as a highly negative aspect of Kuwait's patriarchal society and something they eschewed in the strongest terms.

Among the women in leadership participants wasta received just one mention, from WiL2, the parliamentary consultant, which was in the context of candidate selection, voting and the relative lack of success for women since they were able to stand for parliament: 
They choose candidates who give help in wasta and who offer personal benefits to the voters and that led the voters to a belief that men can do this job better in helping society.

Bailey (2012) who studied perceptions of wasta among Arab women and found them (particularly those classed as having high wasta themselves) reluctant to discuss their own personal uses of it so there is the possibility that like economic capital, this form of social capital is mainly, but not exclusively, under the ownership of men. However, there is no indication in the data that the influence of wasta has weakened or changed in any way since women returned to politics as both candidates and voters. Wasta is associated with corruption, but is a form that is not controlled by any law and hence its diminution relies on individual decision-makers and policymakers discarding the practice. As such it remains powerful and any change would most likely be slow. Having said this, based on the statements of the participants in this study, it is a process which may be accelerated by having more women in positions of influence who can offer strong objections to it publically.

If wasta was one reason, then there were other accounts offered for the relative lack of success since enfranchisement. From the sample of urban educated Kuwaiti women there was a sense that the small minority of women who do gain political influence may be institutionalised or forget that part of their remit is to represent women. Mona exemplified this:

The people who are now in parliament are not doing anything new, just the same things, same ideas, no development.

This disenchantment from the voters' point of view was given a different perspective by one of the women in leadership (WiL4) who attributed the lack of impact of women parliamentarians to the 'system':

It is because of a lot of factors ... the corruption in the political system is a main factor. I again say it is not women's lack of leadership. It is not about the gender, it is about the system and the efficiency. In my opinion it is absolutely not fair to evaluate women's success on the past 10 years' experience of women in leadership. Although she has got her rights, she has not really been given the chance to do something with them with all the corruption going on here politically in Kuwait, due to the battles between the political interests. 
From inside the assembly this study heard the views of a former female MP, WiL5, (an MP at the time of the interview) who referred to the procedural arrangements for considering women's issues:

There is a special committee in the Kuwaiti Parliament responsible for the laws pertaining to women. This committee consists of 4 female MPs and one male MP. The difficulty lies in the Islamic powers and the tribal representatives in the Assembly who are not members of this Committee.

The former MP rejected the approach of specifically legislating on women's issues but rather sought to influence new legislation, amending existing law and relying on general non-discrimination clauses. While this may seem to lack radicalism it is perhaps a necessary pragmatic approach considering the small number of women in the assembly and the strength of the opposing parliamentary interests.

Finally, it is important to highlight that the relative lack of impact of women since their enfranchisement and, albeit low level, entry into representative politics, could be partly due to the ambivalence of Kuwaiti women to enthuse over entry into the political domain, the quantitative study found that even among an educated urban sample $43 \%$ of respondents failed to disagree with the statement that Politics is better left to men as it is their role.

It is also however worth remembering that while formal discrimination in the workplace, education and other public domains in the UK was outlawed by the Sex Discrimination Act 1975 informal discrimination continued. Two means for its continuation are commonly referred to as 'the old boy's network' and 'the glass ceiling'. Both are seen as informal means of denying women equality of opportunity even in circumstances where formal discrimination is illegal. It is worth considering the parallels between wasta, that is so prevalent in the Arab world, and what is referred to as 'the old boy network' in the UK and also whether any similarities might point to this form of social networking being a part of maintaining patriarchy. In the UK 'the old boy network' specifically refers to informal networks that mean that former pupils from the same private schools are mutually supportive. Wasta tends to be more family/ blood relations based. Oakley (2000, p. 38) explains, "In old boy networks, the members of the old boy network transfer the competition and power advantages realized in the 
formal structure onto friendship patterns and alliances within the informal system." This can be compared to wasta which according to Hutchings and Weir (2006, p. 143) "involves social networks of interpersonal connections rooted in family and kinship ties and implicating the exercise of power, influence, and information sharing through social and politico-business networks". However, the old boys' network in the UK is totally gendered while wasta is not necessarily so, as it is rooted in the family and wives, mothers, daughters and sisters can also benefit from its use. In reality, however, with men dominating across most public domains it is they who are most associated with it and wasta has become a bedfellow of corruption with many people, including some of the participants in this study using the two words together in the same utterance.

Moving on to the glass ceiling, this was a term first coined in the late 1970s in the United States and was first used in the Wall Street Journal in 1986 (The Economist, 2009). It described the invisible barrier which seemed to be preventing women from climbing to senior positions, principally in the corporate world and was offered as part of the explanation as to why women made up such a small percentage of senior executives. Grout, Park, and Sonderegger (2007) sought to explain the glass ceiling as an economic phenomenon. The basic assumptions of their model included that women have to work harder than men to achieve equivalent senior positions by virtue of their gender and that when in that position they tend to earn less. However, in Western countries of the $21^{\text {st }}$ century both men and women use personal networking particularly in the employment domain and online networking may have levelled the playing field in this regard. It is possible that Arab women will increasingly take advantage of this to develop their own social networks for their professional lives and that as those networks strengthen, that equal opportunities and anti-discrimination legislation might, hopefully, eventually be introduced into Kuwait resulting in the glass ceiling being at least partially if not significantly lifted. If this happened, then women's empowerment from employment can only increase.

\section{Empowerment through employment}

As already noted, in the recent past Kuwaiti women have attained a significantly stronger position in the workforce both in terms of numbers in employment and in reaching more high profile positions such as prosecutors, ambassadors and business leaders. Though 
widely reported these examples still remain exceptions but the overall trend toward women's participation in employment is undoubted.

The questionnaire which formed the first phase of this research produced findings which were somewhat contradictory regarding the area of employment. The women who took part in the interviews were also equally split ( $\mathrm{n} 10 \mathrm{v} \mathrm{n} 10)$ in agreeing or disagreeing to the statement that there should be more women in senior management positions; something which is perhaps surprising bearing in mind the highly marked absence of women in senior positions in a whole range of employment sectors. Government data from 2011 reveals that of a total of 534 executive positions in the government sector only 55 were held by women (SKCSB, 2013, p.8); this is despite the fact that there were more women working in the government sector than men. The figures show that women were most likely to be in the 'general occupation' category than senior or specialist categories which are dominated by men. The $10.3 \%$ figure for senior executive civil service positions in Kuwait compares with 35.9\% in the United Kingdom (Smith, 2011). Elsewhere in the results of the questionnaire survey (see chapter 5) it was reported that $56.6 \%$ of women agreed that women should have the same opportunity as men to build a successful career.

\section{Work as fulfilment}

The women interviewed for the study were asked for their general opinions of women in the workforce. Here is a selection of their replies which illustrate the type of attitudes among the sample:

Samar: One hundred percent I agree that women should work because it's really good for them personally. Not that without work she will be dead but work will make her life more fulfilled.

Maha: Because she has the same qualifications as men nothing prevents her from doing same job.

Shahad: I agree with [women working]. She will feel herself and depend more on herself. Also she won't need to be married.

Munira: Work is life. I gave up work and stayed at home for 9 months - I couldn't handle that so I went back to work. I stayed home and cooked, took the kids to school and went back home to clean - I hated 
it. My intention was to go on courses and things like that but I found I just didn't have the time - in fact I had more time when I was working.

Fouz: Women are half of the society and women now reach higher positions and I have found that woman do better work than men.

In a comment that is reminiscent of Article 41 of the Kuwaiti constitution, which states that "Work is the duty of every citizen", Samar went somewhat further in extolling the virtues of work for women:

Women should work, it is very important. I would make work obligatory and if a woman does not she should be fined by the government.

Given some of these comments, it is perhaps right to question whether if work is life and the source of fulfilment then why there are only $43 \%$ of Kuwaiti female adults in employment. Part of the answer is surely that employment was among the expectations of an educated urbanised woman more so than some other groups. Women from more traditional backgrounds may adhere more closely to the notion that women's place is in the home.

\section{Equality at work}

Participants were also asked whether they thought that a woman and a man should be treated equally in the workplace:

Huda: Yes, women and men should be treated the same. If he is male and I am female nothing really changes at all.

Samar: Yes. Sometimes women perform better than men so she should have equality in all jobs. It's all about ability, some people can and some can't do certain jobs so it's all about the ability I believe.

Kawther: Yes, it should be equal because there are women who can achieve this. For example, if I want to join the army then I can and there are others who cannot; so we have to have equal opportunities in work.

Shaima: Yes, why not [work]? Women are doing all kinds of jobs now, even driving ambulances and things like that. I think women can do just about any job. 
Equality in the workplace was a valued principle for the participants; however, there were counterarguments represented. In particular, women's physical and mental characteristics were cited as making equality impossible by Mai and Fai and Shahad who also referred to men's greater financial responsibilities as a reason for their earning more:

Mai: I think it's not fair for a woman to be equal to a man in the workplace because she has a female nature so it would not be acceptable for her to be equal to a man.

Fai: In some fields I don't think she can. Especially in her physical ability she cannot do the same jobs as a man.

Shahad: A married man should be above her salary because he has a responsibility to take care of the family. Sometimes the husband gives this extra to his wife.

These comments reflect a pragmatic approach and an understanding for some women that currently men have greater financial responsibilities in the context of a marriage. For single and divorced women this financial 'contract' does not apply. Participants were asked about equal pay: they were asked whether they thought women and men should be paid the same for the same work? Mona, Samar, Maha and Fai had no doubts concerning the principle of equal pay for equal work:

Mona: Yes, why are they not paid equally? They put in the same effort so why should one have a higher salary than the other.

Samar: For sure yes, in Kuwait we have men who get more salary and this is unfair. They have to pass a law that brings fairness to men and women.

Maha: Yes, and sometimes the work she does is better so she should be paid based on her work quality only. Especially because these days, women also pay for the family expenses so she should get equality in pay.

Fai: Yes, he shouldn't get higher salary. And also regarding life expenses these too must be shared equally. He pays his share and I pay mine.

Fai's comment is particularly interesting as it points to the existence of 'partnership' marriages based on a greater equality of responsibilities in the way some western 
marriages are. However, a different note was struck by Munira who echoed the previous comment by Shahad; both pointed to men's greater responsibilities to support the family:

Munira: No it should be different because he pays for the family and kids but my salary is just for me so it's right to be higher than a woman's.

The participant comments above imply that attitudes to equal pay are probably determined by the reality in each household. Some households are clearly two income households while in others the man takes on the traditional role of breadwinner. Where both pay equally to household expenses, both should earn the same but where a man is expected and does in fact pay the living costs then the case for equal pay is less strong, according to this study.

\section{The right to choose work}

The participants were also asked whether women should have the right to choose to work and also whether married woman should work and how this might affect family life. On the right to choose to work the responses were unanimously positive (n20), such as this one from Khawla:

Yes it's important that she has the choice and the right to decide. In the same way as we expect of men that they work and support the family same as when we say he have to work also she should work to protect herself and not be beholden to a man.

There was, however, a qualification in the response of Shahad:

Ninety-five percent of the time she has the right to decide but sometimes there are circumstances where it may be impossible for her to work. Yes, he can decide that she stay in home.

When the question moved to married women all but one of the participants (n19) suggested that marital status should not make any difference to a women's choice to work. For example:

Fouz: Yes, if she chooses to, if not then she will be under men's control. 
Areej: If she wants to yes, she can do both and every woman knows herself. Because she will know if she can do both or not.

Mai: Yes, if she wants to, if she can do both why not work and be a mother or wife at the same time.

Better cooperation in the family, helping with the family finances and self-fulfilment were all mentioned. However, Munira qualified her view and questioned whether married women would want to or indeed would be able to work:

No, this is not necessary. If she doesn't need to do it she probably won't and there are women who simply can't manage between work, kids and husband.

The findings suggest that there was overwhelming support for women's participation in the workforce from the participants - which is unaltered by marital status. Such attitudes would not be out of place in the most gender equal western societies. Of course, it is perhaps right to assume that there would be far less unanimity if the sample had included women from traditional backgrounds.

\section{Work and independence}

The participants were asked to consider the consequences for the family where both partners were working. Some interesting ideas were put forward:

Samar: The woman is now helping in paying the living expenses and that will raise the level of the family and make life better.

Maha: Women will be more social people and will be less pressured and most women help their partner.

Kawther: It affects her. I think a wife will not want one dinar from her husband any more. She can be totally independent and the relationship can become based on love and not money.

Khawla: I can see the positive angle because the work can impact both the man and woman in a family. If the woman works she can get some experience and bring it to the family. Also she can educate and treat her kids in the family differently, in a good way. Also the man in the family when he works he will leave a gap in the family, so it's not about men or women it's about making a balance. 
For the overwhelming majority of the urbanised educated interview participants the working woman was clearly here to stay, married or unmarried. Only one women, Shahad, raised negative impacts and vehemently explained that 'family comes first, work second', but this aside there was a resounding expression of support for women's place in the public domain of work. The leading motivation appeared to be obtaining the satisfaction that comes through work and the opportunity to lead a fuller life.

\section{Work and competence}

There were also repeated assertions that on a meritocratic basis, women could be equal or outstrip the contributions to their jobs compared to men. Mai enthused about the contribution women could make:

Women are amazing at work, creative and very serious in work. I love the fact that women work.

Further positive characteristics came from Khawla:

The Kuwaiti woman is more serious and more productive than her male counterparts.

And similarly Hanan added organisational skills to the list of women's superior qualities:

I see women as being more organised than men who seem more careless and less serious. But still it is the men who are in high positions.

The women in leadership also expressed a range of points about women, work and the family and in some cases these diverged from the sample of educated urbanised women. Drawing on her personal experience a minister (WiL1) questioned whether some women really did want to work:

Requests are made for example to take more leave or requests to finish work early because she has a family, so in this position she shows that in fact she doesn't really want to work but she wants to look after the family.

The minister continued: 
When we request [employees] to do overtime or tell them their role needs her to be at work she always tells me that her husband or brother are not allowing her and in 2015 in Kuwait I can't believe that in these days we still have this problem.

This comment is interesting as it comes from direct experience and reveals that there are still obstacles (patriarchal) standing in the way of women and their desire to play a full part in the work force as well as perhaps a lack of understanding (even from other women who are in positions of leadership) with regard to what women actually want to do as opposed to what their circumstances allow them to do.

\section{Living to work or working to live?}

All but two of those who took part in the interviews (n18) were working; of those not in employment one was retired and the other was still studying. Participants were asked to talk about their own experiences of work and what it meant to them. The most often repeated phrase was that work was their 'life' as well as being rewarding both in financial terms and in terms of self-fulfilment; in other words, a combination of extrinsic and intrinsic motivating factors were evident. There were strong indications that economic motives were behind women's increased entry into the workforce; specifically, financial necessity where the cost of living no longer supported the traditional one male-earner household and more women were living independently as a result of not marrying or being divorced.

'Work as life' was a message that came out really strongly in the interviews and the participants took time to explain in some detail what it meant to them to be participating in the world of work. Work seemed to offer the participants a chance to express themselves in a different and fulfilling way and even though they were not equally paid and despite the problems of unequal treatment in work, it was clear that this was perceived to be far less oppressive than not having the choice to work due to the patriarchal pressures that render women subservient and in the home. Work, it appears from the interviews, can bring freedoms, not least the prospect that a woman can choose not to marry or remarry due to financial pressure. Women are increasingly able to support themselves and in so doing potentially they are able to avoid the most iniquitous aspects of traditional norms and everything that comes with marriage (often negative) that is 
governed by personal status law, as highlighted in earlier chapters. Some women opted to point to extrinsic motivators for working:

Mona: It's the most important thing that women work. While I hope I could relax without work the salary is really important. That's what I feel I want to work, because of the salary.

Samar: I cannot imagine myself sitting at home. Also, how will I pay my way in life? I don't accept someone giving me money for doing nothing.

Maha: Yes, I have to live. That's why I work.

Munira: Yes [I work], it's a source of money.

However, there were equally strong intrinsic motivators for working among the participants. Shahad views working as a form of national service, Areej referred to her vocation as a teacher while Mai, a divorced woman, made reference to working in order to be able to live with her children:

Shahad: I feel I will serve my country also I feel proud [as a teacher] when I see the girls that I taught go on to get great positions.

Areej: Yes, I work. Work is everything for me. I love my work especially because I work within the sector I love. I love teaching students of this age.

Mai: Yes, I do [work], that way I can live with my kids. My work is my own private part of my life. I love it.

Mai's comment is interesting because usually 'home' is seen as the private part of the life and not 'work' which is more attached to a public persona - so this is perhaps important in the context of how women feel governed in the home. For Mai, it seemed that work provided a degree of escape from the home.

Such intrinsic rewards are not necessarily a new phenomenon as one retired participant, Fouz explained:

I am now retired. I worked for 33 years. It is really important to give to society through your work. It was my whole life - I loved it. I loved my work not only when I became a leader at the education institute but 
before also. I felt proud and loved the work when I was a teacher I came every morning with a love and a belief in my job.

Kuwaiti women, so long largely absent or shielded in the public domain have used work to enhance their social relations and visibility treading into the social space hitherto occupied almost entirely by men, as Munira explained, when asked whether she worked:

Now yes I do work. It's again organised my life. Working and being with colleagues gives me a healthy social life. I can meet people and share experiences. I make friends, it is a chance to escape and feel independent sometimes. I also have my own income and decide my expenses and life needs.

Again, Munira's comments reflect those of Mai in that women can perceive work to be an escape from dependence and subservience.

\section{Women in senior positions}

Arguably, the glass ceiling exists in virtually all countries to some extent. While there are examples of Kuwaiti women playing senior roles in a variety of public and private sectors, these are very much exceptions. The Kuwaiti ceiling has become less opaque in recent times as the influences preventing women from rising to the top have become less obvious. The intangible power of wasta has already been discussed, however the construction of an emotional identity was a surprising finding and was presented as an obstacle to women's progression.

The minister (WiL1) explained at interview that there are no insurmountable barriers put in place by the government to women achieving high status positions but she believed that instead women create their own barriers by for example showing insufficient commitment' and being 'too feminine'. She explained:

How will they improve and show society that they are really as eligible for the workplace as men? Here I see many examples of women being given tasks and them responding by saying that they can't do it. The majority of women are like that but when women really work they reach the higher level in jobs. The idea that society is not giving them a chance or the right justice is just an excuse for failure.

The minister seemed to take a rather harsh and unsympathetic view of women's lack of progress in the workforce - both in this research and in other interviews. For example, in 
Gulf Affairs (2015, p.42) she appeared to deny the existence of any impediment to advancement which is certainly not a view shared among the majority of urbanised educated women who took part in the interviews and who raised the issue of wasta so strongly. Of course, she is right to point out that in the strict sense there are no formal legal impediments but arguably it is also remiss not to mention the all-pervading informal forces that are at play, including wasta. The minister (WiL1) continued in what may be seen as a controversial tone where she appeared to suggest that if a woman was to achieve success then she had to act more like a man:

We have examples that show us that when women put her tools to work and not her feminine part she will reach her goals. The tools are the education and her ability to work. I think she may take longer time than men to reach her goals but she will reach them in the end.

In contrast to the government minister, another woman in leadership (WiL2), a consultant to the Kuwaiti parliament did believe that there was discrimination within government when it came to giving senior positions to women:

There is discrimination against women when it comes to women holding senior positions in Kuwait by the government. If it comes to a choice between a man and a woman usually the woman's chances are a lot lower. There is always a kind of border around women in our society. Choices are always made based on the gender not on quality.

A third woman in leadership, a lawyer (WiL4), also perceived women as struggling against powerful patriarchal forces when trying to reach the top of their chosen sphere of work. She spoke of the 'shame' attributed to women working in areas deemed inappropriate for them and the cultural factors holding them back:

The control of men is the main reason for not having a satisfying number of women in senior positions. That results from the structure of the society which contains a majority of people who do not support women going into senior positions due to the strict traditional culture.

A woman in leadership working in media sector at a senior level (WiL4), suggested that in the minds of the Kuwaiti people there were different categories of jobs based on their social acceptability, her comments are particularly enlightening and worth quoting at length: 
The acceptable jobs for a woman can be teaching or any simple office work in the government sector in a segregated field from men, with 8 working hours from the morning till the afternoon; going back home continuing her housewife duties or family responsibilities...This type of women gets their monthly salary and annual holiday allowance without real job responsibilities. With this type of job women can live their life based on the traditional lifestyle that the man and the culture require...

There is also a second group of women seeking other types of jobs that are the ordinary or we can call them a bit unusual; jobs such as working at ministries, organisations, or the private sector. But also there are limited working hours and limited connections with men in the workspace.

Clearly, WiL4 is suggesting that women can enter certain types of employment (segregated to a significant extent from men) without threatening their role as wife and mother and thus presumably meeting less resistance from men. However, if a woman entered more sophisticated employment (working alongside men) then this could be perceived to be a challenge to the patriarchal order. As WiL4 continued to explain:

The third group is the unusual or out of ordinary. From my experience in the field of Mass Communication and Media as an Editor-in-chief of Kuwait News Agency KUNA from 1988 until 2001; when I first worked in that position and earlier than that time, working in that field was new to women and society. No women were taking that step because the media defined such steps at the time with the words SHAME, WRONG, CROSS, NO! It was against having women's face on TV, women's voice on radio, the look of the women, the reputation, all of that affected the acceptance of having women working in unusual work fields and jobs. That is an example.

Of course these sorts of issues are not isolated to Kuwait. In the UK the government's best corporate practice guidelines as presented in the Davies Review in 2011 recommended that $25 \%$ of board members should be women, at the time of publication the figure was just 12.5\% (The Davies Review, 2011). The 2015 review of progress towards these objectives showed that at that point $23.5 \%$ of corporate board members were women, just short of the objective (The Davies Review, 2015). Conversely in Kuwait, one source suggests that just $1.7 \%$ of corporate board positions are occupied by women (Catalyst Inc., 2014). In chapter two of this thesis data was presented which suggested that there was a causal relationship between national religiosity and women's absence from senior corporate positions. This indicates that in Islamic countries such as Kuwait the process of securing representation and power in the private sector is set to be 
a long one. However, as in the UK, if there is a political will towards change, it can come through positive discrimination.

According to the experience of members of the European Union, women's participation in tertiary education does not automatically bring power or economic influence. And, in a religious country such as Kuwait attaining economic power through leadership of major corporations may be extremely difficult. However, it seems from the recent past in the UK that government action can deliver greater empowerment even in the face of the twin concepts of the 'old boy's network' and the 'glass ceiling'. This step change in representation was achieved despite the recommendations having no force in law. Therefore, while religion and patriarchy together with the pervading influence of wasta may present formidable obstacles to women's economic empowerment there is precedent to suggest that government action can be effective at delivering change.

\section{Financial independence}

The data appears to indicate that the majority of women who took part in the interviews believe that education leads to greater labour force participation, and labour participation on more equal terms can in turn lead to more equal income distribution, economic power and ultimately gender equality. To understand whether this might be the case, the experience of the UK is again quite helpful. According to the World Bank (2014) in 2013 $56 \%$ of women aged 15 years and older participated in the labour force in the UK; the equivalent figure for men was $69 \%$ - a gender gap of 13 points. In Kuwait, 44\% of women are engaged in the labour force while $83 \%$ of men participate - a gender gap of 39 points (World Bank, 2014). While there is a substantially larger gap in participation the trend has nevertheless been steadily towards greater participation levels for women with Hosni and Al-Qudsi (1988, p.10) citing participation levels of 12.5\% in 1965 and 18.8\% in 1985. However, levels of participation do not equate to income distribution as data from the UK demonstrates. This is because women tend to work less hours and earn less per hour when they do work. According to Davies and Joshi (1998) in 1968 UK women already made up $37.2 \%$ of the workforce but earned only $19.9 \%$ of work-based income; by $199048.4 \%$ of workers were women earning $31.1 \%$ of income.

Jaumotte (2003) explains that labour force participation rates for women are influenced by the tax system. Across developed countries taxation has tended to move from family 
based (the incomes of both partners) to the individual with tax allowances for individuals making it more worthwhile for married women to become second earners. A second positive influence is state provision of childcare facilities and child benefits. These have risen in developed countries in recent decades. Thirdly, parental leave is another positive influencing factor identified by Jaumotte (2003). Flexible working with widespread availability of part-time employment has also enabled more women to participate in the labour force. Finally, the passing of anti-discrimination legislation such as the UK's Equal Pay Act of 1970 and Sex Discrimination Act 1975 has yielded positive results (although it cannot be said that this legislation yielded results overnight). Families themselves have also voiced a strong preference across Europe for women's participation in the labour force with one study of couples with young children, conducted in 1998, revealing that only one in ten couples preferred the traditional male (only) breadwinner family model (Jaumotte, 2003). There is no such study for Kuwait to compare with but one can assume that this figure would be dramatically higher, although signs of similarity appeared among some of the educated urbanised women in this research study. It is also possible to assume that while participation rates among Kuwaiti women are rising and as a result income distribution is becoming steadily more equal, the lessons from developed countries such as the UK is that reaching equality is a long process and requires a series of government actions that are as yet not on the Kuwaiti horizon.

The questionnaire in this study did ask women for their views on specific financial issues which effect how independent a Kuwaiti woman could be. The first related to access to public funds for housing. As noted previously, only men can apply for such funds which come in the form of low interest loans although some steps have been taken to provide loans to divorced and widowed women. To the statement 'Women should have the same right to public housing funds as men' only $40.3 \%$ either agreed or strongly agreed. Similarly, the questionnaire sought views on a second issue impacting on women's financial independence - the child allowance paid by the government (approximately $\$ 275$ a month for each child). The payment is made to the father something which contrasts to some Western countries such as the UK where it is paid to the mother. To the statement 'The $50 \mathrm{Kd}$ Children Government Allowance should be divided among both parents', only 30.7\% agreed or strongly agreed. Clearly therefore there was no majority support for either of these policies being changed to provide greater financial independence for women. There 
was even less support for the statement 'Both husband and wife should be equally responsible for paying their living expenses' to which only 6.4\% strongly agreed and $15.3 \%$ agreed.

In contrast however, financial independence through employment was widely viewed as a positive thing both in the responses to the questionnaire and in the findings from the participant interviews. In the interviews participants were asked what they felt the consequences of women's financial independence were or would be. 'Greater power', 'responsibility' and 'freedom' were all mentioned. Manar said:

Better family and better lifestyle. Women will not push her husband to spend on her, life is expensive and it is always good to share especially at this time when life's needs and expenses are too much.

However, Huda felt that some married women may not get the independence they might anticipate through having a job as their husbands would seek to retain control of their income:

I think men will still expect to take your salary then give you what they want from it. Now that women are more independent they may seek greater control over their own earnings.

Mona argued that men should not fear their wives becoming more financially independent:

I believe the financial situation will help the family's situation and that will help the man also. Because if she becomes independent then he will feel better on a financial level, the family will be more about cooperation in the relationships not obligation.

In Victorian Britain men and women had sharply different roles assigned to them and women's place was most definitely in the home. Employment, higher education and political participation were most definitely not part of this role (Hughes, 2015). Christianity provided the moral justification for this separation of spheres and as Christianity declined from the 1960s onwards so did the demarcation of roles. What we can learn from this for Kuwait is unclear. There are no ways of formally measuring the levels of secularism in Kuwait but the kind of views expressed in this study suggest that the patriarchal interpretation of religion and religious texts is by no means universally accepted. 
Munira explained how she felt she already had full financial independence within her marriage:

Some women are already financially independent - I talk about myself. My husband does not ask me about my salary. I support family and I share a lot of expenses with my husband and that makes him happy about it. We are almost equal in spending since I don't put pressure on him and I contribute financially. I think it is a must and men can benefit a lot from that. Women's financial independence has a positive impact on the family.

Similarly, a woman in leadership, WiL5, highlighted financial independence as a route to greater empowerment for women:

I think that through financial independence women can gain their independence in decision-making on a step by step basis and we should make sure that society affords them such a level of independence. In the society of the past, man used to propose marriage to a woman who does not work, especially tribal people, but at the present time we notice the evolution whereby they would propose marriage to a woman who works [for example] as a school teacher. I think that if the state gave women financial rewards according to the specialisations and cadres, the same man would aspire to marry a woman with a high income and he would break his duties and responsibilities because they reduce his financial burden.

This raises the intriguing possibility that economic realities may come to supersede the previously all powerful traditions, patriarchal culture and religious beliefs and that this is mainly being driven by women's entry into the workforce. Men may find it hard to resist the attraction of a second family income and the hitherto emasculating stigma of not being the sole provider in the family may dissipate over time as it has done in Britain.

Another woman in leadership (WiL2) believed that the already detectable trend of women pursuing a career or starting their own business was empowering women in Kuwait:

I think today's woman is independent financially. She has her own career and business and that will give her more power and she won't be led by men and will be more independent in her opinion and that will also benefit society and make it stronger because she is half of that society. 
Most of the comments made on financial independence for women were made in the context of a marriage. However, there are of course many single, divorced and widowed women who face particular challenges in trying to achieve financial independence. This was discussed with the then MP (WiL5) who participated in the women in leadership interviews. At interview the issue was raised as to whether women could become financially independent if they are unmarried or divorced with the availability of a salary, and whether women could practically speaking get divorced under the existing laws. If for example her income is $\mathrm{KD} 800$ and the cheapest apartment is rented for some KD 300 dinars and a car instalment is around KD 200 in addition to food requirements, with child expenses then this would make it very difficult to get divorced and depend entirely on herself. She replied:

No, no, of course not on such a budget and with children. However, I think that the Labour Law is good for women, and it allows them to work and get as many leaves and vacations as needed. The same case is with the Civil Service Commission Law and the Labour Law in the Private Sector [No. 6 of 2010].

There was an indication from the former MP (WiL5) that men, including male lawmakers, were feeling threatened by women's increasing financial independence. She referred to traditional Islamist and tribal interests to restrict a woman's social role to one within the family, subordinate to the male and primarily responsible for serving the husband and raising children. She noted the attempt by some lawmakers to put forward the idea of the salaried spouse, paid to stay at home as reproductive labour rather than productive:

Many members were in agreement with the idea that a woman should stay at home and be a housewife and at the same time get her salary, and I refer to such laws as "Stay at Home" laws. MPs who raise such calls are the Islamists and members representing the tribes.

So, despite the benefits to the family, for both men and women, there is also a clear indication that some groups of law makers are not fully on board with the changes taking place and perceive that the negatives outweigh the benefits. In other words, women's subservience and their place in the private sphere is to these sections of society more important than the economic and wider societal benefits that women playing a full role in the labour force brings. 


\section{Emotions as a perceived weakness in women}

In contrast to the positively asserted characteristics that women bring to the work domain, there was evidence throughout the interview data that women can accept their own stereotype with regard to emotions. The suggestion was repeatedly made that women cannot operate successfully in the public domain because of emotionality or mutual jealousy. There are examples in the data of women being described by their own gender as unsuitable for the judiciary, ineffective as politicians, inhibited in the workplace, and more prone to divorce, all because of their emotions, seemingly believing and reiterating a stereotype often put forward by men; Shaima exemplifies this:

I am against women becoming judges because a woman is more emotional she will judge with her heart not her mind.

When asked what was holding back women from greater participation in politics Areej replied:

It's her feelings. Sometimes her emotions prevent her doing more.

Areej also saw the female propensity to emotion as potentially harmful to the workplace:

Women should improve themselves on different levels but the only problem is her emotions. She feels jealous of other women but men never get jealous of other men. There are some emotions in her nature that affects her at work.

There was an echoed sentiment among the women in leadership, as WiL3 commented:

Another reason is that women feel jealous of other women in the workplace. I just got a phone call to inform me that women in high positions were fighting each other because they are women; so usually from my experience they don't support each other.

Women's emotions were one of the reasons identified for the rising divorce rate which prompted a woman in leadership, WiL1, a government minister, to disagree with the proposal that women should have equal divorce rights to men:

No, because she is fast, impulsive and emotional in her decisions. I think part of the divorce problem arises because they are both not 
prepared for marriage. God won't allow [equal rights in divorce] and we don't want to play around with religion.

The government minister is espousing views that are supportive of Islamist politics, though it would be difficult to characterise this as Islamic feminism, the phenomenon discussed in chapter three.

Woman as an emotional being is a narrative that stretches well beyond Kuwait and the Middle East. In Victorian Britain, for example, women were portrayed by the medical profession with pseudo-science describing them as weaker, more emotional and hysterical (Hughes, 2015). With such authoritative sources supporting patriarchy, it is unsurprising that both men and women accepted the portrayal. However, few in developed countries, for example in Europe, still use it as a disqualifying characteristic in civic life and to hear it repeated so regularly in this study can be said to be significant and a symptom of the patriarchal stronghold in Kuwait.

If Kuwaiti women are perceived as emotional which could translate as weak, then perhaps, at least according to one of the women in leadership (WiL1), a successful woman is seen as one who has lost this emotionality, something constructed as undesirable:

Also the society these days calls any successful woman an 'iron woman' and I don't see any reason for that.

Whatever the scientific evidence, and it seems this is more of a classic social construction, concerning women's hormones and emotions, it is clear that in some societies the narrative of women being prisoners to their emotions is more powerful than others. In this study the concept of the emotional woman was prominent in the minds of urbanised education women. For some it was seen as a reason why women were unsuited to presiding over courts and dispensing justice. In Western countries the idea of women as governed by emotions has shrunk in prominence. In its place a new image of powerful often masculinised women has gained popularity, embodied by political leaders such as Germany's Angela Merkel and Britain's Margaret Thatcher, the latter famously labelled the 'Iron Lady'. It was not always so and historical documentation shows that the emotionality narrative was strong in the $18^{\text {th }}$ and $19^{\text {th }}$ century. Proceedings of the Old 
Bailey (2015) portrays gender roles in $18^{\text {th }}$ century Britain, highlighting the emotionality of women:

Men, as the stronger sex, were thought to be intelligent, courageous, and determined. Women, on the other hand, were more governed by their emotions, and their virtues were expected to be chastity, modesty, compassion, and piety. Men were thought to be more aggressive; women more passive. These differences were echoed in the faults to which each sex was thought to be prone. Men were prone to violence, obstinacy, and selfishness, while women's sins were viewed as the result of their tendency to be ruled by their bodies and their emotions, notably lust, excessive passion, shrewishness, and laziness. (Proceedings of the Old Bailey, 2015)

The emotionality of women is a concept derived from religion, both Islam and Christianity. Hadiths define women as deficient in their religion and intellect, governed by menstruation and eager to lead good men astray, while men are rational, women are emotional and were designed to be so to fulfil the role God planned for them. According to this reasoning, it is a role that does not include sitting in judgement over others (Roald, 2001, p.132). And this doctrine has been passed down through the ages, yet although a social construction, women in reality are being held back by it, and they are held back by both men and women who believe this. Arguably however, a greater presence in the public sphere will undoubtedly make the depiction of women as emotionally weak less easy to sustain and furthermore as women enjoy the benefits of higher education and appear more frequently in the professions and in positions of leadership the emotional woman could become a thing of the past as it has largely become in Britain.

\section{Empowerment through education}

In the sphere of education women have made significant gains in recent decades, and the percentage of young literate women in Kuwait is now equal to that of young literate men. There were 50,718 female students registered at Kuwait University in 2011/12 against 22,487 males. There are also more female than male students in private universities and colleges (SKCSB, 2013, p.8).

An educated female population in Kuwait has been established a long time. The 1985 Kuwaiti census reported that more than 70 per cent of native female workers had at least completed secondary education, compared to just 29.3 per cent of native male workers. 
However, as already noted, while women dominate Kuwait university enrolment this may be partly due to the fact that men are more likely to study abroad while women may be prevented from doing so by their male guardians (UNICEF, 2011, p.3). Nevertheless, participation in higher education and girls and women's overall educational attainment represents one of the most significant changes in Kuwait, although they have been well represented in Kuwait's universities since the 1960s, particularly compared with other countries in the region. In this research study, because education was a domain where women had been strongly represented for decades there were no specific questions on the topic. However, given the links between education, formal educational qualifications and career success and a sense of empowerment, not to mention greater financial independence it is surprising that a strong meritocratic tendency emerged from the participants. For example, Huda argues that politicians should be qualified in political science:

Today girls have access to university and can, if they want, study political science. They now know they will have the chance to run for election. Basically their voice will be heard, [the degree] will not be just a piece of paper.

Education was seen as a long term driver of change in terms of national development as well as in empowering women. Kawther, working as a teacher, put the matter succinctly:

Education is the most important area. I am a teacher so I feel how it changes people in the long term. It has a spreading effect throughout society and can be a force for good to counter the tribal, traditional attitudes that are really at the roots of many of women's problems.

It was not just culture and social relations that education can improve. Maha saw it in more economic terms:

Better education will give better human resources in Kuwait. In the global marketplace a high quality workforce is essential unless we want to go backwards. In such a small country we cannot afford to just develop the male half of the population. Luckily I think the government understands this which is why so many women graduate.

According to a woman in leadership, a former MP (WiL5), there was much still to do to improve Kuwait's education system. While she acknowledged that there are obviously some progressive people working in education she believed that many others were likely 
to hold to traditionalist attitudes to girls and women, and this was perceived to be inherently contradictory:

I think the educational system has a considerable impact in influencing society. I don't believe that the present traditional education system is capable of creating a girl who is intellectually independent and who is self-confident. If the school does not believe in the importance of letting the girl achieve leadership positions and in the excellence of the girl as well as the boy and the need to develop independent decisionmaking, how can she [the teacher] convey the information? For example, how can she [the teacher] explain to girls how to become ministers and be capable of competing [with men] if she does not believe in the woman's ability to occupy such positions.

WiL5 also spoke about the route to greater empowerment for women, arguing that while it may be a slow-moving route, the momentum it brings is likely to be permanent and profound. Education effectively leads to financial independence which leads to personal independence and empowerment:

I think that women today are getting stronger, but slowly, and the rights of women have taken women to a stage of empowerment. The main factor that makes women stronger is education and financial independence. If we deal with education, the females represent the majority of students at the University of Kuwait, and that would give them job opportunities to work in the future as university graduates with good salaries, even if a woman does not get married, she would be able to secure the basic requirements of life with full independence, without needing help.

In the most extremist manifestations of Islam, Boko Haram of Nigeria, the Taliban of Afghanistan and Pakistan, men deny women access to education and others such as the group known as Islamic State severely restrict the curriculum to Islamic studies (Naklheh, 2014). Clearly, the control of the supply of education to girls and women is seen to be essential to preserve the patriarchy among some. However, beyond these extreme examples the education of women is firmly established in Kuwait, as described in chapter two. Possessed of this education women have used it to establish their position in the public sphere.

\section{Chapter Summary}


From the known developments in Kuwait in the recent past and from the literature review documented earlier in this thesis it was clear that the themes of empowerment through civic participation (including politics) and through employment would feature strongly in this research. Education is undoubtedly another domain where women have secured advances.

It is always of particular interest when unanticipated themes or sub-themes emerge and in this chapter there have been two: wasta as central to Kuwait's patriarchal system and culture; and women's perception of themselves as too emotional for certain forms of civic participation. Men, it seems, benefit from their wasta while women have to contend with their emotions.

Enfranchisement was almost universally welcomed but there was a range of different forms of cynicism, something after all associated with politicians the world over. Finance, reputational damage, wasta, the marginalisation of women's issues inside the parliament and could be seen in some cases with scepticism, in the decade since enfranchisement women's political participation in the formal processes of elections and legislating has been an important principle but for now at least disappointing in practice.

The most unity among the interviewees was in the employment domain where the commonly held perception was that women should work and in many cases needed to work for both financial and self-fulfilment reasons, satisfying intrinsic and extrinsic needs. The participants believed that women had many desirable qualities and could outperform men in many respects. 'A women's place is in the home' was certainly not found to be a widely supported attitude among the participants. Suggesting perhaps a break in practice with norms and traditions but also there was the suggestion that work provided 'escapism' from those traditions which demand women remain in the home. The interview findings definitely demonstrated strong evidence that women have emerged into the public sphere and they are making full use of their educational attainments.

It is also important to note that compared to other topics and other parts of the interviews, the educated urbanised women in this research were confident and open in their discussions of the recent past and of the domains of politics, employment and education. This could be plainly seen in their non-verbal communication, they were more 
likely to be using hand gestures to support their points and be leaning forward than when discussing other issues that are perceived as more controversial.

The next chapter shifts away from the recent past and the public domain and focuses instead on how women perceive their lives in the present day, particularly in terms of justice, equality and gender relations. 


\section{CHAPTER SEVEN}

\section{EXPLORING WOMEN'S PERCEPTIONS OF EQUALITY AND SOCIAL JUSTICE IN TODAY'S KUWAIT}

In chapter six, findings were presented with regard to the women's views and opinions on the public domains of politics, employment and education. The findings in particular emphasised that the majority of participants held meritocratic views regarding the workplace, pay and financial independence and the principle of equality in the political and employment domains. In this chapter a wider concept of gender equality is considered, as perceived by the sample of educated urbanised women who were interviewed (n20) and the five women in leadership. The aim of this chapter is to present how these same Kuwaiti women, educated and urbanised, experience their gender in terms of equality and social justice within both civic life and the household. It is also the aim of the chapter to address the second research question - "How does the Kuwaiti educated urbanised woman view equality in the arena of social justice in Kuwait?"

The line of interview enquiry which produced the results documented in this chapter was particularly influenced by the findings of the questionnaire that was completed prior to the interviews taking place. As chapter five noted, the results of the questionnaire were very interesting with regard to women's agreement or disagreement pertaining to questionnaire items that focused on equality under the law. Specifically, the results of the survey were somewhat contradictory when it came to broad statements regarding equality. To the statement "Women should have equal rights under the law" $77.2 \%$ agreed or strongly agreed. However, to the statement "Women should be equal to men in society" only $32.3 \%$ gave similar agreement. This suggested a distinct difference in how women perceived equality under the law and within society. This chapter aims to shed further light on this anomaly. In doing so it moves into the controversial area of sharia and discusses how the women who took part in the interviews perceive Islam, or more rightly, men's ownership of religious knowledge, and its effect on their position in Kuwaiti society. 
First the chapter considers women and the judicial system, including the absence of female judges in Kuwait. This is done for two reasons, first to highlight another significant area of inequality, but also because the appointment of female judges could be vital to further reforms of personal law that can be extremely discriminatory and impact so negatively and inequitably on women. In both areas the discussion is informed by the contradictions found in the questionnaire results. The chapter then moves on to consider patriarchy and the public-private separation of men and women that it seeks to preserve. A discussion of attitudes to marriage and divorce follows. Finally, the controversial area of sharia and how the participants perceive Islam is documented. The discussion here is bolstered by participant explanations of how sharia impacts on their position in Kuwaiti society through their own personal experiences. The findings suggest that while women have emerged into the public sphere, in the political, educational and employment domains there remains a powerful conservative force in place, controlling their lives in the private sphere even though these forces have not been able to confine a large number of women to this domain exclusively.

\section{Women and justice in Kuwait}

The women who took part in the interviews mainly saw equality as the 'natural order of things' derived from joint membership of the human race. Thus for example, when discussing the workplace Farah spoke about 'humanity' which was a common theme in the data:

Yes. Women should definitely have equal rights regarding employment because in the end she is human.

The women were able to translate this human rights perspective into equal opportunities, equal pay in the workplace, equal political rights and, for many, equal financial and family responsibilities. However, interestingly, for Kawther male dominance was not the natural order of things. In fact, she saw it as quite the opposite:

Women should be totally independent. If God wanted her to be lower than men, then he wouldn't have given her a brain to think independently but instead would give her a brain designed just to follow men. I don't think it is god who wants women to be just followers; I think this is what men want. 
And, even more specifically, Hanan believed that men had not willingly or deliberately ceded greater equality to women; instead they were actively working to prevent the empowerment of women:

I feel men didn't give the rights to women, we had to fight for them, and men are unhappy that women have got more rights now. They are not giving them willingly.

Some participants even perceived sharing and equality as a route to happiness. When speaking about her son, Mona stated:

I want him to feel that he shares the planet with women and that there is another gender here to share life with in an equal way. I am sure if he came to understand that he will have a happy life.

However, in the domain of justice and the law the picture became less clear and the equality concept less well defined and unanimous. Arguably, the reason for this is that justice and law is a domain closely related to religion, specifically Islam. To restate the discussion in chapter three, the legal system in Kuwait is highly patriarchal. Only men sit as judges and females in the legal profession as a whole are rare; there is no jury system. The system can be divided into two parts: there is a courts system dealing with civil, criminal and commercial and a second one comprising of sharia courts which handles personal status/ family law.

Perhaps the most central dynamic at the heart of Kuwaiti life are the opposing influences of, firstly the Kuwaiti Constitution of 1962 with its emphasis on democratic principles, equality before the law and public freedoms; and secondly the country's tribal history and traditions; and thirdly Islam. Once again to recap, Article 2 asserts that "Islamic Law shall be a main source of legislation", while Article 7 states that "Justice, freedom and equality are the pillars of society", and Article 29 provides for "equality before the law". However, it is the following verse in the Qur'an on which the differential status of women in terms of testimony is mainly based: "And get two witnesses of your own men, and if there are not two men then a man and two women such as you choose for witnesses - so that if one of them errs, the other can remind her ... " [Al-Qur'an 2:182]. Thus as already discussed in chapters one and two, the ability of women to bear witness and consequentially the notion of women sitting as judges becomes far more controversial than women's enfranchisement. 


\section{Women as judges}

In Islamic countries, judges are male by tradition. Males are seen as being capable of being moral leaders, being capable of making legitimate interpretations of religious law and of handing out punishment. Yet, as noted in previous chapters, women are appearing more frequently in the legal profession in Kuwait as lawyers and since 2013 as prosecutors appointed by the Ministry of Justice. They are allowed to hold positions as investigative judges and to work as lawyers. In 2010, twenty per cent of the members of the Kuwait Bar Association were women (UNICEF, 2011). Having women judges, when their presence in the courtroom is becoming less unusual in these other roles, would seem a logical progression; however, resistance to this step is strong from conservative elements of society. As reported in chapter five, the results of the questionnaire identified mixed attitudes to women and their position under the law and in the legal system: while there was majority agreement $(29.1 \%$ strongly agreed and $48.1 \%$ agreed $)$ to the statement 'Women should have equal rights under the law', the practical steps to achieving this such as having women judges and changing specific laws divided the respondents. Almost half $(49.9 \%)$ of all the women who participated in the survey disagreed or strongly disagreed with the statement that 'Men are better suited to making law than women' while the other half agreed, strongly agreed or were not sure. However, only $12.6 \%$ strongly agreed that 'women should be allowed to sit as judges', with a further $16.7 \%$ agreeing. Seemingly, the educated urbanised Kuwaiti women who took part in the questionnaire wanted more rights but relied on men to concede them.

This conflict was explored further in the interviews. The interview participants were asked for their opinions of women as judges and whether they felt that there would be female judges in Kuwait in the future. The researcher asked: "Do you think women should be allowed to become judges or is the law better left to men?" For some participants a positive answer was in no doubt:

Kawther: Yes. What are women lacking that means they cannot become a judge? Women have more feelings so they may have greater empathy with the cases and would be better in giving her opinion as a judge. 
Khawla: She can be the same as man in judgment; nothing prevents her. As a woman you are judge in your house with your kids.

Shahad: Yes, they will be more understanding in women cases in society. And I would like to see women judges and lawyers, exactly like when we accept having women working as doctors.

Huda: Yes, she can be a judge but not as a replacement for men but an addition - again they are the same, they are equal.

Thus the research did find some support for women being appointed to sit as judges. As illustrated in the comments, meritocratic principles were repeated and women's exposure to aspects of life such as motherhood were put forward as positive benefits that women could bring to the judiciary. Some participants knew it was the norm in other countries and saw no reason why it could not happen in Kuwait. This is illustrated by one of the women in leadership participants, WiL2, who referred to the Kuwaiti constitution which provides for equal treatment of women, for her this alone made not allowing the appointment of women judges untenable:

...Yes for sure. How can I tell half of society that they are not able to be a judge? What is the reason and how do I use logic to explain that? I accept the Kuwaiti constitution and so how can I put a policy forward that doesn't give women the right to be equal [as promised in the constitution]. Many women in the world are judges.

However, two distinct threads of opposition to women becoming judges were also found in the qualitative data. The first and most prominent was the belief that a woman's psychological characteristics make her unsuited, specifically her emotionality. Thus the issue of women being emotional beings (as discussed in the previous chapter) reared its head once more as a potential obstacle to women becoming judges, as illustrated by the response of one of the women in leadership participants (WiL1) to the question of whether women should be allowed to sit as judges and what benefits this might bring:

Yes, definitely yes. We need to talk about what prevents women from being judges and I ask give me the reasons that she can't be a judge? Why when in the cases around the whole world women judges are great and really successful? Why should it be any different here? ... I think a woman as a judge would be successful in this position, if she separates her emotions. 
Five other participants also spoke of women as being emotional beings, and thus they were rendered unable to make clear judgements - unless they became free from these emotional shackles. Interestingly, 'emotions' were not interpreted by these participants as a positive empathetic quality but as a serious block on them becoming judges:

Manar: No, I don't like that idea [woman as judges]. Women can't work in all types of jobs. Being a judge is about more than leadership; it is a decision making position and I don't think that women are made for decision-making. It is mostly because of woman's soft emotions that she can't go for such job.

Dalal: No, they are too emotional. I don't see women are suitable for being judges. Women follow their own feelings and when it comes to tears or hard cases their heart breaks easily...being a judge needs a tough heart that doesn't look at the opposing sides but focuses on the evidence given in the case.

As noted in chapter six, the narrative of women as emotional beings (perceived to be a negative characteristic) was found to be a recurring theme in the interviews. It is also clear that the emotional narrative supported a second ground of opposition - the belief that women should not sit as judges on 'moral' religious grounds. However, for those religious conservatives who ban women judges, there are only relatively weak justifications to be found in Islam (it is perhaps implied but far from explicit and it is a line of dispute for Islamic feminists), nor is there anything explicit in the Qur'an. Nevertheless, it is a narrative that has a stronghold in Kuwaiti society, and one that due to its religious underpinnings is adhered to by men - and women. For example, Mai states:

No, we cannot have women sitting as judges. Based on Islam that is not possible.

Hence the question of women as judges is a divisive one. However, the current trajectory, which is seeing more and more women enter the legal profession, suggests that this could be a breakthrough area in the near future.

\section{Women judges in the future?}

Interviewees were asked if they felt that there would be female judges in Kuwait in the future. Some participants reported having seen judges on Western media broadcasts, in 
movies and TV series. However, it would be wrong to surmise that those with knowledge of successful women judges in other countries would be less swayed by the traditional view of women. Indeed, there was a full range of views, with the participants clearly being able to compartmentalise the prospect of women judges in the future into fact or fiction, for example:

Mona: Yes. I feel they will be soon. I think women are more serious and suited to being a judge.

Reem: The time is coming soon when we see a man standing before a woman judge. Globally it is already accepted and in Kuwait I see it's very close.

Hanan: She can be a judge but I don't think it will happen in reality. No, I think this will never happen.

Samar: No there will not be women judges in the future. Our leaders are men; that is why they are not allowing women judges.

The women in leadership participants considered where the momentum would come from for a breakthrough on the appointment of female judges. For two of them, first WiL4 and second WiL2, it would be from male dominated politics:

We need more people in the government to be brave and defend women's equal rights as regards the laws in Kuwait.

There should be an Islamic party which supports women being appointed as judges.

Perhaps surprisingly, one of our women in leadership participants, a government minister, suggested that there were in fact no obstacles to women becoming judges in today's Kuwait. While this may be legally true it surely underestimates the range of opposing elements in Kuwait society. The minister, WiL1, suggested that it was down to women to demonstrate their readiness to sit as judges:

If a woman wants to she can be a judge and I don't think there is anything to prevent her from being judge or any position, it's all about the woman herself. If she can prove it at other levels, then the policy makers will give her the right to become judge. 
Overall, considering data from both the questionnaire and the interviews it is clear that those with generally liberal views see the appointment of women judges as entirely logical. And as already discussed, women's entrance into the legal profession in Kuwait as lawyers and prosecutors could also be seen as paving the way for such a development. In the UK for example, women started graduating with law degrees in the UK in 1888. The 1919 Sex Disqualification (Removal) Act removed the legal impediment to women's entry into the legal profession and by 1922 women were working as lawyers (Buchanan, 2015). However, it took 74 years after the first woman graduated with a law degree for the first female judge to be appointed in 1962 (Buchanan, 2015). And, while women do sit as judges in most countries, the reality is that this does not mean equal representation or a good level of judicial diversity. Again, in the UK in 1992 just 6.5\% of judges were women; this had risen to $16.8 \%$ by 2005 and now in 2015 stands at $25 \%$ (Courts and Tribunals Judiciary, 2015). Additionally, in the UK for example in 2005, $81 \%$, of the senior judiciary had degrees from Oxford or Cambridge, $76 \%$ had attended fee-paying schools, and half went to boarding schools (Thomas, 2005, p. 8). However, for Europe as a whole there is near parity with $48 \%$ of judges across the continent being women (Hale, 2014). And, where judicial diversity has been raised in Europe this has largely been a result of political leadership (Thomas, 2005).

Nevertheless, it could be argued that equality in terms of judicial appointments has taken a long time to achieve across Europe. However, and very importantly, even in countries with majority Muslim populations such as Indonesia and Malaysia, women have been appointed judges (Abdelkader, 2014). Moreover, in some countries in the Gulf region, such as Bahrain and Qatar, female judges have been appointed since 2006 (Abdelkader, 2014). This begs the question of why the appointment of female judges in Kuwait would be such a major step in the Gulf region. However, without the political will and with sections of society believing that women are too emotional to be judges (as suggested by some participants in this study) the consequences of such a move become increasingly difficult, because the attention is taken away from equality and appointments on a meritocratic basis, and instead are based on beliefs that are prevalent in Kuwait society that women are not emotionally stable enough to be appointed. This issue becomes even more heightened considering that the appointment of female judges in Kuwait would also be felt in other countries such as Saudi Arabia where women, as already noted, 
cannot drive and where female investment bankers and female lawyers are unable to drive themselves home from work (BBC, 2015).

Yet, the importance of overcoming this hurdle becomes increasingly apparent when considering that male judges sit to deliver justice within a patriarchal society which has embedded within it legal frameworks covering the public and the private. Both sets of laws discriminate against women in the private domain - however the private (personal) law is particularly discriminatory. As already noted, much of the private domain in Kuwait is governed by Islamic sharia law with a large part of this encapsulated Code of Personal Status 1984 (no. 51/1984) also referred to here as the Personal Status Law which covers Sunni Muslims and the uncodified Ja'fari interpretation of personal status issues which is applied to Shi'a Muslims. The Personal Status Law is a law based on the Maliki School of Islamic jurisprudence and as such assigns less weight to a woman's testimony than a man's (as previously noted, this is a potential serious obstacle to women taking up judiciary appointments). It also covers among other things marriage, divorce, obedience/maintenance, post-divorce maintenance/financial arrangements and family disputes.

To recap, the most discriminatory legal provisions are those regarding marriage. Under the law, a woman can never be free to make a decision to marry on her own. In contrast to a man, she is not free to enter into her marriage contract but instead must have a male guardian (wali) do this on her behalf, irrespective of her age. A woman aged between 15 and 25 years can be forbidden by her guardian from getting married, and although there is the possibility of appealing to the courts she can still not marry should the court rule against her. Furthermore, the minimum age for marriage registration is 17 for men and 15 for women which contravenes international standards which recommend a minimum age of marriage at 18 for both sexes. A marriage can only be valid if witnessed by two Muslim men. Moreover, a man is legally entitled to have up to four wives at the same time, without the need for permission or even the knowledge of his existing spouse(s). There are no laws aimed at preventing domestic violence, marital rape or the sexual harassment of women in general.

Some of the issues raised by personal laws are discussed in this chapter. However, it is important to note (as explained in the methods chapter of this thesis) that issues such as domestic violence and rape were not discussed at interview. Conducting this 'exploratory' 
feminist social research in Kuwait required a very careful risk assessment and principally to avoid harm to participants the decision was taken to avoid some of the most acutely sensitive issues. Raising such issues such as rape within marriage (which as noted above is not illegal) would have likely brought discomfort and embarrassment to the participants, which is something that the researcher sought to avoid.

\section{Patriarchy and control of women in public and private}

\section{Marriage and divorce}

In Kuwait tradition, the concept of marriage was tribal, often involving related families encouraging their offspring to marry cousins or other relatives in order to strengthen and grow the influence of the tribe, or less frequently to marry someone from another tribe perhaps to heal disputes between families (El-Haddad, 2003). Under such arrangements the families of those marrying would have a thorough knowledge of the partner's background. While the families may be well informed, the prospective groom can have his marriage arranged without ever having seen the face or any part of the body of his bride to be (El-Haddad, 2003). For their part Sunni women cannot choose to marry someone without the consent of their families or male guardian while Shiite women can make such a decision independently (Al-Mughni, 2010). In the majority of cases, marriage continues to be an arrangement between families, although marriages cannot be concluded without the consent of both spouses (Al-Mughni, 2010).

Divorce is a prevalent issue in Kuwait with the divorce rate rising. Divorce also lies at the heart of any discussion of patriarchal control. Again, to re-state, in Kuwait, under the Personal Status Law 51/1984, article 97, 104 a man has the right to unilaterally repudiate his wife without going to court (Al-Mughni, 2010, p. 231) on the other hand, a woman can only do so in limited circumstances and then only after a court ruling. A woman has the right to seek divorce for a few specified reasons only, including if she has been abandoned or abused, or if the husband has failed to pay her alimony. The woman will have to prove injury. A husband on the other hand can divorce his wife "arbitrarily." A court can rule a husband who divorces his wife without her consent to pay the wife financial compensation (Al-Mughni, 2010). Divorce matters are handled in the family (sharia) courts. Interestingly, in Britain up until the introduction of the Matrimonial 
Causes Act 1857 divorce was a matter for ecclesiastical courts and women were at the same kind of disadvantage as they are in today's Kuwait (Squibb, 1977).

In the UK men and women have equal treatment under divorce laws including matters such as child custody (although traditionally custody goes to the woman), and in Kuwait, a woman may also be granted custody of the children upon a divorce. Indeed, according to the personal status law (Article 189), the mother has the most right to custody of her children in the event of divorce. A divorced mother will have custody of her sons until they reach the age of 15 years and of her daughters until they are married. Other rules apply to the Shiite Muslim minority. Among Shiites a divorced mother has custody of her daughter until the daughter is 9 and of her son until he is 15 . Once they reach this age the child has the right to choose with parent they will live with. Child support exists and is offered by the state, but this benefit is always paid to the father (Al-Mughni, 2010). There is no concept of joint custody in the way there is in the UK so while women may be favoured in custody rules they still face a possible personal catastrophe when the child gets older. There are also incidents of men reversing custody in court by demonstrating the mother is 'unfit' such as the case when a judge granted custody to the father when he was shown a picture of the mother in a bikini (Hunter, 2014).

In the questionnaire which preceded the interviews, the results indicated that more women were in support of equal treatment in divorce matters $(43.9 \%, \mathrm{n} 192)$ than against it $(37.3 \%, \mathrm{n} 163)$ though not by a wide margin. Similarly, when asked what they felt about the escalation in divorce rates, some interview participants mentioned traditional marriages as the source of the divorce problems while others took the opposing view that it is the move away from traditional arrangements and changing attitudes that are to blame. For example, Huda explained:

The older generations still support traditional [arranged] marriages so it is difficult to fix the situation.

Hanan also saw the divorce rate as a social problem but perhaps not as detrimental to women as having to stay in a relationship against her will, a point then reiterated by Farah:

I think [the divorce rate] is unacceptable and arises because before they get married they don't spend enough time getting to know each other. 
But if the woman does not want to be with her husband it is harmful for the society.

It's simple, if they don't like to live with each other they should end the contract.

It should be remembered that while it is possible for women to seek a divorce it is a lot easier for Kuwaiti men to do so, as Samar emphasised:

It should be fairer and the law of divorce should be amended. It is too easy for men to divorce and too complicated for women. Sometimes the men divorce without any notice.

For Shaima the rising divorce rate was a reflection of Kuwaiti society moving away from it Islamic principles:

I think that we shouldn't act against Islam and I think that the divorce rate is going up because we are moving away from Islam. I don't like that society is not following the Islamic rules. We have to give the girls education on matters such as married life in high schools, about what benefits them and the rules.

Dalal saw the rising rate as a reflection of women's increasing independence:

I don't see it as a bad thing because it means woman are standing up for themselves and what they want out of life.

A few participants (n4), like Shaima mentioned education in the context of marriage and divorce, believing that better preparation for marriage through education would reduce both the divorce rate and the social pressures to marry. Samar described how both the marrying generation and their parents need to change their approaches:

Marriage should not be a result of social pressure. There must be a full acceptance from both sides. For example, many families these days, when their daughters are at university or reaching graduation they start to worry about marriage. Love and relationships are not accepted at all so they push them for the traditional without the couple themselves analysing the prospects of the relationship which leads to disconnection and that causes divorce. In that point we have to not only educate the new generation but also to educate the parents about that.

Similarly, one of the women in leadership participants (WiL1), a government minister, also made reference to education as the means to tackle the rising divorce rate. 
... [we need to] educate the new generation on the definition of marriage itself and analyse it for them also help them to understand what marriages refer to.

However, another woman in leadership (WiL2), a parliamentary consultant, saw a link between the level of education and higher divorce rate.

I think also that divorce is common with the women in higher education who are more likely [to divorce] than women with a normal education.

Finally, and quite surprisingly given her profession - a lawyer who handles divorce cases, another woman in leadership (WiL4) disagreed with women having the right to divorce and argued that the legal aspects of divorce should continue to be dealt with by Sharia courts:

I don't think it is good for our society [for women to have divorce rights]. In my point of view, I think we have to follow the sharia law and not allow women to get divorce. Because we are better holding the current Islamic law as it suits the culture and tradition in Kuwait and the region, and serves the people's needs.

As illustrated, there was a wide variation in the perceived reasons for the rise divorce rate and the fact that now $50 \%$ of marriages in Kuwait end in divorce. While some participants saw education as a solution to assist women and families to understand what marriage means and the rules it is governed by to steer them from entering into marriage 'unaware', others perceived a move away from traditional values as the very root of the problem. Differences in social attitudes are commonplace whatever the context, as the British Social Attitudes Survey regularly demonstrates (NatCen Social Research, 2014). However, in the context of a strong patriarchal society with a tradition (if not a current reality) of women as wives and mothers before anything else, it could be viewed as extremely threatening to the established order, or extremely liberating depending on the perspective.

The participants were also asked to consider divorce laws and the way women and men are treated by them. Again a wide range of views were offered. Kawther and Manar respectively exemplified the contrasting views: 
It's a relationship between two people so she should have the right to say no to a marriage and also choose to end her marriage.

I think she shouldn't [have divorce rights] because this is religion. The man is the one who God has given the right to divorce.

However, Maha's experience of divorce in Kuwait illustrates quite clearly how the Personal Status Law can have a devastating impact on women:

My divorce experience...it was really bad for me, I was scared all the time. I changed my phone number and my job because I always had the fear that he may come back, because the law and the court gave him this right. Also the judge told me during the divorce that he can get you back in three months. That is the injustice in divorce.

To the question of whether women should have the same rights as men in divorce, one woman in leadership (WiL4) from the media sector went even further and suggested that in fact the rights should be transferred to women in a reversal of the current situation. This would take it even further than the UK where divorce is un-gendered in a legal sense:

Equal divorce rights is a dream but I think it will happen sometime in the future. Personally I think women are more likely to protect the family but it is no good for both parties to have the right to divorce. The authority to divorce should be with women and men's right to divorce should be limited. This is because in my opinion I see women will protect her family and really want to have a good stable family more than men do in society.

As with other topics of discussion at the interviews, the issue of divorce produced a very broad range of opinions. This was also reflected in the lack of consensus in the questionnaire which preceded the interviews and which produced only a small majority in favour of equal rights in divorce $(43.9 \%, \mathrm{n} 192$ were against it, 37.3\%, n163 with the balance unsure). As to why this should be, clearly the survey sample had a significant minority who either supported the Personal Status Law or were reluctant to indicate otherwise, even in an anonymous survey. But there must be further reasons why women, in such significant numbers, would hold a view that runs so counter to their own interests. While it is impossible to say with any certainty why women have adopted a kind of false consciousness, it is true to say that there are women who believe, for a variety of reasons, that extending divorce rights to women would make a societal problem even worse. 


\section{Sharia, patriarchy and control of the private sphere}

The efforts of men to confine women to the private sphere are driven by Islam. It is a fundamental tenet of Islamic jurisprudence (sharia) that males are viewed as the guardians (wali) of women. In this sense in Kuwait and other countries where Sharia is applied, women have a status resembling that of children in a 'Western' context. Furthermore, men are the source of all religious knowledge and ulemas (possessors of religious knowledge) have always by tradition been men. Hence the religious knowledge on which sharia is based is male knowledge. As reported in chapter five, the results of the questionnaire illustrated that less than a quarter of women either agreed or strongly agreed that "Men are better suited to making law than women", thus the majority of women who took part in the questionnaire are decidedly at odds with the very basis of law and justice as practiced under Islam.

The participants who took part in the interviews were asked for their opinions on the division between civil courts and Sharia courts and specifically their opinions and views on why many matters that personally affected women were dealt with under Sharia.

Mona suggested a move to civil law and had an optimistic view on whether this could be achieved, citing the change that has already occurred in Kuwait:

Religious people seem to think that if they do not follow traditions they will go to hell. Some of these traditions are not actually linked to religion and I think they pick and choose the laws based on their own needs and wants. This is not acceptable. I think it is possible to change it to civil laws because in the past women couldn't even walk in the street but now they can even go out of the country alone.

A reason for the civil-religious split in the system of justice was tentatively put forward

\section{by Hanan:}

... Maybe because family cases are sensitive so that's why they go to religious courts - I don't know but it may be this is the reason.

The use of the word 'sensitive' is interesting here as it suggests that civil courts are not able to deal with such matters appropriately, or perhaps sensitive means, a threat to societal norms and traditions, or the interests of men. Indeed, Farah, Kawther and Khawla respectively, voiced more feminist interpretations of the situation, perceiving the division to be a device to maintain patriarchy in the private sphere: 
I think men might hold some fear of women or fear of losing control of them and that is why they intimidate her through sharia law.

The ones who created the law are men so definitely they will use the Sharia for their own benefits and I have the belief that they don't want women to be in a situation that they become equal to men.

Because the society is a male society and everyone looks after their own interests. It should be changed and I start with my own kids, my school when I teach. When I was in school it was different and the male population was against women going to school.

In contrast, Shahad and Mai voiced either approval or religious resignation to the use of Sharia courts:

Yes, I agree that women's issues should be dealt with in sharia courts. Because Sharia gives her all her rights.

Again, this is Islam - it is God's will. I can't change it.

Noticeably, the women participants who referred to Islam and God as the reason for the status quo did so with short remarks and a reticent air which communicated an unspoken 'let's move on'.

Turning to specific issues or laws that affect women in the family/ private domain only one in five women who took part in the questionnaire agreed or strongly agreed with the statement 'Women should obey their husband and male relatives.' However, at the same time less than half (39.3\%) either agreed or strongly agreed with the statement 'It is harmful for women to be under the guardianship of their in-laws.' This could be seen as somewhat contradictory. Likewise, the statement 'Both husband and wife should be equally responsible for paying their living expenses' was only agreed to or strongly agreed to by $21.7 \%$ of the sample. Thus the survey results suggested quite clearly that a large majority of the respondents did not support the idea that women should be completely independent in their personal lives. This further suggests that the women's understanding of and desire for equality in the private or family domain can be very different to the way it is expressed in public domains, such as employment and polity.

Endeavouring to explore this further in the interviews, participants were asked for their opinions on the matter of guardianship. For some participants such as Hanan and 
Maha, where a law or practice is perceived as being derived from Islam then women can be resigned to guardianship, but this is not to say that they like the situation or do not question it:

In Islam women should be under guardianship. We can't change the situation. It is really hard to change and I don't like it honestly.

And very similarly from Maha,

There is a law which gives my guardian the full right to decide on things instead of me. That comes from Sharia Islam. That should be changed, but how? It's so difficult.

The woman in leadership currently practising as a lawyer (WiL3) was asked her opinion of the role of guardianship in Kuwaiti life:

[Male Guardianship] hurts women because there are a range of relatively small things that women suffer from as a result of it. For example, if one of her kids wants to apply for a scholarship outside of Kuwait they will not allow them to go unless the male has signed the documents, even if the mother has approved it. On the other hand, if the father agrees and the mother is against it, there is nothing she can do to stop it.

However, other examples of the negative impact of personal law on women were found in the interview data which cannot be dismissed as 'small things'. Such as the widow Khawla unable to complete government paperwork after her husband's death as her children's guardianship had passed to the deceased's father, Maha being refused the opportunity to study abroad by her father, and the bruising divorce experiences of Samar and Kawther. These issues are discussed below.

\section{Personal experiences of the law}

As already noted, under the Personal Status Law family matters are covered by Sharia law and dealt with within the government-run Sharia court system. In these courts the testimony of a man equates to that of two women and there are only male judges. Shiite and Sunni Muslims have recourse to courts that adhere to their respective schools of Islam. 
The participants were asked to recall their own personal experiences or those of their friends and relations, of the Kuwaiti legal system, including the Personal Status Law. Of the twenty participants, $\mathbf{1 6}$ recalled specific laws that had disadvantaged them or their friends. For Maha her experience centred on guardianship and the curtailing of her freedom of movement:

I personally wanted to go and study abroad but my father refused and I know by law he can forbid that.

Samar recalled her friend having her kids taken away while Mai reported that a lot of her friends had had dealings with the Personal Status Law and they had all been negative. Khawla recounted her feelings after her husband had died when she was trying to organise her affairs and could not do so without a male guardian (wali):

When my husband died the guardianship [of the children] went directly to the grandfather on my husband's side. And I feel that is unfair because I could not make decisions or do any governmental paper work without the attendance of the guardian of my children such as the father of my husband or brothers of my husband. I feel constrained and can't support my children.

What Khawla is referring to is Article 209 of the personal status law; this states that the person with the foremost right to the guardianship of a child is the father, followed by the father's father and thereafter the male relations in the order of inheritance rights. Without guardianship in law she could not act on her children's behalf in any official capacity, perhaps organising their education, applying for benefits etc. and this clearly distressed her. Though not recounting a personal experience, Samar also highlighted the injustice of the guardianship laws:

A mother cannot do any legal paperwork for her kids such as register them at schools, issue civil ID, issue passports or any legal document.

The workplace, divorce and lack of legal status were highlighted as examples where injustices in the legal system can negatively impact on women by Hanan and Farah respectively:

One time my friend applied for a job they did a pregnancy test and because of the result they did not let her have the job. 
My friend wanted to get divorced and the investigator in the police station got her to give a statement which turned the whole case against her.

While these two comments may not refer to specific articles under the Personal Status Law they do reflect the lack of legal protection for women, compared to their counterparts in other countries such as the UK.

Samar $\mathbf{M}$ focussed on financial matters and government benefits which are greatly favourable to men and restricted or unavailable to women, which she believed restricted their financial independence:

The law that prevents woman from taking the 70 thousand KD house loan from the government. The man is the one who benefits from the government allowances given to the family. Such as the children's monthly allowance, the marital allowance, and the big housing loan with no interest. That is all going to the man and if the marriage ends in divorce, the house is his and the divorced woman suffers.

There are 346 articles in the Personal Status Law. Taken individually they may be dismissed as small things. However, taken together they represent a comprehensive codification of women's subordination and gender inequality. It is a detailed ordering of the private domain along patriarchal lines and as it is based on an interpretation of holy texts it is especially difficult to question. Sixteen out of 20 women offered their views and opinions and shared their negative experiences of personal law at interview - that is a significant majority. It is an indicator therefore that while women may, due to tradition, upbringing and religion be indoctrinated to accept a legal system that is discriminatory (and as the questionnaire results indicated they are not prepared to challenge), on closer examination women might not be as content as they appear to be. Mai, one of the most religious participants, expressed the view that because the law is derived from Islam it cannot be questioned even though it may be unfair:

I am more Islamic and my opinion is that it is right that sharia is used and that God wants women to have this role and I would never be against it. It is not fair but that is Islamic law and in the end I can't be against it.

Arguably however, if Kuwait really does hold itself out as being for equality and human rights then this is something that needs to be opened up in discussion in Kuwait. This is 
important because across a range of items the survey respondents did not perceive the legal system to be fair to women and not one participant at interview defended the system. However, there were differences in emphasis particularly on whether the law was a patriarchal, oppressive tool or whether it was simply a natural derivation of Islam. It is an important finding however that so many of the interview participants (n16) did perceive the law to be patriarchal and oppressive. For example:

Farah: No its not [fair] at all, because it has been written by men only.

Samar: [It is not] fair at all, it's all on the side of men you feel afraid if you go to court and sometimes I feel I want to go to a woman and get them better help than going to court because they are unjust to me.

Hanan: In Kuwait we have the Islamic Personal Status Law and this means the men have the major role in women's life in the family. For example, the husband with the wife and daughters also the brother with the sister because in Islam women should be under Guardianship. We can't change the situation - it is really hard to change and I don't like it honestly.

\section{Challenging the personal law status?}

Videoing the interviews which took place was particularly helpful in many respects, not least with translation from Arabic to English but also through this technique it was possible to clearly observe the participant's body language and this was very interesting when questions were asked on topics related to religion, Islam and Sharia. Some of the participants offered short dismissive answers, occasionally appearing irritated by the question and demonstrating this through facial expressions and body language (frowning, crossing arms and leaning back for example). This however should not be seen as surprising as such questions are considered sensitive and extremely controversial in Kuwait and the wider Gulf region. For example, one of the women in leadership (WiL1), a government minister, was representative of those who believed that merely considering or discussing Sharia laws let alone questioning them, is immoral and/or against Islam. When participants were asked to consider family law in the sharia courts and whether they thought it was harmful to women to be under the guardianship of their in-laws she replied:

I think for any laws which come from sharia I can't even talk about it. Any law that came from God I will never seek to change it or be against 
it because it is for certain the best law and no one is better than God in creating policy and laws.

However, in contrast, another woman in leadership participant's view was much closer to a feminist one. The former lawmaker's (WiL5) analysis regarding what lay behind the efforts of the tribal and Islamist interests to deny women rights and empowerment in matters such as divorce was that it is an attempt to maintain male dominance in society and in the home. She went on to explain that such dominance was often expressed in acts of violence:

They are seeking to tighten the grip around women as much as possible, in order to endure the marital home and life, because in the most part they engage in violence against women.

Another woman in leadership (WiL4), a key figure in the Kuwaiti media, took a radical view on the need to replace the sharia legal system with a civil one:

I think the Individual's Status Law of Kuwait must be destroyed. It really needs to be restructured in order to have more rights for women in the law of divorce, housing, parent custody, and so on. It needs a lot of work. The society is still controlled by religion, $90 \%$ of the society follows the religion. I am talking about how society looks at her voice as haram (sin), her work as sin, and her rights as sin, so she is organised in an Islamic system and not in a civil system.

However, the same woman in leadership (WiL4) also noted the lack of political will to change the existing system:

Still we don't have a strong voice that's saying let's deal with women with civil legal standards and not religions standards. No one is calling for a civil legal system in society. Did you hear about any time that any parliament member called for the civil system?

The answer to this question is clearly no, and any parliamentarian who made such a call would be courting unimaginable controversy to say the least and this of course raises the question as to where change may come from? The answer appears to be that it may come from one item or article at a time, perhaps on the basis that something is ruled unconstitutional. However, the former lawmaker participant (WiL5), pointed out that attempts have been made to uplift the status of women in such matters but these have been blocked by conservative and tribal interests in parliament: 
We presented laws that uplift the status of women in the long run and help with her development such as laws that serve a woman married to a non-Kuwaiti, and the laws regarding the right of divorced women and widows to get a house and the rights of citizenship currently given to men. Such legislation is opposed by the very MPs who claim to support women by offering them a salary to stay at home.

Such rights as the right for women to pass on citizenship to their children will not, according to another woman in leadership (WiL4), come easily:

A woman also has to take a part of the responsibility to obtain all kinds of citizenship rights. Women must know that no right comes without asking for it. Know your right and find a way to get it...laws are against women such as the guardianship, which is completely under men's control.

Six years after women first took their seats in the Assembly nothing has happened to contradict Esfandiari (2004) who argued that little could be achieved in the quest for equal legal status while family law remained based on sharia, and rules derived from particular interpretation of Islam prevailed in the social sphere. The women who took part in the interviews understood that women lack divorce rights and they were aware of (and some had personally experienced) clear manifestations of patriarchal control. Thus this research also illustrates how women can both perceive and experience laws that are discriminatory, but this does not necessarily pave a clear path to reform.

Personal law status impacts on many aspects of women's lives in Kuwait. As well as the issues highlighted in this chapter such as rights in divorce and guardianship and so on there are also further connected restrictions on her movements and the right to pass her citizenship onto her children. Regarding movement, it is true to say that things have changed a great deal since the days that women were barely seen out in public without their male guardians. However, in the questionnaire with regard to responses the statement 'Women should be able to pass their Kuwaiti nationality on to their children' only 19.2\% agreed and $10.1 \%$ strongly agreed. This is particularly surprising as it is a relatively uncontroversial issue and not one that is significantly related to Islam. Indeed, this lack of citizenship equality would seem to go against the country's constitution which contains provisions for equal treatment. Likewise, in the questionnaire respondents were asked to express agreement or disagreement to the statement 'Women should be completely independent in their personal life and there was relatively little support for such an 
unequivocal statement of independence with only $7.3 \%$ strongly agreeing and 11\% agreeing. Thus despite the injustices elucidated in the interviews, the questionnaire results could be said to provide a clearer indication perhaps that it seems unlikely that calls for change will come from the majority of educated urbanised women in Kuwait.

\section{Chapter summary}

Independence has many dimensions. In the previous chapter, the financial dimension was discussed with support expressed for greater economic independence. However, personal freedom is another and very important form of independence that this chapter considered.

The perceptions of the women interviewed (as well as the responses to the questionnaire which took place prior to the interviews) tend to reinforce the central theme of chapter two of this thesis; that being the contradictory nature of developments relating to a woman's role in Kuwaiti society.

In terms of what this chapter adds to an understanding of the various interests and their influences on policy, it can be said that the interview findings took forward a key theme identified from the questionnaire - namely the lack of a majority support for relatively uncontroversial matters which would advance the interests of Kuwaiti women. Yet, overall both the questionnaire results and the findings from the interviews displayed attitudes broadly supportive of greater gender equality. This contradiction was particularly identifiable where the issues focused on entered the religious sphere. And while some may term this contradiction as a form of 'false consciousness' (which will be discussed further in chapter nine), it is equally important to note that the reluctance of some of the interview participants to express opinions in favour of gender equality in domains dominated by religion appeared to be not because such beliefs are not held but because they challenge Islam directly. Thus, it is highly likely that some participants felt it extremely difficult when asked to express their opinions (probably for the first time) to a researcher in the context of a study like this one. However, the next chapter explores the interview participant's hopes for the future - a time yet to come, a time of change that will benefit their children. The future is not about 'them', it is about their children. Thus, with this distance in mind, it is in the next chapter that women's perceptions on gender equality are more freely revealed. 


\section{CHAPTER EIGHT}

\section{HOPES, AMBITIONS AND ATTITUDINAL \\ CHANGE: EXPORING KUWAITI WOMEN'S PERCEPTIONS ON EQUALITY IN THE FUTURE}

Having presented the findings of the recent experiences of women in the public domains of politics, employment and education in chapter six; and having reported the perceptions that these educated, urbanised Kuwaiti women have on equality, social justice and patriarchy in chapter seven, this chapter orientates itself mainly towards the future. Thus, this chapter aims to address the third research question - "How do educated urbanised woman in Kuwait view their future empowerment and development of social policy?" Furthermore, and flowing from this overarching research question, what do women want for their children? Do women have ambitions in the context of equality and women's empowerment? What will need to happen for their hopes (if any) to be realised? And in this context, what do women perceive that men think about women's empowerment? It should be noted that data on the numbers and genders of the participants' children was not collected. When asking questions relating to their children's future it was clarified that in the case where they did not have a child of a particular gender or perhaps no children at all, that the question should be considered as referring to the daughters and sons of Kuwaiti women in general.

Of course, as already noted, any research into women's empowerment in a country where such a concept is highly controversial and where women's subservient positioning lies at the heart of the central, political, moral and religious discourse is especially difficult. Both the research questions asked and the manner in which they were asked reflected this challenge. Being already aware before the research began that the study would be limited by what could reasonably be investigated throughout the interviews questions (negating for example questions about sexual harassment, marital rape and domestic violence), the findings presented in this chapter clearly indicate that while some 
participants perceive that men's personal status is an obstacle to women's empowerment, there is also a degree of optimism about men's support for legal reform in the future.

The chapter begins by setting out and discussing the findings along the themes of hope and ambition among the 20 interviewees. It goes on to consider, through the perceptions of women, whether attitudinal change among men, is already detectable or likely in the future. Thereafter it considers women's overall perceptions of what the future holds, where will progress come from, and whether it will it come at all.

\section{Hope}

As already emphasised, even though the women in the sample are urbanised and educated many of the issues discussed are nevertheless controversial even to this group. It had been hypothesised that one way for women to express their views while avoiding this controversy to some degree was to project their views as aspirations for their children or for future generations in general. The logic being that women may find it difficult to want change for themselves - particularly when that change challenged their traditions and religion, but they may want something different for their children especially their daughters and future generations of women. The participant's body language when discussing the future was animated, leaning forward and confident and this strongly indicated that the approach adopted was indeed far less intrusive for them and less controversial for them. Indeed, the participants were eager to project their hopes and ambitions onto future generations.

When asked about their hopes for their daughters, equality, independence, fairness, justice and freedom were all words that featured regularly in what were mainly rather brief generalised answers such as when Mona commented:

I want my daughter to live in the country without suffering discrimination.

Hanan had similarly broad brush aspirations for her daughter but exemplified this by referring to her job chances: 
Anything that gives fairness and equality with men. For example, when applying for jobs they should recruit people based only on their qualifications, not gender.

It is perhaps significant that Hanan referred to a civic domain rather than a religious one such as Sharia, presumably because it is less controversial and change in the civic domain has precedent. Although Samar, when asked what was limiting progress, was comfortable and determined enough to make the point that Islam was part of the problem:

Religion and Islam is limiting our development ... The law should give more freedom and power to women and reduce the role of Islam.

These comments are particularly controversial to hear from a Kuwaiti woman's mouth and other women who made comments involving Islam tended to restrict themselves to statements of fact without going on to voice an opinion. This is illustrated first by Mai and then Fouz:

It is not fair but that is Islamic law, and in the end I can't be against it.

I can't be against the Sharia ... especially as it is the law which comes from Islam so I am with that and what is mentioned in Islam is a red line.

The 'red line' phrase is significant. Throughout the interviews some participants stayed firmly away from crossing the red line, others came close to it, and instances where it was crossed were rare.

Phrases such as 'better life', 'more independence', 'more freedom' and 'equality' were the most prominently emerging messages from the interviews in regards to women's futures in Kuwait. As such they represented rather generalised aspirations:

Samar: I don't want my daughter to suffer as I did. I want her to have a better life with full justice.

Khawla: To get more women in society who are totally independent, standing on their own two feet.

Shaima: I hope my daughters have more power in life to be independent in the future. I hope to see women not categorised 
because they are women. Women are human and should never be treated differently than men, especially at this time because women today have all the abilities life needs.

The hopes expressed by the participants for future female generations were almost all couched in terms of gender equality, not really surprising bearing in mind the content and context of the interview and the study as a whole.

Two other themes emerged from a small numbers of participants. Firstly, there was a tendency among some women (n4) to place the future into a global context where a greater openness to other countries and cultures would take future generations to a better brighter place. Kawther exemplifies this:

We have to build a new generation of women that can fit in globally and which know their rights. Every day they can see the lives of women in other countries, on the Internet and on satellite TV. Their expectations are raised. This kind of thing can only build and build.

Secondly, two women, Manar and Mai, whose interviews had been consistently characterised by a more religious, conservative tone expressed their hopes for future generation in terms of their daughters following the word of Islam.

\section{Shades of Islamic Feminism}

Similar to the feminist position described by Härpe (1989) and González (2013), Kawther specified Islam as the route through which women could achieve greater empowerment:

I want my daughter to get more freedom and choice and not be under a man's control and to use the name of God to take these benefits.

Essentially, as discussed in chapter three (where some theoretical constructs which may be relevant to the study were set out), it was suggested that for Islamic feminists it is not Islam itself that is seen as standing in the way of women's empowerment but the way that it is interpreted by those men who have, or have had the power to produce religious knowledge González (2013). Mai also offered a contribution that fits well with Islamic feminism when she called for a reinterpretation of Islam more suited to today's world: 
[A correct] understanding of Islam is the main issue. It is not being interpreted in a way that fits for the new generation. They should make it flexible and more aimed at helping people to live in the modern world because in the future the new generations will compare it with other religions that help society more and they may leave [Islam] in times to come, so it is better to try to make it easier and more comfortable now.

Again this represents a highly controversial suggestion that Muslims may convert to another religion or presumably have no religion at all, although this latter possibility was not actually voiced. Which is hardly surprising considering that according to most leading Islamic scholars, apostasy carries the death penalty (Griffel, 2008)? A bill to codify the death penalty for apostasy actually passed through parliament in 2012, but while the assembly was dominated by Islamist groups it was rejected by the Emir and thankfully never became law. Nevertheless, punishments can still be harsh for those convicted of being critical of religion. In the case of Hamad Al-Naqi, the defendant was found guilty of defaming both regional leaders and the Prophet Muhammed in Twitter posts (something he denied). He was sent to prison for ten years. In prison he had to be kept in solitary confinement for his own protection, in the way that child sex offenders in the UK often are (IHEU, 2012).

Unlike Saudi Arabia's sharia-based justice system, Kuwait's can be traced back to Egypt and ultimately from France and it is therefore a civil law jurisdiction, despite the Constitution saying that Sharia is the main source of law. The Kuwaiti interpretation of sharia is also lot more liberal than in neighbouring Saudi Arabia, and attempts by conservative elements to change this have failed. As a result, Kuwait does not employ punishments such as stoning, amputation and physical torture in the way that some Conservatives have demanded (Marcovitz, 2014).

During the interviews comments of hope for the coming generation were repeatedly heard and this also included hope for their sons and future male generations. When asked What are your hopes for your sons? All but one of the respondents (n19) responded along the lines that they hoped that their sons would increasingly see women as their equals, Samar's response illustrates this well:

[I hope] they understand the meaning of equality in gender and remove women from the box that they create for them. 
The notion of women being in a box is an interesting metaphor. The box has been consciously constructed by men; the view that women's subordination is the natural order of things is clearly rejected here.

Only Munira took a different view of the hopes for her son when she responded:

Whatever he wants is fine with me. [I would like him] to get a university education and qualifications. If he gets the right qualifications, he will get better a position in society.

\section{Ambitions}

There was a generally optimistic tone among the participants when it came to discussing the participant's ambitions for women in the future, although positive change was seen as a generational process rather than a speedy transformation. For example, when Samar was asked whether the future would see more women in higher positions and in policymaking positions in the country she commented:

Yes, for sure, because in my mother's generation things were better than the generation before and now I can see in my generation that females are getting most of the majors. I think in my kids' generation that will be even better. Before we did not see women in the police or army and that has changed now.

Reem also focussed on the public domain of labour, hoping for a more meritocratic labour market:

I'd like to see more equality and more freedom. I'd like to see my daughter work in any field she'd like to work in and take up higher positions, equal to what I wish to have for my son. I don't want anything limiting her opportunities like gender differences and other cultural issues.

Interview participants were asked where they felt the major changes would be seen in Kuwait and were given as prompts including work, education, politics and law. The responses were largely unelaborated and in some cases they appeared to be expressing where they hoped change would come from rather than what their expectation was. Perhaps this arose from a lack of prior analysis on the part of participants which would have made it easier for them to voice a more thorough opinion. Nevertheless, 
overwhelmingly education was seen as the source of positive change. The following examples were typical:

Manar: Education is the most important really; it is the key for change. When we educate the generations all will come correctly in both politics and law. I do believe that education from the early age will last for a long time and will affect the future of society in Kuwait.

Dalal: Education; if we change it we will change society.

Areej: If you change people by knowledge then you will have development in the country.

The problem with the assertion that education will be the source of change in Kuwait is that already for some time women have been over-represented at higher levels of education and it is difficult to see what would change if more women received a higher education. The crux of the issue here is the form of education - what issues are women educated on? For example, equality, human rights and so on? Even then, education alone is not a panacea to securing women's equality and empowerment. However, it is arguable that the women who expressed their views and opinions about the need for education were in fact referring more to 'awareness' and the need to change attitudes in society rather than formal education. It should also be noted that the interview participants selfselected from a questionnaire that was mainly distributed at university campuses, so a bias towards education is perhaps also understandable.

Law was in fact the next most mentioned vehicle for change after education - something highlighted by both Fai and Sawsan:

Law is the most important. If we change it we will force society to the change for better.

Laws that will give women more freedom.

When participants were asked to point to specific reforms which had benefited them or their female friends Areej made a specific suggestion that the reforms would help future generations when they came to retirement, referring to the incentives for women to retire early. Three participants mentioned maternity leave regulations supporting women after childbirth (in a similar way to the UK) and one other mentioned unemployment 
allowances to help women who do not work. However, the other participants were unable to recall any policy change that they considered had helped either them or their female friends. It was also pointed out that those that had been introduced were in line with traditional/ Islamist thinking because they all related to women's place in the private domain.

\section{Women's perceptions of today's Kuwaiti man}

'Awareness raising' education and legal reforms are needed - but of course any change to law will only come predominantly with a change in attitude from males who head the patriarchal society. Thus, although the study did not include male participants, questions were asked about how women felt men perceived the situation and the need for greater equality. The participants were asked how, in their own experience, men had reacted to pro-women reforms that have already taken place in Kuwait (described in chapter two).

Clearly the women who took part in the interviews were urbanised educated women and this is likely to mean that they know, and in some cases are married to, men who are more pragmatic and even supportive of greater gender equality than those from other backgrounds. This may be particularly true of the women in leadership participants. And of course, the male population of Kuwait will hold a full range of views on the question of women's social role, empowerment and equality, just as women hold an equally broad range of views (as illustrated in this thesis). However, turning to the private domain and husband-wife relations when the participants were asked to express their views on whether they felt men's understanding of their role was changing - particularly given the shared role as economic providers, it became clear that for the majority of the participants the shifting economic realities were feeding through to some men's attitudes within the home. For example, Fai, Dalal, Areej, respectively and decisively commented that the 'man's perception as provider' was finished:

They don't see themselves as providers anymore. Both men and women feel more independent and everyone takes care of themselves.

They don't see it as their duty at all. This is finished.

It's not like that anymore because women are calling for equal opportunities. Men have started seeing women as more independent 
and are starting to have the image of her that is more like a western woman.

Kawther made the interesting observation that, in fact, men didn't really feel this responsibility anyway but that instead it was an attitude they showed publically in order to meet social expectations:

It's a joke that men feel responsible. It's only an act or a show in front of society but in real life no they don't.

Potentially, Kuwaiti men are conflicted between the clear financial benefits of an additional income in the household and the de-masculinizing effect of not being seen to be wholly providing for their wives. What is evident is that with more and more Kuwaiti women having their own income their financial dependence on men is lessening.

It is also striking that when asked to identify which domain they saw as being the key to the development of women's empowerment, the need for increased economic empowerment through changes to the work domain received no mention whatsoever. This could be because women perceive that they already have economic empowerment, and thus this is something already established. Indeed, from the findings some households appeared to operate in a way that would be considered progressive in a Western society; sharing responsibilities in the family and pooling financial resources to meet the cost of living, and in this sense it could be suggested that there is some evidence that husbands do support gender equality. Of course, this is not indicative of all men, or indeed that economic equality is sought by all women. In contrast, for example for Mai, man's role as provider was part of the natural order of things:

It is the way of the world that there should be a man behind the woman, supporting her.

This is very much in line with how Kuwaiti society is formally and legally organised at the moment and is in line with the 'natural order of things' discourse. It is a view more likely to be heard from more religious women.

Although the participants did not raise any concerns about economic equality, this does not mean to say that there is no need to get women into the top employment positions in 
Kuwait. For some participants this was considered essential for gender equality for the next generation. For example, Maha stated:

Changing policy and breaking the glass ceiling will help women escape from the limitation. It will gradually change the mentality of the new generation to break all constraints and compete to achieve success to prove the quality of work and not to think about gender.

\section{Future politics}

In the questionnaire, when presented with the statement "In ten years' time there will be more women MPs and more equality for women" almost half (46.7\%) agreed or strongly agreed, $34.6 \%$ disagreed or strongly disagreed, and $18.8 \%$ indicated they were not sure. However, when interviewed all but one of the 20 participants expressed support for their daughters (hypothetically if they did not have one) participating in politics, with some also enthusiastic about them running as a candidate. For example, Shahad and Samar were both mothers keen to see their daughter's active in politics:

For sure, vote and also run herself. I don't have any problem with that and wish that she would do it.

I fully support this and I will really push her. I would love it if she had an interest in politics.

While the finding is certainly not generalisable, it does suggest perhaps that there could be fewer barriers to participation from within the family in the future and that this may be progressive over time. However, notably, the expressions of support from women do not take into account support within the family from men - and of course given that households are male headed then arguably support also needs to come from men. The following section considers this.

\section{Women's perceptions of attitudinal change among men?}

There were a number of opportunities during the interviews for women to put forward their views on men's attitudes to change. Of course, among Kuwaiti men there are a broad range of perspectives from what could be characterised as a liberal, modernist and internationalist to the tribal, traditional, conservative and Islamist perspectives. So the 
participants' responses are likely to vary according to which men they were thinking about when responding. Similarly, marital status can be assumed to shape a women's view of men. The findings, however, clearly brought forth two distinct perceptions from the participants; that they should accept living in a world where women are equal and men respect them, or alternatively that men should understand their role in protecting, providing for and supporting women.

When asked about whether or not they perceived that men would like to see more equal opportunities for women in Kuwait, most participants (n14) dismissed the idea. As the following comments illustrate, some of the participants believed that men's own interests ran counter to women securing additional rights and that such rights and any moves towards equality were seen as a threat to the patriarchal structures in society:

Samar: They love to see themselves as above women.

Sawsan: No, men still don't want women to be on their level.

Manar: No, they still feel they are responsible for their women.

Dalal: No, he will always feel that woman is the enemy.

While most of the answers were brief Shahad offered a little more explanation:

They don't really like the idea of equal opportunities but if it comes from the leaders, from government, they won't refuse it. An example of this is about the voting for women - they were not keen on it but once it happened they accepted it.

There was also some optimism for the future as Khawla commented:

Not yet. Maybe the new generation because the older generation did not want equality - it is too new for them.

However, participant perceptions of attitudinal change among men was also apparent with regard to how men might feel about the recent reforms that have taken place in Kuwait as well as the need for further reforms as Farah and Mona illustrate:

They [men] are working on that now and trying hard to get more equality for women. 
Yes, they will support equal opportunities, because at the end of the day it is their family, their daughters that we are talking about.

In particular, two participants, Shahad and Areej linked this change to men's openness to external influences - the idea of influences from neighbouring countries, which are seen as being more progressive, leading men to support more pro-women policies:

[Men] are accepting anything for a better system and they look to Qatar and Dubai and hope for the same type of changes here in Kuwait.

They feel it's better and they are cooperating to make Kuwait more developed. Because they wish to better themselves and I think now they don't want their country to be behind the other Gulf countries.

The consultant to the Kuwaiti assembly who was also a pioneering female political candidate (WiL2) expressed a belief that men's attitudes were changing in a more gender egalitarian way even in unexpected quarters:

Yes, it is changing. In the future I see men supporting women in more than one of my campaigns. Already a man from an Islamic party wrote about my campaign and was pushing for me.

Would a change in male attitudes (if there is one) translate into more men voting for women candidates at future elections? This, as already noted, is arguably key to increasing representation in the Kuwaiti assembly, if as actual election results suggest there is little solidarity among women voters when it comes to supporting women standing as candidates. Interestingly however, the interview participants were equally split between giving positive responses either suggesting that men would vote for female candidates in the future or that they already did (n10) and those who felt that there would be no move in this direction (n10). Khawla and Munira represented the former group whose experiences of the men around them were positive in terms of support for female candidates:

Yes, they do now these days. They don't care about the gender they want to vote for the best candidate they see. My father always votes for woman and respects women's decisions.

Yes, a lot. My husband always gives women his vote. There are in fact feminist reasons sometimes. But also when he explained to me his point of view about what that specific woman candidate did personally and 
the power she has in her thoughts it made sense to me! Actually women candidates are not any women, they are the best of the best; they are really into political rights...He voted for Safa Al Hashim [female candidate] and he was really happy about it.

Huda's comments were optimistic about changing male attitudes to women in politics generally:

The next generation should take their responsibility and I want them to be role models and seek better education and apply it to their work and I want their minds to be more open. Men have started to vote for women and they want to believe in them.

Of course not all participants agreed with these sentiments and certainly not all of them could draw on personal examples of men voting or intending to vote for women candidates. For example, Mai could not perceive that men would accept female political candidates and vote for them in the future:

No it's hard to do that and it will never happen I think because the development of the country hasn't reached that point.

Equally, Samar believed that men were not ready for greater equality in political representation:

Sometimes if they [men] see a better female candidate than the male candidate he will not give her his vote because he feels that his position in society will be undermined when she gets into a position of power.

Arguably however, the data does indicate that there is some male support for women's equality, though expressed through the perceptions and experiences of women. Nevertheless, change can only come if those with power support women or at least allow it. The women in leadership participants were particularly vocal regarding obstacles to change at the top - corruption, for example WiL3, the lawyer, commented:

Men [male politicians] are not really happy with the changes. I think they [the reforms] are still not effective in achieving better circumstances for women. I can't see a better scenario, even with men who do want change, because we have not got good male and female role models, this is because of the corruption that we live with. 
Similarly, another woman in leadership, a writer and journalist and key figure in the media sector (WiL4), used the question to introduce her belief that men were also stuck in a cycle of corruption:

They [men] feel they want a better lifestyle but the corruption in the society is not allowing them. For example, I raised my boy to follow all the laws but when he started his own business he couldn't stay on the right track because the system needed him to work around the laws but as I said I raised him in a law-abiding way but society needs him to act differently and it was really hard for him. Because he raised with ethics.

Implicit in these comments is the suggestion that even in the case of someone who wants to progress in life in an ethical way, corruption is the default path in Kuwait and those who do not follow that path may fail as a result. Corruption, such as the paying of bribes is known to be widespread in both public and private sectors (Al-Daihani, 2015). This will particularly affect women who are more recent entrants into the domains where corruption is practiced. And, if the findings of this research are to go by, if they are less inclined to use these practices then their chances of being successful at the 'game' are severely weakened.

\section{Future campaigning?}

The questionnaire had indicated that the majority of women who took part in it rejected the notion that now that women can vote there is no need to continue campaigning on women's issues. To the statement "Now that women have the right to vote in elections there is no need to campaign for any further rights" only 16.1\% agreed or strongly disagreed while $78.3 \%$ either disagreed or strongly disagreed with the rest unsure. This was also reflected in the participant interviews, for example Huda commented:

We should not stop because there is too much left that we haven't yet achieved. There are many things left to do.

When asked about the future, the women interviewed continually referred to the progressive improvements they hoped for, suggesting that to meet this demand for change women will need to have their voices heard in the years ahead. What the data appeared to suggest overall is that Kuwait is undergoing change, albeit slow change, towards greater equality. This is likely to continue. Kuwait does not sit in a bubble and its 
citizens are open to external influences that are likely to keep Kuwait on the track to achieving greater equality - in particular growing exposure to the Internet, and through it the wider world, and this is something that will likely have a decisive and lasting effect on Kuwait and the wider region as put forward by one of the women in leadership participants, a senior media figure (WiL4):

I think before it was difficult to express hopes for change but now it is easier and no one can prevent [women] from seeing the international effects on freedom. So the new generation will learn about women's issues online. The spreading globalisation and the rise of social media are bringing people closer together and they are exchanging their experiences. Now, for example, we can follow what women in Saudi Arabia are doing to try to win the right to drive cars through Twitter or Instagram exactly as it is happening and without the established media controlling the message.

Likewise, WiL3, a lawyer, pointed out that social media could be a growing influence that also changes men's attitudes by exposing them to more liberal attitudes to women and women's empowerment:

I think men will be more proactive in society in the future and will push for more freedoms and more rights for women because they will more open-minded with the increasing use of social media we are seeing right now.

WiL3 and WIL4 are both essentially pointing out that social media (and this can include television networks) are increasingly globalised and everyday Kuwaiti men and women are exposed to alternatives. In particular, alternative societies in which women are seen fulfilling different roles - and these societies are often seen as successful. In short, male control of the messages which are read and viewed by women is faltering and this is likely to have lasting consequences.

\section{Chapter summary}

This chapter presented the findings that were mostly oriented to the future. While there was a general tendency towards optimism most of the responses were generalised rather than detailed and specific. This is perhaps understandable as compared to the past and the present (discussed in the previous two chapters), the future is imaginary and a matter for speculation. The urbanised educated Kuwaiti women in this study called for greater 
equality, freedom and justice for future generations with the exception of two religious and conservative women who saw the future in terms of following the holy texts.

If the majority perspective can be viewed as a 'human rights' one that would not be out of place in a western secular context, then it could be said that two other minority positions were also established, the aforementioned religious conservative one and the Islamic feminism which were detected in some of the responses.

There was also a tendency for participants to believe that globalisation and the new media that (which they are the first to have access to) will play an important role in shaping the future, something also expressed by women in leadership. Furthermore, according to these findings, arguably the pressure for increased gender equality will continue. And thus, achieving the vote is the beginning of an ongoing process not an end in itself. 


\section{CHAPTER NINE}

\section{EVALUATION OF THE STUDY}

\section{Introduction}

Having presented the findings of the research in the last three chapters, this chapter presents an evaluation of the study where new or reinforced strands of understanding of women's resistance to patriarchy and the search for empowerment in the $21^{\text {st }}$ century in Islamic Kuwait is discussed.

As emphasised in chapter three, this exploratory study did not aim to apply a rigid theoretical framework but instead, where appropriate, it sought to evaluate the applicability of a number of theoretical approaches to the research findings. These approaches were found in the radical feminism of Mackinnon $(1987,1989)$ and Willis (1992) the work of Walby (1989, 1996, 1997, 2007, 2009, 2011), Islamic feminism (González, 2013; Badran, 2008; Mir-Hosseini, 2004) and finally Lukes on power (1974, 2005). In doing so this chapter seeks to assess to what degree the research reaffirms, contradicts, adds to or merely remains unattached to the theories discussed in chapter three.

Radical feminism was considered as potentially useful as it is associated with critiques of the most blatant forms of patriarchy which while may be less easily seen in western countries is certainly still on view in Islamic societies such as Kuwait. Walby offers useful frameworks for the analysis of change and progress that she herself has applied to the UK and Europe and these were thought to be potentially helpful to understand societies beyond this. The work on Islamic feminism was included to help interpret the views expressed by participants and specifically to understand whether the range of views expressed could be tentatively categorised into some form of heuristic typology. Lastly, adding a non-feminist perspective to the mix, Lukes theorising on power was selected as potentially helpful in understanding issues such as why so many women are obeisant and relatedly, why do so many Kuwaiti women espouse views which appear contrary to their own interests. As already noted, being an exploratory study the theoretical framework 
was thus a speculative one - based on assumptions such as common pathways shared by women seeking empowerment in different societies with greatly varying cultures.

The discussion focuses on the most interesting and perhaps most revelatory themes to emerge from the findings of the research. First the chapter considers the public-private sphere dichotomy, and how it manifested in the research findings. For example, the chapter begins with a focuses on the efforts to confine women and asks whether, when these efforts fail is it a sign that patriarchy is a fading force? It also considers what the research suggests about the emergence of women into the public sphere. The chapter goes on to discuss the question of domestic labour versus market labour which is particularly relevant given that the move to market labour is happening in Kuwait today. This leads into the question of marriage and divorce and what this study suggests about marriage's future role - will it continue as the main tool for keeping women in the private domain or will it morph into a more western like partnership of equals? Thereafter the chapter turns to another prominent aspect of the study, the political and civic participation of Kuwaiti women and what this study has added to an understanding of the significance of this participation.

The question of feminism among Kuwaiti women and how it should be characterised is also considered. The chapter questions whether the findings of this study confirm the rise of Islamic feminism in Kuwait or whether secular feminism emerges as the dominant form. Connected to this is the question of what the research has revealed about power, patriarchy and religion - in short, does the research help to understand obeisance?

Finally, the chapter considers the future and draws upon the research findings to evaluate the likely trajectory of women's empowerment in Kuwait.

\section{The value of domestic production and women's emergence in the public domain of market labour.}

Religions tend to be patriarchal and today Islam is the clearest example of this as sustained in the Qur'an, the Hadiths and Sharia. Women are ascribed a sexual power that bodes destruction and which men need to be protected from. The same can be seen in the biblical portrayal of Eve in the Garden of Eden. The Islamic response to this danger is concealment, whereby women are concealed by restricting them to the private sphere. 
Arguably, the degree of confinement and concealment is one of the most reliable indicators of the strength of patriarchy in a society.

In pre-oil Kuwait this confinement of women was a fundamental social principle. Then, there was a saying widely used (similar to the historic oft uttered British phrase 'the women's place is in the home') which translates as, “A woman should go out of her house only twice in her whole life; first when she goes to her husband's house and second when she goes to her grave" (Alessa, 2010, p.9). Anthropologist Michelle Rosaldo (1974) argued that women's subordination is universal irrespective of religion and that it is only the degree that varies. She attempted to find a framework for understanding why relationships between the sexes are universally asymmetrical. Her preferred approach is to look at the way humans are socially and culturally organised, specifically the division of public and domestic (private) spheres. According to Rosaldo (1974), women are domestically orientated primarily as a result of their reproductive and child-rearing role and that the public-domestic division "provides the necessary framework for an understanding of male and female roles in any society" (p.24). Furthermore, women are subordinate to men because of this confinement to the private (domestic) sphere and the low value assigned to domestic labour. Walby (1990, p.175) interprets Rosaldo's indicator of the strength of patriarchy and the level of subordination as being the level of confinement of women to the private sphere and their isolation from their fellow women in society.

In Islam perhaps more than in any other form of social structure there are stark examples of this concealment. Women's bodies are clothed from head to toe, their movements are restricted or subject to male accompaniment or at least approval, and they are often segregated in public places such as schools and universities. Therefore, if the view is taken that women's emergence from the private domestic sphere is a sign of a weakening of patriarchal control then it could be concluded that the findings of this research suggest that patriarchy is weakening in Kuwait. First through education, then employment and most recently in politics where women have been entering public domains forcefully in recent decades in the same way they did in the UK starting nearly one hundred years ago.

In 2005, a report by the United Nations Development Programme (UNDP) on gender equality in the Arab region pointed out that male hegemony had sequestered women in the family home as mother, nurturers and carers and it condemned this confinement as 
an opportunity lost to society. The research findings documented in this thesis however challenges this and suggests an alternative reality whereby Kuwaiti women have de facto moved into the public domain and even more importantly perhaps the findings from the interviews tentatively suggest that women's attitudes and aspirations may be supportive of this move.

The educated urbanised women who participated in both the questionnaire and the interviews indicated that they mostly strove for an end to confinement and did so my voting with their feet as they stepped into higher education and employment. Only $29.3 \%$ of respondents to the questionnaire disagreed or strongly disagreed with the idea that women should have just as much chance to build a successful career as men. And, in the interviews a very strong theme was evident where women emphasised that work was an important part of their lives, to such an extent that for some it formed an important part of their very identity - it was clear to see that the women were motivated by both intrinsic and extrinsic factors. Women wanted the choice whether to work or not and felt this should be the case whether or not they were married. Arguably, the move into employment will undoubtedly change the nature of Kuwaiti society permanently and decisively in favour greater empowerment for women whatever actions patriarchal forces (such as the stay at home allowance) attempt. Certainly it is true to say that the labour force participation of women in the UK stimulated gender equality and there is no reason to suggest that the same will not happen in Kuwait.

Walby reconstructs the concept of a social system into one comprising of regimes of inequality on the one hand and institutional domains on the other, in a framework which facilitates the consideration of multiple sets of social relations simultaneously. This research however, is limited to gender relations in Kuwait; not because other regimes of inequality do not exist as they surely do, with citizenship, tribal, sectarian and ethnic inequality being among them. Therefore, while Walby's work on intersectionality may be valuable in another context, for this particular study it has been found to be of limited use. Nevertheless, Walby's discussion of the current state of gender relations in Europe is interesting in that it may provide pointers as to what kind of issues may be relevant in Kuwait in the future.

In the European context, Walby analyses the growth in women's paid employment and how it led to a generational gap opening between younger women with their access to 
employment and older generations where women were more likely to be homemakers (Walby, 1997). Taking this mainly materialist perspective she then traced how this provided impetus to organisational and institutional change, the law, politics and the distribution of educational opportunities (Walby, 1996, 1997). It does appear that in that understanding the trajectory of women's empowerment in one context can help in forming assessment of the likely future for women in another. Yet, reaching the level of women's empowerment in Kuwait as seen in Western Europe is likely to take a long time in what is, arguably, a context far more dominated by patriarchy and religion than $20^{\text {th }}$ century Europe ever was.

However, Walby's analysis of domestic labour does prompt a consideration of how the treatment of domestic labour in Kuwait is influencing gender relations and women's empowerment. In line with Rosaldo (1974), Walby (2009) suggests that a symptom of the public-private division in gender relations is the lack of social and economic value assigned to domestic labour. The transformation of women's labour from household production to free wage labour is a key theme in Walby's recent work (2009), she argues that in a patriarchal society there is no value placed on work undertaken in the home such as housework and care work, and that this has a disempowering effect which is reversed when women emerge from the home and enter the labour market. This trend was clearly seen in the UK and it is underway in Kuwait too. According to Walby (2009): "the modernization of gender relations in the economy is constituted by the transition from domestic to market labour for women and a decline in the domestic sector as the basis for women's livelihood" (p.110). This assertion can be considered in the Kuwaiti context. In this thesis, a great deal of momentum towards the same kind of transformation in Kuwait has been revealed. The women who took part in the research wanted waged labour work and they wanted it on the same terms as their male counterparts. If this momentum stays in place, then it is likely to be a key driver toward gender equality in Kuwait as it has been in other countries. It is no accident that women's move into the labour force in the UK was accompanied by legislation aimed at putting equality on a legal footing. As already noted, beginning in the 1960s, manufacturing jobs predominantly filled by men were increasingly replaced by service sector jobs associated more with women (ONS, 2013). Participation rates started to rise quickly. In 1960, $39.5 \%$ of women were in the labour force (Sorrentino, 1983, p. 25) a figure which had risen to $53 \%$ by 1971 and $67 \%$ in 2013 (ONS, 2013, p.1). This rapid increase came as 
legislation starting with the 1970 Equal Pay Act, 1975 Sex Discrimination Act, and 1975 Employment Protection Act brought the law more into line with the new realities of the workforce (ONS, 2013). However, while the expansion of public sector jobs in Kuwait in areas such as health, education and administration have also drawn women into the labour force, protective legislation has not been so forthcoming.

Walby's assertion that the failure to place an economic value on domestic labour undermines the position of women in developed 'western' societies (Walby, 2009, p.109) is a very interesting one to apply to Kuwait. It is a key tenant of Islamist opposition policy that the state should fund allowances for women to stay at home (Kareem, 2013). The government has already allowed this for women over 55 but the opposition wanted this broadened to cover all women 24 and older. This arguably is a decisive step to reverse the trend of women increasingly entering what were previously male only public domains and it is an attempt to confine them to the private sphere. Islamists in the Kuwaiti parliament have been seeking to substantially increase unemployment benefit for women and the scope of entitlement (effectively paying them for their domestic labour) to such a level that market labour would be financially unviable or at least unnecessary. Perhaps sensing that women were starting to flood male public domains this measure was a reluctant last chance attempt to stem the flow. When proposing the change, it was argued that the allowance would "create more jobs and help maintain the social structure" (al-Saleh cited in Kareem, 2013).

At the time of writing the proposal has yet to become law and it may not become law, not least because of the strain it would put on public finances. However, in any event, such was the strength of the desire to work and the intrinsic value placed on work by the educated urbanised women participating in this research that it could be argued that the 'genie has already escaped the bottle'. This research has shown that intrinsic motivating factors are highly important, not simply financial rewards and thus it is difficult to imagine this being reversed. Remember, Shahad wanted to work to "serve my country". Areej stated "Work is everything for me." Retired teacher Fouz said "It is really important to give to society...it [work] was my whole life." The data clearly suggested that women can see work as an escape from domestic life and for some women work can be perceived to be something to be prioritised - a way to secure independence, selfworth and privacy, something to be treasured. Therefore, even if incentives were put in 
place to entice women to stay at home, for educated women who enjoy their work then there is perhaps no going back.

Another complicating factor in the case of Kuwait is that it is arguable that domestic labour is assigned a value in Kuwait and that this value is extremely low. This assertion is founded on the understanding that there are approximately 600,000 domestic workers, mainly from low wage economies of south and south-east Asia, current performing domestic labour in the homes of Kuwaiti women (Ahmad, 2010). That is virtually one for every adult Kuwaiti woman. The minimum monthly wage for a non-Kuwaiti domestic worker in Kuwait is $\$ 147$ while the average monthly wage for a Kuwaiti worker is more than 1,000 dinars $(\$ 3,650)$ and the unemployment benefit for a Kuwaiti woman is 350 dinars $(\$ 1,200)$ (Kareem, 2013). This however also raises the possibility that the influx of domestic labour into Kuwait since the 1970s has been a factor in women's emergence in the public domain of wage labour. According to Ahmad (2010) while there were only 12,000 migrant domestic workers in the mid-1970s by 2010 nine out of ten Kuwaiti households employed at least one. This surely must have assisted to create opportunities for Kuwaiti women to move into the male public domain of waged labour. However, this remains an assumption as empirical evidence to support this is lacking. And, interestingly, the interview participants in this study made no reference to this as a factor, preferring instead to offer the desire for self-fulfilment, assertion of independence and a desire to participate in society and make a contribution to the country; though perhaps it is human nature to express the intrinsic value of a particular action rather than extrinsic considerations. Nevertheless, and regardless of women's opinions - Islamic politicians in Kuwait are attempting to assign economic value to domestic labour.

\section{Wasta}

Based on the findings of this research, it can be argued that in the public sphere wasta is perceived as working against women's interests. Participants viewed wasta as acting as a degrading influence on social, political and economic progress. The strength of feeling was particularly significant because remarks about wasta were unprompted and no questions included the word. Huda believed that the public sector was based on wasta and as this is where the overwhelming majority of women work and this in turn suggests that there are issues for women in terms of access to senior positions and promotions in general. Mona offered the strong statement that "... wasta is a disaster" and Halaa said: 
"Personal interest is preventing legislative reform while wasta just ignores the law." Whether these informal processes that go to make up wasta in Kuwait and the 'old boys' network' or the 'glass ceiling' in the UK dissipate over time is a key question. Walby (1997) certainly highlighted generational differences in the societies of Western Europe arising from increasing educational attainment which saw the opportunities for the younger generation transformed compared to the previous one. There is no reason to think a parallel process is not occurring in Kuwait but whereas in the UK and elsewhere there was political momentum to provide a legislative underpinning for gender equality in the workplace this cannot really be detected in Kuwait. The Constitution glaring omits mention of gender equality when stating the principle of equality among its citizens regardless of "race, origin, language, or religion."

\section{Political citizenship and emergence in the public sphere}

Women have gained a far greater degree of political citizenship in Kuwait in the aftermath of the Iraqi invasion and occupation of the country (Tetreault, 1993). Walby (2009) argues that as women gain political citizenship "they are more able to effectively contest ... exclusion from the public [sphere]" (p.110). This has been reflected in Kuwait's recent history and in this research where the educated urbanised women of Kuwait demonstrated their determination to retain and build on their political citizenship through political participation in the form of voting and by supporting candidature among women in general and their own daughters specifically. Indeed, 73.5\% (n321) of respondents who took part in the questionnaire believed women should support female candidates while participation at elections was supported by a similar number $(73.4 \%$, n321). Political citizenship has undoubtedly arrived in Kuwait. Women make up the majority of voters. However, these are votes for a quasi-democratic institution. The government appoints some of the assembly's members and the Emir can veto any law it passes, and even dissolve the assembly altogether as recent history has seen. There is then the question of political identity; women do not always identify themselves first and foremost with their gender, something true in Kuwait and the UK. This calls into question whether political citizenship in Kuwait is as significant for women's empowerment as it is the UK. Only time will answer this question with any certainty. 
Women's representation in the Kuwaiti assembly has had a stuttering start and already a degree of scepticism has set in concerning the quality and motives of those seeking to enter politics. Nevertheless, the right to vote and hence have women's views taken into account is a vital step with major long term consequences, even though in numerical terms it may be a long road ahead in terms of democratic representation. This assertion is perhaps strengthened considering how despite having an active women's movement in the UK the number of women MPs grew from 16 to 19 in five decades.

Norris and Lovenduski (1995) aimed to model precisely which factors determined the level of women's representation in democratic bodies. Writing in the UK, it is nevertheless interesting to consider their model in the context of Kuwait. They based their model on 'demand' and 'supply' factors. Demand was determined by a) how well qualified women were to run for office and b) how willing elites were to select female candidates. The supply factors were a) the degree to which the women were resourced (financially, time-wise and experience) and b) their drive, motivation and level of interest in politics. On demand point a) it could be argued that there are an increasing number of women qualified to be political representatives in Kuwait with graduates working in various professions as well as academics and members of women's organisations. Point b) is at the same time crucial and yet potentially could be seen as irrelevant, this is because there or no political parties in Kuwait. The absence of a party structure to encourage the selection of women candidates in the way New Labour did in the UK could pose a major threat to women's representation. Although, this could change should the ruling family actively support the participation of women candidates. Considering supply, for point a) more women have two out of these three types of resources, money through employment, time through the availability of migrant domestic labour, although they could be seen as lacking in experience. Finally, and perhaps most significantly, as illustrated in this research, there is the question of motivation. The women in this study wanted to vote, they wanted to vote for women, they wanted their daughters to vote and even stand for election. Huda vehemently stated "...we should not stop because there is too much left that we haven't yet achieved. There are many things left to do." And, the notion that having won the right to vote women should stop campaigning was the most disagreed to statement of all in the questionnaire responses; $78.3 \%$ (n342) either disagreed or strongly disagreed. 


\section{Marriage: the principal means of private sphere confinement for adult Kuwaiti women}

In her assessment of the state of women's empowerment in Kuwait, Al-Munghi (2010, p.230) wrote, "Kuwaiti society continues to uphold the notion that the role of women should be primarily limited to the domestic sphere, taking care of children." As a general statement this holds true but it does need to be qualified. The main tool for confining women to the private sphere in adulthood is marriage (though when this is not in use there is the broader provision of male guardianship). However, there is also a need to recognise that significant interests and influences exist that are keen to accelerate the modernisation of the country, among which are many women themselves and members of the ruling elite. Data published by the United Nations shows that for women aged between 25 and 44 (prime family raising age) 36\% were not married (UNData, 2012). Less than $42 \%$ of the respondents to the questionnaire were married. Furthermore, in Kuwait, in the 10 years from 2003 to 2013 the ratio of divorces to marriages as a percentage rose from 32.5\% in 2003 to 46.4\% in 2013 (SKCSB, 2013). The equivalent statistic for England and Wales (for 2012) was 45\% (ONS, 2014).

Perhaps one reason for the large number of divorce petitions filed by Kuwaiti women is the court's willingness to consider increasingly frivolous grounds under an ever broadening definition of 'injury'. As already noted, news reports in Kuwait have reported on divorce petitions which have included incorrect etiquette when eating peas and squeezing toothpaste incorrectly (Toumbi, 2013). Similarly, in Kuwait (Al- Enzi, 2015) and Saudi Arabia (Al- Tamimi, 2012) smoking is sufficient grounds for a petition to be granted. This does suggest that women are using the permissible grounds of 'injury' in its broadest sense to file for divorce.

The findings of the questionnaire revealed that $11.4 \%$ (n50) of respondents were divorced and 2 of the 20 women who participated in the interviews (Dalal and Kawther) were divorced. The rise in the divorce rate is significance in terms of women's empowerment with increasing numbers of women who aim to live independently postmarriage and this is outside the traditional 'married woman in the private domain' life path. Divorce, or perhaps women seeking divorce, runs counter to the patriarchal, Islamist, traditional framing of how a women's life should proceed. Most Kuwaiti 
women must now know someone who is divorced. At the same time, however, it should be remembered that the divorce laws in Kuwait are highly discriminatory in favour of men and for every newly created independent woman there may well be many more left struggling.

\section{Types of feminism revealed in this study}

The dominant definition of Islamic feminism is that it is feminism working within the system, trying to change it through rational reinterpretation of the holy texts (Badran, 2008; González, 2013). Islamic feminism rejects the (male) interpretation of the holy texts which has led to situation where on the one hand women are to be totally dependent on their husbands and on the other the man can divorce his wife simply by stating that is what he is doing, without the consent of the women (Mir-Hossieni, 2006).

The responses to the questionnaire indicated that many participants rejected the notion that women should not sit as judges $(29.3 \%, \mathrm{n} 128)$, and this is a direct challenge to the prevailing conservative stance underpinned by rather weak and often challenged Qur'anic substantiation. Importantly however, the majority did not reject it. Furthermore, during the interviews 14 women supported women becoming judges while the 6 who did not either thought women were too emotional or simply said that having women judges was against Islam. There were no attempts during the interviews to argue for women judges using religious justifications as one would expect an Islamic feminist to do.

Another example was the opposition to the Sharia system of justice as applied in the family courts in Kuwait. In some ways Muslim feminism can be seen as more radical than secular feminism. It could be argued that rather than side-stepping the religious underpinning of the patriarchy as secular feminism can do, Islamic feminism takes on detailed arguments concerning Islam and women. Secular feminists would see such debates as futile bearing in mind the evidence of the strong link between religion and male dominance.

The secular feminism revealed in this study expressed itself in terms familiar in the West: meritocracy, equal opportunities, equal rights, non-discrimination, social justice and civic participation. There were also repeated references to other countries, usually in the context of positive examples, suggesting that this secular feminism is also internationalist. 
Nevertheless, with patriarchy so powerful, underpinned by religion, with women at the early stages of entering the public sphere, with the right to vote so recently won, and with women's activism mainly found in the affluent, educated urbanised women of Kuwait, the most obvious parallels are with the second wave of feminism of the 1970s.

Only minor traces of Islamic feminism could be detected among those women supporting empowerment (and remember not all did, or rather did not see empowerment in what was being proposed, i.e. women as judges, equal pay, ending discrimination etc.). Most pro-empowerment women used human rights language, or perhaps it is better termed 'natural justice' language. Five of the educated urbanised women in the study used the word 'God' somewhere in their answers, meaning that 15 women made no mention of God at all, something which supports the conclusion that Islamic feminism was not the dominant form of feminism to be revealed in this study.

\section{Power, patriarchy and religion: ownership of the means of production of religious knowledge}

Marx described how in a capitalist society ownership of the means of production afforded power to the capitalist while the worker, lacking any such ownership, was relegated to a subservient position. This is because social position in a capitalist society is economically determined (Marx, 1906). In early Islamic societies the social structure was based on piety and religious knowledge and this has a legacy which still has enormous influence today. Indeed, it could be said that ownership of the means of production of religious knowledge is to Islam what ownership of the means of production of physical goods is to the capitalist society Marx was describing. While capitalism had its capitalists, bourgeoisie and proletariat, Islamic society permitted only one exception to classlessness - the ulemas (men of knowledge). Thus ownership of the means of the production of religious knowledge is and has always been in the hands of men despite the term ulema being gender neutral (Robinson, 1999). However, while Islam has a number of schools of religious knowledge (Madhhab) all of which place men in the dominant position some, in practice, are more favourable to women than others. The Maliki School is dominant in Kuwait (among Sunnis) and is generally considered somewhat more favourable to women (Robinson, 1999). 
Ali (2000) argues Islam and Islamic law should not be viewed as a monolithic system but rather as one which can be interpreted in a 'literalist' way or in a 'progressive' way. Further, there is nothing inevitable about the apparent contradictions between Islam and secular human rights norms and values and how they are expressed in human rights instruments. Nevertheless, from a feminist viewpoint whether it is a literalist or a progressive perspective being applied the interpretation in Islamic countries is invariably the exclusive domain of men. Islamic feminists, of course, are challenging this while those taking a natural justice or human rights approach to women's empowerment would seek to take the dialogue (between men and women concerning women's empowerment) out of any kind of religious context. This research, which did not seek to be representative of the whole female Kuwaiti population, heard more of the latter kind of thinking than the former.

\section{Reflection on power, obeisance and rebelliousness: Why most obey and some do not.}

This study gave voice to the views and opinions of educated urbanised Kuwaiti women. Yet it was not a unified voice. While liberal attitudes were widely expressed there were also plentiful reminders that gender equality is not a universally accepted concept in Kuwait. Consider the questionnaire results which indicated that $51.3 \%$ of respondents rejected the proposal that women should become judges, 49.6\% did not believe that women should be able to pass on their nationality to their children, and $38.4 \%$ disagreed or strongly disagreed with the statement that women should be equal to men in society. Those in agreement with, and those dissenting to, the proposition that women's main role in society was as a wife and mother were almost equally represented among the questionnaire respondents. Consider also how the women interviewed for this study accepted the "woman as emotional beings' narrative associated with religious and patriarchal societies. MacKinnon (1984) may ascribe this emotionality label as part of male dominance which leads to differences being interpreted through reference to male standards. The male image reflects the image of what a human being ought to be whereas women are different from men and need protection (MacKinnon, 1984). Protection in Kuwait has previously come in the form of the veil, segregated education, confinement to the home and where a woman does work, job segregation, as well as men's financial obligations towards them which are a form of this protection. However, for those urbanised and 
educated women who took part in interviews, the findings of this research indicated that they neither sought nor valued this protection. Remember Kawther who stated: “... I think a wife will not want 1 dinar from her husband anymore". Arguably, the very fact that the women who took part in this research demonstrated their capacity for independent thought is a strong indicator that women can and do value a degree of independence and they do not simply want to follow men. Thus it would be wrong to ascribe 'false consciousness' to the participant's expressions, views and opinions or to assert what MacKinnon (1989, p.115) referred to as the "authority of interpretation" and "the claim to speak for all women". Such an approach would be both simplistic and problematic as it denies the women in this study the right to own and interpret their own experiences.

Both the questionnaire and the interview findings suggested that some Kuwaiti women are comfortable and assured when asserting rights that have either already been granted or have been admitted to the policy agenda as legitimate areas of debate; voting at elections, the passport laws, housing loans, are each examples of these. In contrast the participants were, in many cases, reluctant to engage in areas of discussion which the producers of religious knowledge have demarked as falling within the bounds of Islamic principles. This was noticeable not only in their words but also in their body language. The anonymity of the questionnaire, however, produced a greater willingness to reject some of these principles including the principle of wali (male guardianship) which only one in five women appeared to support.

What emerges is a picture of women expressing views which sometimes appear radical and other times appear to accept their own oppression. Indeed, the findings were quite revealing where some of the participants appeared to support the 'emotionality narrative' which renders women subservient to men. Empowerment, but not necessarily at the expense of piety, was one of the perspectives revealed while another was a straightforward 'western' style equality/social democratic standpoint.

This brings forth a consideration of power and obeisance; why did the educated urbanised women who took part in the research obey men's laws that are oppressive to women and how did they arrive at this state of belief? The findings certainly did not suggest that the women who took part in the research feared their husbands, many participants in the questionnaire supported oppositional statements and the women who 
took part in the interviews openly criticised male behaviour. This assertion is perhaps also supported by the rising volumes of divorce petitions. What the research made clear however is that women do fear religion, God, the Qur'an and religious authority. Among the women in this research, direct challenges to religious knowledge and norms were far rarer than challenges to men.

As discussed in chapter three, Lukes' believes that power is achieved through internal constraints imposed upon the subject. Through these constraints the subject acquires beliefs which in turn facilitate the path to domination through consent, a process which can be either coercive or non-coercive (Lukes, 2005). From the findings in this study it is possible to interpret men's power over women in Kuwait as partly coercive and partly non-coercive. Overall a coercive framework is in place comprising a patriarchy underpinned by cultural traditions and religious knowledge which is translated into laws and which closely control the lives of women in both the public and private spheres. These laws can be classed as coercive because they are backed by the coercive power of punishment and this of course is arguably central to the functioning of any legal system (Schauer, 2015). Sanctions in Kuwait are accompanied by a wide range of social pressures which are culturally and/or religiously based. These pressures invoke and sustain duties. According to Green (2015, p.6) "A duty is a norm to which its subjects must conform, not one to which they may conform when suits them, benefits them, or when they consider it right to do so." The key duties covered in this study included the duty to obey husbands and male guardians and the duty to fulfil the domestic role as wife and mother. The first duty was agreed (or strongly agreed) to by just $20.1 \%$ of the questionnaire participants while for the primacy of the wife/mother duty this figure was $35.9 \%$. This demonstrates that non-coercive power, even in a religious society like Kuwait may be only partially effective.

Referring again to Lukes' model (2005), is it possible to observe 'thin' or 'thick' acquiescence? Arguably, this study has revealed examples of both. Thin acquiescence, a resignation to dominant values, was heard in the voices of the women who took part in the interviews when they shared their pessimistic perceptions of male willingness to cede empowerment to women, their frustration at male dominated wasta and their doubts that women would one day be judges. On the other hand, thick acquiescence was seen among the questionnaire respondents who actively failed to support women as judges, 
reaffirmed their duty to obey their husbands and male relatives and disagreed with a range of statements which supported either equality or a woman's material interests. This is not to say that the study revealed overwhelming acquiescence on the part of the urban educated women of Kuwait who took part in the research. Indeed, a substantial amount of opinion was oppositional and even feminist by 'western' standards. However, the point that is simply being made here is that it was possible to detect examples of Lukes' two forms of acquiescence.

This study, in regards to the significant number of times Kuwaiti women espoused views which seemed to support the status quo, or at least failed to express views in support of women's empowerment tends to support Gidden's critique of Lukes' belief that interests and power are linked. Gidden's wrote, "People are not always inclined to act in accordance with their own interests. ... The concept of interest ... has nothing logically to do with that of power (Giddens, 1979, p.90). Some of the Kuwaiti women in this study did not align their expressed views with any objective definition of their interests.

\section{Looking forward: the long road ahead}

Finally, based on both this study and the collective evidence available it is possible to reflect on where, how and why change, specifically women's empowerment, may come in the future. The findings do suggest agreement with Al Munghi's (2010) analysis that access to education has led to greater financial independence, and Al Munghi is also right to say that "women now have the unprecedented potential to directly influence Kuwaiti society" (p.224). However, although the link between education, employment, financial empowerment and ultimately equality and women's empowerment may indeed exist and even represent an unstoppable force, it is nevertheless a force which moves very, very slowly - even in secular societies where patriarchy is less pronounced. The lesson from British social policy is that if it moves at all is to a great degree down to deliberate actions; actions often undertaken by men. The struggle for women's suffrage in the UK may have involved middle class women and they may have indeed played a role in the achievement of voting rights but arguably the recent dramatic rise in the number of MPs in the British parliament was a result of one political party's change in approach when the Labour Party introduced all women shortlists, guaranteeing that a high number of female candidates would be fielded by that party. For the 1997 election, which they won by a 
landslide, the Labour Party had women only shortlists in half of the 100 most winnable seats and the result was that women's representation in parliament took a giant stride forwards (Kelly \& White, 2009). Changes to the tax system and the introduction of antidiscrimination legislation were also largely carried out my male dominated governments. The recommendations in the Davis Report, published in 2011, which proved effective in assisting women in greater numbers to take a seat at the table in British corporate boardrooms were also made by a man. Similarly, in Kuwait, women's enfranchisement was voted through by an all-male parliament (Olimat, 2009) and subsequent positive reforms such as the 2009 amendment to the passport laws enabling women to obtain a passport without the permission of their male guardian (Mckee, 2009) and access to housing loans for unmarried women (Almunajjed, 2012) were by and large granted by men either sitting in the Constitutional Court, the National Assembly or in government ministries.

It seems therefore that if any lesson is to be learnt from the UK it is perhaps that real equality comes from changes to the law of the land and not extra-legal occurrences such as women sitting as judges, or women taking a place at the boardroom, or indeed the lifting the glass ceiling. This is certainly not to say that all of these changes are unnecessary and these changes would of course support the empowerment of women, but ultimately equality remains in the hands of men. In Kuwait it is men who are the interpreters of religious knowledge - and religion dictates that women should be concealed and controlled by men. There is no strong evidence to suggest (nor was there evidence in this study) that women could or even desire to produce and interpret religious knowledge to secure equality within Islam.

Since Kuwait came into being in its current form when Mub rak the Great (1896-1915) seized the throne by killing his two half-brothers, Kuwait has always been subject to opposing groups of men either in open conflict or under an unwritten compromise realised through a socio-political contract which governs a number of patron-client relationships (Casey, 2007). The actors have been the princes of the ruling elite, the urban dwellers comprising Sunni merchant families (badar), tribesmen (bad ) and Shiites. In recent times Islamists have become another part of this complex but all male patchwork. That there is a parliament and a constitution at all is a result of one major compromise between the ruling family and the hadar who saw it as a means to ensure 
their interests would be accounted for. Women's 'settlement' in any future social contract will likely dictate the degree to which they are empowered in future. In addition to this, changes in the relationship between religion and the state along the Islamist-secular continuum will be influential which ever direction this moves in. The relatively benign conditions for women in Kuwait (compared for example with Saudi Arabia) is probably attributable to the fact that Islamist and Conservative male groups comprise the opposition in Kuwait rather than the government and this is one reason why women politicians have been perceived as government-friendly rather than radical reformers and campaigners.

In the UK the late 1960s and 1970s saw widespread industrial unrest and militancy. Campaigners for women's rights successfully managed to associate their cause with working class men. An alliance of interests was formed and in most cases organised through trade unions. Women used the withdrawal of their labour through strikes as a powerful mechanism in pressing for equal pay. The most notable example of this was the Ford sewing machinists strike in 1968 (TUC, 2006). This successful action was instrumental in the establishment of the National Joint Action Campaign Committee for Women's Equal Rights (NJACCWER) in 1969 and strongly influenced the passing of the Equal Pay Act in 1970 (TUC, 2006). As well as the women's actions it should also be noted that being keen to join the European Economic Community Britain would have had to comply with the Treaty of Rome required member states to adopt the principle of equal pay for women (Davis, n.d.). Further industrial action followed, as did further legislation, as women (supported by many men, particularly trade unionists) kept up the pressure on government. With so many families now reliant on women's full or part-time incomes the male interests opposing equality and equal pay diminished to the point that the main remaining voice of opposition were business owners suggesting the economy would collapse under the weight of the additional costs of paying women the same as men (Davis, n.d.).

It may surprise some but workplace militancy is often seen in Kuwait and often involves women workers. Pay, conditions and job security are the most common causes of action. In particular, 2011 saw widespread labour unrest sparked by a strike of oil sector employees which once successful spread to other public sector workers (International Trade Union Confederation, 2012). The same year half of the national carrier Kuwait 
Airway's fleet was grounded until the government ceded to pay demands (Al Arabiya, 2011). Unrest also reappeared in 2014 when public sector workers again went on strike for higher pay (Saleh, 2014). And, in 2014, women workers in Kuwait had what could be described as their 'Ford sewing machinist' moment when the government terminated a school meals contract. Eight hundred women faced losing their jobs, a vast number in a country with Kuwait's population. Sixty of the women stormed the offices of the minister for education and staged a sit in demanding a transfer of undertakings to the new contractor (Trenwith, 2014). Thus, in terms of equal pay, Kuwaiti women's demands have been long established and as early as 1943 the Equal Pay Campaign Committee (EPCC) was established (Alessa, 2010). By and large women receive equal pay for equal work in the public sector, however the problems of job segregation and discrimination in career advancement remain very serious problems as this study has highlighted.

Returning to the UK, by the mid-1990s the tone of the women's movement and also the approach of politicians had changed. Specifically, women had increasingly become viewed as a crucial source of votes, and the then Labour opposition fashioned a platform of women-friendly policies to attract votes, something which was ultimately highly effective (Annesley et al., 2007). One tangible result of this was the Equality Act 2010 but also specific policies such as the provision of childcare, criminal justice laws protecting vulnerable female victims, and in political terms (as already noted) the introduction of allwomen shortlists for Labour Party candidates (Annesley et al., 2007). The Labour Party prospered from its popularity among female voters and remained in power from 1997 to 2010, and by that time it could be suggested that it had become clearly established that any party hoping to govern needed to appeal to female voters.

Whether the UK experience offers a viable blueprint for the greater empowerment of Kuwaiti women is highly debateable. The two main reasons for this are that there are no political parties, as previously mentioned, and that politics in Kuwait is far more tribal and sectarian than it is gendered. Standing on a platform of women-friendly policies may well occur among individual female or reform-minded male candidates but for those candidates mainly concerned with tribal or sectarian interests this would not happen and the chances of a bloc forming that is agreed to a programme of greater gender equality seems inconceivable, unless, and this is crucial, there is strong backing from the government. 
Nevertheless, there are undoubtedly entrenched social trends in Kuwait which are likely to see the strength and intensity of patriarchy in the country diminish slowly over time, not dissimilarly to how recent British social history unfolded. Women will remain educated, they will maintain and increase their presence in previously male dominated areas of employment and as the private sector in Kuwait grows at the expense of the solidly male-dominated public sector women will increase their economic power through entrepreneurship and business leadership. All these trends are underway already but it is a long road ahead.

At the end of the day women's empowerment in Kuwait may come down to events that are relatively unconnected - economics and globalisation, the broader social contract between the rulers of Kuwait and the citizenry, the desire or pressure to meet international norms and so on. However, what this thesis has added, is an insight into the lives of educated, urbanised Kuwaiti women and the findings certainly reveal an energy, a sense of injustice, and a desire for change - all bubbling beneath the surface. Thus, there is certainly no going back.

\section{Chapter Summary}

This chapter presented an evaluation of the study of Kuwaiti women's resistance to patriarchy. In doing so, the findings of the current study were considered and a range of theoretical approaches were applied, as well as a comparative analysis (between Kuwait and the UK) which sought to add a cross-contextual dimension to the evaluation.

The way that women in Kuwait have steadily emerged from the private domain of home and family into areas of civic life such as politics, education and employment has mirrored to some extent experiences in other societies and this study confirms that such an emergence is a precursor to increased women's empowerment and greater gender equality.

Women were found to be vociferous in their opposition to wasta not just for its role in supporting patriarchy but for its deleterious effect on society as a whole. 
Women's desire to be educated, participate in politics and pursue a career indicated that their emergence into the public sphere is arguably permanent and irreversible. In addition to this the study found that the traditional/ conventional model of the male-headed family unit around which so much of Kuwaiti law, policies and practices have been based is not as dominant as it once was with single women and divorced women now significant groups.

In terms of manifestations of feminism among urbanised educated women in Kuwait, this study found that the dominant form of expression followed similar lines to western feminism in its appeal to social justice and human rights. There were also some signs of Islamic feminism where women blamed inaccurate interpretation of Islam for gender equality. The task of Islamic feminism (seeking empowerment through reinterpretation) seems a very difficult one while men have such a secure grip on the means of production of religious knowledge.

On a theoretical level this research has been useful in a number of ways in terms of evaluating the relevance of mainly 'western' theories to the Islamic context. Those authors who put the private-public sphere dichotomy as central to gender relations were strongly vindicated by this study (Rosaldo, 1974; Walby, 2009). Other aspects of the theories applied were less useful. For example, the intersectionality of interests that was identified by Walby in a western European context understandably underplayed the role of religion which is so decisive in a country like Kuwait.

On the question of power this study's main contribution has been to confirm that the women of Kuwait do not always express views that are aligned with an objective assessment (insofar as one is possible) of their interests or always oppose propositions which challenge these interests.

Finally, with regard to the future, the findings of this study were considered to hypothesise on the future path of women's empowerment in Kuwait. The United Kingdom and Kuwait are vastly different societies but there are similarities in terms of women's emergence into the public sphere, the diminishing role of the traditional family unit, access to education, political participation and growing economic empowerment. These similarities enable a determination to be made about how we should view the future of women's role in Kuwaiti society. 


\section{CHAPTER TEN}

\section{SUMMARY AND CONCLUSIONS}

This final chapter presents a summary of the thesis and its conclusions. In doing so it enhances an understanding of women's empowerment in Islam and women's resistance to patriarchy in Kuwait.

\section{Summary of the thesis}

The introduction was prefaced by a description of the researcher's personal journey. It offered an explanation of why it was important to the researcher to understand the way urbanised educated women in Kuwait interpret their lives, their relations with men and their views on the past, present and future of Kuwaiti society.

The thesis began by setting out a brief history of the country and a summary of the economic, political, and legislative and policy domains - particularly from a women's rights perspective to provide some much needed context for the research. This context made it clear that the study was justified given the absence of Kuwaiti women's voices in academic consideration of patriarchy and women's empowerment in an Islamic context. The aims and research questions were also introduced and used as key delimiters throughout the course of the research. To remind the reader(s) these were:

- How has the recent development of social policy pertaining to women's rights in Kuwait been perceived by educated urbanised educated Kuwaiti women?

- How does the Kuwaiti educated urbanised educated woman in Kuwait view the existing social policy in Kuwait?

- How do educated urbanised women in Kuwait view their future empowerment and development of social policy? 
In CHAPTER ONE a review of literature was presented which focused on the political and legal framework of Kuwait, the role of religion in Kuwaiti society and the subordinate position of women in the country. The chapter described and sought to understand the recent developments in the field of women's rights in order to establish the key issues and discourses that might reasonably be expected to surface in a study such as this. Different analytical perspectives were included in the review including gender politics and economic determinism. From this review it was clear that the modest gains in women's position in Kuwaiti civic society contrasted with the steadfastly patriarchal subordination of women in the private sphere.

CHAPTER TWO investigated the contradictory nature of men's policies and practices towards women and it illustrated clearly how two distinct tracks had become apparent. Along one track, the civil, government-led, modernising elements and influences in Kuwaiti society appeared to be taking women to a future with greater economic and social empowerment. On the other, the private, religious, traditionalist and patriarchal track women were facing subordination to their husbands and male guardians, as well as huge discrimination and disadvantage in matters of family and personal status laws.

This discovery influenced the research which sought to understand women's perceptions of what had happened, was happening and would happen in the future regarding social policy and women's empowerment.

CHAPTER THREE presented a range of theoretical approaches which were considered to be potentially useful to this study. Being exploratory research the choice of which theories to include was a tentative one and involved making assumptions, in particular as to whether or not a theory which had been put forward in a western context could be applicable in a much contrasting setting. 'Intersectionality' theory (the work of Walby), 'radical feminism' (the approach offered by MacKinnon, Willis and others), the social anthropologist Rosaldo, whose work on the division of public and domestic (private) spheres proved highly useful, as well as the 'nature of power' advocated by Lukes were all selected on the basis that they had the potential to be useful in interpreting the research findings. These theories were bolstered by the application of Islamic feminism which is a perhaps a more obvious choice given the nature of this study but one which in itself is also exploratory given that the voices of Kuwaiti women have rarely been heard in social research. 
CHAPTER FOUR set out the methods used in the research in what was to have two phases; the first part comprising a quantitative questionnaire and the second in-depth interviews. The chapter went to great lengths to explain the research challenges in undertaking what could be seen, for many, as a controversial area of investigations and it provided details as to how these challenges would be met and importantly what compromises needed to be made. Ethical considerations featured prominently.

CHAPTER FIVE presented the results of the quantitative questionnaire. The high participation level suggested that there was a willingness among educated urbanised Kuwaiti women to participate in social research despite the relative paucity of such research. The results of the questionnaire indicated an overall desire for greater levels of participation in the political domain and civic participation more generally. The need for further campaigning for women's rights was also recognised. However, not everything was clear cut: a belief in the overall principle of equal rights for women did not fully translated into specific policy areas such as divorce and nationality rights where opinion was divided and conservative views commonplace. Another finding was the apparent existence of a civic-religious dichotomy as reflected in a greater willingness to support causes and policies that were in civic domains than those closely related to Islam. It was also apparent that students and younger women were more likely to advocate equal rights than non-student women in older age groups. Finally, a substantial number of women reported views which could be interpreted as being against their interests. The results of the questionnaire firmed up the areas for further exploration in the interviews with educated, urbanised Kuwaiti women which were presented in chapters six, seven and eight.

CHAPTER SIX was oriented to the recent past (the last decade or so). Kuwaiti women described their views on the issues of political participation, employment, financial independence and men's use of wasta as a means to conduct their affairs, something which drew particular opprobrium from many interview participants. Overall women demonstrated a firm desire for greater gender equality across these civic, public domains. Parallels were drawn and contrasts made with the UK and other Western societies on issues such as wasta and the 'old boys' network', enfranchisement and political representation and the effect of war on gender relations. The chapter argued that wasta was a highly prominent perception among Kuwaiti women, as was the acceptance of the 
'woman as emotional being' narrative. In addition to these sub-themes the chapter argued that across the domains of politics, employment and education women were aspirational, determined and were set to be a growing and permanent presence.

CHAPTER SEVEN focussed on the present day (which at the time the interviews took place was between July 2012 and December 2012) and considered how the interview participants interpreted the current position of women in Kuwaiti society. The main areas of enquiry revolved around attitudes to the concept of gender equality, justice (including women's role in the judiciary) and the wider legal system. In this chapter the emphasis also shifted from the public sphere to private. The interview findings indicated that support for female judges was split according to whether a women's nature was seen as empathetic or too emotional. Some interviewees shared their experiences or provided examples of injustices under the Sharia legal system. However, as emphasised in the chapter, it was visibly clear that the women who participated in the interviews were more comfortable discussing issues in the public, civic domains than in the private sphere, particularly where it infringed on religion. The chapter suggested that while overall the urbanised educated women in the study were broadly supportive of greater gender equality there were contradictions whereby women withheld support for relatively uncontroversial matters which would advance the interests of Kuwaiti women particularly identifiable where the issues entered the religious sphere. It was argued that the findings reflected a reluctance to challenge the prevailing male interpretation of Islam and its holy texts.

CHAPTER EIGHT was predominantly forward looking with an interest in understanding women's perceptions of how life would be for the forthcoming generations. Overall, it could be said that the urbanised educated women of Kuwait who took part in the interviews were optimistic for the future and that this was a result of their increasing empowerment in the domains of politics, education and employment and as a result their emerging presence in the public sphere. However, the findings also revealed a level of scepticism with regard to what extent men were supportive of greater gender equality. This chapter reconfirmed the desire for greater gender equality as revealed in the previous two findings chapters. There was optimism among the women but this was mainly articulated in generalised terms with calls for justice, equality and freedom. Most of the women expressed their views in ways which would not be out of 
place in a western secular context though there were signs of both Islamic feminism and religious conservatism among a small number of women. The chapter suggested that globalisation of Kuwait's opening up to the world would be an important factor in progressing women's empowerment as part of an overall modernising agenda.

CHAPTER NINE offered an evaluation of the research study. Here a series of threads were identified with the help of the theoretical approaches discussed in chapter three. Among these threads was the attempt of men to confine women to the private sphere and what the effect of women's emergence into the public sphere may be. It was argued that this emergence was the clearest indication of the weakening of patriarchy in Kuwait. However, considering the example of British women it was suggested that women's empowerment is a slow and gradual and, very importantly, it requires a degree of complicity from men.

The evaluation also considered the treatment of domestic labour and the particular nature of this in Kuwait where there is almost one migrant domestic worker for every Kuwaiti adult woman. In this chapter an attempt was also made to characterise the nature of the feminism projected through the voices of the women in this study. Rebelliousness and obeisance were both considered and then the chapter closed with a personal assessment of the road ahead in term of women's empowerment in Kuwait.

\section{Conclusion}

An important new voice has been given to the perceptions and aspirations of educated urbanised women of Kuwait through this research. In doing so the study has provided an enhanced understanding of women's empowerment in Islam.

The women who took part in the research expressed their firm desire to maintain the stride they have taken into the public sphere, into the university lecture halls, into the workplace, into the polling booths and into parliament itself. In the interviews the women mainly expressed themselves using the language of 'natural justice' and equality. While sometimes tentative to cross certain religiously declared lines (such as the reluctance to support women judges) there is no disguising their desire for greater empowerment and to be seen as the equals of men. The majority of the women who 
took part in the research clearly recognised the injustices in the current legal framework within which they live but were unsure as to whether men also recognised this.

If the motivation of educated urbanised Kuwaiti women was easy to see, then the question of how and when this empowerment will be achieved is more problematic. Taking the UK as an example, it is clear that such change results from a very long process. In Kuwait the forces for change and the forces resistant to change both appear irresistible. However, globalisation, economics, the global human rights agenda and the aspirations of women themselves are ranged against deeply rooted patriarchy underpinned by Islam and centuries of tradition. It is a long road ahead but the direction of travel is clear. This study has demonstrated that urbanised educated women have stepped out of the home into civil life and they are determined to stay there. And regardless of the twists and turns in the road which surely lie ahead, it is nevertheless an exciting time to be a woman in Kuwait.

\section{Recommendations for further research}

The recommendations made here are confined to the Gulf region in the specific context of women's empowerment.

First, the central dynamic of the opposing forces of women aiming to emerge into the public sphere and men trying to confine them to the private sphere warrants further study.

Second, an investigation which focuses on male perceptions of gender relations and women's empowerment would bolster the findings of this thesis.

Third, a historical analysis of the concept of ownership of the means of production of religious knowledge would be valuable with a view to developing theory in this area. 


\section{LIST OF REFERENCES}

Abdelkader, E. (2014), 'To Judge or Not to Judge: A Comparative Analysis of Islamic Jurisprudential Approaches to Female Judges in the Muslim World (Indonesia, Egypt and Iran)', 37 Fordham International Law Journal 309 Available at: http://ir.lawnet.fordham.edu/ilj/vol37/iss2/2 [Accessed April 13 2015]

Abdo, M. F. (1989), 'The urbanisation of Kuwait since 1950: planning, progress and issues.' [Doctoral thesis], Durham University. [Online] Available at: http://etheses.dur.ac.uk/1366/ [Accessed 12 February 2011].

Abu-Lughod, L. (1998), Remaking Women: Feminism and Modernity in the Middle East. Princeton: Princeton University Press

Adami, E. (2009), 'We/YouTube: Exploring Sign-Making in Video-Interaction.' Visual Communication, 8(4): 379-400.

Agliati, A., Vescovo, A., and Anolli, L.M. (2005), 'Conversation Patterns in Icelandic and Italian People: Similarities and Differences in Rhythm and Accommodation.' In L.M. Anolli, S. Duncan, M.S. Magnusson, \& G. Riva, The bidden structure of interaction. From neurons to culture patterns (223-236). Amsterdam: IOS.

Ahmad, N. (2009), 'A Critical Appraisal of 'Triple Divorce' in Islamic Law.' International Journal of Law, Policy and the Family 23 (1): 53-61

Ahmad, A. (2010), 'Migrant Workers in Kuwait: The Role of State Institutions.' [online] Available at: http://www.mei.edu/content/migrant-workers-kuwait-role-stateinstitutions, [Accessed $3^{\text {rd }}$ May 2015]

Ahmadinejad, T (2005), 'The Future of Women in Kuwaiti Politics.' Washington Report on Middle East Affairs, 24 (7): 65-66, Academic Search Complete, EBSCOhost, [Accessed 8 February 2011].

Ahmed, M.K. Jahan, S. (2014), 'Feminist Discourse and Islam: A Critique' International Review of Social Sciences and Humanities 6 (2): 1-11

Al Arabiya (2011), 'Kuwait to Meet Demands of Striking Airline Workers' [Website] Available at: http://english.alarabiya.net/articles/2011/10/25/173609.html [Accessed 12 November 2015]

Al Arabiya (2015), 'Kuwait Plans \$155 bln Projects despite Oil Slump' [Website] Available at: http://english.alarabiya.net/en/business/economy/2015/01/11/ [Accessed 23 July 2015].

Alexander, M. (2009), 'We do complexity too! Sociology, chaos theory and complexity science' conference paper presented at the Annual Conference of The Australian Sociological Association 2009: The Future of Sociology Available at: http://www98.griffith.edu.au/dspace/bitstream/handle/10072/31042/60938_1.pdf;jses 


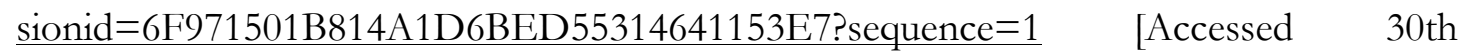
December 2014]

Almunaijed, M. (2012), 'Women Lose Out on Affordable Housing' Arab News [Online] Available at: http://www.arabnews.com/women-lose-out-affordable-housing [Accessed 16 March 2016].

al-Ajmi, R., and Elhagrasey, G. (2010), 'Factors and Policies Affecting Employment Choice in Kuwaiti Public and Private Sectors: The Role of Demographic Variables.' International Journal of Business and Public Administration, 7 (2): 151-162, Business Source Complete, EBSCOhost, [Accessed 29 May 2011].

al-Anzi, A. and Gharaibeh, M. (2006), 'Political Culture of Kuwaiti High School Students: a Comparative Study of Government and Private Foreign Curriculum Schools.' Digest of Middle East Studies, 15:35-61. Available at: doi: 10.1111/j.19493606.2006.tb00003.x [Accessed 23 May 2011]

al-Atiqui, S. (2013), 'One Man One Vote' [Website] Available at: http://carnegieendowment.org/sada/2013/09/12/one-man-one-vote/gmyf [Accessed 8 September 2015]

Al Jazeera (2009), Kuwait elects first women MPs. last updated 17 May 2009 Available at: http://www.aljazeera.com/news/middleeast/2009/05/20095171338473416.html

[Accessed 22 June 2015].

Al-Kuwait Al-Youm (2011), 'Official Gazette.' Kuwait: Government of Kuwait

Alsafy N.N., Alhendal, E.S., Shurooq H. Alhawaj, S.H., Medhat, El-Shazly, K. Kamel, A.I. (2011), 'Knowledge of primary care nurses regarding domestic violence.' Alexandria Journal of Medicine 47: 173-180

Alessa, A. (2010), Women's Movement in: Kuwait, Egypt, Iran and the UK London: AuthorHouse UK

Ali, Y. (1998), 'Islam and the Extension of Citizenship Rights to Women in Kuwait.' Journal for the Scientific Study of Religion, 37 (1): 131-144, Academic Search Complete, EBSCOhost, [Accessed 8 February 2011]

Ali, S. S. (2000), Gender and Human Rights in Islam and International Law: Equal before Allah, Unequal Before Man? Kluwer Law International, The Hague.

Amin, S. H., (1991), Legal System of Kunait. Glasgow: Royston.

Amnesty (2008), 'Kuwait: Death Penalty.' [online] Available at www.amnesty.org/en/library/info/MDE17/001/2008/en [Accessed 5 September 2012]

Annesley, C. Gains, F. Rummery, K. (2007), Women and New Labour Engendering Politics and Policy? Bristol: Policy Press

Arab Human Rights Index (2013), ‘Arab Charter on Human Rights' [online] Available at: http://www.pogar.org/publications/other/laws/humanrights/acharter-04e.pdf [Accessed 20 July 2015] 
Arab Times (2015), 'Society Seeks to Criminalize Domestic Violence in All Forms.' [website] Available at http://www.arabtimesonline.com/society-seeks-to-criminalizedomestic-violence-in-all-forms/ [Accessed 28 September 2015].

Assiri, A. (2007), 'The 2006 Parliamentary Election in Kuwait: A New Age in Political Participation.' DOMES: Digest of Middle East Studies, 16 (2): 22-43, Academic Search Complete, EBSCOhost, [Accessed 8 February 2011]

Barnett, A. (2013), 'Regulation, Trust, and Cronyism in Middle Eastern Societies: The Simple Economics of 'Wasta'.' The Journal of Socio-Economics, 44: 41-47.

Bartky, (1988), 'Foucault, Femininity and the Modernization of Patriarchal Power' in Feminism and Foucault: Paths of Resistance. eds. Lee Quinby and Irene Diamond. Northeastern Univ. Press 61-86

Badran, M. (2008), 'Engaging Islamic Feminism: Provincializing Feminism as a Master Narrative', in Anitta Kynsilheto (ed.) Islamic Feminism: Current Perspectives. (Finland: Tampere Peace Research Institute Occasional Paper No. 96, 2008)

Badran, M. (2011), Feminism in Islam, Chennai: One World Publication.

Bailey, D.C. (2012), Women and Wasta: The Use of Focus Groups for Understanding Social Capital and Middle Eastern Women The Qualitative Report 17 (3) Available at: http://nsuworks.nova.edu/cgi/viewcontent.cgi?article=1742andcontext=tqr , [Accessed 23 June 2015

Bhala, R. (2011), Understanding Islamic Law New York: Lexis Nexus

BBC News (2005), 'Kuwait Names First Woman Minister.' [online] Available at: http://news.bbc.co.uk/1/hi/world/middle_east/4085486.stm [Accessed 23 July 2015]

BBC News (2011), 'Emir of Kuwait dissolves parliament.' [online] Available at: http://www.bbc.co.uk/news/world-16053422 [Accessed 7 September 2015]

BBC News (2015), 'Saudi Women's Small Steps on Path to Progress.' [online] Available at: http://www.bbc.co.uk/news/world-middle-east-32282856 [Accessed 6 March 2016]

Boghardt, L. P. (2006), Kuwait Amid War, Peace and Revolution: $1979-1991$ and New Challenges. Basingstoke: Palgrave Macmillan

Brown, N.J. (2001), 'Arab Judicial Structures.' [online] available at http://www.undppogar.org/publications/judiciary/nbrown/kuwait.html [Accessed 7 July 2015]

Bryman, A. (2008), Social Research Methods. Oxford: OUP

Buchanan, K. (2015), 'Women in History: Lawyers and Judges' Available at: http://blogs.loc.gov/law/2015/03/women-in-history-lawyers-and-judges/ [Accessed 19 May 2015]

'Business Law Handbook, Kuwait' (2012), Vol 1 Washington DC: International Business Publications

Casey, M.S. (2007), The History of Kuwait Westport CT: Greenwood Press 
Catalyst.org (2014), 'Women on Boards’ [Website] last updated March $3^{\text {rd }} 2014$ Available at http://www.catalyst.org/knowledge/women-boards [Accessed 24 June 2015].

Cazes, S., Verick, S. (2013), The Labour Markets of Emerging Economies: Has Growth Translated into More and Better Jobs? Geneva and Basingstoke, UK: ILO and Palgrave Macmillan.

Centre for the Advancement of Women in Politics (2010), Women Members of the UK Judiciary. [Website] Available at: http://www.qub.ac.uk/cawp/UKhtmls/judges.htm [Accessed 3 February 2015]

Cesario, J. and Higgins, E.T. (2008), 'Making Message Recipients "Feel Right" How Nonverbal Cues Can Increase Persuasion' Psychological Science 19(5): 415-420

Chapman, T. (2004), Gender and Domestic Life: Changing Practices in Families and Households Basingstoke: Palgrave Macmillan

Chouliaraki, L. (2006), The Spectatorship of Suffering. London: Sage Publications

Clark, C., Silverman, J., Shahrouri, M., Everson-Rose, S., and Groce, N. (2010), 'The role of the extended family in women's risk of intimate partner violence in Jordan.' Social Science and Medicine, 70 (1): 144- 151

Clarkson Freeman, P.A., Penney, D.S., Bettmann, J.E and Lecy, N. (2013), 'The Intersection of Health Beliefs and Religion Among Somali Refugees: A Qualitative Study', Journal of Religion \& Spirituality in Social Work: Social Thought 32 (1): 1-13 DOI: 10.1080/15426432.2013.749141

Colb-Rubin, J. (2007), 'Lagging far Behind: Women in the Middle East' The Middle East Review of International Affairs Vol 11 (2), Article 2/8 - June 2007

Comte, A ([1865] 2009), A General View of Positivism London: Routledge

Cooke, M., (1994), ‘Arab Women Arab Wars.' In Gocek, Fatma Muge, and Balaghi, Shiva, (eds.), Reconstructing Gender in the Middle East: Tradition, Identity and Power. New York: Columbia University Press

Coolican, H. (2004), Research Methods and Statistics in Psychology. London: Hodder Stoughton

Courts and Tribunals Judiciary (2015), 'Judicial Diversity Statistics 2015.' [Website] Available at: https://www.judiciary.gov.uk/about-the-judiciary/who-are-thejudiciary/diversity/judicial-diversity-statistics-2015/ [Accessed 17 October 2015].

Creswell, J. (2012), Qualitative Inquiry and Research Design: Choosing Among Five Approaches London: Sage

Cunningham, R.B. and Sarayrah, Y.K. (1994), Taming wasta to achieve development. Arab Studies Quarterly, 16 (3): 29-41

al-Daihani, B. (2015), 'Govt Admits Corruption and Bribes Rampant - Now What?' Kunait Times [Website] Available at: http://news.kuwaittimes.net/govt-admitscorruption-and-bribes-rampant-now-what/ [Accessed 19 October 2015] 
Daley, C. and Nolan, M. (eds) (1994), Suffrage and Beyond: International Feminist Perspectives, Auckland: Auckland University Press

Darraj, S.M. (2010), The Universal Declaration of Human Rights New York: Infobase

Davies Review, The (2015), 'Women on Boards Davies Review Annual Report 2015' [online] Available at:

https://www.gov.uk/government/uploads/system/uploads/attachment_data/file/4154 54/bis-15-134-women-on-boards-2015-report.pdf [Accessed 22 May 2015].

Davies, H.B. and Joshi, H.E (1998), 'Gender and income inequality in the UK 19681990: feminization of earning or of poverty?' Journal of the Royal Statistical Society: series a: statistics in society. 161(1): 33-61 Oxford: Blackwell Publishing.

Davies, M. (n.d.), 'An Historical Introduction to the Campaign for Equal Pay.' [Website] Available at: http://www.unionhistory.info/equalpay/roaddisplay.php?irn=820 [Accessed 12 November 2015]

Darvishpour, M. (2003), "Islamic feminism": compromise or challenge to feminism? Iran bulletin- Middle East Forum, Summer 2003, 55-58

al-Dekhayel, A. (2000), Kuwait: Oil, State and Political Legitimation. London: Ithaca Press

Dinkha, J., and Dakhli, M. (2009), 'Perceived Discrimination in the Arabian Gulf: The Case of Migrant Labor in Kuwait.' Psychology Journal, 6(2): 47-59, Academic Search Complete, EBSCOhost, [Accessed 8 February 2011].

Al-Diwan Al-Amiri (2015), 'Al Sabah and Kuwait' [website] Available at: http://www.da.gov.kw/eng/picsandevents/ [Accessed 25 September 2015]

Durkheim, Emile (1997) [1951], Suicide: a study in sociology. The Free Press

Economist Intelligence Unit (2009), 'Woman Power: Four Women Become MPs in Kuwait's Election.' [online] Available at: http://www.economist.com/research/articlesBySubject/displaystory.cfm?subjectid $=949$ 9701andstory_id=E1_TPGRVGDN [Accessed 25 May 2011]

Economist, The (2009), 'The Glass Ceiling.' last updated May $5^{\text {th }} 2009$ [online] Available at: http://www.economist.com/node/13604240, [Accessed 5 April 2015]

Edieth Y. W. (2005), 'Global Burqas' Texas Journal of Women and the Law, 14(2): 179-199, Academic Search Complete, EBSCOhost, [Accessed 23 February 2011].

El-Haddad Y. (2003), 'Major Trends Affecting Families in The Gulf Countries' [online] Available at: http://www.un.org/esa/socdev/family/Publications/mtelhaddad.pdf [Accessed 21 February 2012].

Encyclopaedia of Nations (2007), 'Kuwaiti Judicial System' [online] Available at: http://www.nationsencyclopedia.com/Asia-and-Oceania/Kuwait-JUDICIAL-

SYSTEM.html [Accessed 10 June 2011]

Engineer, A.A. (2008), The Rights of Women in Islam 3rd Ed New Delhi: Sterling 
al-Enzi, M. (2015), 'Stomach bug bites Kuwait' Kuwait Times [online] Available at: http://news.kuwaittimes.net/stomach-bug-bites-kuwait/, [Accessed 7 May 2015]

Epstein, C. F. (1981), 'Women in Sociological Analysis: New Scholarship Versus Old Paradigms' in E. Langland and W. Gove (editors) A feminist perspective in the academy: the difference it makes. Chicago: University of Chicago Press.

Esfandiari, H. (2004), ‘The Woman Question’ Wilson Quarterly Spring 2004 pp. 56-63

European Commission (2012), 'Women in Economic Decision-Making in the EU Luxembourg: Publications Office of the European Union' [online] Available at: http://ec.europa.eu/justice/gender-equality/files/women-on-boards_en.pdf [Accessed 18 May 2015].

Eyadat, Z. (2013), Islamic Feminism: Roots, Development and Policies. Global Policy, 4(4): 359-368.

Feldmann, H. (2007), Protestantism, labor force participation, and employment across countries. American Journal Economics and Sociology 66(4): 795-816

Fonow, M. and Cook, J. (1991), Beyond Methodology: Feminist Scholarship as Lived Research Indiana University Press

Freedom House, (2010), Women's Rights in the Middle East and North Africa Lanham, Maryland: Rowman and Littlefield Publishers

Freedom House (2014), 'Freedom of the Press: Kuwait.' [website] Available at: https://freedomhouse.org/report/freedom-press/2014/kuwait [Accessed 25 September 2015].

Gaddis, I., Klasen, S. (2014), 'Economic Development, Structural Change, and Women's Labor Force Participation: A Reexamination of the Feminization U Hypothesis' Journal of Population Economics 27(3): 639 681. [online] Available at: http://link.springer.com/article/10.1007/s00148-013-0488-2 [Accessed 9 September 2015]

General Organization for Housing Welfare, Kuwait, (2009), 'Statistics and Tables' Available at: http://www.housing.gov.kw/en/housing.aspx [Accessed 17 March 2012]

Ghosh, P. (2013), Kuwait May Allow Women as Air Force Pilots, But Gender Equality Remains Elusive in Kingdom. International Business Times [Website] Available at: http://www.ibtimes.com/kuwait-may-allow-women-air-force-pilots-gender-equalityremains-elusive-kingdom-1060166 [Accessed 10 September 2015]

Gibreel G. (2001), The Ulema: Middle Eastern Power Brokers. Middle East Quarterly Fall 2001, 15-23

Giddens (1979), Central Problems in Social Theory: Action, Structure, and Contradiction in Social Analysis Berkley CA: University of California Press

Glaser, B.G. and Strauss, A.L. (1967), The Discovery of Grounded Theory: Strategies for Qualitative Research, Chicago: Aldine Publishing Company 
Goldman, R., Pea, R, Barron, B. and Derry, S. (2010), Video Research in the learning sciences, Routledge: New York

Goodwin, C. (2000), Action and Embodiment within Situated Human Interaction. Journal of Pragmatics, 32: 1489-522

González, A.L. (2013), Islamic Feminism in Kuwait. [ebook] Available at: http://www.palgraveconnect.com/pc/doifinder/10.1057/9781137304742.0001.

[Accessed: 23 September 2015].

Gossman, M., Miller, J. H. (2012), “The Third Person in The Room': Recording the Counselling Interview for the Purpose of Counsellor Training - Barrier to Relationship Building or Effective Tool for Professional Development?' Counselling and Psychotherapy Research, 12 doi: 10.1080/14733145.2011.582649. [Accessed 21 February 2015]

Gottlieb, J., Toye, R. (2013), The aftermath of suffrage; Women, gender, and politics in Britain, 1918-1945 Basingstoke, Palgrave Macmillan

Green, L. (2015), 'The Forces of Law: Duty, Coercion and Power.' Oxford Legal Studies Research Paper No. 12/2015. [online] Available at http://ssrn.com/abstract=2588588 orhttp://dx.doi.org/10.2139/ssrn.2588588,

[Accessed 3 March 2015]

Griffel, F. (2008), 'Apostasy.' Encyclopaedia of Islam, 3d ed. Edited by Gudrun Krämer, Denis Matringe, John Nawas and Everett Rowson. Leiden, The Netherlands: Brill

Grout, P. Park, I.U. and Sonderegger, S. (2007), 'An Economic Theory of the Glass Ceiling' Working Paper No. 07/183 University of Bristol: Centre for Market and Public Organisation [online] Available at: http://www.bristol.ac.uk/medialibrary/sites/cmpo/migrated/documents/wp183.pdf [Accessed 18 May 2015]

Gulf Affairs (2015), 'Labor Market Dynamics in the GCC States' Autumn 2015 [online] Available at: http://www.oxgaps.org/files/interview_al-sabeeh.pdf [Accessed 14 October 2015]

Hale, B. (2014), 'Women in the Judiciary.' Fiona Woolf Lecture for the Women Lawyers Division of the Law Society 27 June 2014 [online] Available at: https://www.supremecourt.uk/docs/speech-140627.pdf , [Accessed 2 April 2015]

Halim, S. and Meyers, M. (2010), News Coverage of Violence Against Muslim Women: A View from the Arabian Gulf, Communication, Culture and Critique.' 3 (1): 85-104, Communication and Mass Media Complete, EBSCOhost, [Accessed 24 May 2011].

Hammersley, M. (2010), 'A Selective and Partially Annotated Bibliography on Transcription in Social Research.' Unpublished.

Hanley, D.C. (2003), 'Dr. Rasha Al-Sabah on Women's Rights in Kuwait.' Washington Report on Middle East Affairs, 22 (10): 77, Academic Search Complete, EBSCOhost, [Accessed 8 February 2011].

Härpe, J. (1995), “Islamisk feminism”, Kvinnor och fundamentalism, 10, 1995. 
Heath, C., Luff, J., Hindmarsh, P. (2010), Video in Qualitative Research London: Sage Publications

Hendrickson, J. (2013), 'Fatwa.' in Bulliet, R., G. Bowering, D. Cook, P. Crone, W. Kadi, R. L. Euben, K. Fahmy, D. J. Stewart, M. Q. Zaman, F. Griffel, B. Haykel, M. Mirza, R.W. Hefner, T. Kuran, McAuliffe, J. and Ebrahim. M. The Princeton Encyclopedia of Islamic Political Thought. Princeton: Princeton University Press. 173-174

Hertel, B. (1988), 'Gender, Religious Identity and Workforce Participation' Journal for the Scientific Study of Religion, 27(4): 574-592.

Hesse-Biber, S.N. and Leavy P.L. (2007), Feminist Research Practice. [e-book]. Thousand Oaks: SAGE Publications, Inc. Available at: http://srmodev.ifactory.com/view/feminist-research-practice/SAGE.xml [Accessed 15 June 2011]

H'Madoun, M. (2010), 'Religion and Labor Force Participation of Women.' University of Antwerp, Faculty of Applied Economics Working Papers [online] Available at: https://www.uantwerpen.be/images/uantwerpen/container1244/files/TEW\%20\%20Onderzoek/Working\%20Papers/RPS/2010/RPS-2010-007.pdf [Accessed 16th June 2012]

Holland, J. and Ramazanoğlu C. (2002), Feminist methodology: challenges and choices London: Sage Publications

Holloway, W. and Jefferson, T. (2000), Doing Qualitative Research Differently: Free Association, Narrative and the Interview Method, London: Sage Publications.

Holst, C. (2012), 'Book Review of Sylvia Walby, The Future of Feminism.' Acta Sociologica 55 (3): 299-301

Holtgreaves (2014), The Oxford Handbook of Language and Social Psychology Oxford: Oxford University Press

Hosni, D.A. and Al-Qudsi, S.S. (1988), 'Sex Discrimination in the Labour Market of Kuwait' International Journal of Manpower, 9(3): 10-22

Howard, J.A. (1999), 'Book Review - Gender Transformations, by Sylvia Walby.' Contemporary Sociology, 28 (2): 166-167

Human Rights Watch (2015), 'Kuwait: UPR Submission 2014' [website] Available at: https://www.hrw.org/news/2015/01/11/kuwait-upr-submission-2014 [Accessed 25 September 2015].

Hunter, L. (2014), 'A Kuwaiti Mom Lost Custody of Her Kids Because She Wore a Bikini to the Beach' [online] Available at: http://www.ryot.org/kuwaiti-mom-losescustody-of-her-kids-bikini/704073 [Accessed 17 October 2015].

Hutchings, K. and Weir, D. (2006), 'Guanxi and Wasta: A comparison.' Thunderbird International Business Review, 48(1): 141-156, Business Source Premier, EBSCOhost, [Accessed 16 May 2015]. 
Ibrahim, Y. (1990), 'Middle East Tensions: A Kuwaiti Prince Sees Wider Rights.' [online] Available

http://query.nytimes.com/gst/fullpage.html?res=9C0CE1DC153AF937A257,

[Accessed 17 March 2011]

International Humanist and Ethical Union (IHEU) (2012), 'Freedom of Thought 2012: A Global Report on Discrimination Against Humanists, Atheists and the Nonreligious' [online] Available at: http://iheu.org/newsite/wpcontent/uploads/IHEU $\% 20$ Freedom $\% 20$ of $\% 20$ Thought $\% 202012$.pdf [Accessed 7 March 2016]

International Labour Organization (ILO) (2010), 'Labour Force Participation Rates by Gender $1993 \quad-\quad 2006$ ' [online] Available at: http://kilm.ilo.org/KILMnetBeta/default2.asp, [Accessed 1 February 2012]

International Labour Organisation (ILO) (2015) 'Country Profiles: Kuwait' [online] Available at: http://www.ilo.org/ilostat/faces/home/statisticaldata/ContryProfileId?_afrLoop=1262 897771605182 [Accessed 23 July 2015].

International Monetary Fund (2013), 'Kuwait: Selected Issues IMF Country Report No. 13/337' [online] Available at: http://www.imf.org/external/pubs/ft/scr/2013/cr13337.pdf [Accessed 20 September 2015]

International Trade Union Confederation (2012), 'Annual Survey of Violations of Trade Union Rights - Kuwait,' [online] Available at: http://www.refworld.org/docid/4fd889415.html [Accessed 16 March 2016]

InterParliamentary Union (2015), 'Parline Database - KUWAIT: Majles Al-Ommah (National Assembly)' [website] Available at: http://www.ipu.org/parlinee/reports/arc/2171_12_Dec.htm [Accessed 25 December 2015].

Izzak, B. (2008), 'Hijab-less Ministers Broke the Law.' [online] Available at

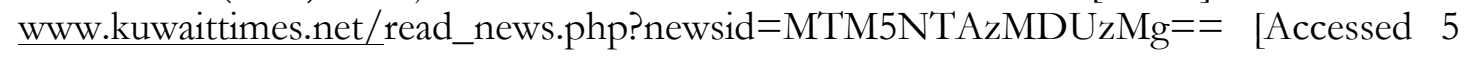
September 2011]

Jael, D. (1999), 'Vote on Women's Rights Shows Deep Rift in Kuwait Society.' New York Times, 20 December, Academic Search Complete, EBSCOhost, [Accessed 8 February 2011].

al-Jassar, M. (2009), 'Constancy and Change in Contemporary Kuwait City: The Sociocultural Dimensions of the Kuwait Courtyard and Diwaniyya. [online] Available at http://search.proquest.com/docview/305034561?accountid=14680 $\quad$ [Accessed 7 February 2015]

Jewitt, C. (2012), 'An Introduction to Using Video for Research.' NCRM Working paper 03/12 [online] Available at: http://eprints.ncrm.ac.uk/2259/4/NCRM_workingpaper_0312.pdf [Accessed 10 February 2015] 
Joffe H. and Yardley L. (2004), 'Content and Thematic Analysis.' In: Marks, D., and Yardley. L., eds.2004. Research Methods for Clinical and Health Psychology. London: SAGE Publications, Ltd. [online] Available at: http://srmo-dev.ifactory.com/view/researchmethods-for-clinical-and-health-psychology/n4.xml [Accessed 27 June 2011]

Jones, H. (2000), Women in British Public Life, 1914-50: Gender, Power and Social Policy. Harlow, Essex: Pearson Education Limited

Joseph, S. and Najmabadi, A. (2005), Encyclopedia of Women and Islamic Cultures: Family, law, and politics Leiden: Brill

Juliá, M., and Ridha, H. (2001), 'Women and war: the role Kuwaiti women played during the Iraqi occupation' Journal of International Development, 13(5) : 583-598.

Jupp, V. (2006), The Sage Dictionary of Social Research Methods London: Sage

Kandari, Y., and Hadben, I. (2010), 'Tribalism, sectarianism, and democracy in Kuwaiti culture.' Digest of Middle East Studies, 2: 268 Academic OneFile, EBSCOhost, [Accessed 23 June 2015]

Kareem, M. (2013), 'Rise in Unemployment Benefits Marginalizes Kuwaiti Women' [Website] AL Monitor Available at: http://www.almonitor.com/pulse/originals/2013/06/kuwait-women-rights-unemployed.html\#

[Accessed 24 September 2015].

Kassin, S. M., Kukucka, J., Lawson, V. Z., and DeCarlo, J. (2014), 'Does Video Recording Alter the Behavior of Police during Interviews: A Mock Crime-andinvestigation Study.' Law and Human Behavior, 38: 73-83.

al-Kazi, L. (2008), 'Divorce: A Structural Problem not just a Personal Crisis.' Journal of Comparative Family Studies, 39 (2): 241-257, Academic Search Complete, EBSCOhost, [Accessed 12 April 2011].

Keddie, N. R. (2006), Women in the Middle East. Princeton: Princeton University Press

Kelly, L., Burton, S., and Regan, L. (1994), 'Researching Women's Lives or Studying Women's Oppression? Reflections on what constitutes Feminist Research', in Maynard, M. and Purvis, J. (eds.), Researching Women's Lives from a Feminist Perspective London: Taylor and Francis

Kelly, R. and White, I. (2016), 'All Women Shortlists.' Briefing Paper Number 5057 London: House of Commons Library

Kelly, M. (2010), 'Clothes, Culture, and Context: Female Dress in Kuwait', Fashion Theory: The Journal of Dress, Body and Culture, 14(2) 215-236, Academic Search Complete, EBSCOhost, [Accessed 8 February 2011]

Kent, A. and Potter, J. (2014), 'Discursive Psychology' in Holtgreaves, T. (ed.) The Oxford Handbook of Language and Social Psychology Oxford: Oxford University Press

Khalaf, S. Hammoud, H. (1987), 'The Emergence of the Oil Welfare State: The Case of Kuwait' Dialectical Anthropology 12 (3): 343-357 
Khedr, A. (2010), 'Kuwait's Legal System and Legal Research' [online] Available at: http://www.nyulawglobal.org/globalex/Kuwait.htm, [Accessed 11 September 2011].

Kish, L. (1965), Survey Sampling. New York: John Wiley

Krause, W. (2009), 'Gender and Participation in the Arab Gulf in Transformation of the Gulf Politics, Economics and the Global Order Held, D. Ulrichson, K. (eds) Abingdon: Routledge

Kuwait Credit Bank (2011), 'Women's Loans' [website] Available at: http://www.kcb.gov.kw/sites/English/Pages/WomenLoans.aspx [Accessed 29 September 2015].

Kuwait Government (2013), 'Geography of Kuwait' [online] Available at: http://www.e.gov.kw/sites/kgoenglish/portal/pages/visitors/aboutkuwait/kuwaitatagla ne_geographicallocation.aspx [Accessed 3 November 2014]

Kuwait Government (2013b), 'Population of Kuwait' [online] Available at: http://www.e.gov.kw/sites/kgoenglish/portal/Pages/Visitors/AboutKuwait/KuwaitAt aGlane_Population.aspx\# [Accessed 3 November 2014]

Kuwait Politics Database (2009), Roll Call of Kuwaiti MPs. [website] Available at: http://www.kuwaitpolitics.org/positions60.htm [Accessed February 25 2012].

Letsa, A. (2004), 'Islamists Concerned at "Americanisation of Education" in Kuwait Background, Argument and Possible Reasons.' [online] Available at: www.hig.divaportal.org/smash/get/diva2:212960/FULLTEXT01 [Accessed May 28 2011]

Lewis, G. (1988), Eva Gore-Booth and Esther Roper: A Biography London: Pandora

Lukes, S. (1974), Power: A radical view $1^{\text {st }}$ Edn. Palgrave Macmillan

Lukes, S. (2005), Power: A radical view $2^{\text {nd }}$ Edn. Palgrave Macmillan

Mackinnon, C. (1984) [1991], 'Difference and Dominance: On Sex Discrimination in: Katharine T. Bartlett and Rosanne Kennedy.' Feminist Legal Theory USA, UK: Westview Press, pp. 81-83.

MacKinnon, C.A. (1987), Feminism Unmodified: Discourses on Life and Law Harvard University Press

MacKinnon, C.A. (1989), Toward a Feminist Theory of the State, Cambridge, MA: Harvard University Press

al-Mahmîd, K. (1994), 'The Mission of the Muslim Women', paper presented at the first post-liberation Conference on Women's Role in Cultural, Social, and Economic Development, Kuwait, 11-13 April.

Maier, S. (2006), 'Lifting the Veil in the Middle East' N.Y. Times, June 19, 2006

[Website] Available at http://www.nytimes.com/2006/06/19/opinion/19ihtedmaier.2004169.html [Accessed 14 November 2012] 
Maktabie, R. (2015), 'Reluctant feminists? Islamist MPs in Kuwaiti parliamentary documents after 2005.' Presented at the British Society for Middle Eastern Studies (BRISMES) Annual Conference [online] Available at: https://brismes2015.files.wordpress.com/2015/06/rania-maktabi-reluctantfeminists-2-june-2015.pdf [Accessed 23 February 2012].

Maltbie, A.R. (2010), 'When the Veil and the Vote Collide.' McGeorge Law Review; 41 (4): 967

Mamoud, N. (2013), 'Islamic Apostasy Laws - a Big Disgrace in the 21st Century' [online] Available at: http://www.secularism.org.uk/blog/2013/08/islamic-apostasylaws--a-big-disgrace-in-the-21st-century [Accessed 19 October 2015].

Mandell, N. (1995), Feminist Issues: Race, Class and Sexuality, Scarborough, Ontario: Prentice-Hall.

Mariampolski, H. (2001), Qualitative Market Research: A Comprehensive Guide. Thousand Oaks: Sage

Marinero, X. (2009), 'Kuwait Constitutional Court Rules Women Do Not Need Permission to Get Passport' [website] Available at: http://jurist.org/paperchase/2009/10/kuwait-constitutional-court-rules-women.php [Accessed 28 September 2015].

Marcovitz, H. (2014), Kuwait Broomhall, PA: Mason Crest

Marks, D., and Yardley. L., eds. (2004), Research Methods for Clinical and Health Psychology. London: SAGE Publications, Ltd. [online] Available at: http://srmodev.ifactory.com/view/research-methods-for-clinical-and-health-psychology/n4.xml [Accessed 27 June 2011]

Marx, K. (1906), Capital: A Critique of Political Economy, Vol. I. The Process of Capitalist Production. Frederick Engels, Ernest Untermann, eds. Samuel Moore, Edward Aveling, trans. 1906. Library of Economics and Liberty. 26 May 2015. [online] Available at: http://www.econlib.org/library/YPDBooks/Marx/mrxCpA.html [Accessed 26 May 2015].

Martin, A. (2013), 'Factsheet: Separation and Divorce a Summary of Statistics for the UK' Relate [online] Available at: https://www.relate.org.uk/files/relate/separationdivorce-factsheet-jan2014.pdf, [Accessed $2^{\text {nd }}$ May 2015].

McElroy, W. (2010), The Roots of Individualist Feminism in 19th-Century America (Excerpted from Freedom, Feminism, and the State, published by The Independent Institute: Oakland, California

McColgan, A. (1999), Women under the Law: The False Promise of Human Rights. London and New York: Routledge

McKee, M. (2009), 'Kuwait Constitutional Court Rules Women Lawmakers Not Required to Wear Headscarf [online] Women Living under Muslim Laws Available at: http://www.wluml.org/node/5658, [Accessed 23 June 2012]. 
Mckinsey \& Co. (2014), 'Women Matter 2014 GCC Women in Leadership - from the First to the Norm Unlocking Women's Potential to Enhance Organizational Effectiveness in the Gulf Cooperation Council (GCC) States'. New York: Mckinsey and Company

Mehdizadeh, N. (2013), 'Beyond Cultural Stereotypes: Educated Mothers’ Experiences of Work and Welfare in Iran' Critical Social Policy 33: 243-265, doi:10.1177/0261018312449809

Meriwether, M. L. and Tucker, J.E. (1997), A Social History of Women and the Family in the Middle East. New York: Westview Press

Metle, M.H. (2001), 'Education, Job Satisfaction and Gender in Kuwait. International Journal of Human Resource Management, 12(2): 311-332, Business Source Complete, EBSCOhost, [Accessed 12 April 2011].

Meyer, K., Rizzo, H. and Ali, Y. (1998), 'Islam and the Extension of Citizenship Rights to Women in Kuwait.' Journal for the Scientific Study of Religion, 37(1): 131-144, Academic Search Complete, EBSCOhost, [Accessed 8 February 2011]

Millen, D. (1997), Some Methodological and Epistemological Issues Raised by Doing Feminist Research on Non-Feminist Women Sociological Research Online, 2(3) [online] Available at: http://www.socresonline.org.uk/2/3/3.html [Accessed 9 February 2012]

Ministry of Justice (2007), 'Divorce Survey' [online] Available at: http://www.csb.gov.kw/Socan_Statistic_EN.aspx?ID=12 [Accessed 10 February 2012].

Ministry of Justice (2011), Study of Domestic Violence in Kuwait Kuwait: MoJ

Ministry of Justice (2015), 'Proving a Revocable Divorce' [website] Available at: http://www.e.gov.kw/MOJ_en/Pages/ServiceContent/1699RevocableDivorce.aspx\# [Accessed 29 September 2015].

Ministry of Planning (2005), 'Statistics and Information Sector, Annual Statistical Abstract 2005' [online] Available at: http://www.csb.gov.kw/Socan_Statistic_EN.aspx?ID=18 [Accessed 11 February 2012]

Mir-Hosseini, Z. (2006), 'Muslim Women's Quest for Equality: Between Islamic Law and Feminism' Critical Inquiry, 32 (4): 629-645

al-Mughni, H. (1990, 2000), Politics of Women's Organisations in Kunvait: A Study of Class, Gender and Patriarchy. London, San Francisco and Beirut: Saqi Books

al-Mughni, H (2001), Women in Kuwait: The Politics of Gender. London: Saqi Books

al-Mughni, H (2005), Women's Rights in the Middle East and North Africa - Kunait, 14 October 2005, [online] Available at: http://www.refworld.org/docid/47387b6cc.html [accessed 26 January 2016]

al-Mughni, H (2010), 'Kuwait' In Women's Rights in the Middle East and North Africa: Progress Amid Resistance, ed. Sanja Kelly and Julia Breslin New York, NY: Freedom House 
al-Mughni, H (2010b), The Rise of Islamic Feminism in Kuwait in Haya al-Mughni (ed.) Revue des mondes musulmans et de la Méditerranée [online], edition 128 December 2010, Available at: http://remmm.revues.org/6899 [Accessed 8 September 2015]

al-Mughni, H. and Tétreault, M. (2000), Citizenship, Gender and the Politics of Quasi States in Suad Joseph (ed.) Gender and Citizenship in the Middle East Syracuse, NY: Syracuse University Press

al-Munajjed, M. (2010), 'Divorce in Gulf Cooperation Council Countries Risks and Implications' Booz and Co. [online] Available at: http://www.strategyand.pwc.com/media/file/Divorce_in_Gulf_Cooperation_Council_ Countries.pdf [Accessed 29 September 2015].

Musawah (2015), 'Family Law Texts' [online] Available at: http://www.musawah.org/resources/family-law-texts [Accessed 25 September 2015].

al-Nakib, F. (2014), Public Space and Public Protest in Kuwait, 1938-2012. City, 18(6): 723-734.

Naklheh, E. (2014), 'ISIS Ideology is Grounded in Saudi Education' [website] Available at: $\quad$ http://www.mintpressnews.com/isis-ideology-is-grounded-in-saudieducation/198461/ [Accessed 15 October 2015].

al-Nashmi, E., Cleary, J., Molleda, J., and McAdams, M. (2010), 'Internet Political Discussions in the Arab World: A Look at Online Forums from Kuwait, Saudi Arabia, Egypt and Jordan. International Communication Gazette, 72 (8): 719-738, Academic Search Complete, EBSCOhost, [Accessed 8 February 2011].

National Council of Women's Organizations (2013), 'The Equal Rights Amendment.' [online] Available at: http://www.equalrightsamendment.org/misc/ERA_overview.pdf [Accessed 18 February 2016].

NatCen Social Research (2014) British Social Attitudes Survey 2014 [online] Available at: http://www.bsa.natcen.ac.uk/latest-report/british-social-attitudes-32/key-

findings/introduction.aspx [Accessed 17 October 2015].

Nationality Law, 1959 [Kuwait], [online] Available at:

http://www.unhcr.org/refworld/docid/3ae6b4ef1c.html [Accessed 27 May 2011]

Nazar, F, and Kouzekanani, K. (2007), 'Attitudes towards Violence against Women in Kuwait', Middle East Journal, 61(4) 641-654, Academic Search Complete, EBSCOhost, [Accessed 24 May 2011]

Nazir, S. and Tomppert, L. (2010), Women's Rights in the Middle East and North Africa: Citizenship and Justice Oxford: Freedom House

Neuwirth, J. (2002), 'Sex Discriminatory Laws: A Challenge to the Integrity of International Law.' Human Rights, 29(3): 3-15. Available at http://search.proquest.com/docview/214024794?accountid=14680 [Accessed 26 January 2016] 
Norris, P. and Lovenduski, J. (1995), Political Recruitment Cambridge: Cambridge University Press)

Keddie, N.R. (2004), A Woman's Place: Democratization in the Middle East, 103 Current History 25(27): 25-30

Oakley, J. G. (2000), 'Gender-based barriers to senior management positions: Understanding the scarcity of female CEOs', Journal of Business Ethics. 27(4): 321-334

Office for National Statistics (ONS) (2013), 'Full report - Women in the labour market.' [online] Available at: http://www.ons.gov.uk/ons/dcp171776_328352.pdf [Accessed 27 October 2015]

Office for National Statistics (ONS) (2014), Marriages in England and Wales (Provisional), 2012 [online] Available at: http://www.ons.gov.uk/ons/dcp171778_366530.pdf, [Accessed 1 May 2015

Olimat, M. S. (2009), 'Women and Politics in Kuwait.' Journal of International Women's Studies, 11(2): 199-212

Olimat, M. S. (2012), 'Arab Spring and Women in Kuwait.' Journal of International Women's Studies, 13(5): 180-194. Available at: http://vc.bridgew.edu/jiws/vol13/iss5/16 [Accessed 1 August 2015]

Parliament.uk (2004), 'Women in the House of Commons' [website] Available at: http://www.parliament.uk/about/how/guides/factsheets/members-elections/m04/ [Accessed 2 August 2015]

Proceedings of the Old Bailey (2015), 'Gender in the Proceedings' [website] Available at: http://www.oldbaileyonline.org/static/Gender.jsp, [Accessed 19 May 2015]

Prusher, I.R. (2000), 'Kuwaiti Women Seek Right to Vote', [online] Christian Science Monitor, 8 August, Academic Search Complete, EBSCOhost, [Accessed 8 February 2011].

Public Authority for Housing Welfare (2011), 'Public Authority of Housing Welfare Laws' [online] Available at: http://www.housing.gov.kw/Attachments/PAHW\%20Rules\%20Modified\%202011.pdf, [Accessed 27 January 2016]

al-Qatari, H. (2013), 'Kuwait's conservative tribes make election gains' Associated Press [website] http://bigstory.ap.org/article/kuwaits-conservative-tribes-make-election-gains [Accessed 8 September 2015].

Ramazanoglu, C. (1989), Feminism and the Contradictions of Oppression London: Routledge

Rand, S. and Bierema, L. (2009), Exploring the Nature of the "Old Boy's Network" in the United States: Using Electronic Networks of Practice to Understand Gendered Issues in HRD University Forum for Human Resource Development. [online] Available at:

https://www.academia.edu/330707/Exploring_the_Nature_of_the_Old_Boys_Networ k_In_the_United_States_Using_Electronic_Networks_of_Practice_to_Understand_Gen dered_Issues_In_HRD_[Accessed 9 May 2015] 
Redman, J.C. (2014), 'The diwaniyya: Guestroom sociability and bureaucratic brokerage in Kuwait (Order No. 3639718).' Available from ProQuest Dissertations and Theses A and I. (1620842565). Available at: http://search.proquest.com/docview/1620842565?accountid=14680 [Accessed 2 September 2015]

Reema S., Swigart, V., Hamdan-Mansour, A.M., Banimustafa, R. and Constantino, R.E. (2013), An Ethnographic-Feminist Study of Jordanian Women's Experiences of Domestic Violence and Process of Resolution, Health Care for Women International, 34:9, 775-794, DOI: 10.1080/07399332.2012.673661

Rennebohm, M. (ed.) (2011), 'Kuwaiti Women Struggle for Suffrage (Blue Revolution), 2002-2005' [website] Available at: http://nvdatabase.swarthmore.edu/content/kuwaitiwomen-struggle-suffrage-blue-revolution-2002-2005 [Accessed 23 September 2015].

Reuters (2009), FACTBOX: Who are Kuwait's first women lawmakers? [online] Last updated 17 ${ }^{\text {th }}$ May 2009 Available at: http://www.reuters.com/article/2009/05/17/uskuwait-elections-women-factbox-sb-idUSTRE54G0I720090517 [Accessed 14 May 2012]

Reuters (2009b), 'Kuwait Women Can Get Passport Without Man's Consent.' [online] last updated $21^{\text {st }} \quad$ October 2009 Available at: http://in.reuters.com/article/2009/10/21/idINIndia-43325720091021_[Accessed 5 September 2012]

Reuters (2010), 'Mob Attacks Kuwait TV Station over Royal 'Insult'” [website] Available at: http://uk.reuters.com/article/idINIndia-52253820101018 [Accessed 5th September 2012]

Ribbens J., and Edwards R. (1998), Feminist Dilemmas in Qualitative Research. [e-book]. London: SAGE Publications Ltd. Available at: http://srmodev.ifactory.com/view/feminist-dilemmas-in-qualitative-research/SAGE.xml [Accessed 15 June 2011]

Riley, D. (1983), 'The free mothers: pronatalism and working women in industry at the end of the last war in Britain' History Workshop Journal 11: 59-118

Rizzo, H. (2005), 'Democracy and Women's Rights in Kuwait', Insights on Law and Society, 5(3): 20-30, Academic Search Complete, EBSCOhost, [Accessed 8 February 2011].

Rizzo, H., Meyer, K., and Ali, Y. (2002), Women's Political Rights: Islam, Status and Networks in Kuwait, Sociology, 363: 639-662, Academic Search Complete, EBSCOhost, [Accessed 8 February 2011]

Roald, A-S. (2001), Women in Islam: the Western Experience London: Routledge

Roberts H. (1981), Doing Feminist Research London: Routledge and Kegan

Robinson, N. (1999), Islam: A Concise Introduction Curzon Richmond

Wright, E.O. and Rogers, J. (2010), 'Gender Inequality' in Contemporary American Society: How it Really Works. New York: W. W. Norton. 
Rosaldo, M.Z. (1974), 'A Theoretical Overview' in Lamphere, L. and Rosaldo, M.Z. editors. (1974) Women, Culture, and Society. Stanford University Press. Stanford, California

Rousseau, R. (2013), Politics, Elections and the "Reality" of Women's Rights in Kuwait Diplomatic Courier [Website] Available at: http://www.diplomaticourier.com/politicselections-and-the-reality-of-women-s-rights-in-kuwait/ [Accessed 7 September 2015]

Saadouli, N. (2010), 'Assessing the Effectiveness of State Manpower Growth and Restructuring Programmes: The Case of Kuwait.' International Journal of Management, 27: 745-753, Business Source Complete, EBSCOhost, [Accessed 12 February 2011]

al-Sabah, S.M. (1983), Development Planning in an Oil Economy and the Role of Women: The Case of Kuwait. London: Eastlords Publications

al-Sabah, M. (2013), Gender and Politics in Kuwait: Women and Political Participation in the Gulf. London: GBR: I.B. Tauris. ProQuest ebrary. Web. [Accessed 23 September 2015].

Salem P. (2007), 'Kuwait: Politics in a Participatory Emirate' Carnigie Papers No. 3 June 2007 Beirut: Carnigie Endowment

Salih, A. (2010), 'Localizing the Private Sector Workforce in the Gulf Cooperation Council Countries: A Study of Kuwait', International Journal of Public Administration, 33 (4)169-181, Business Source Complete, EBSCOhost, [Accessed 29 May 2011].

Sanghani, R. (2015), 'The real reasons female Tory MPs are quitting Parliament' The Telegraph [online] last updated 22 Jan 2014 Available at: http://www.telegraph.co.uk/women/womens-politics/10588196/The-real-reasonsfemale-Tory-MPs-are-quitting-Parliament.html , [Accessed 4 April 2015]

Sarantakos S. (2005), Social Research $3^{\text {rd }}$ Edition Basingstoke: Palgrave Macmillan

Sarhrouny, Y, Choukri, D. (2007), 'Kuwait: Citizens' Perceptions of Women in Politics.' National Democratic Institute for International Affairs [online] Available at: https://www.ndi.org/node/13774 [Accessed 4 April 2015]

Schauer, F. (2015), The Force of Law Cambridge, Mass: Harvard University Press

al- Sharekh, A. (2007), Study and Survey on the Personal Status Laws and the 2006 Kuwait Elections. New York: Freedom House

al-Shehab, A.J. (2008), 'Gender and Racial Representation in Children's Television Programming in Kuwait: Implications for Education.' Social Bebavior and Personality: An International Journal, 36(1): 49-63, Academic Search Complete, EBSCOhost, [Accessed 8 February 2011].

Shah, N.M., Shah, M.A., Chowdhury, R.I. and Menon, I. (2002), 'Foreign Domestic Workers in Kuwait: Who Employs How Many?' Asian and Pacific Migration Journal, Vol. 11, No. 2, pp. 247-69

Shah, N.M. (2004), 'Women's Socioeconomic Characteristics and Marital Patterns in a Rapidly Developing Muslim Society, Kuwait.' Journal of Comparative Family Studies, 35 (2): 163-183, Academic Search Complete, EBSCOhost, [Accessed 25 May 2011]. 
Sherryl, K., (2007), Feminist Fieldwork Analysis. [e-book]. Thousand Oaks: SAGE Publications, Inc. [online] Available at: http://srmo-dev.ifactory.com/view/feministfieldwork-analysis/SAGE.xml [Accessed 15 June 2011].

Sholkamy, H. (2011a), 'Creating Conservatism or Emancipating Subjects? On the Narrative of Islamic Observance in Egypt.' IDS Bulletin, 42: 47-55. [online] Available at: doi: 10.1111/j.1759-5436.2011.00200.x [Accessed 5 ${ }^{\text {th }}$ June 2011].

Sholkamy H. (2011b), 'Islam and Feminism in Contestations Issue 1' [online] Available at: http://www.contestations.net/issues/issue-1/religion-and-gender-justice/ [Accessed 18 June 2011].

Shultziner, D. (2008), 'Gaining the Vote: The Women's Rights Movement in Kuwait.' Conference Papers -- American Political Science Association, pp. 1-35, Academic Search Complete, EBSCOhost, [Accessed 8 February 2011].

Shultziner, D. and Tétreault, M. A. (2011), Paradoxes of Democratic Progress in Kuwait: The Case of the Kuwaiti Women's Rights Movement.' Muslim World Journal of Human Rights: 7(2):Article 1. [online] DOI: 10.2202/1554-4419.1192 Available at: http://www.bepress.com/mwjhr/vol7/iss2/art1 [Accessed 5 April 2012]

Siddiqui, M. (2006), 'Islam and Feminism: are they poles apart?' [website] Sunday Herald $7^{\text {th }}$ May 2006 Available at: http://www.gla.ac.uk/media/media_70691_en.pdf [Accessed 17 June 2011]

Schwandt T. (2007), 'Feminist Ethics.' In: A. S. Thomas, Ed.2007. The Sage Dictionary of Qualitative Inquiry. Thousand Oaks: SAGE Publications, Inc. [online] Available at: http://srmo-dev.ifactory.com/view/the-sage-dictionary-of-qualitative-inquiry/n126.xml [Accessed 25 June 2011]

Sheshtar, M. (2008), 'Kuwait House Speaker Denounces Threat Against MP' Kuwait News Agency [website] Available at: http://www.kuna.net.kw/ArticlePrintPage.aspx?id=1882021 andlanguage=en [Accessed 26 June 2011]

Smith, A. ([1776] 1976), An Inquiry into the Nature and Causes of the Wealth of Nations, Oxford: Oxford University Press.

Smith, A. (2011), 'Women Leading the Way in Senior Civil Service Positions.' The Guardian [online] last updated $14^{\text {th }}$ December 2011 Available at: http://www.theguardian.com/public-leaders-network/2011/dec/14/women-leadingcivil-service-posts [Accessed September 14 2014]

Squibb, G. D. (1977), Doctors' Commons. Oxford: Oxford University Press

Sorrentino, C. (1983), 'International Comparisons of Labor Force Participation 1960-81' Monthly Labor Review Feb 1983 23-36

Standing, H. (1992), 'Employment.' in Ostergaard, L. (ed.) Gender and Development: A Practical Guide London: Routledge 
State of Kuwait Central Statistical Bureau (SKCSB) (2013), 'Annual Bulletin for Vital Statistics Marriage and Divorce' [online] Available at: http://www.csb.gov.kw/Socan_Statistic_EN.aspx?ID=12, [Accessed April 4 2015].

State of Kuwait Central Statistical Bureau (SKCSB) (2013b), 'Annual Statistical Abstract 2013' [online] Available at: http://www.csb.gov.kw/Socan_Statistic_EN.aspx?ID=18 [Accessed 24 September 2015].

State of Kuwait Central Statistical Bureau (SKCSB) (2014), 'Labor Force Survey 2014 (October - December)' [online] Available at: http://www.csb.gov.kw/Socan_Statistic_EN.aspx?ID=64, [Accessed September 14 2015]

Stephenson, L. (2011), 'Women and the Malleability of the Kuwaiti Diwaniyya' Journal of Arabian Studies, 1(2): 183-199

Sutrisno, A. Nguyen, N.T. and Tangen, D.J. (2014), 'Incorporating Translation in Qualitative Studies: Two Case Studies in Education.' International Journal of Qualitative Studies in Education 27(10) DOI: 10.1080/09518398.2013.837211

al-Suwaidi, A. (1993), 'Developments of the Legal Systems of the Gulf Arab States.' Arab Law Quarterly 8 (4): 289-301 Published by: BRILL Article Stable URL: http://www.jstor.org/stable/3381723 [Accessed 12 February 2012]

al-Tamimi, J. (2012), 'Saudi Women Can Divorce Smoking Husbands' Gulf News [online] Available at: http://gulfnews.com/news/gulf/saudi-arabia/saudi-women-can-divorcesmoking-husbands-judge-says-1.1050629, [Accessed 2 March 2015]

Taylor, S. J., and Bogdan, R. (1984), Introduction to Qualitative Research Methods: The Search for Meanings. New York: John Wiley and Sons.

Tétreault, M.A. (1993), 'Civil Society in Kuwait: Protected Spaces and Women's Rights.' Middle East Journal, 47 (2): 275-291

Tétreault, M., and Al-Mughni, H. (1995), 'Gender, citizenship and nationalism in Kuwait.' British Journal of Middle Eastern Studies, 22(1-2): 64-80.

Tétreault, M.A. (2001), 'A State of Two Minds: State Cultures, Women, and Politics in Kuwait.' International Journal of Middle East Studies 33 (2) 203-22

Tétreault, M., Meyer, K., \& Rizzo, H. (2009), ‘Women’s Rights in the Middle East: A Longitudinal Study of Kuwait.' International Political Sociology, 3(2): 218-237.

Thomas, C. (2005), 'Judicial Diversity in the United Kingdom and other Jurisdictions a Review of Research, Policies and Practices.' [online] Available at: http://www.ucl.ac.uk/laws/judicial-

institute/files/Judicial_Diversity_in_the_UK_and_other_jurisdictions.pdf [Accessed 19th May 2015]

Tijani, O. (2008), 'Gendering the Iraq-Kuwait Conflict: Literary Representations of Kuwaiti Women's Resilience and Resistance.' [online] Journal of Arabic Literature pp. 250- 
269 Brill Academic Publishers Academic Search Complete, EBSCOhost, [Accessed 18 February 2011].

Toumi, H. (2012), 'Kuwait to appoint women as lawyers, judges.' Gulf News [website] Available at: http://gulfnews.com/news/gulf/kuwait/kuwait-to-appoint-women-aslawyers-judges-1.1076722 [Accessed 22 September 2015]

Toumi, H. (2012b), 'Campaign to fight favouritism launched.' Gulf News [website] Available at: http://gulfnews.com/news/gulf/kuwait/campaign-to-fight-favouritismlaunched-1.1067242/ [Accessed 22 September 2015]

Toumi, H. (2013), 'Kuwaiti woman seeks divorce over poor table manners.' Gulf News [website] Available at: http://gulfnews.com/news/gulf/kuwait/kuwaiti-woman-seeksdivorce-over-poor-table-manners-1.1272043 [Accessed 22 July 2014]

Toumi, H. (2013b), 'Kuwaiti MPs push for reinstating co-education.' Gulf News [website] Available at: http://gulfnews.com/news/gulf/kuwait/kuwaiti-mps-push-for-reinstatingco-education-1.1191933 [Accessed 23 September 2015].

Trenwith, C. (2014), 'Gov't urged to help end Kuwait's longest strike in history.' Arabian Business [website] Available at: http://www.arabianbusiness.com/gov-t-urged-help-endkuwait-s-longest-strike-in-history-556376.html\#.VkPs6fkrLNN [Accessed 12 November $2015]$

Trenwith, C. (2015), 'Women's rights last on Kuwait gov't's new priority list.' Arabian Business [Website] Arabian Business Available at: http://www.arabianbusiness.com/women-s-rights-last-on-kuwait-gov-t-s-new-prioritylist-596515.html\#.Ve6D3vlViko [Accessed 8 September 2015].

Trades Union Congress (TUC) (2006), 'Equal Pay Heroes Honoured.' [website] Available at: $\quad$ https://www.tuc.org.uk/equality-issues/equal-pay/equal-pay-heroes-honoured [Accessed 12 November 2015]

UKPoliticalinfo (2015), 'Women MPs and parliamentary candidates since 1945.' [website] Available at: http://www.ukpolitical.info/FemaleMPs.htm [Accessed 23 September 2015]

United Nations (2015), 'Treaty Collection: Convention on the Elimination of All Forms of Discrimination against Women.' [online] Available at: https://treaties.un.org/pages/viewdetails.aspx?src $=$ treatyandmtdsg_no $=$ iv-

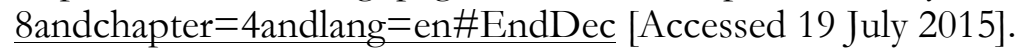

United Nations Committee on the Elimination of Discrimination against Women (UNCEDAW) (2004), 'Concluding comments of the Committee on the Elimination of Discrimination against Women: Kuwait. Thirtieth session 12-30 January 2004.' Excerpted from: Supplement No. 38 (A/59/38) [online] Available at: http://www.un.org/womenwatch/daw/cedaw/cedaw25years/content/english/CONCL UDING_COMMENTS/kuwait/kuwait-CO-1-2.pdf [Accessed 24 September 2015]

UNDP-POGAR (2006), 'Gender and Citizenship Initiative.' Available at: http://gender.pogar.org/countries/country.asp?cid=15 [Accessed 29 May 2010]. 
United Nations Development Programme, UNDP (2010), 'Human Development Index 2010.' [online] Available at: hdr.undp.org/sites/default/files/.../hdr_2010_en_complete_reprint.pdf $\left[\right.$ Accessed $23^{\text {rd }}$ June 2012]

UNESCO Institute of Statistics (2010) 'Kuwait: Education' [online] Available at: http://www.uis.unesco.org/DataCentre/Pages/country-profile.aspx?code=KWT

[Accessed 26 January 2016]

UNICEF (2011), 'Kuwait Gender Equality Profile.' [online] Available at: http://www.unicef.org/gender/files/Kuwait-Gender-Eqaulity-Profile-2011.pdf

[Accessed 20 May 2015]

UNWomen (2014), 'Spring Forward for Women Programme: Kuwait.' [website] Available at: http://spring-forward.unwomen.org/en/countries/kuwait [Accessed 2nd March 2015]

Usta, J., Farver, J. A. N., and Pashayan, N. (2007), 'Domestic violence: The Lebanese experience.' Public Health, 121: 208-219.

Verloo, M. (2006), 'Multiple Inequalities, Intersectionality and the European Union.' European Journal of Women's Studies 13 (3) 211-228

Wade, L. (2013), 'Gender and the Body Language of Power.' [website] Available at: https://thesocietypages.org/socimages/2013/12/27/gendered-and-the-body-languageof-power/ [Accessed 14 February 2015]

Walby, S. (1989), Theorising Patriarchy Oxford, UK: Blackwell

Walby, S. (1996), 'Comparative analysis of gender relations in employment in Western Europe.' Women in Management Review, (11) 5: 9-16

Walby, S. (1997), Gender Transformations London: Routledge

Walby, S. (2007), 'Complexity Theory, Systems Theory, and Multiple Intersecting Social Inequalities.' Philosophy of the Social Sciences (37): 449-470

Walby, S. (2009), Globalization and Inequalities: Complexity and Contested Modernities London: Sage

Walby, S. (2011), The Future of Feminism Cambridge: Polity Press

Walby, S. Armstrong, J. and Strid, S. (2012) [2010] 'Intersectionality: Multiple Inequalities in Social Theory.' Sociology 46: 224

Walsh, M. and Wrigley C. (2001), 'Womanpower: The Transformation of the Labour Force in the UK and the USA Since 1945.' Recent Findings of Research in Economic and Social History 30, Summer 2001

Weber M. (1905), The Protestant Ethic and the Spirit of Capitalism. English Translation 1930. London: Unwin Hyman 
Webster J. and Watson, R. (2002), Analyzing the Past to Prepare for the Future: Writing a Literature Review MIS Quarterly, 26 (2) xiii-xxiii

Weiffen, B. (2008), 'Liberalizing Autocracies in the Gulf Region? Reform Strategies in the Face of a Cultural-Economic Syndrome.' World Development, 36 (12) 2874-2952 Special Section: Social Movements and the Dynamics of Rural Development in Latin America Available at: DOI: 10.1016/j.worlddev.2008.01.009. [Accessed February 13 2012].

Western, D.J. (2008), 'Islamic "Purse Strings": The Key to The Amelioration of Women's Legal Rights in The Middle East.' Air Force Law Review, 61: 79-147, Academic Search Complete, EBSCOhost, [Accessed 16 February 2011].

Widdicombe, S. (2011), 'I am a Believer but not a Conformist': Negotiating Claims to being Religious among Syrian Christians and Muslims.' Journal of Community \& Applied Social Psychology, 21(6): 468-483, Psychology and Behavioral Sciences Collection, EBSCOhost, [Accessed 6 September 2013].

Wigglesworth, R. (2010), 'Kuwait signals 'redesign' of state economy.' Financial Times [website] Available at: http://www.ft.com/cms/s/0/9804f9f6-7256-11df-9f8200144feabdc0.html\#axzz48hQKIDHw [Accessed 21 February 2012]

Willis, E. (1992) [1984] 'Radical Feminism and Feminist Radicalism', in No More Nice Girls: Countercultural Essays, Wesleyan University Press

Women's Study and Research Center/United Nations Development Fund for Women (WSRC/UNIFEM) (2008), 'Women in the Political Arena and Indications of their Success Therein: The Case of Kuwait'.

World Bank (2013), Opening Doors: Gender Equality and Development in the Middle East and North Africa, Mena Development Report. New York: World Bank Publications

World Bank (2014), 'Kuwait: World Development Indicators' [website] Available at: http://databank.worldbank.org/data/views/reports/tableview.aspx [Accessed July 23 2015]

World Economic Forum (2105), 'The Global Gender Gap Report 2014' [website] Available at: http://reports.weforum.org/global-gender-gap-report-2014/ [Accessed 20 September 2015]

World Health Organisation (2015), 'Kuwait: Statistics.' [website] Available at: http://www.who.int/countries/kwt/en/ [Accessed 22 July 2015]

Worth, R.F. (2009), 'First Women Win Seats in Kuwait Parliament.' [online] New York Times Available at: http://www.nytimes.com/2009/05/18/world/middleeast/18kuwait.html?_r=0

[Accessed June 22 2015].

Wrigley, C. J. (1999), 'Women in the Labour Market and in the Unions' in J. McIlroy, N. Fishman and A. Campbell (eds.), British Trade Unions and Industrial Politics, 1945-79, Vol. 2 Aldershot: Ashgate 
al-Wugayan, A., and Alshimmiri, T. (2010), 'Encouragement of Entrepreneurship in Affluent Economies: The Case of Kuwait.' International Business and Economics Research Journal, 9(6): 1-10, Business Source Complete, EBSCOhost, [Accessed 26 May 2011].

Yuval-Davis, N. (2006), 'Intersectionality and Feminist Politics.' European Journal of Women's Studies 13(3): 193-209

Zuhur, S. (2003), 'Women and Empowerment in the Arab World', Arab Studies Quarterly, 25 (4): 17-38, Academic Search Complete, EBSCOhost, [Accessed 8 February 2011]. 


\section{APPENDICES}

\section{Appendix 1: Survey Questionnaire}

\section{Women and Social Policy in Kuwait}

\section{Survey Questionnaire}

\section{Section One: About you}

1. What is your marital status? $\quad$ Single $\square \quad$ Married $\square \quad$ Divorced $\square$ Widowed $\square$

2. Employment: Which applies to you?

Employed full-time $\square \quad$ Employed part-time $\square$ Not Employed $\square \quad$ Student $\square \quad$ Retired $\square$

3. Are you a university graduate? Yes $\square \quad$ No $\quad \square \quad$ Still Studying $\square$

4. Which age group applies to you?
Under $25 \square \quad 25-35 \square \quad 35-45 \square$
$45-55 \square$
$55-65 \square$
65 or over $\square$

5. Did you vote in the last election in $2^{\text {nd }}$ Feb 2012 ?

Yes $\square \quad$ No $\square \quad$ Not eligible

Section Two: Your attitudes Strongly agree: 5; Agree: 4; Not sure:3;

\section{Disagree: 2; Strongly disagree: 1}

\begin{tabular}{|c|c|c|c|c|c|}
\hline \# & $\begin{array}{l}\text { Stat } \\
\text { eme }\end{array}$ & 5 & 4 & 3 & 2 \\
\hline 6 & Women should have equal rights under the law & & & & \\
\hline 7 & $\begin{array}{l}\text { Now that women have the right to vote in elections there is no need to } \\
\text { campaign for any further rights. }\end{array}$ & & & & \\
\hline
\end{tabular}




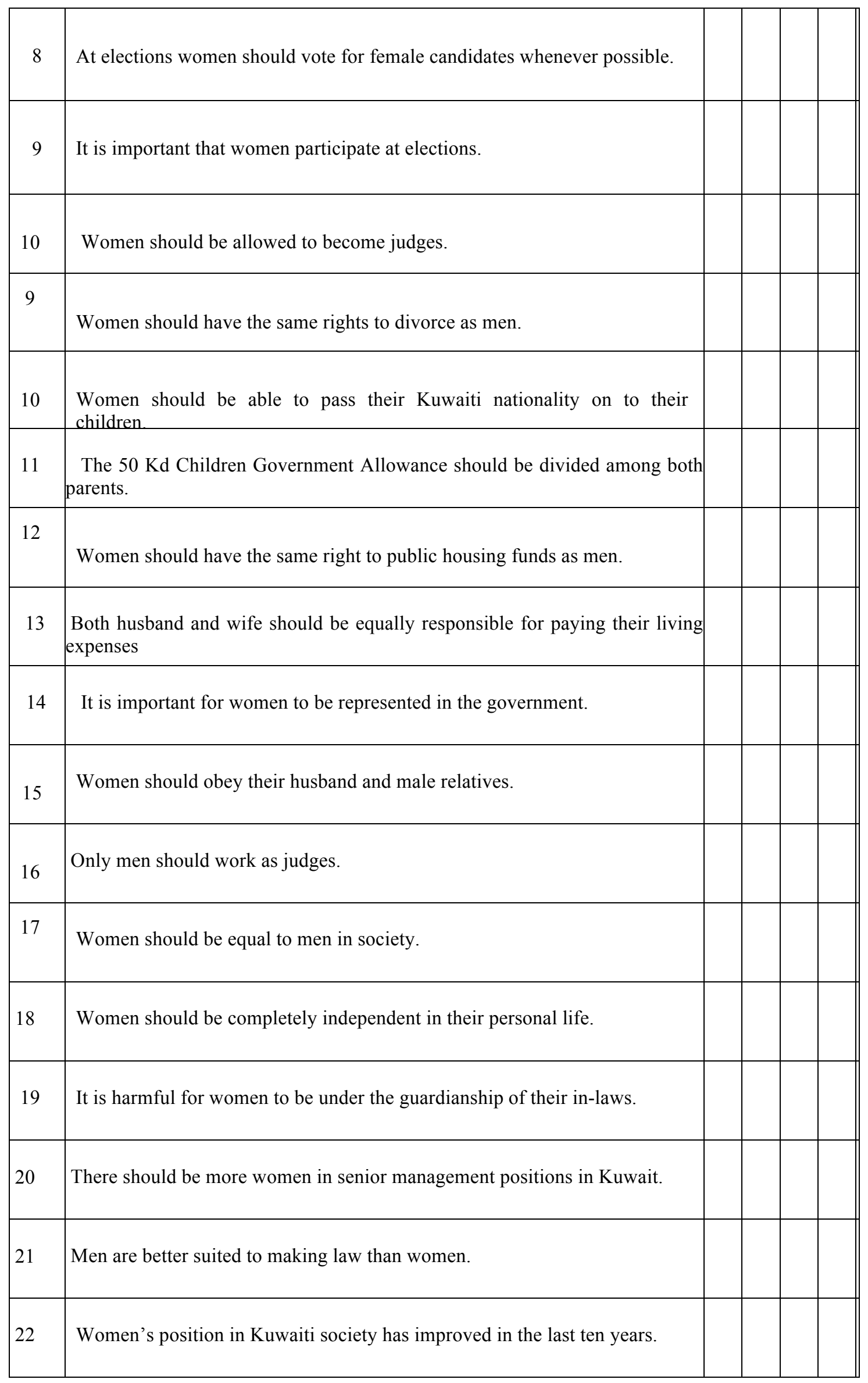




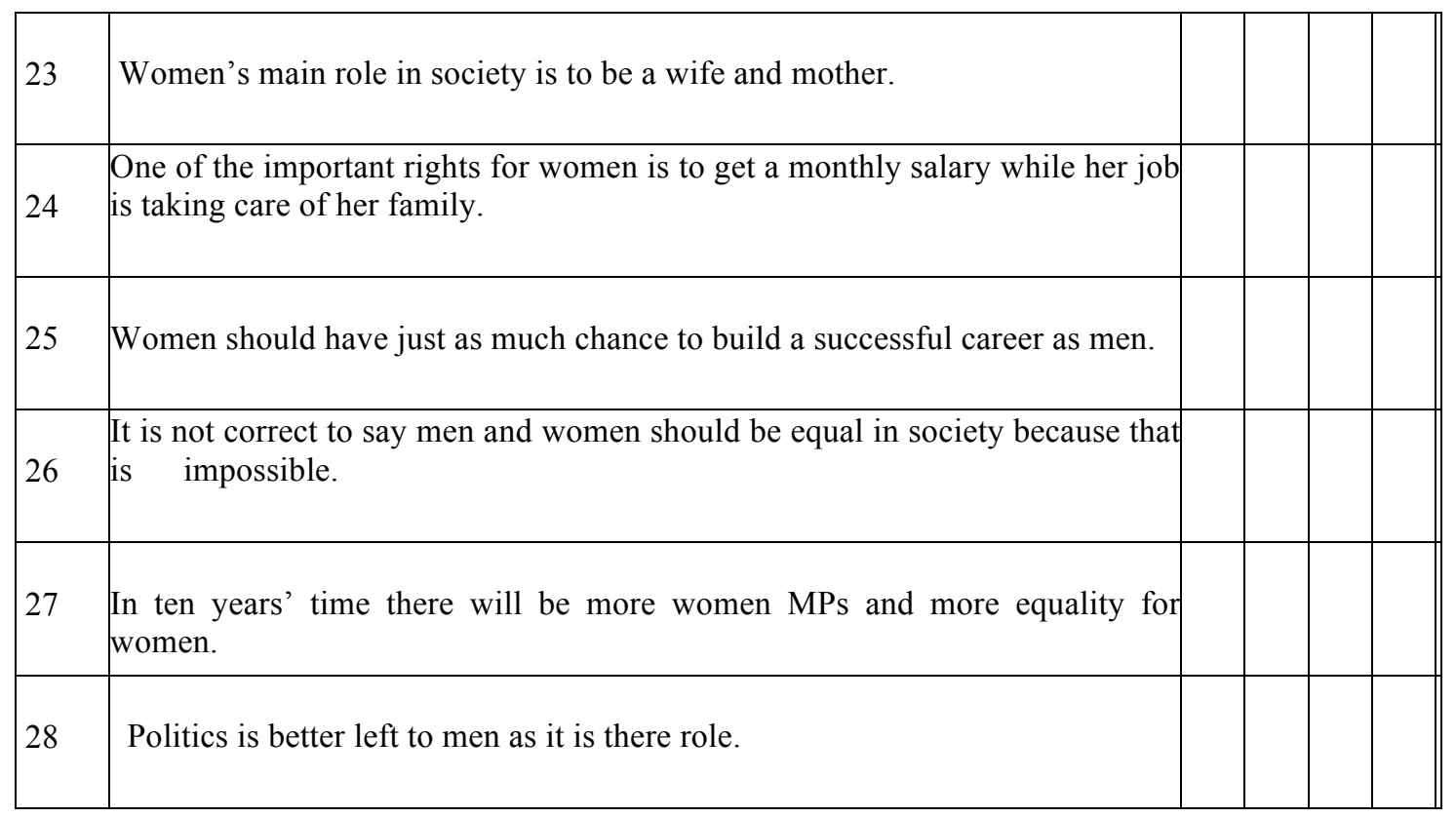

Do you have any further comments on women's position in society in Kuwait?

Please indicate whether you would be willing to participate further in this research study, for example by attending a research interview Yes No

If yes please provide a means of contacting you (email, mobile phone) 
Appendix 2: Participant Information Sheet

\section{Participant Information Sheet}

Project Title: Kuwaiti women's perceptions of their legal rights and social position: progress or illusion?

You are receiving this briefing sheet as you have expressed an interest in participating in a research study on the topic of women's rights in Kuwait. Before confirming your participation could you take a few moments to read through the information on this page which explains a little more about the study and what your participation involves?

\section{What is the study about?}

There have been many changes in Kuwait in recent years with regard to women's legal rights and their social position. A lot has been written by politicians and academics about these changes but I really want to understand how Kuwaiti women really feel about the changes and the best way to do this is to ask them.

\section{What will you be asked to do?}

I will arrange a time to meet you at a convenient place and time in Kuwait City. We will then talk about some issues related to the topic for about 30 minutes. I will use a video recorder to record the conversation.

\section{What happens then?}

I will transcribe the conversation but will remove anything that can personally identify you. When all the interviews have been completed I will analyse them and 
parts of the interviews may be used when I prepare my thesis. I will also contact you by email when the study is complete just to confirm how it went and if you are interest in reading my thesis I will explain how you can obtain a copy.

\section{Your anonymity and confidentiality}

While I will need to keep your contact details to arrange the interview, when the interview is transcribed and the analysis written up and eventually published as a thesis your name or any other personal details will not be used. Instead a pseudonym will be used to protect your anonymity. Your contact details will be kept securely and will not be passed to any other person.

Important Note: Your participation in this project is completely voluntary. You can withdraw from the project at any time including during the interview. You can choose not to answer any particular question asked during the interview.

Thank you for reading this information if you have any questions regarding the study or your participation please do not hesitate to contact me by email at XXXXX@yahoo.com. On the other side of this page is a consent form which you need to complete and sign prior to the interview. Please return the completed form to me by contacting my personal Phone to pick up the form not later than $++/++/+++$ 
Appendix 3: Participant de-briefing email

\section{Participant De-briefing communication (sent by email)}

Project Title: Kuwaiti women's perceptions of their legal rights and social position: progress or illusion?

Dear [Participant's Name]

In [month/year] you kindly agreed to participate in the above-titled research study. The data from the interview was analysed and some extracts from the interview were used in the preparation of my written thesis.

As promised prior to the interview your participation your anonymity has been protected and you name and personal details have not been passed to anyone else.

The finished thesis is due to be submitted in [month/ year] and should you be interested in reading a copy of the study it will be available from

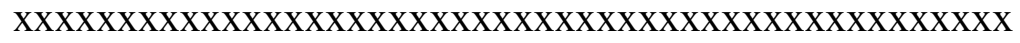

If you have any questions about this study, please feel free to contact me by email. Thanks again for your valuable contribution.

Ghadeer M Aseri

Email: xxxxxxx@yahoo.com 


\section{Appendix 4: Outline Interview Schedule}

\section{Project Title: Kuwaiti women's perceptions of their legal rights and social position: progress or illusion?}

Note: As set out in the Methods Chapter this study is adopting a semi-structured interview approach. Therefore, the researcher will not conduct the interviews with a specific list of pre-prepared, pre-ordered questions but rather will have the following outline to hand.

Part One: Briefing Section

- what the interview is about

- reconfirm that the interview will be recorded

- why they were chosen as an interviewee

- how long the interview is expected to last

- their rights as participants in the research, and

- confirm that written informed consent has been received (if it has not verbal consent must be obtained).

Part Two: Main body of the interview

- Women and political participation

- Women in the workplace

- Legislation and new policies

- Personal Status Law and Sharia courts

- Perceptions of justice in Kuwait - positives and negatives

Part Three: Concluding and explaining what will happen next

- Offer final opportunity to contribute remarks on anything not yet covered

- Explain what will happen to the recording and the data on it

- Confirm that a debriefing communication will be sent when the study is concluded

- Confirm your contact details should they wish to contact you at anytime

- Thank them for their participation 


\section{Appendix 5: Informed Consent Form}

To: Ghadeer M Aseri

\section{Consent Form}

Title of Research Study: Kuwaiti women's perceptions of their legal rights and social position: progress or illusion?

I have received and read the 'Participant Information Sheet' (see overleaf) and having done so, I freely agreed to participate in this study.

I also understand the following points regarding my participation:

- My participation is voluntary.

- I am free to choose not to answer any of the questions put to me.

- I may withdraw from the interview at any time.

I have also been advised that the interviews will be video recorded and transcribed and that parts of the interview may be used in the researcher's $\mathrm{PhD}$. thesis. Any identifying information will be removed from the transcript.

Participant's Name (printed)

Signature

Date 